\title{
RESOLUCIONES DEL CONSEJO DE SEGURIDAD DE LAS NACIONES UNIDAS (1/10/ 2004-30/9/2005)
}

\section{AFGANISTÁN}

\section{RESOLUCIÓN 1589}

(24 de marzo de 2005)

\section{El Consejo de Seguridad,}

Recordando sus resoluciones anteriores sobre el Afganistán, en particular su resolución 1536 (2004), de 26 de marzo 2004, por la que se prorrogó el mandato de la Misión de Asistencia de las Naciones Unidas en el Afganistán (UNAMA) hasta el 26 de marzo de 2005,

Reiterando su firme determinación de preservar la soberanía, la independencia, la integridad territorial y la unidad nacional del Afganistán,

Expresando una vez más su satisfacción por las elecciones presidenciales que se llevaron a buen término el 9 de octubre de 2004,

Reconociendo la necesidad urgente de hacer frente a los problemas actuales en el Afganistán, entre ellos la lucha contra los estupefacientes, la falta de seguridad en ciertas zonas, las amenazas terroristas, el desarme completo en toda la nación, la desmovilización y reintegración de las Fuerzas de las Milicias Afganas y la disolución de los grupos armados ilegales, la preparación oportuna de las elecciones parlamentarias, provinciales y de distrito, el desarrollo de las instituciones del Gobierno del Afganistán, la aceleración de la reforma en el sector de la justicia, la promoción y protección de los derechos humanos y el desarrollo económico y social,

Reafirmando, en ese contexto, su continuo apoyo a la aplicación de las disposiciones del Acuerdo de Bonn, de 5 de diciembre 2001, y de la Declaración de Berlín, de $1^{\circ}$ de abril de 2004, incluidos sus anexos, y prometiendo que seguirá apoyando ulteriormente al Gobierno y al pueblo del Afganistán a medida que reconstruyen su país, refuerzan los cimientos de una democracia 


\section{DOCUMENTACIÓN}

constitucional y ocupan el lugar que les corresponde en la comunidad de las naciones,

Recordando y subrayando la importancia de la Declaración de Kabul sobre las relaciones de buena vecindad (S/2002/1416), de 22 de diciembre de 2002, y alentando a todos los Estados interesados a que sigan aplicando la Declaración de Kabul y la Declaración sobre el comercio, el tránsito y las inversiones exteriores firmada en Dubai en septiembre de 2003,

Expresando su reconocimiento y su resuelto apoyo a la labor que realizan el Secretario General y su Representante Especial para el Afganistán y destacando la función esencial e imparcial que las Naciones Unidas siguen desempeñando en la promoción de la paz y estabilidad en el Afganistán,

1. Acoge con beneplácito el informe del Secretario General de 18 de marzo de 2005 (S/2005/183);

2. Decide prorrogar el mandato de la UNAMA por un nuevo período de doce meses contados a partir de la fecha de aprobación de la presente resolución;

3. Destaca la importancia de establecer con urgencia una estructura para celebrar lo antes posible elecciones libres y limpias, acoge complacido a ese respecto el anuncio hecho por el Órgano Conjunto de Gestión Electoral de que las elecciones para la cámara baja del parlamento (Wolesi Jirga) y los consejos provinciales tendrán lugar el 18 de septiembre de 2005 , exhorta a la UNAMA a que siga prestando el apoyo necesario para facilitar la celebración oportuna de las elecciones con la participación más amplia posible e insta a la comunidad de donantes a que aporte rápidamente el apoyo financiero necesario sobre la base de esa estructura y en estrecha coordinación con el Gobierno del Afganistán y la UNAMA y que considere la posibilidad de aportar contribuciones a las misiones de observadores electorales;

4. Destaca la importancia de la seguridad para que las elecciones parlamentarias, provinciales y de distrito sean fidedignas y, con ese fin, exhorta a los Estados Miembros a que aporten personal, equipo y otros recursos para ampliar la Fuerza Internacional de Asistencia para la Seguridad, crear equipos provinciales de reconstrucción en otras partes del Afganistán y mantener una coordinación estrecha con la UNAMA y el Gobierno del Afganistán;

5. Observa complacido las gestiones internacionales para ayudar a establecer el nuevo parlamento afgano y para que funcione eficientemente, lo que será crucial para el futuro político del Afganistán y para la acción en pro de un Afganistán libre y democrático; 
6. Observa complacido los importantes progresos realizados en el proceso de desarme, desmovilización y reintegración de conformidad con el Acuerdo de Bonn, alienta al Gobierno del Afganistán a que prosiga su activa labor encaminada a acelerar ese proceso para completarlo en junio de 2006, disuelva los grupos armados ilegales y liquide las existencias de municiones y pide a la comunidad internacional que preste más asistencia en esa labor;

7. Observa complacido el empeño demostrado hasta la fecha por el Gobierno del Afganistán para poner en práctica su estrategia nacional de lucha contra los estupefacientes, aprobada en mayo de 2003, incluso mediante la puesta en práctica en febrero de 2005 de su plan de acción contra los estupefacientes para ese año, que refleja una renovada determinación del Gobierno de hacer frente al cultivo, la producción y el tráfico de drogas, insta al Gobierno a que adopte medidas resueltas para poner fin al procesamiento y el comercio de drogas y aplique las medidas concretas establecidas en el plan en materia de creación de instituciones, campañas de información, medios alternativos de subsistencia, prohibición y cumplimiento coercitivo de la ley, justicia penal, erradicación, reducción de la demanda y tratamiento de los adictos y cooperación regional e insta a la comunidad internacional a que preste toda la asistencia posible al Gobierno en la tarea de llevar cabalmente a la práctica todos los aspectos del plan;

8. Apoya la lucha contra el tráfico ilícito de drogas y sustancias precursoras en el Afganistán y en los Estados y países vecinos a lo largo de las rutas de tráfico, incluso estrechando la cooperación entre ellos para hacer más estrictos los controles antidrogas y frenar así las corrientes de drogas y acoge complacido, en ese contexto, la firma el $1^{\circ}$ de abril de 2004 de la Declaración de Berlín sobre la lucha contra los estupefacientes en el marco de la Declaración de Kabul sobre las relaciones de buena vecindad, de 22 de diciembre de 2002;

9. Pide a la UNAMA que siga prestando apoyo a la labor en curso para establecer un sistema judicial justo y transparente, con inclusión de la reconstrucción y reforma del sector penitenciario, a fin de consolidar el imperio de la ley en todo el país;

10. Exhorta a que se respeten plenamente los derechos humanos y el derecho internacional humanitario en todo el Afganistán y, a ese respecto, pide a la UNAMA que, con el apoyo de la Oficina del Alto Comisionado de las Naciones Unidas para los Derechos Humanos, siga prestando asistencia en la aplicación cabal de todas las disposiciones de derechos humanos de la nueva constitución del Afganistán, en particular las relativas al pleno ejercicio por las mujeres de sus derechos humanos, encomia a la Comisión Independiente de 


\section{DOCUMENTACIÓN}

Derechos Humanos del Afganistán por su valiente labor de vigilar el respeto de los derechos humanos en el país, así como de promover y proteger esos derechos, acoge complacido a este respecto el informe de la Comisión de fecha 29 de enero de 2005 y la estrategia nacional propuesta para el sistema de justicia de transición y pide que se preste apoyo internacional en ese empeño;

11.Observa complacido el desarrollo del Ejército Nacional del Afganistán y de la Policía Nacional del Afganistán y la labor en curso para incrementar su capacidad, que constituyen pasos importantes en pro del objetivo de que las fuerzas de seguridad del Afganistán ofrezcan protección y aseguren el imperio de la ley en todo el país;

12.Exhorta al Gobierno del Afganistán a que, con asistencia de la comunidad internacional, incluidas la Coalición de la Operación Libertad Duradera y la Fuerza Internacional de Asistencia para la Seguridad, con arreglo a las respectivas funciones que les han sido o les sean asignadas, siga haciendo frente a la amenaza a la seguridad y estabilidad del Afganistán que plantean los agentes de Al-Qaida, los talibanes y otros grupos extremistas, la violencia interna entre las fuerzas de las milicias y las actividades delictivas, en particular la violencia relacionada con el tráfico de drogas;

13. Pide al Secretario General que le informe oportunamente de la marcha de los acontecimientos en el Afganistán y haga recomendaciones sobre la función que cabrá en el futuro a la UNAMA después de las elecciones parlamentarias;

14. Decide seguir ocupándose activamente de la cuestión.

\section{RESOLUCIÓN 1623}

(13 de septiembre de 2005)

\section{El Consejo de Seguridad,}

Reafirmando sus anteriores resoluciones sobre el Afganistán, en particular sus resoluciones 1386 (2001), de 20 de diciembre de 2001, 1413 (2002), de 23 de mayo de 2002, 1444 (2002), de 27 de noviembre de 2002, 1510 (2003), de 13 de octubre de 2003, y 1563 (2004), de 17 de septiembre de 2004 ,

Reafirmando su firme determinación de preservar la soberanía, la independencia, la integridad territorial y la unidad nacional del Afganistán,

Reafirmando además sus resoluciones 1368 (2001), de 12 de septiembre de 2001, y 1373 (2001), de 28 de septiembre de 2001, y reiterando su apoyo 
a la acción internacional para erradicar el terrorismo de conformidad con la Carta de las Naciones Unidas,

Reconociendo que la responsabilidad por la seguridad y el orden público en todo el país incumbe a los propios afganos y observando con satisfacción la cooperación del Gobierno de la República Islámica del Afganistán con la Fuerza Internacional de Asistencia para la Seguridad,

Recordando la importancia del Acuerdo de Bonn y de la Declaración de Berlín, en particular el anexo I del Acuerdo de Bonn en el que, entre otras cosas, se dispone la extensión progresiva de la Fuerza Internacional de Asistencia para la Seguridad a otros centros urbanos y otras zonas fuera de Kabul,

Destacando también la importancia de extender la autoridad del gobierno central a todas las partes del Afganistán, de respetar los valores democráticos, de llevar plenamente a cabo el proceso de desarme, desmovilización y reinserción, de disolver los grupos armados ilegales, de reformar el sector de la justicia, de reformar el sector de la seguridad, incluida la reconstitución del Ejército Nacional Afgano y de la Policía Afgana, y de luchar contra el comercio y la producción de estupefacientes, y reconociendo que se han realizado algunos progresos en estos y otros ámbitos con la ayuda de la comunidad internacional,

Reconociendo los retos que enfrenta el Afganistán respecto de la situación en materia de seguridad en algunas partes del país,

Celebrando en este contexto el compromiso de los principales países de la Organización del Tratado del Atlántico del Norte de crear nuevos equipos de reconstrucción provinciales,

Celebrando también el papel desempeñado por la Fuerza Internacional de Asistencia para la Seguridad y de la Coalición de la Operación Libertad Duradera prestando asistencia para que tuvieran lugar las elecciones nacionales,

Expresando su reconocimiento a Italia por haber relevado a Turquía en el mando de la Fuerza Internacional de Asistencia para la Seguridad, y a los países que aportaron su contribución al Cuerpo de Ejército Europeo, y reconociendo con gratitud las contribuciones que han hecho numerosos países a la Fuerza Internacional de Asistencia para la Seguridad,

Tomando nota de la carta de fecha $1^{\circ}$ de septiembre de 2005 dirigida al Secretario General de las Naciones Unidas por el Dr. Abdullah Abdullah, Ministro de Relaciones Exteriores de la República Islámica del Afganistán (S/2005/574, anexo),

Determinando que la situación en el Afganistán sigue constituyendo una amenaza para la paz y la seguridad internacionales, 


\section{DOCUMENTACIÓN}

Decidido a asegurar la plena ejecución del mandato de la Fuerza Internacional de Asistencia para la Seguridad, en consulta con el Gobierno de la República Islámica del Afganistán,

Actuando a estos efectos en virtud del Capítulo VII de la Carta de las Naciones Unidas,

1. Decide prorrogar por un período de doce meses a partir del 13 de octubre de 2005 la autorización concedida a la Fuerza Internacional de Asistencia para la Seguridad, según se define en las resoluciones 1386 (2001) y 1510 (2003);

2. Autoriza a los Estados Miembros que participan en la Fuerza Internacional de Asistencia para la Seguridad a que adopten todas las medidas necesarias para cumplir su mandato;

3. Reconoce la necesidad de reforzar la Fuerza Internacional de Asistencia para la Seguridad y, a este respecto, insta a los Estados Miembros a que aporten personal, equipo y otros recursos a esa Fuerza, y a que hagan contribuciones al Fondo Fiduciario establecido en virtud de la resolución 1386 (2001);

4. Insta a la Fuerza Internacional de Asistencia para la Seguridad a que continúe trabajando en estrecha consulta con el Gobierno de la República Islámica del Afganistán y con el Representante Especial del Secretario General, así como con la Coalición de la Operación Libertad Duradera, en la ejecución del mandato de la Fuerza;

5. Pide al mando de la Fuerza Internacional de Asistencia para la Seguridad que, por intermedio del Secretario General, le presente informes trimestrales sobre la ejecución de su mandato;

6. Decide seguir ocupándose activamente de la cuestión.

\section{BOSNIA Y HERZEGOVINA}

\section{RESOLUCIÓN 1575}

(22 de noviembre de 2004)

\section{El Consejo de Seguridad,}

Recordando todas sus resoluciones anteriores sobre los conflictos en la ex Yugoslavia y las declaraciones de su Presidencia sobre el particular, incluidas las resoluciones 1031 (1995), de 15 de diciembre de 1995, 1088 (1996), de 12 de diciembre de 1996, 1423 (2002), de 12 de julio de 2002, 1491 (2003), de 11 de julio de 2003 y 1551 (2004), de 9 de julio de 2004, 
Reafirmando su determinación de lograr una solución política para los conflictos en la ex Yugoslavia, preservando la soberanía e integridad territorial de todos los Estados dentro de sus fronteras internacionalmente reconocidas,

Destacando su pleno apoyo a la función que sigue desempeñando el Alto Representante en Bosnia y Herzegovina,

Subrayando su determinación de apoyar la aplicación del Acuerdo Marco General de Paz en Bosnia y Herzegovina y los anexos de éste (denominados colectivamente “Acuerdo de Paz”, S/1995/999, anexo), así como las decisiones en la materia del Consejo de Aplicación de la Paz,

Recordando todos los acuerdos relativos a la situación de las fuerzas mencionadas en el apéndice B del anexo 1-A del Acuerdo de Paz y recordando a las partes su obligación de seguir cumpliendo esos acuerdos,

Recordando además las disposiciones de su resolución 1551 (2004) relativa a la aplicación provisional de los acuerdos sobre la situación de las fuerzas que figuran en el apéndice B del anexo 1-A del Acuerdo de Paz,

Destacando su agradecimiento al Alto Representante, al Comandante y al personal de la Fuerza Multinacional de Estabilización (SFOR), a la Organización para la Seguridad y la Cooperación en Europa (OSCE), a la Unión Europea y al personal de otras organizaciones y organismos internacionales en Bosnia y Herzegovina por su contribución a la aplicación del Acuerdo de Paz,

Destacando que el regreso general y coordinado de los refugiados y desplazados de toda la región sigue siendo indispensable para lograr una paz duradera,

Recordando las declaraciones de las reuniones ministeriales de la Conferencia sobre la Aplicación del Acuerdo de Paz,

Tomando conocimiento de los informes del Alto Representante, incluido el más reciente, de 6 de octubre de 2004 (S/2004/807),

Decidido a promover la solución pacífica de los conflictos de conformidad con los propósitos y principios de la Carta de las Naciones Unidas,

Recordando los principios pertinentes que figuran en la Convención sobre la Seguridad del Personal de las Naciones Unidas y el Personal Asociado, aprobada el 9 de diciembre de 1994, así como la declaración formulada por su Presidencia el 10 de febrero de 2000 (S/PRST/2000/4),

Observando con satisfacción y alentando la labor que realizan las Naciones Unidas para que el personal de mantenimiento de la paz cobre conciencia acerca de la prevención y el control del VIH/SIDA y otras enfermedades transmisibles en todas las operaciones de mantenimiento de la paz, 


\section{DOCUMENTACIÓN}

Recordando las decisiones que figuran en el párrafo 8 del comunicado de la Cumbre de Estambul de la Organización del Tratado del Atlántico del Norte (OTAN), de 28 de junio de 2004, donde se indica la intención de ésta de poner término a las operaciones de la SFOR en Bosnia y Herzegovina antes de que concluya el año 2004 y de establecer un cuartel general de la OTAN en Sarajevo que constituirá la presencia militar residual de la OTAN,

Recordando también que en la resolución 1551 (2004) se tomó nota de la intención de la Unión Europea de poner en marcha una misión de la Unión Europea en Bosnia y Herzegovina, con un componente militar, a partir de diciembre de 2004, en las condiciones indicadas en la carta de fecha 29 de junio de 2004 dirigida al Presidente del Consejo de Seguridad por el Ministro de Relaciones Exteriores de Irlanda y Presidente del Consejo de la Unión Europea $(\mathrm{S} / 2004 / 522 * / \mathrm{anexo})$,

Tomando nota de las cartas intercambiadas entre la Unión Europea y la OTAN que recibió el 19 de noviembre de 2004 sobre la forma en que esas organizaciones colaborarán en Bosnia y Herzegovina, en la que ambas organizaciones reconocen que corresponderá a la EUFOR la principal función de estabilización para la paz en relación con los aspectos militares del Acuerdo de Paz (S/2004/916; S/2004/915),

Tomando nota además de que la Presidencia de Bosnia y Herzegovina, ha confirmado en nombre de Bosnia y Herzegovina, incluidas sus entidades componentes, las disposiciones relativas a la EUFOR y a la presencia del Cuartel General de la OTAN (S/2004/917),

Observando con beneplácito, a la luz de la próxima misión de la Unión Europea, la creciente participación de ésta en Bosnia y Herzegovina,

Observando con beneplácito además los signos tangibles de los progresos realizados por Bosnia y Herzegovina hacia la integración europea,

Determinando que la situación imperante en la región sigue constituyendo una amenaza para la paz y la seguridad internacionales,

Actuando de conformidad con el Capítulo VII de la Carta de las Naciones Unidas,

1. Reafirma una vez más su apoyo al Acuerdo de Paz, así como al Acuerdo de Dayton de 10 de noviembre de 1995 sobre el establecimiento de la Federación de Bosnia y Herzegovina (S/1995/1021, anexo) y exhorta a las partes a que cumplan estrictamente las obligaciones contraídas en virtud de ellos;

2. Reitera que la responsabilidad primordial de que el Acuerdo de Paz se siga aplicando debidamente recae en las propias autoridades de Bosnia y Her- 
zegovina y que, para que la comunidad internacional y los principales donantes sigan dispuestos a asumir las cargas políticas, militares y económicas que entrañan la aplicación del Acuerdo y la reconstrucción, todas las autoridades de Bosnia y Herzegovina tendrán que cumplir el Acuerdo de Paz, participar activamente en su aplicación y en la reconstrucción de la sociedad civil, y en particular en la plena cooperación con el Tribunal Internacional para la ex Yugoslavia, en la consolidación de las instituciones mixtas, que propician la construcción de un Estado autónomo que funcione plenamente y sea capaz de integrarse en las estructuras europeas y en la tarea de facilitar el regreso de los refugiados y desplazados;

3. Recuerda una vez más a las partes que, en virtud del Acuerdo de Paz, se han comprometido a cooperar plenamente con todas las entidades que participan en su aplicación y que se mencionan en él o con las que haya autorizado el Consejo de Seguridad, entre ellas el Tribunal Internacional para la ex Yugoslavia, en su tarea de administrar justicia imparcialmente, y subraya que la plena cooperación de los Estados y entidades con el Tribunal Internacional comprende, entre otras cosas, poner a su disposición a todos los acusados y facilitarle información en apoyo de sus investigaciones;

4. Destaca su pleno apoyo a la propuesta de que el Alto Representante siga desempeñando una función en la supervisión de la aplicación del Acuerdo de Paz y orientando y coordinando las actividades de las organizaciones y los organismos civiles que ayudan a las partes en esa labor y reafirma que, de conformidad con el anexo 10 del Acuerdo de Paz, el Alto Representante es la autoridad máxima sobre el terreno en cuanto a la interpretación de los aspectos civiles de la aplicación del Acuerdo de Paz y que, en caso de controversia, puede dar su interpretación, hacer recomendaciones y tomar las decisiones con fuerza obligatoria que considere necesarias respecto de las cuestiones enumeradas por el Consejo de Aplicación del Acuerdo de Paz en Bonn los días 9 y 10 de diciembre de 1997;

5. Expresa su apoyo a las declaraciones de las reuniones ministeriales de la Conferencia sobre la Aplicación del Acuerdo de Paz;

6. Reafirma su intención de seguir atentamente la aplicación del Acuerdo de Paz y la situación en Bosnia y Herzegovina, teniendo en cuenta los informes que le sean presentados con arreglo a los párrafos 18 y 21 infra y las recomendaciones que figuren en ellos, así como su disposición a considerar la imposición de medidas si alguna de las partes deja de cumplir en grado apreciable las obligaciones contraídas en virtud del Acuerdo de Paz;

7. Reconoce el apoyo prestado por las autoridades de Bosnia y Herzegovina a la fuerza de la Unión Europea y la continuación de la presencia de la 


\section{DOCUMENTACIÓN}

OTAN y que han confirmado que ambas son los sucesores legales de la SFOR en relación con el cumplimiento de sus misiones para los fines del Acuerdo de Paz, sus anexos y apéndices y las resoluciones pertinentes del Consejo de Seguridad de las Naciones Unidas y pueden adoptar las medidas que sean necesarias, incluido el uso de la fuerza, para garantizar el cumplimiento de los anexos 1-A y 2 del Acuerdo de Paz y las resoluciones del Consejo en la materia;

8. Rinde homenaje a los Estados Miembros que participaron en la fuerza multinacional de estabilización creada en virtud de su resolución 1088 (1996), y expresa su reconocimiento por la labor y los logros que realizaron en Bosnia y Herzegovina;

9. Observa con satisfacción la intención de la Unión Europea de iniciar una operación militar de la Unión Europea en Bosnia y Herzegovina a partir de diciembre de 2004;

10. Autoriza a los Estados Miembros, actuando por conducto de la Unión Europea o en cooperación con ésta, a establecer, por un período inicial de 12 meses, una fuerza de estabilización multinacional (EUFOR) como sucesor legal de la SFOR, bajo mando y control unificados, que desempeñará su cometido en relación con la aplicación del anexo 1-A y el anexo 2 del Acuerdo de Paz en cooperación con la presencia del Cuartel General de la OTAN, de conformidad con las disposiciones convenidas entre la OTAN y la Unión Europea, y comunicadas al Consejo en cartas de fecha 19 de noviembre de 2004, en donde se reconoce que la EUFOR desempeñará la principal función de estabilización para la paz en relación con los aspectos militares del Acuerdo de Paz;

11. Acoge con beneplácito la decisión de la OTAN de poner fin a la operación de la SFOR en Bosnia y Herzegovina antes de que concluya el año 2004 y de mantener una presencia en Bosnia y Herzegovina mediante el establecimiento de un Cuartel General para seguir prestando asistencia en la aplicación del Acuerdo de Paz junto con la EUFOR y autoriza a los Estados Miembros a que, actuando por intermedio de la OTAN, o en cooperación con ella, establezcan un Cuartel General de la OTAN como sucesor legal de la SFOR bajo mando y control unificados, que desempeñará su cometido en relación con la aplicación del anexo 1-A y el anexo 2 del Acuerdo de Paz en cooperación con la EUFOR, de conformidad con las disposiciones convenidas entre la OTAN y la Unión Europea y comunicadas al Consejo en cartas de fecha 19 de noviembre de 2004, en donde se reconoce que la EUFOR desempeñará la principal función de estabilización para la paz en relación con los aspectos militares del Acuerdo de Paz; 
12. Reconoce que el Acuerdo de Paz y las disposiciones de sus resoluciones anteriores en la materia serán aplicables a la EUFOR y a la presencia de la OTAN y con respecto a ellas, tal como lo han sido a la SFOR y con respecto a ésta y que, en consecuencia, las referencias en el Acuerdo de Paz, en particular en el anexo 1-A y sus apéndices, y en las resoluciones pertinentes, a la IFOR o la SFOR, la OTAN y el Consejo del Atlántico del Norte, serán aplicables en lo sucesivo, según proceda, a la presencia de la OTAN, la EUFOR, la Unión Europea y al Comité Político y de Seguridad y Consejo de la Unión Europea, respectivamente;

13. Expresa su intención de considerar las condiciones de una nueva autorización, según sea necesario, a la luz de la evolución de la aplicación del Acuerdo de Paz y de la situación en Bosnia y Herzegovina;

14. Autoriza a los Estados Miembros a que, actuando de conformidad con los párrafos 10 y 11 supra, tomen todas las medidas necesarias para aplicar los anexos 1-A y 2 del Acuerdo de Paz y hacerlas cumplir, insiste en que las partes seguirán siendo consideradas responsables por igual del cumplimiento de esos anexos y seguirán estando sujetas por igual a las medidas coercitivas de la EUFOR y de la presencia de la OTAN que puedan ser necesarias para lograr la aplicación de dichos anexos y proteger a la EUFOR y a la presencia de la OTAN;

15. Autoriza a los Estados Miembros para que, a instancias de la EUFOR o el Cuartel General de la OTAN, adopten todas las medidas necesarias en defensa de la EUFOR o la presencia de la OTAN, respectivamente, y presten asistencia a ambas organizaciones para el cumplimiento de su cometido, y reconoce el derecho de la EUFOR y de la presencia de la OTAN a tomar todas las medidas necesarias para defenderse en caso de ataque o amenaza de ataque;

16. Autoriza a los Estados Miembros para que, actuando de conformidad con los párrafos 10 y 11 supra, tomen, en virtud del anexo 1-A del Acuerdo de Paz todas las medidas necesarias a fin de hacer cumplir las normas y los procedimientos establecidos relativos al mando y el control del espacio aéreo de Bosnia y Herzegovina con respecto a todo el tráfico aéreo civil y militar;

17. Exige que las partes respeten la seguridad y libertad de desplazamiento del personal de la EUFOR, de la presencia de la OTAN y de otros funcionarios internacionales;

18. Pide a los Estados Miembros que actúen por conducto de la Unión Europea y a los Estados Miembros que actúen por conducto de la OTAN, o en cooperación con ellas, le informen sobre la actividad de la EUFOR y de la presencia del Cuartel General de la OTAN, respectivamente, por los cauces apropiados, al menos cada tres meses; 


\section{DOCUMENTACIÓN}

19. Invita a todos los Estados, en particular los de la región, a que sigan proporcionando el apoyo y los recursos apropiados, incluidas facilidades de tránsito, a los Estados Miembros que actúen de conformidad con lo dispuesto en los párrafos 10 y 11 supra;

20. Reitera su reconocimiento por el despliegue por la Unión Europea de su Misión de Policía en Bosnia y Herzegovina desde el $1^{\circ}$ de enero de 2003;

21. Pide también al Secretario General que siga presentándole los informes del Alto Representante, de conformidad con el anexo 10 del Acuerdo de Paz y las conclusiones de la Conferencia de Londres sobre la Aplicación del Acuerdo de Paz celebrada los días 4 y 5 de diciembre de 1996 (S/1996/1012), y las conferencias posteriores, sobre la aplicación del Acuerdo de Paz y, en particular, sobre el cumplimiento por las partes de las obligaciones contraídas en virtud de dicho Acuerdo;

22. Decide seguir ocupándose del asunto.

\section{BURUNDI}

\section{RESOLUCIÓN 1577}

(1 de diciembre de 2004)

\section{El Consejo de Seguridad,}

Recordando su resolución 1545 (2004), de 21 de mayo de 2004, y la declaración de su Presidente de fecha 15 de agosto de 2004 (S/PRST/2004/30),

Reafirmando su firme determinación de que se respeten la soberanía, la independencia, la integridad territorial y la unidad de Burundi y recordando la importancia de los principios de buena vecindad y no injerencia y de la cooperación regional,

Reafirmando también su pleno apoyo al proceso del Acuerdo de Paz y Reconciliación en Burundi, firmado en Arusha el 28 de agosto de 2000 (en adelante, "el Acuerdo de Arusha"), haciendo un llamamiento a todas las partes en Burundi para que cumplan íntegramente sus obligaciones y asegurándoles que está resuelto a apoyar los esfuerzos de Burundi por lograr que concluya con éxito la transición mediante la realización de elecciones libres e imparciales,

Acogiendo con satisfacción los positivos logros alcanzados hasta ahora por las partes en Burundi, incluso desde el despliegue de la Operación de las Naciones Unidas en Burundi (ONUB) el $1^{\circ}$ de junio de 2004, 
Acogiendo con satisfacción, en particular, el acuerdo firmado en Pretoria por las partes en Burundi el 6 de agosto de 2004 y la posterior aprobación por el Parlamento de una Constitución provisional, el 20 de octubre de 2004, que proporciona garantías a todas las comunidades de que estarán representadas en las instituciones posteriores a la transición,

Alentando a todas las partes en Burundi a que continúen su diálogo en un espíritu de compromiso, en particular durante la campaña destinada a explicar la Constitución provisional y elaborar un código electoral, con miras a lograr una solución política duradera,

Recordando que no existe alternativa alguna a la celebración de elecciones conforme a lo estipulado en el Acuerdo de Arusha, e instando a las autoridades de transición a llevar a su término el proceso electoral que se prevé celebrar hasta el 22 de abril de 2005 ,

Encomiando las gestiones realizadas por los Estados participantes en la iniciativa regional para Burundi, especialmente Uganda y la República Unida de Tanzanía, y el mecanismo de facilitación, en particular Sudáfrica, en apoyo del proceso de paz en Burundi y alentándolos a seguir colaborando en las iniciativas de las partes en Burundi,

Alentando también a la comunidad internacional de donantes a que respondan a las solicitudes hechas por el Gobierno de Burundi para fortalecer sus instituciones judiciales nacionales y su capacidad como Estado de derecho,

Condenando todos los actos de violencia, así como las violaciones de los derechos humanos y del derecho internacional humanitario,

Reiterando su enérgica condena de la matanza de Gatumba y reafirman$d o$ que quienes cometen esos crímenes deben ser llevados ante la justicia,

Tomando nota del informe conjunto de la ONUB, la Misión de las Naciones Unidas en la República Democrática del Congo (MONUC) y la Oficina del Alto Comisionado de las Naciones Unidas para los Derechos Humanos relativo a la matanza de Gatumba del 13 de agosto de 2004 (S/2004/821), y tomando nota también de la declaración hecha por el Gobierno de Burundi el 29 de octubre de 2004 (S/2004/867) y de su compromiso de llevar a término con prontitud su investigación de la matanza de Gatumba, con apoyo internacional, si procede,

Tomando nota asimismo del informe del Secretario General de fecha 15 de noviembre de 2004 (S/2004/902),

Teniendo presente que subsisten obstáculos a la estabilidad de Burundi y determinando que la situación en ese país sigue constituyendo una amenaza a la paz y la seguridad internacionales en la región, 


\section{DOCUMENTACIÓN}

Actuando en virtud del Capítulo VII de la Carta de las Naciones Unidas,

1. Decide que el mandato de la ONUB, definido en su resolución 1545 (2004), se prorrogue hasta el $1^{\circ}$ de junio de 2005 ;

2. Insta a todos los gobiernos y partes interesadas de la región a denunciar el empleo y la incitación al empleo de la violencia, condenar sin equívocos las violaciones de los derechos humanos y el derecho internacional humanitario y cooperar activamente con la ONUB y la MONUC, así como con los Estados en sus esfuerzos por poner fin a la impunidad;

3. Exhorta a los Gobiernos de la República Democrática del Congo y de Rwanda a que cooperen sin reservas con el Gobierno de Burundi para asegurar que se complete la investigación sobre la matanza de Gatumba y que sus responsables sean llevados ante la justicia;

4. Pide a la ONUB y la MONUC que sigan proporcionando asistencia, en el marco de sus mandatos, a las autoridades de Burundi y de la República Democrática del Congo con miras a facilitar la conclusión de la investigación de la matanza de Gatumba y a reforzar la seguridad de las poblaciones vulnerables;

5. Profundamente preocupado por el hecho de que las Fuerzas Nacionales de Liberación (Palipehutu-FNL) del Sr. Agathon Rwasa se hayan hecho responsables de la matanza de Gatumba, expresa su intención de considerar la adopción de medidas apropiadas que puedan aplicarse a las personas que amenacen el proceso de paz y reconciliación nacional de Burundi;

6. Pide al Secretario General que lo mantenga informado, en forma periódica, sobre la evolución de la situación en Burundi, la aplicación del Acuerdo de Arusha, la ejecución del mandato de la ONUB y las medidas que adopten las autoridades de Burundi, siguiendo las recomendaciones del Consejo, en la lucha contra la impunidad, y que presente un informe al respecto cada tres meses;

7. Decide seguir ocupándose activamente de la cuestión.

\section{RESOLUCIÓN 1602}

(31 de mayo de 2005)

\section{El Consejo de Seguridad,}

Recordando sus resoluciones relativas a Burundi y, en particular, las resoluciones 1545 (2004), de 21 de mayo de 2004, 1565 (2004), de $1^{\circ}$ de octubre de 2004, 1577 (2004), de $1^{\circ}$ de diciembre de 2004, y 1596 (2005), de 18 
de abril de 2005, así como las declaraciones de su Presidencia, en particular las de fecha 15 de agosto de 2004 (S/PRST/2004/30), 14 de marzo de 2005 (S/PRST/2005/13) y 23 de mayo de 2005 (S/PRST/2005/19),

Reafirmando su firme compromiso con la soberanía, la independencia, la integridad territorial y la unidad de Burundi y recordando la importancia de los principios de buena vecindad y no injerencia y de la cooperación regional,

Reafirmando también su pleno apoyo al proceso del Acuerdo de Paz y Reconciliación en Burundi, firmado en Arusha el 28 de agosto de 2000 (en adelante, "el Acuerdo de Arusha"), haciendo un llamamiento a todas las partes de Burundi para que cumplan íntegramente sus obligaciones y asegurándoles que está resuelto a apoyar los esfuerzos de Burundi para que la transición concluya con éxito mediante la celebración de elecciones libres y limpias,

Observando con satisfacción los positivos logros alcanzados hasta ahora por las partes de Burundi, incluso desde el despliegue de la Operación de las Naciones Unidas en Burundi (ONUB) el $1^{\circ}$ de junio de 2004,

Observando con satisfacción, en particular, que el pueblo de Burundi aprobó en un referendo el 28 de febrero de 2005 la Constitución para el período posterior a la transición,

Tomando nota con satisfacción de la declaración que firmaron el 15 de mayo de 2005 en Dar es Salam el Presidente de Burundi, Sr. Domitien Ndayizeye, y el líder del grupo rebelde Palipehutu-FNL, Sr. Agathon Rwasa, y tomando nota en particular de que ambas partes se comprometieron a poner término de inmediato a las hostilidades, a llegar a un acuerdo en el plazo de un mes sobre una cesación permanente del fuego y a negociar sin alterar el proceso electoral,

Exhortando a la comunidad internacional a aprovechar estos positivos acontecimientos políticos para aumentar su asistencia al desarrollo económico y social de Burundi,

Observando con satisfacción que próximamente se celebrarán las elecciones en la forma prevista en el Acuerdo de Arusha, tomando nota con satisfacción del calendario confirmado en la más reciente reunión de los Estados miembros de la iniciativa regional para la paz en Burundi, que tuvo lugar el 22 de abril de 2005 en Entebbe, haciendo un llamamiento a las autoridades de transición para que cumplan estrictamente este calendario en la celebración de cada elección y exhortando a todos los partidos y candidatos en $\mathrm{Bu}-$ rundi a que respeten el código de conducta electoral durante la campaña, se 


\section{DOCUMENTACIÓN}

abstengan de actos que puedan desbaratar el proceso y acepten los resultados de las elecciones,

Alentando al Gobierno de transición a que, con la cooperación de la ONUB, siga aumentando la participación de la mujer en el proceso político,

Tomando nota de los progresos realizados en la reforma del sector de la seguridad, así como en el desarme y la desmovilización de excombatientes, e insistiendo, en este sentido, en la necesidad de poner en práctica sin demora una estrategia nacional de reintegración a fin de consolidar más la paz y la estabilidad,

Encomiando las gestiones realizadas por los Estados Miembros participantes en la iniciativa regional para Burundi, especialmente Uganda y la República Unida de Tanzanía, y el mecanismo de facilitación, en particular Sudáfrica, en apoyo del proceso de paz en Burundi y alentándolos a seguir colaborando en las iniciativas de las partes de Burundi,

Alentando también a la comunidad internacional de donantes a que atiendan a las solicitudes hechas por el Gobierno de Burundi para afianzar sus instituciones judiciales nacionales y su capacidad como Estado de derecho,

Condenando todos los actos de violencia, la amenaza del uso de la fuerza y las infracciones de los derechos humanos y del derecho internacional humanitario, e insistiendo en la necesidad de que las autoridades de Burundi hagan frente a este problema, particularmente en lo que respecta a la violencia contra las mujeres y los niños y otras personas vulnerables,

Reiterando su enérgica condena de la matanza perpetrada en Gatumba el 13 de agosto de 2004 y su empeño en que quienes cometieron esos crímenes y todos los responsables de infracciones de los derechos humanos y del derecho internacional humanitario sean sometidos a la acción de la justicia,

Considerando que, para consolidar una paz duradera en la región, es esencial poner término al clima de impunidad en Burundi y en la región de los Grandes Lagos de África en su conjunto,

Tomando nota con satisfacción del informe del Secretario General de fecha 19 de mayo de 2005 (S/2005/328),

Teniendo presente que subsisten obstáculos a la estabilidad de Burundi y determinando que la situación en ese país sigue constituyendo una amenaza a la paz y la seguridad internacionales en la región,

Actuando en virtud del Capítulo VII de la Carta de las Naciones Unidas,

1. Decide prorrogar el mandato de la ONUB hasta el 1 de diciembre de 2005 ; 
2. Insta a todas las partes de Burundi a que redoblen sus esfuerzos a fin de que la transición culmine con éxito y se llegue a la reconciliación nacional y la estabilidad del país a más largo plazo y, en particular, a que se abstengan de todo acto que pueda redundar en perjuicio de la cohesión del proceso del Acuerdo de Arusha;

3. Espera con interés las recomendaciones que ha de presentar el Secretario General a más tardar el 15 de noviembre de 2005 sobre la función que desempeñarán las Naciones Unidas en la prestación de apoyo a Burundi, incluso sobre el posible ajuste del mandato y el número de efectivos de la ONUB, de conformidad con el avance que se haya registrado sobre el terreno;

4. Espera con interés también la propuesta detallada que ha de presentar el Secretario General, descrita en los párrafos 53 y 54 de su informe, para el establecimiento de un mecanismo de apoyo internacional en la etapa posterior a la transición en Burundi;

5. Pide al Secretario General que en sus informes sobre la situación en Burundi siga reseñando las medidas que se adopten en la lucha contra la impunidad;

6. Acoge complacido el empeño puesto por la ONUB para poner en práctica la política del Secretario General de tolerancia cero respecto de la explotación y el abuso sexuales y asegurar el cumplimiento cabal por su personal del código de conducta de las Naciones Unidas; pide al Secretario General que siga tomando todas las medidas necesarias al respecto y mantenga informado al Consejo; e insta a los países que aportan contingentes a que adopten medidas preventivas y disciplinarias apropiadas para asegurar que se investiguen debidamente esos actos y sean castigados en los casos en que esté involucrado su personal;

7. Decide seguir ocupándose activamente de la cuestión.

\section{RESOLUCIÓN 1606}

(20 de junio de 2005)

\section{El Consejo de Seguridad,}

Reafirmando su apoyo al proceso del Acuerdo de Paz y Reconciliación en Burundi, firmado en Arusha el 28 de agosto de 2000,

Convencido de la necesidad, para consolidar la paz y reconciliación en Burundi, de establecer la verdad, investigar los crímenes e identificar y some- 


\section{DOCUMENTACIÓN}

ter a la justicia a quienes tienen la responsabilidad mayor respecto de los crímenes de genocidio, de lesa humanidad y de guerra cometidos en Burundi después de la independencia, a fin de disuadir de la comisión de crímenes de esta índole en el futuro y de poner término al clima de impunidad en Burundi y en la región de los Grandes Lagos en general,

Destacando que hace falta prestar una asistencia internacional adecuada a Burundi para ayudar al pueblo de ese país a poner fin a la impunidad, promover la reconciliación y establecer una sociedad y un gobierno bajo el imperio de la ley,

Habiendo tomado nota de la carta que, con fecha 24 de julio de 2002, dirigió al Secretario General el entonces Presidente de la República de Burundi, Sr. Pierre Buyoya, para pedir que, de conformidad con el Acuerdo de Arusha, se estableciera una comisión judicial internacional de investigación,

Habiendo tomado nota también del informe que, con fecha 11 de marzo de 2005 (S/2005/158), le transmitió el Secretario General tras la misión de evaluación que había enviado a Burundi del 16 al 24 de mayo de 2004 a fin de examinar la conveniencia y viabilidad de establecer una comisión de esa índole,

Habiendo escuchado la opinión del Gobierno de Transición de Burundi, expresada el 15 de junio de 2005 por su Ministro de Justicia, Sr. Didace Kiganahe, sobre las recomendaciones formuladas en ese informe, que apuntan al establecimiento de una comisión mixta de la verdad y de un tribunal especial en la estructura judicial de Burundi,

Reconociendo la importancia crucial que tiene la reconciliación para la paz y la unidad nacional en Burundi y compartiendo la opinión de que una comisión de la verdad futura debería contribuir a este fin,

1. Pide al Secretario General que entable negociaciones con el Gobierno y consultas con todas las partes interesadas de Burundi acerca de la forma de llevar a la práctica sus recomendaciones y que le presente un informe sobre los detalles de la ejecución, incluidos los costos, las estructuras y el calendario, a más tardar el 30 de septiembre de 2005;

2. Decide seguir ocupándose de la cuestión. 


\section{CHIPRE}

\section{RESOLUCIÓN 1568}

(22 de octubre de 2004)

\section{El Consejo de Seguridad,}

Acogiendo con beneplácito el informe del Secretario General sobre la operación de las Naciones Unidas en Chipre de fecha 24 de septiembre de 2004 (S/2004/756),

Reiterando su llamamiento a las partes para que evalúen y resuelvan con la debida urgencia y seriedad la cuestión humanitaria de las personas desaparecidas, y acogiendo con beneplácito a este respecto la reanudación de las actividades del Comité sobre Personas Desaparecidas en agosto de 2004,

Acogiendo con beneplácito el examen por el Secretario General de la operación de mantenimiento de la paz de las Naciones Unidas en Chipre (UNFICYP) de conformidad con la resolución 1548 (2004), de 11 de junio de 2004,

Observando que el Gobierno de Chipre conviene en que, en vista de la situación reinante en la isla, es necesario que la Fuerza de las Naciones Unidas para el Mantenimiento de la Paz en Chipre (UNFICYP) permanezca en ella después del 15 de diciembre de 2004,

Tomando nota de la evaluación del Secretario General de que la situación de seguridad de la isla se ha vuelto cada vez más benigna en los últimos años y que una reanudación de las hostilidades en Chipre es cada vez menos probable,

Acogiendo con beneplácito la intención del Secretario General de hacer un nuevo examen del mandato, antes de su próxima prórroga, del nivel de efectivos y del concepto de las operaciones de la UNFICYP, teniendo en cuenta los acontecimientos sobre el terreno y las opiniones de las partes,

Haciendo suyas la gratitud del Secretario General con el Gobierno de Chipre y el Gobierno de Grecia por sus contribuciones voluntarias a la financiación de la UNFICYP y su solicitud de nuevas contribuciones voluntarias de otros países y organizaciones,

Observando con satisfacción y alentando la labor realizada por las $\mathrm{Na}-$ ciones Unidas en todas sus operaciones de mantenimiento de la paz para que el personal de mantenimiento de la paz cobre conciencia de la prevención y el control del VIH/SIDA y otras enfermedades transmisibles,

1. Reafirma todas sus resoluciones pertinentes sobre Chipre, en particular la resolución 1251 (1999), de 29 de junio de 1999, y las ulteriores; 


\section{DOCUMENTACIÓN}

2. Hace suyas las recomendaciones del Secretario General para modificar el concepto de operaciones y el nivel de efectivos de la UNFICYP formuladas en su informe de 24 de septiembre de 2004;

3. Decide prorrogar el mandato de la UNFICYP por un nuevo período que terminará el 15 de junio de 2005;

4. Insta a los turcochipriotas y a las fuerzas turcas a que levanten sin demora todas las restricciones restantes impuestas a la UNFICYP y les exhorta a que restablezcan en Strovilia el statu quo militar anterior al 30 de junio de 2000;

5. Pide al Secretario General que le presente un informe sobre la aplicación de esta resolución junto con el examen antes mencionado;

6. Decide seguir ocupándose de la cuestión.

\section{RESOLUCIÓN 1604}

(15 de junio de 2005)

\section{El Consejo de Seguridad,}

Acogiendo con beneplácito el informe del Secretario General sobre la operación de las Naciones Unidas en Chipre de fecha 27 de mayo de 2005 (S/2005/353),

Reiterando su llamamiento a las partes para que evalúen y resuelvan con la debida urgencia y seriedad la cuestión humanitaria de las personas desaparecidas y observando complacido a este respecto que el Comité sobre Personas Desaparecidas reanudó en agosto de 2004 sus actividades,

Observando con beneplácito que el Secretario General ha procedido a un examen de la operación de mantenimiento de la paz de las Naciones Unidas en Chipre, de conformidad con la resolución 1568 (2004), de 22 de octubre de 2004,

Observando que el Gobierno de Chipre está de acuerdo en que, en vista de la situación reinante en la isla, es necesario que la Fuerza de las Naciones Unidas para el Mantenimiento de la Paz en Chipre (UNFICYP) permanezca en ella después del 15 de junio de 2005 ,

Tomando nota de que el Secretario General ha determinado que la situación de seguridad de la isla continúa siendo estable y prosigue la calma a lo largo de la Línea Verde, aunque hay problemas en algunas zonas estratégicas, y observando complacido en este contexto que haya disminuido el número de incidentes causados por las dos partes, 
Acogiendo con beneplácito la intención del Secretario General de mantener bajo atento examen las operaciones de la UNFICYP, teniendo siempre en cuenta los acontecimientos en el terreno y las opiniones de las partes, y de presentar recomendaciones al Consejo para que se introduzcan los nuevos ajustes que correspondan en el mandato, el número de efectivos y el concepto de las operaciones de la UNFICYP una vez que considere que ha transcurrido tiempo suficiente desde la aplicación del nuevo concepto de las operaciones de la UNFICYP para hacer esa determinación,

Tomando nota con satisfacción de que los turcochipriotas y las fuerzas turcas han levantado las restricciones sobre la libertad de circulación de la UNFICYP y tomando nota a este respecto de que la UNFICYP cuenta con una buena cooperación de ambas partes,

Observando complacido que ha habido siete millones de cruces de grecochipriotas hacia el norte y turcochipriotas hacia el sur y alentando a que se abran nuevos puestos de cruce,

Expresando preocupación por el aumento de la delincuencia a lo largo de la línea de cesación del fuego e instando a las dos partes a que cooperen en mayor medida para resolver esta cuestión,

Acogiendo con beneplácito todas las gestiones encaminadas a promover los contactos y los actos bicomunales, incluso por parte de las Naciones Unidas, e instando a las dos partes a que promuevan nuevos contactos entre las dos comunidades y levanten los obstáculos que puedan interponerse a ellos,

Haciendo suyas la gratitud del Secretario General con el Gobierno de Chipre y el Gobierno de Grecia por sus contribuciones voluntarias a la financiación de la UNFICYP y su solicitud de nuevas contribuciones voluntarias de otros países y organizaciones,

Observando con satisfacción y alentando la labor realizada por las Naciones Unidas en todas sus operaciones de mantenimiento de la paz para que el personal de mantenimiento de la paz cobre conciencia de la prevención y el control del VIH/SIDA y otras enfermedades transmisibles,

1. Reafirma todas sus resoluciones sobre Chipre, en particular la resolución 1251 (1999), de 29 de junio de 1999, y las ulteriores;

2. Decide prorrogar el mandato de la UNFICYP por un nuevo período que terminará el 15 de diciembre de 2005;

3. Exhorta a los turcochipriotas y a las fuerzas turcas a que restablezcan en Strovilia el statu quo militar anterior al 30 de junio de 2000;

4. Pide al Secretario General que le presente un informe sobre la aplicación de esta resolución para el $1^{\circ}$ de diciembre de 2005; 
5. Acoge con satisfacción las medidas que está adoptando la UNFICYP para aplicar la política del Secretario General de tolerancia cero de la explotación y el abuso sexuales y asegurar el cumplimiento pleno por su personal del código de conducta de las Naciones Unidas, pide al Secretario General que siga adoptando todas las medidas necesarias al respecto y que le mantenga informado y exhorta a los países que aportan contingentes a que adopten las medidas preventivas que procedan, incluida la instrucción para tomar conciencia de la cuestión antes del despliegue, y que adopten las medidas disciplinarias y de otra índole que sean necesarias para asegurar que se rinda cuenta plenamente de los casos en que su personal haya incurrido en tal conducta;

6. Decide seguir ocupándose de la cuestión.

\section{CORTE INTERNACIONAL DE JUSTICIA}

\section{RESOLUCIÓN 1571}

(4 de noviembre de 2004)

El Consejo de Seguridad,

Tomando nota con pesar de la dimisión del magistrado Gilbert Guillaume, que surtirá efecto el 11 de febrero de 2005,

Tomando nota asimismo de que, como consecuencia, se producirá una vacante en la Corte Internacional de Justicia durante el resto del mandato del magistrado Gilbert Guillaume, que deberá llenarse de conformidad con las disposiciones del Estatuto de la Corte,

Observando que, de conformidad con el artículo 14 del Estatuto, la fecha de la elección para llenar la vacante deberá ser fijada por el Consejo de Seguridad,

Decide que la elección para llenar la vacante tendrá lugar el 15 de febrero de 2005 en una sesión del Consejo de Seguridad, y en una sesión de la Asamblea General en su quincuagésimo noveno período de sesiones. 


\section{CÔTE D'IVOIRE}

\section{RESOLUCIÓN 1572}

(15 de noviembre de 2004)

\section{El Consejo de Seguridad,}

Recordando su resolución 1528 (2004), de 27 de febrero de 2004, así como las declaraciones pertinentes de su Presidente, en particular las de 6 de noviembre de 2004 (S/PRST/2004/42) y 5 de agosto de 2004 (S/PRST/ 2004/29),

Reafirmando su enérgica determinación de preservar la soberanía, la independencia, la integridad territorial y la unidad de Côte d'Ivoire, y recordando la importancia de los principios de buena vecindad, no injerencia y cooperación regional,

Recordando que hizo suyo el acuerdo firmado por las fuerzas políticas de Côte d'Ivoire en Linas-Marcoussis el 24 de enero de 2003 (S/2003/99) (Acuerdo de Linas-Marcoussis), aprobado por la Conferencia de Jefes de Estado sobre Côte d'Ivoire celebrada en París los días 25 y 26 de enero de 2003, y el Acuerdo firmado en Accra el 30 de julio de 2004 (Acuerdo de Accra III),

Deplorando la reanudación de las hostilidades en Côte d'Ivoire y las repetidas violaciones del acuerdo de cesación del fuego de 3 de mayo de 2003,

Profundamente preocupado por la situación humanitaria en Côte d'Ivoire, especialmente en el norte del país, y por la utilización de los medios de comunicación, en particular la radio y la televisión, para incitar al odio y la violencia contra los extranjeros en Côte d'Ivoire,

Recordando enérgicamente las obligaciones de todas las partes de Côte d'Ivoire, tanto el Gobierno de Côte d'Ivoire como las Forces Nouvelles, de abstenerse de toda violencia contra los civiles, incluidos los civiles extranjeros, y de cooperar plenamente con las actividades de la Operación de las Naciones Unidas en Côte d'Ivoire (ONUCI),

Acogiendo con beneplácito los esfuerzos que realizan el Secretario General, la Unión Africana y la Comunidad Económica de los Estados del África Occidental (CEDEAO) para restablecer la paz y la estabilidad en Côte d'Ivoire,

Determinando que la situación en Côte d'Ivoire sigue constituyendo una amenaza para la paz y la seguridad internacionales en la región,

Actuando en virtud del Capítulo VII de la Carta de las Naciones Unidas,

1. Condena los ataques aéreos cometidos por las Fuerzas Armadas Nacionales de Côte d'Ivoire (FANCI), que constituyen una violación flagrante 


\section{DOCUMENTACIÓN}

del acuerdo de cesación del fuego de 3 de mayo de 2003, y exige a todas las partes de Côte d'Ivoire en el conflicto, tanto al Gobierno de Côte d'Ivoire como a las Forces Nouvelles, que respeten plenamente la cesación del fuego;

2. Reitera su total apoyo a las acciones emprendidas por la Operación de las Naciones Unidas en Côte d'Ivoire (ONUCI) y las fuerzas francesas, de conformidad con el mandato conferido en la resolución 1528 (2004) y con la declaración de su Presidente de 6 de noviembre de 2004 (S/PRST/2004/42);

3. Destaca una vez más que no puede haber solución militar a la crisis y que la plena aplicación de los Acuerdos de Linas-Marcoussis y Accra III sigue siendo la única manera de resolver la crisis que persiste en el país;

4. Insta, por consiguiente, al Presidente de la República de Côte d'Ivoire, los jefes de todos los partidos políticos del país y los líderes de las Forces Nouvelles a que comiencen de forma inmediata y resuelta a cumplir todos los compromisos que han contraído en virtud de esos acuerdos;

5. Expresa su pleno apoyo a los esfuerzos que realizan el Secretario General, la Unión Africana y la CEDEAO y los alienta a que prosigan sus gestiones encaminadas a relanzar el proceso de paz en Côte d'Ivoire;

6. Exige que las autoridades de Côte d'Ivoire dejen de transmitir todos los programas de radio y televisión que inciten al odio, la intolerancia y la violencia, pide a la ONUCI que fortalezca su función de supervisión a este respecto, y exhorta al Gobierno de Côte d'Ivoire y las Forces Nouvelles a que tomen todas las medidas necesarias para velar por la seguridad y la protección de los civiles, incluidos los nacionales extranjeros, y de sus bienes;

7. Decide que todos los Estados tomarán, durante un período de trece meses a partir de la fecha de aprobación de esta resolución, las medidas necesarias para impedir que, de forma directa o indirecta, se suministren, vendan o transfieran a Côte d'Ivoire, desde sus territorios o por sus nacionales, o utilizando buques o aeronaves de su pabellón, armamentos o cualquier material conexo, en particular aeronaves militares y equipo, independientemente de que procedan o no de sus territorios, o que se ofrezca cualquier tipo de asistencia, asesoramiento o capacitación en relación con actividades militares;

8. Decide que las medidas impuestas en virtud del párrafo 7 supra no serán aplicables a:

a) Los suministros y la asistencia técnica destinados únicamente al apoyo o uso de la ONUCI y las fuerzas francesas que le prestan apoyo;

b) Los suministros de equipo militar no letal destinados únicamente a usos humanitarios o de protección, y la asistencia técnica y la capacitación 
conexas, previa aprobación del Comité establecido en virtud del párrafo 14 infra;

c) Los suministros de indumentaria de protección, incluidos chalecos antibalas y cascos militares, que exporten temporalmente a Côte d'Ivoire el personal de las Naciones Unidas, los representantes de los medios de comunicación y el personal humanitario, de desarrollo y conexo, exclusivamente para su propio uso;

d) Los suministros que se exporten temporalmente a Côte d'Ivoire para las fuerzas de un Estado que esté tomando medidas, de conformidad con el derecho internacional, en forma exclusiva y directa para facilitar la evacuación de sus nacionales y de las personas sobre las que tiene responsabilidad consular en Côte d'Ivoire, previa notificación al Comité establecido en virtud del párrafo 14 infra;

e) Los suministros de armas y material conexo y la capacitación y asistencia técnica destinadas únicamente al apoyo o el uso en el proceso de reestructuración de las fuerzas de defensa y seguridad de conformidad con el apartado f) del párrafo 3 del Acuerdo de Linas-Marcoussis, tal como fue aprobado anticipadamente por el Comité establecido en virtud del párrafo 14 infra;

9. Decide que todos los Estados tomen, durante un período de doce meses, las medidas necesarias para impedir la entrada en sus territorios o el tránsito por él de todas las personas, designadas por el Comité establecido en virtud del párrafo 14 infra que constituyan una amenaza para el proceso de paz y reconciliación nacional en Côte d'Ivoire, en particular quienes obstaculicen la aplicación de los acuerdos de Linas-Marcoussis y Accra III, de cualquier otra persona que sea hallada responsable de cometer graves violaciones de los derechos humanos y el derecho internacional humanitario en Côte d'Ivoire sobre la base de la información pertinente, de toda otra persona que incite públicamente al odio y la violencia y de toda otra persona que, según el Comité, contravenga las medidas impuestas en virtud del párrafo 7 supra, pero teniendo en cuenta que ninguna de las disposiciones del presente párrafo podrá obligar a un Estado a denegar la entrada en su territorio a sus propios nacionales;

10. Decide que las medidas impuestas en virtud del párrafo 9 no serán aplicables cuando el Comité establecido en virtud del párrafo 14 infra determine que el viaje de que se trate está justificado por motivos humanitarios, incluidas las obligaciones religiosas, o cuando el Comité llegue a la conclusión de que al conceder una exención se promoverían los objetivos de las re- 
soluciones del Consejo en cuanto al logro de la paz y la reconciliación nacional en Côte d'Ivoire y de la estabilidad en la región;

11. Decide que todos los Estados, durante el mismo período de 12 meses, congelarán inmediatamente los fondos y otros activos financieros y recursos económicos que se encuentren en sus territorios en la fecha de aprobación de la presente resolución o en cualquier momento posterior y que sean de propiedad o estén bajo el control directo o indirecto de las personas designadas de conformidad con lo dispuesto en el párrafo 9 supra por el Comité establecido en virtud del párrafo 14 infra, o que obren en poder de entidades que sean de propiedad o estén bajo el control directo o indirecto de cualquier persona que actúe en su nombre o siguiendo sus instrucciones, según determine el Comité, y decide también que todos los Estados velarán por impedir que cualesquiera fondos, activos financieros o recursos económicos puedan ser puestos a disposición o en beneficio de esas personas por sus nacionales o por cualquier persona o entidad que se encuentre en sus territorios;

12. Decide que las disposiciones del párrafo 11 no serán aplicables a fondos, otros activos financieros y recursos económicos que:

a) Los Estados pertinentes hayan determinado que son necesarios para gastos básicos, a saber, el pago de productos alimentarios, alquileres o hipotecas, medicamentos y tratamiento médico, impuestos, primas de seguros y tasas de servicios públicos, o exclusivamente para el pago de honorarios profesionales razonables y el reembolso de gastos en que se haya incurrido en relación con la prestación de servicios legales, u honorarios o tasas por servicios para la conservación o el mantenimiento rutinario de fondos congelados con arreglo a las leyes nacionales, otros activos financieros y recursos económicos, tras notificación por parte de los Estados pertinentes al Comité establecido en virtud del párrafo 14 infra de la intención de autorizar, cuando proceda, el acceso a dichos fondos, otros activos financieros y recursos económicos y en ausencia de una decisión negativa por parte del Comité en el plazo de dos días laborables a partir de la notificación;

b) Los Estados pertinentes hayan determinado que son necesarios para el pago de gastos extraordinarios, siempre y cuando esta determinación haya sido notificada por los Estados pertinentes al Comité y haya sido aprobada por el Comité, o

c) Los Estados pertinentes hayan determinado que son objeto de gravamen o decisión judicial, administrativo o arbitral, en cuyo caso los fondos, otros activos financieros o recursos económicos podrán utilizarse para levantar el gravamen o cumplir la decisión a condición de que el gravamen se hubiese impuesto o la decisión se hubiese adoptado antes de la fecha de la pre- 
sente resolución, no beneficie a persona alguna referida en el párrafo $11 \mathrm{su}$ pra o a alguna persona o entidad identificada por el Comité, y haya sido notificado por los Estados pertinentes al Comité;

13. Decide que, al final del período de 13 meses contado a partir de la fecha de aprobación de la presente resolución, el Consejo de Seguridad examinará las medidas impuestas en los párrafos 7, 9 y 11 supra, a la luz de los progresos realizados en el proceso de paz y de reconciliación nacional en Côte d'Ivoire, como se definió en los Acuerdos de Linas-Marcoussis y Accra III, y expresa su disposición a examinar la modificación o terminación de estas medidas antes del plazo mencionado de trece meses solamente si los Acuerdos de Linas-Marcoussis y Accra III han sido aplicados cabalmente;

14. Decide establecer, de conformidad con el artículo 28 de su reglamento provisional, un Comité del Consejo de Seguridad integrado por todos los miembros del Consejo (el Comité) encargado de las siguientes tareas:

a) Designar a las personas y entidades sujetas a las medidas impuestas en los párrafos 9 y 11 supra y actualizar esta lista periódicamente;

b) Pedir información a todos los Estados interesados, en particular a los de la región, sobre las medidas que han tomado para aplicar las medidas impuestas en los párrafos 7, 9 y 11 supra, y cualquier otra información que pueda considerar útil, incluso proporcionarles la oportunidad de enviar representantes para que se reúnan con el Comité a fin de debatir más detalladamente cualquier cuestión pertinente;

c) Examinar las solicitudes de exención establecidas en los párrafos 8, 10 y 12 supra y tomar decisiones al respecto;

d) Hacer pública la información pertinente por conducto de los medios apropiados, incluida la lista de personas a que se hace referencia en el apartado a) supra;

e) Promulgar las directrices que sean necesarias para facilitar la aplicación de las medidas impuestas en los párrafos 11 y 12 supra;

f) Presentar informes periódicos al Consejo sobre su labor, con sus observaciones y recomendaciones, en particular sobre medios de fortalecer la eficacia de las medidas impuestas en los párrafos 7, 9 y 11 supra;

15. Pide a todos los Estados interesados, en particular a los de la región, que informen al Comité, en el plazo de noventa días a partir de la fecha de aprobación de la presente resolución, sobre las decisiones que hayan tomado para aplicar las medidas impuestas en los párrafos 7, 9 y 11 supra, y autoriza al Comité a que pida cualquier otra información que pueda considerar necesaria; 


\section{DOCUMENTACIÓN}

16. Insta a todos los Estados, a los órganos pertinentes de las Naciones Unidas y, según proceda, a otras organizaciones y partes interesadas, a que cooperen plenamente con el Comité, en particular proporcionando cualquier información de que dispongan sobre posibles violaciones de las medidas impuestas en los párrafos 7, 9 y 11 supra;

17. Expresa su determinación de examinar sin demora cualquier nueva medida tendiente a velar por la supervisión y aplicación eficaces de las disposiciones previstas en los párrafos 7, 9 y 11 supra, en particular el establecimiento de un grupo de expertos;

18. Pide al Secretario General que presente un informe al Consejo, a más tardar el 15 de marzo de 2005, sobre la información recibida de todas las fuentes pertinentes, incluidos el Gobierno de Reconciliación Nacional de Côte d'Ivoire, la ONUCI, la CEDEAO y la Unión Africana, sobre los progresos realizados en la consecución de los objetivos enunciados en el párrafo 13 supra;

19. Decide que las medidas impuestas en los párrafos 9 y 11 supra entrarán en vigor el 15 de diciembre de 2004, a menos que el Consejo de Seguridad determine antes de esa fecha que los signatarios de los Acuerdos de Linas-Marcoussis y Accra III han cumplido todos sus compromisos en virtud del Acuerdo de Accra III y han comenzado a aplicar plenamente el Acuerdo de Linas-Marcoussis;

20. Decide mantenerse activamente informado del asunto.

\section{RESOLUCIÓN 1584}

(1 de febrero de 2005)

\section{El Consejo de Seguridad,}

Recordando sus resoluciones 1572 (2004), de 15 de noviembre de 2004, y 1528 (2004), de 27 de febrero de 2004, así como las declaraciones de su Presidencia sobre la cuestión, en particular las de 16 de diciembre de 2004 (S/PRST/2204/48), 6 de noviembre de 2004 (S/PRST/2004/42) y 5 de agosto de 2004 (S/PRST/2004/29),

Reafirmando su absoluta determinación de preservar la soberanía, la independencia, la integridad territorial y la unidad de Côte d'Ivoire y recordando la importancia de los principios de buena vecindad, no injerencia y cooperación regional,

Recordando que hizo suyo el acuerdo firmado por las fuerzas políticas de Côte d'Ivoire en Linas-Marcoussis el 24 de enero de 2003 (S/2003/99) 
(Acuerdo de Linas-Marcoussis), aprobado por la Conferencia de Jefes de Estado sobre Côte d'Ivoire celebrada en París los días 25 y 26 de enero de 2003 y el Acuerdo firmado en Accra el 30 de julio de 2004 (Acuerdo de Accra III),

Deplorando una vez más las reiteradas transgresiones del acuerdo de cesación del fuego de 3 de mayo de 2003,

Recordando con firmeza a todas las partes en Côte d'Ivoire, al Gobierno del país y a las Forces Nouvelles que tienen la obligación de cumplir plenamente el acuerdo de cesación del fuego de 3 de mayo de 2003, abstenerse de todo acto de violencia, en particular contra civiles, incluidos los civiles extranjeros, y de cooperar plenamente con las actividades de la Operación de las Naciones Unidas en Côte d'Ivoire (ONUCI),

Observando con beneplácito las gestiones que realizan el Secretario General, la Unión Africana y la Comunidad Económica de los Estados de África Occidental (CEDEAO) para restablecer la paz y la estabilidad en Côte d'Ivoire y reafirmando a este respecto su pleno apoyo a la misión de facilitación que está llevando a cabo el Presidente de la República de Sudáfrica, Sr. Thabo Mbeki, en nombre de la Unión Africana,

Observando también con beneplácito la decisión relativa a Côte d'Ivoire que adoptó el 10 de enero de 2005 el Consejo de Paz y Seguridad de la Unión Africana en Libreville (Gabón) y tomando nota del comunicado que emitió en esa ocasión,

Considerando que la situación en Côte d'Ivoire sigue constituyendo una amenaza para la paz y la seguridad internacionales en la región,

Actuando en virtud del Capítulo VII de la Carta de las Naciones Unidas,

1. Reafirma la decisión que adoptó en el párrafo 7 de la resolución 1572 , de 15 de noviembre de 2004, de que todos los Estados, en particular los Estados vecinos de Côte d'Ivoire, tomaran las medidas necesarias para impedir que, de forma directa o indirecta, se suministraran, vendieran o transfirieran a Côte d'Ivoire armas o pertrechos y se ofreciera asistencia, asesoramiento o capacitación de todo tipo en relación con actividades militares;

2. Autoriza a la ONUCI y las fuerzas francesas que le prestan apoyo a que, dentro de los límites de sus posibilidades y sin perjuicio del mandato enunciado en la resolución 1528 (2004) y en el párrafo 3 de la presente resolución, procedan a:

a) Supervisar la observancia de las medidas impuestas en el párrafo 7 de la resolución 1572 (2004), en cooperación con el grupo de expertos a que se hace referencia en el párrafo 7 de la presente resolución y, de ser necesario, con la Misión de las Naciones Unidas en Liberia (MINUL), la Misión de las 


\section{DOCUMENTACIÓN}

Naciones Unidas en Sierra Leona (UNAMSIL) y los gobiernos que corresponda, incluso inspeccionando, cuando lo estime necesario y prudente sin previo aviso, la carga de las aeronaves y demás vehículos de transporte que utilicen puertos, aeropuertos, aeródromos, bases militares y puestos fronterizos en Côte d'Ivoire;

b) Recoger, según proceda, las armas y pertrechos que hayan ingresado en Côte d'Ivoire en transgresión de las medidas impuestas en el párrafo 7 de la resolución 1572 (2004) y disponer de ellos como corresponda;

3. Pide que las fuerzas francesas que prestan apoyo a la ONUCI, además de su mandato enunciado en la resolución 1528 (2004), proporcionen, según proceda, asistencia de seguridad a la ONUCI en la realización de las tareas indicadas en el párrafo 2 de la presente resolución;

4. Reconoce que, para desempeñar las tareas mencionadas en el párrafo 2 de la presente resolución, se requiere que la ONUCI cuente con personal civil que tenga la pericia correspondiente, en la medida en que no se necesiten recursos adicionales;

5. Exige que todas las partes en Côte d'Ivoire, incluidos el Gobierno del país y las Forces Nouvelles, den acceso sin trabas, en especial al equipo, los lugares y las instalaciones mencionados en el párrafo 2 de la presente resolución, a la ONUCI y a las fuerzas francesas que le prestan apoyo para que puedan desempeñar las tareas mencionadas en los párrafos 2 y 3 de la presente resolución;

6. Pide al Secretario General y al Gobierno de Francia que le comuniquen de inmediato, por conducto del Comité establecido en el párrafo 14 de la resolución 1572 (2004) (el Comité), cualquier obstáculo o dificultad con que tropiecen en el desempeño de las tareas indicadas en el apartado b) del párrafo 2 de la presente resolución a fin de que pueda considerar la adopción de todas las medidas que procedan contra las personas o grupos que obstaculicen el desempeño de esas tareas;

7. Pide al Secretario General que, en consulta con el Comité y como se señala en el párrafo 17 de la resolución 1572 (2004), establezca en un plazo de treinta días contados a partir de la aprobación de la presente resolución y con un mandato de seis meses, un grupo de expertos integrado como máximo por tres miembros (el Grupo de Expertos) que tengan la pericia necesaria para ejercer el mandato siguiente:

a) Examinar y analizar la información recogida por la ONUCI y las fuerzas francesas en el contexto de su mandato de supervisión mencionado en el párrafo 2 de la presente resolución; 
b) Recoger y analizar toda la información pertinente en Côte d'Ivoire, en los países de la región y, de ser necesario, en otros países, en cooperación con los gobiernos de éstos, acerca de los movimientos de armas y pertrechos y el suministro de asistencia, asesoramiento o adiestramiento relativos a actividades militares, así como de las redes que operen en transgresión de las medidas impuestas en el párrafo 7 de la resolución 1572 (2004);

c) Examinar y recomendar, cuando proceda, los medios por los cuales se podría poner a los Estados interesados, en particular los de la región, en mejores condiciones para aplicar efectivamente las medidas impuestas en el párrafo 7 de la resolución 1572 (2004);

d) Presentarle, por conducto del Comité dentro de los noventa días siguientes al establecimiento de éste, un informe por escrito acerca de la aplicación de las medidas impuestas en el párrafo 7 de la resolución 1572 (2004), que incluya recomendaciones al respecto;

e) Mantener periódicamente al Comité al corriente de sus actividades;

f) Intercambiar con la ONUCI y las fuerzas francesas, según proceda, información que pueda resultar útil para el desempeño de su mandato de supervisión a que se hace referencia en el párrafo 2 de la presente resolución;

g) Proporcionar al Comité en sus informes una lista, debidamente corroborada, de las personas que, según haya determinado, hayan actuado en transgresión de las medidas impuestas en el párrafo 7 de la resolución 1572 (2004) y de aquellas que, según haya determinado, les hayan prestado apoyo en esas actividades, con miras a la posible adopción de medidas en su contra;

h) Cooperar con los demás grupos de expertos que corresponda, en particular el relativo a Liberia que fue establecido en las resoluciones 1521, de 22 de diciembre de 2003, y 1579 de 21 de diciembre de 2004;

8. Insta al Gobierno de Côte d'Ivoire y las Forces Nouvelles, específicamente a sus fuerzas armadas, a que cooperen con la ONUCI presentando, dentro de los 45 días siguientes a la fecha de aprobación de esta resolución, una lista completa de los armamentos que obren en poder de esas fuerzas armadas y en poder de fuerzas paramilitares y las milicias asociadas a ellas, así como su localización, en particular aeronaves y su armamento de toda índole, misiles, dispositivos explosivos, piezas de artillería de todo calibre, incluida la artillería antiaérea, y vehículos blindados y no blindados, a fin de ayudar a la ONUCI a desempeñar las tareas mencionadas en el párrafo 2 de la presente resolución y de prestar ayuda para emprender la reagrupación de todas las fuerzas de Côte d'Ivoire implicadas y poner en práctica el programa nacional de desarme, desmovilización y reinserción de los combatientes, de conformidad con la resolución 1528 (2004); 


\section{DOCUMENTACIÓN}

9. Pide al Secretario General que, según proceda, le transmita por conducto del Comité la información que haya recogido la ONUCI, de ser posible examinada por el Grupo de Expertos, acerca del suministro de armas y pertrechos a Côte d'Ivoire;

10. Pide también al Gobierno de Francia que, según proceda, le transmita por conducto del Comité la información que hayan recogido las fuerzas francesas, de ser posible examinada por el Grupo de Expertos, acerca del suministro de armas y pertrechos a Côte d'Ivoire;

11. Insta a todos los Estados, a los órganos competentes de las Naciones Unidas y, según proceda, a las otras organizaciones y partes interesadas a que cooperen plenamente con el Comité, el Grupo de Expertos, la ONUCI y las fuerzas francesas, en particular comunicándoles la información que obre en su poder acerca de posibles transgresiones de las medidas impuestas en el párrafo 7 de la resolución 1572 (2004);

12. Expresa su profunda preocupación por la utilización de mercenarios por las dos partes en Côte d'Ivoire e insta a ambas partes a que pongan término de inmediato a esta práctica;

13. Recuerda que en el párrafo 15 de la resolución 1572 (2004) pidió a todos los Estados, en particular los de la región, que comunicaran al Comité lo que hubiesen hecho para poner en práctica las medidas impuestas en el párrafo 7 de la resolución 1572 (2004);

14. Manifiesta su propósito de examinar las recomendaciones del Secretario General que figuran en su informe de fecha 9 de diciembre de 2004 (S/2004/962), incluida su adición (S/2004/962/Add.1);

15. Decide seguir ocupándose activamente de la cuestión.

\section{RESOLUCIÓN 1594}

(4 de abril de 2005)

\section{El Consejo de Seguridad,}

Recordando sus resoluciones 1528 (2004), de 27 de febrero de 2004, 1572 (2004), de 15 de noviembre de 2004 y 1584 (2005), de $1^{\circ}$ de febrero de 2005, así como las declaraciones de su Presidencia sobre la cuestión, en particular las de 16 de diciembre de 2004 (S/PRST/2004/48) y 6 de noviembre de 2004 (S/PRST/2004/42),

Reafirmando su absoluta determinación de preservar la soberanía, la independencia, la integridad territorial y la unidad de Côte d'Ivoire y recordan- 
do la importancia de los principios de buena vecindad, no injerencia y cooperación regional,

Recordando que hizo suyo el acuerdo firmado por las fuerzas políticas de Côte d'Ivoire en Linas-Marcoussis el 24 de enero de 2003 (S/2003/99) (Acuerdo de Linas-Marcoussis), aprobado por la Conferencia de Jefes de Estado sobre Côte d'Ivoire celebrada en París los días 25 y 26 de enero de 2003 y el Acuerdo firmado en Accra el 30 de julio de 2004 (Acuerdo de Accra III),

Observando con beneplácito las gestiones que realizan el Secretario General, la Unión Africana y la Comunidad Económica de los Estados de África Occidental para restablecer la paz y la estabilidad en Côte d'Ivoire, y reafirmando a este respecto su pleno apoyo a la misión de facilitación que está llevando a cabo el Presidente de la República de Sudáfrica, Sr. Thabo Mbeki, en nombre de la Unión Africana,

Tomando nota del informe del Secretario General de fecha 18 de marzo de 2005 (S/2005/186),

Considerando que la situación en Côte d'Ivoire sigue constituyendo una amenaza para la paz y la seguridad internacionales en la región,

Actuando en virtud del Capítulo VII de la Carta de las Naciones Unidas,

1. Decide que el mandato de la Misión de las Naciones Unidas en Côte d'Ivoire y de las fuerzas francesas que la apoyan se prorrogue por un período de un mes hasta el 4 de mayo de 2005;

2. Insta a todas las partes en Côte d'Ivoire a que de manera inmediata y activa busquen una solución duradera y justa a la crisis actual, en particular valiéndose de la mediación de la Unión Africana dirigida por el Presidente Thabo Mbeki;

3. Decide seguir ocupándose activamente de la cuestión.

\section{RESOLUCIÓN 1600}

(4 de mayo de 2005)

\section{El Consejo de Seguridad,}

Recordando sus resoluciones 1528 (2004), de 27 de febrero de 2004, 1572 (2004), de 15 de noviembre de 2004, 1584 (2005), de $1^{\circ}$ de febrero de 2005, y 1594 (2005), de 4 de abril de 2005, así como las declaraciones de su Presidencia sobre la cuestión, en particular las de 16 de diciembre de 2004 (S/PRST/2004/48) y 6 de noviembre de 2004 (S/PRST/2004/42), 


\section{DOCUMENTACIÓN}

Reafirmando su firme determinación de preservar la soberanía, la independencia, la integridad territorial y la unidad de Côte d'Ivoire, y recordando la importancia de los principios de buena vecindad, no injerencia y cooperación regional,

Recordando que hizo suyo el acuerdo firmado por las fuerzas políticas de Côte d'Ivoire en Linas-Marcoussis el 24 de enero de 2003 (S/2003/99) (Acuerdo de Linas-Marcoussis), aprobado por la Conferencia de Jefes de Estado sobre Côte d'Ivoire que se celebró en París los días 25 y 26 de enero de 2003, y el Acuerdo firmado en Accra el 30 de julio de 2004 (Acuerdo de Accra III),

Observando con beneplácito las gestiones que realizan el Secretario General, la Unión Africana y la Comunidad Económica de los Estados de África Occidental para restablecer la paz y la estabilidad en Côte d'Ivoire, y reafirmando a este respecto su pleno apoyo a la misión de facilitación en curso emprendida por el Presidente de la República de Sudáfrica, Sr. Thabo Mbeki, en nombre de la Unión Africana,

Considerando que la situación en Côte d'Ivoire sigue constituyendo una amenaza para la paz y la seguridad internacionales en la región,

Actuando en virtud del Capítulo VII de la Carta de las Naciones Unidas,

1. Acoge con beneplácito la firma del acuerdo sobre el proceso de paz en Côte d'Ivoire (Acuerdo de Pretoria) (S/2005/270) por las partes de Côte d'Ivoire en Pretoria el 6 de abril de 2005, bajo los auspicios del Presidente Thabo Mbeki, encomia al Presidente Thabo Mbeki por el papel esencial que ha desempeñado, en nombre de la Unión Africana, para restablecer la paz y la estabilidad en Côte d'Ivoire, y reafirma su pleno apoyo a sus gestiones de mediación;

2. Exhorta a todas las partes a ejecutar plenamente el Acuerdo de Pretoria y les recuerda que en ese Acuerdo han decidido remitir al mediador, el Presidente Thabo Mbeki, toda diferencia que surja en la interpretación de cualquier parte del Acuerdo;

3. Acoge también con beneplácito la decisión tomada por el Presidente Thabo Mbeki en cuanto a los requisitos para ser Presidente de la República, indicados en la carta que, con fecha 11 de abril de 2005, dirigió al Presidente de la República de Côte d'Ivoire, Sr. Laurent Gbagbo (S/2005/270), y toma nota con satisfacción del anuncio hecho por el Presidente Laurent Gbagbo el 26 de abril de 2005 de que todos los candidatos designados por las partes políticas firmantes del Acuerdo de Linas-Marcoussis podrían optar a la Presidencia; 
4. Insta a todas las partes de Côte d'Ivoire a tomar todas las medidas necesarias para garantizar que las próximas elecciones generales sean libres, limpias y transparentes;

5. Decide que el mandato de la Operación de las Naciones Unidas en Côte d'Ivoire y de las fuerzas francesas que le prestan apoyo se prorrogue por un período de un mes, hasta el 4 de junio de 2005;

6. Decide seguir ocupándose activamente de la cuestión.

\section{RESOLUCIÓN 1603}

(3 de junio de 2005)

\section{El Consejo de Seguridad,}

Recordando las resoluciones y declaraciones anteriores de su Presidencia sobre la situación en Côte d'Ivoire,

Reafirmando su firme determinación de preservar la soberanía, la independencia, la integridad territorial y la unidad de Côte d'Ivoire y recordando la importancia de los principios de buena vecindad, no injerencia y cooperación regional,

Recordando que hizo suyo el Acuerdo firmado por las fuerzas políticas de Côte d'Ivoire en Linas-Marcoussis el 24 de enero de 2003 (S/2003/99) (Acuerdo de Linas-Marcoussis), aprobado por la Conferencia de Jefes de Estado sobre Côte d'Ivoire celebrada en París los días 25 y 26 de enero de 2003, y el Acuerdo firmado en Accra el 30 de julio de 2004 (Acuerdo de Accra III),

Acogiendo con beneplácito las gestiones que realizan el Secretario General, la Unión Africana y la Comunidad Económica de los Estados de África Occidental (CEDEAO) para restablecer la paz y la estabilidad en Côte d'Ivoire,

Acogiendo con beneplácito, en particular, las gestiones de mediación que lleva a cabo el Presidente de la República de Sudáfrica, Sr. Thabo Mbeki, en nombre de la Unión Africana, y reafirmándole su pleno apoyo,

Acogiendo con beneplácito la firma por las partes en Côte d'Ivoire, el 6 de abril de 2005 en Pretoria, del acuerdo sobre el proceso de paz en Côte d'Ivoire (Acuerdo de Pretoria), bajo los auspicios del Presidente Thabo Mbeki, y expresando su satisfacción con las primeras medidas que han tomado las partes en Côte d'Ivoire para llevar a la práctica ese acuerdo, y en particular con el acuerdo sobre el proceso de desarme, desmovilización y reintegración a que se llegó el 14 de mayo de 2005 y con la restitución de la situación de la 


\section{DOCUMENTACIÓN}

radio y la televisión de Côte d'Ivoire a la existente antes del 24 de diciembre de 2004,

Reafirmando sus resoluciones 1325 (2000), de 31 de octubre de 2000, sobre las mujeres, la paz y la seguridad, 1379 (2001), de 20 de noviembre de 2001, y 1460 (2003), de 30 de enero de 2003, sobre los niños y los conflictos armados, así como sus resoluciones 1265 (1999), de 17 de septiembre de 1999, y 1296 (2000), de 19 de abril de 2000, sobre la protección de los civiles en los conflictos armados,

Expresando profunda preocupación por las denuncias de faltas de conducta, incluida la explotación sexual, formuladas contra efectivos de mantenimiento de la paz desplegados en países de África, afirmando que esos efectivos deben comportarse de conformidad con su código de conducta y reafirmando que habrá una política de tolerancia cero de la conducta ilícita y de la explotación y el abuso sexuales de toda índole en los contingentes para el mantenimiento de la paz,

Habiendo tomado nota del informe del Secretario General de 18 de marzo de 2005,

Habiendo tomado nota también de la carta del Representante Permanente de la República de Sudáfrica de 24 de mayo de 2005 (S/2005/340),

Expresando su preocupación por el constante agravamiento de la situación humanitaria y de seguridad, particularmente en la parte occidental del país,

Considerando que la situación en Côte d'Ivoire sigue constituyendo una amenaza para la paz y la seguridad internacionales en la región,

Actuando en virtud del Capítulo VII de la Carta de las Naciones Unidas,

1. Hace suyo el Acuerdo de Pretoria y exige que todos sus signatarios y todas las partes de Côte d'Ivoire a los que concierna lo apliquen plenamente y sin dilación;

2. Destaca al respecto que el incumplimiento por los signatarios del Acuerdo de Pretoria, o por cualquier otra parte de Côte d'Ivoire a que concierna, de cualquiera de los compromisos contraídos en Pretoria en presencia del Presidente Thabo Mbeki pondría en peligro el proceso de paz de Côte d'Ivoire y constituiría un obstáculo para la aplicación del Acuerdo de LinasMarcoussis y del Acuerdo de Accra III y, en consecuencia, reafirma su intención de aplicar los párrafos 9 y 11 de la resolución 1572 (2004) si las partes dejan de cumplir los compromisos contraídos en virtud de los Acuerdos de Linas-Marcoussis y de Pretoria;

3. Encomia al Presidente Thabo Mbeki por la función esencial que ha desempeñado, en nombre de la Unión Africana, para restablecer la paz y la 
estabilidad en Côte d'Ivoire, reafirma su pleno apoyo a sus gestiones de mediación, recuerda a los signatarios del Acuerdo de Pretoria que deberán pedir al Presidente Thabo Mbeki que dirima las controversias que puedan surgir sobre la interpretación de ese Acuerdo en todo o en parte y alienta al Secretario General, al Presidente Thabo Mbeki y a la Unión Africana a seguir colaborando estrechamente en la aplicación del Acuerdo de Pretoria;

4. Toma nota con satisfacción de las disposiciones del Acuerdo de Pretoria en que se reafirma la constatación de sus signatarios acerca de la necesidad de celebrar elecciones presidenciales en octubre de 2005 y elecciones legislativas inmediatamente después y de su acuerdo de invitar a las Naciones Unidas a participar en la labor de la Comisión Electoral Independiente y el Consejo Constituyente y en la organización de las elecciones generales, así como de la decisión adoptada por el Consejo de Ministros el 28 de abril de 2005 de celebrar la primera vuelta de las elecciones presidenciales el 30 de octubre de 2005;

5. Acoge con satisfacción la decisión tomada por el Presidente Thabo Mbeki en cuanto a quiénes pueden postular a la Presidencia de la República, indicada en la carta que envió al Sr. Laurent Gbagbo, Presidente de la República de Côte d'Ivoire, con fecha 11 de abril de 2005 (S/2005/270), y toma nota con satisfacción del anuncio hecho por el Presidente Laurent Gbagbo el 26 de abril de 2005 de que todos los candidatos designados por los partidos políticos firmantes del Acuerdo de Linas-Marcoussis podrían postular a la Presidencia;

6. Exige que todas las partes de Côte d'Ivoire adopten todas las medidas necesarias para asegurar que las próximas elecciones generales sean libres, justas y transparentes;

7. Pide al Secretario General que, sobre la base del Acuerdo de Pretoria, designe, a título excepcional y previa consulta con la Unión Africana y el Presidente Thabo Mbeki, a un alto representante para las elecciones en Côte d'Ivoire (el Alto Representante), que actuará de manera autónoma con respecto a la Operación de las Naciones Unidas en Côte d'Ivoire (ONUCI), para que preste asistencia en particular en la labor de la Comisión Electoral Independiente y del Consejo Constituyente y que, sin perjuicio de las funciones del Representante Especial del Secretario General, tendrá el mandato siguiente:

a) Verificar, en nombre de la comunidad internacional, que en todas las etapas del proceso electoral, incluidos el establecimiento de un registro de votantes y la emisión de cédulas de votación, se den todas las garantías necesarias para celebrar elecciones presidenciales y legislativas abiertas, libres, 


\section{DOCUMENTACIÓN}

limpias y transparentes en los plazos previstos en la Constitución de la República de Côte d'Ivoire;

b) Impartir, en estrecha cooperación con la ONUCI y el proceso de mediación, todo el asesoramiento y la orientación necesarios al Consejo Constituyente, la Comisión Electoral Independiente y otros organismos o institutos pertinentes para ayudarles a prevenir y resolver cualquier dificultad que pueda poner en peligro la celebración de elecciones abiertas, libres, limpias y transparentes en los plazos previstos en la Constitución de la República de Côte d'Ivoire, con la atribución a este respecto de hacer las determinaciones que sean necesarias;

c) Dar cuenta de inmediato al Consejo, por conducto del Secretario General, e informar al Presidente Mbeki, mediador de la Unión Africana, de cualquier dificultad que pueda poner en peligro la celebración de elecciones abiertas, libres, limpias y transparentes y presentarles, de ser necesario, las recomendaciones que estime apropiadas;

d) Mantener al Consejo, por conducto del Secretario General, y al Presidente Thabo Mbeki, periódicamente informados de todos los aspectos de su mandato;

e) Solicitar y recibir información y asesoramiento técnico de la ONUCI, así como de otras fuentes;

8. Decide que el mandato del Alto Representante a que se hace referencia en el párrafo 7 terminará una vez celebradas las próximas elecciones generales en Côte d'Ivoire;

9. Insta a la comunidad de donantes a proporcionar al Alto Representante todos los recursos financieros necesarios para desempeñar cabalmente su misión;

10. Toma nota del acuerdo sobre el proceso de desarme, desmovilización y reintegración y sobre la reestructuración de las fuerzas armadas, firmado el 14 de mayo de 2005 en Yamoussoukro por los Jefes de Estado Mayor de las Fuerzas Armadas Nacionales de Côte d'Ivoire (FANCI) y de las fuerzas armadas de las Forces Nouvelles (FAFN), exige que las partes pongan en práctica cabalmente ese acuerdo para que el proceso de desarme, desmovilización y reintegración pueda comenzar sin dilación, reafirma a este respecto los párrafos 9 y 11 de la resolución 1572 (2004), reafirma también el párrafo 8 de la resolución 1584 (2005) en cuanto a la confección de una lista completa de las armas que obren en su poder y exige el desarme y el desmantelamiento inmediatos de las milicias en todo el territorio nacional; 
11. Decide prorrogar el mandato de la ONUCI y de las fuerzas francesas que la apoyan hasta el 24 de junio de 2005, con miras a renovarlo, en este caso concreto, por un período de siete meses;

12. Autoriza al Secretario General a comenzar la planificación y los preparativos necesarios, incluso en lo concerniente a la constitución de contingentes y efectivos policiales, así como en lo relativo al apoyo requerido y otras disposiciones, para facilitar el despliegue oportuno en caso de que el Consejo decida aumentar la dotación autorizada de los efectivos y fuerzas de policía de la ONUCI y modificar su mandato;

13. Destaca la importancia de incorporar la perspectiva de género en las operaciones de mantenimiento de la paz y en la consolidación de la paz después del conflicto y de contar con la debida pericia a ese respecto y alienta a la ONUCI a ocuparse activamente de esta cuestión;

14. Insta a los donantes y a las instituciones financieras internacionales a que presten el apoyo necesario para la aplicación del Acuerdo de Pretoria, en particular el programa de desarme, desmovilización y reintegración y el proceso electoral, mediante la pronta asignación de recursos financieros;

15. Exhorta a todas las partes a cooperar plenamente en el despliegue y las operaciones de la ONUCI, en particular garantizando la seguridad y la libertad de circulación del personal de las Naciones Unidas y el personal asociado en todo el territorio de Côte d'Ivoire;

16. Observa con beneplácito las medidas tomadas por la ONUCI para aplicar la política del Secretario General de tolerancia cero de la explotación y el abuso sexuales y asegurar el cumplimiento pleno por su personal del código de conducta de las Naciones Unidas, pide al Secretario General que siga adoptando todas las medidas necesarias al respecto y que le mantenga informado y exhorta a los países que aportan contingentes a que adopten las medidas preventivas que procedan, incluida la instrucción para tomar conciencia de la cuestión antes del despliegue, y que adopten las medidas disciplinarias y de otra índole que sean necesarias para asegurar que se rinda cuenta plenamente de los casos en que su personal haya incurrido en tal conducta;

17. Pide al Secretario General que siga manteniéndolo periódicamente al corriente de la evolución de la situación en Côte d'Ivoire y de la ejecución del mandato de la ONUCI y de los Acuerdos de Linas-Marcoussis y de Pretoria y que le presente cada tres meses un informe al respecto;

18. Pide también a Francia que lo siga informando periódicamente sobre todos los aspectos de su mandato en Côte d'Ivoire; 


\section{DOCUMENTACIÓN}

19. Invita a la Unión Africana a que lo mantenga periódicamente al corriente de la aplicación de las disposiciones del Acuerdo de Pretoria y, de ser necesario, le formule las recomendaciones que considere necesarias;

20. Expresa su pleno apoyo al Representante Especial del Secretario General en Côte d'Ivoire;

21. Decide seguir ocupándose activamente de la cuestión.

\section{RESOLUCIÓN 1609}

(24 de junio de 2005)

\section{El Consejo de Seguridad,}

Recordando sus anteriores resoluciones y declaraciones de su Presidencia sobre la situación en Côte d'Ivoire,

Recordando también sus resoluciones 1561 (2004), de 17 de septiembre de 2004, relativa a la situación en Liberia, y 1562 (2004), de 17 de septiembre de 2004, relativa a la situación en Sierra Leona,

Reafirmando su firme determinación de preservar la soberanía, la independencia, la integridad territorial y la unidad de Côte d'Ivoire y recordando la importancia de los principios de buena vecindad, no injerencia y cooperación regional,

Recordando que hizo suyo el acuerdo firmado por las fuerzas políticas de Côte d'Ivoire en Linas-Marcoussis el 24 de enero de 2003 (S/2003/99) (Acuerdo de Linas-Marcoussis), aprobado por la Conferencia de Jefes de Estado sobre Côte d'Ivoire que se celebró en París los días 25 y 26 de enero de 2003, el acuerdo firmado en Accra el 30 de julio de 2004 (Acuerdo de Accra III) y el acuerdo firmado en Pretoria el 6 de abril de 2005 (Acuerdo de Pretoria),

Habiendo tomado nota del informe del Secretario General de 17 de junio de 2005 (S/2005/398 y S/2005/398/Add.1) y de su informe de 2 de marzo de 2005 sobre la cooperación entre misiones y las posibles operaciones transfronterizas entre la Misión de las Naciones Unidas en Sierra Leona, la Misión de las Naciones Unidas en Liberia y la Operación de las Naciones Unidas en Côte d'Ivoire (S/2005/135),

Expresando grave preocupación porque la situación humanitaria y de seguridad siga empeorando, especialmente después de los trágicos acontecimientos ocurridos en la parte occidental del país,

Considerando que la situación en Côte d'Ivoire sigue constituyendo una amenaza para la paz y la seguridad internacionales en la región, 
Actuando en virtud del Capítulo VII de la Carta de las Naciones Unidas,

1. Decide prorrogar el mandato de la ONUCI y de las fuerzas francesas que la apoyan, en este caso concreto, por un período de siete meses que concluirá el 24 de enero de 2006;

2. Decide que, a partir de la fecha de aprobación de la presente resolución, la ONUCI tendrá el mandato siguiente:

Vigilancia de la cesación de las hostilidades y de los movimientos de grupos armados

a) Observar y vigilar el cumplimiento de la declaración conjunta de cesación de las hostilidades de 6 de abril de 2005 y del acuerdo general de cesación del fuego de 3 de mayo de 2003, prevenir, en la medida de sus posibilidades y dentro de las zonas en que esté desplegada, todo acto hostil, particularmente en la Zona de Confianza, e investigar las transgresiones de la cesación del fuego;

b) Hacer de enlace con las Fuerzas Armadas Nacionales de Côte d'Ivoire (FANCI) y los elementos militares de las Forces Nouvelles para promover, en coordinación con las fuerzas francesas, el restablecimiento de la confianza entre todas las fuerzas de Côte d'Ivoire implicadas;

c) Ayudar al Gobierno de Reconciliación Nacional a vigilar las fronteras, prestando especial atención a la situación de los refugiados de Liberia y a los desplazamientos de combatientes a través de las fronteras;

Desarme, desmovilización, reinserción, repatriación y reasentamiento

d) Ayudar al Gobierno de Reconciliación Nacional a proceder al reagrupamiento de todas las fuerzas de Côte d'Ivoire implicadas y a velar por la seguridad de sus lugares de desarme, acantonamiento y desmovilización;

e) Apoyar al Gobierno de Reconciliación Nacional en la ejecución del programa nacional de desarme, desmovilización y reinserción de los combatientes, prestando especial atención a las necesidades especiales de las mujeres y los niños;

f) Coordinar estrechamente con las misiones de las Naciones Unidas en Sierra Leona y en Liberia la ejecución de un programa de repatriación y reasentamiento voluntarios de los excombatientes extranjeros, prestando especial atención a las necesidades especiales de las mujeres y los niños, en apoyo de la labor del Gobierno de Reconciliación Nacional y en cooperación con los gobiernos interesados, las instituciones financieras internacionales competentes, las organizaciones internacionales de desarrollo y los países donantes;

g) Asegurar que los programas mencionados en los apartados e) y f) tengan en cuenta la necesidad de adoptar un planteamiento regional coordinado; 


\section{DOCUMENTACIÓN}

h) Poner en lugar seguro, neutralizar o destruir las armas, municiones u otro material militar entregados por los excombatientes;

Desarme y desmantelamiento de las milicias

i) Ayudar al Primer Ministro del Gobierno de Reconciliación Nacional a formular el plan de operaciones conjuntas para el desarme y el desmantelamiento de las milicias previsto en el artículo 4 del Acuerdo de Pretoria, y supervisar su aplicación;

j) Poner en lugar seguro, neutralizar o destruir las armas, las municiones y otro material militar entregados por las milicias;

Protección del personal de las Naciones Unidas, de las instituciones y de la población civil

k) Proteger al personal, las instalaciones y el equipo de las Naciones Unidas, velar por la seguridad y la libertad de circulación del personal de las Naciones Unidas y, sin perjuicio de la responsabilidad del Gobierno de Reconciliación Nacional, proteger, en la medida de sus posibilidades y dentro de las zonas en que esté desplegada, a los civiles que se encuentren bajo una amenaza inminente de violencia física;

1) Contribuir a proteger, en coordinación con las autoridades de Côte d'Ivoire y de Sudáfrica, la seguridad de los miembros del Gobierno de Reconciliación Nacional;

Vigilancia del embargo de armas

m) Vigilar, en cooperación con el Grupo de Expertos establecido en la resolución 1584 (2005) y, de ser necesario, con la Misión de las Naciones Unidas en Liberia (UNMIL), la Misión de las Naciones Unidas en Sierra Leona (UNAMSIL) y los gobiernos de que se trate, la observancia de las medidas impuestas en el párrafo 7 de la resolución 1572 (2004), incluso inspeccionando, si lo consideran necesario y sin aviso previo, el cargamento de las aeronaves y todo vehículo de transporte que utilice los puertos, aeropuertos, aeródromos, bases militares y puestos fronterizos de Côte d'Ivoire;

n) Recoger, en la forma que resulte apropiada, las armas y el material cuya presencia en el territorio de Côte d'Ivoire constituya una transgresión de las medidas impuestas en el párrafo 7 de la resolución 1572 (2004) y disponer de ellos de manera adecuada;

Apoyo a la asistencia humanitaria

o) Facilitar el libre desplazamiento de personas, mercancías y asistencia humanitaria, entre otros medios ayudando a crear las condiciones de seguridad necesarias y teniendo en cuenta las necesidades especiales de los grupos vulnerables, en particular las mujeres, los niños y las personas de edad; 


\section{Apoyo al restablecimiento de la administración del Estado}

p) Facilitar, con el concurso de la Unión Africana, la CEDEAO y otros colaboradores internacionales, al Gobierno de Reconciliación Nacional el restablecimiento de la autoridad del Estado en todo el territorio de Côte d'Ivoire, que es esencial para la recuperación social y económica;

Apoyo a la organización de elecciones abiertas a todos, libres, limpias y transparentes

q) Prestar toda la asistencia técnica necesaria al Gobierno de Reconciliación Nacional, a la Comisión Electoral Independiente y a otros organismos o entidades pertinentes, con el apoyo de la Unión Africana, la CEDEAO y otros colaboradores internacionales, para organizar elecciones presidenciales y legislativas abiertas a todos, libres, limpias y transparentes dentro de los plazos previstos en la Constitución de la República de Côte d'Ivoire;

r) Proporcionar, según corresponda, información, asesoramiento y asistencia técnicas al Alto Representante a que se hace referencia en el párrafo 7 de la resolución 1603 (2005), de 3 de junio de 2005;

s) Contribuir, en la medida de sus posibilidades y dentro de las zonas en que esté desplegada, a la seguridad de los lugares en que se llevará a cabo la votación;

Asistencia en materia de derechos humanos

t) Contribuir a la promoción y protección de los derechos humanos en Côte d'Ivoire, prestando especial atención a la violencia contra los niños y las mujeres, vigilar y ayudar a investigar las violaciones de esos derechos para poner fin a la impunidad, y mantener informado periódicamente de las novedades a este respecto al Comité del Consejo de Seguridad establecido en virtud de la resolución 1572 (2004);

Información pública

u) Promover la comprensión del proceso de paz y de la función de la ONUCI entre las comunidades locales y las partes mediante el servicio de información de la Misión, incluido su servicio de radiodifusión;

v) Vigilar los medios de difusión de Côte d'Ivoire, en particular con respecto a cualquier incidente de instigación al odio, la intolerancia y la violencia por parte de los medios de comunicación, y mantener informado periódicamente de la situación a este respecto al Comité del Consejo de Seguridad establecido en virtud de la resolución 1572 (2004);

Orden público

w) Ayudar al Gobierno de Reconciliación Nacional, junto con la Unión Africana, la CEDEAO y otras organizaciones internacionales, a restablecer la 


\section{DOCUMENTACIÓN}

presencia de la policía civil en todo el territorio de Côte d'Ivoire, asesorarlo en relación con la reestructuración de los servicios de seguridad interna y prestar asistencia a las partes de Côte d'Ivoire en la aplicación de medidas de seguridad temporales y provisionales en la parte septentrional del país, con arreglo a lo previsto en el párrafo 6 del Acuerdo de Pretoria;

x) Ayudar al Gobierno de Reconciliación Nacional, en forma concertada con la Unión Africana, la CEDEAO y otras organizaciones internacionales, a restablecer la autoridad del poder judicial y el imperio de la ley en todo el territorio de Côte d'Ivoire;

3. Autoriza, por el período indicado en el párrafo 1 supra, un aumento del componente militar de la ONUCI de hasta 850 efectivos más, así como un aumento del componente de policía civil por un límite máximo de 725 agentes de policía civil, incluidas tres unidades de policía constituidas, y el personal civil necesario;

4. Autoriza al Secretario General a adoptar todas las disposiciones necesarias para aplicar como corresponde las medidas pertinentes previstas en los párrafos 19 a 23 y en los apartados b) a e) del párrafo 76 de su informe sobre la cooperación entre misiones y las posibles operaciones transfronterizas entre la Misión de las Naciones Unidas en Sierra Leona (UNAMSIL), la Misión de las Naciones Unidas en Liberia (UNMIL) y la Operación de las Naciones Unidas en Côte d'Ivoire (ONUCI), de 2 de marzo de 2005 (S/2005/135), a reserva del acuerdo de los países que aportan contingentes y, cuando proceda, de los gobiernos interesados y sin perjuicio del desempeño de los mandatos de esas misiones de las Naciones Unidas;

5. Pide al Secretario General que obtenga el acuerdo de los países que aportan personal militar y de policía civil a la UNMIL, la UNAMSIL y la ONUCI para redesplegar el personal que sea necesario con carácter temporal con el fin de reforzar cualquiera de las tres misiones mencionadas que corresponda, teniendo en cuenta la necesidad de asegurar un desempeño efectivo de los mandatos actuales de esas misiones;

6. Autoriza, a reserva de las medidas previas necesarias mencionadas en los párrafos 4 y 5 anteriores, incluidos los acuerdos de los países que aportan contingentes y, cuando proceda, los gobiernos interesados, el redespliegue temporal del personal militar y de policía civil entre la UNMIL, la UNAMSIL y la ONUCI para hacer frente a los problemas que no se puedan tratar con el número máximo de personal autorizado de una misión determinada, a reserva de las condiciones siguientes:

a) El Secretario General le informará de antemano de su intención de hacer tal redespliegue, incluidos su alcance y duración, en el entendimiento de 
que para llevar a cabo el refuerzo mencionado anteriormente, el Consejo de Seguridad tendrá que adoptar la decisión correspondiente;

b) Todas las fuerzas redesplegadas seguirán contabilizándose en el límite máximo autorizado de personal militar y civil de la misión de la que son transferidas y no contabilizará en el límite máximo de la misión a la que son transferidas;

c) Cualquier transferencia de ese tipo no conllevará un aumento de los límites máximos combinados del personal militar y civil desplegado en la ONUCI, la UNAMSIL y la UNMIL determinados por el Consejo de Seguridad en los mandatos respectivos de las tres misiones;

d) Tales transferencias no conllevarán la prórroga del plazo de despliegue del personal desplegado con arreglo al mandato de su misión original, a menos que el Consejo de Seguridad decida otra cosa;

7. Decide revisar el número de efectivos de la ONUCI antes del 31 de diciembre de 2005, incluido el componente de policía civil, a la luz de la situación imperante en Côte d'Ivoire después de las próximas elecciones generales y en función de las tareas que queden por cumplir, con miras a una nueva reducción si procede;

8. Autoriza a la ONUCI a utilizar todos los medios necesarios, en la medida de su capacidad y dentro de las zonas en que esté desplegada, para cumplir su mandato;

9. Pide a la ONUCI que ejerza su mandato en estrecha cooperación con las misiones de las Naciones Unidas en Sierra Leona y en Liberia, especialmente en lo que respecta a la prevención de la circulación de armas y combatientes a través de sus fronteras comunes y la aplicación de los programas de desarme y desmovilización;

10. Subraya la importancia de incorporar la perspectiva de género en las operaciones de mantenimiento de la paz y en la consolidación de la paz después de los conflictos y de contar con la debida especialización a ese respecto, y alienta a la ONUCI a ocuparse activamente de esa cuestión;

11. Acoge con beneplácito los esfuerzos realizados por la ONUCI para aplicar la política de tolerancia cero del Secretario General sobre explotación y abusos sexuales y garantizar que su personal cumpla plenamente el código de conducta de las Naciones Unidas, pide al Secretario General que siga tomando todas las medidas necesarias a ese respecto y lo mantenga informado, y exhorta a los países que aportan contingentes a que tomen las medidas preventivas que corresponda, incluida la capacitación previa al despliegue para tomar conciencia del asunto, y adopte las medidas disciplinarias y de otro 


\section{DOCUMENTACIÓN}

tipo necesarias para asegurar que tales actos se investiguen debidamente y que se imponga el castigo que proceda en los casos en que se vea involucrado su personal;

12. Autoriza a las fuerzas francesas a utilizar, a partir de la fecha de aprobación de la presente resolución, todos los medios necesarios para apoyar a la ONUCI, de conformidad con el acuerdo concertado entre ésta y las autoridades francesas $\mathrm{y}$, en particular, para:

- Contribuir a la seguridad general de la zona de acción de las fuerzas internacionales;

- Intervenir a petición de la ONUCI en apoyo de los elementos de ésta cuya seguridad se vea amenazada;

- En consulta con la ONUCI, intervenir en caso de actos beligerantes, si las condiciones de seguridad así lo exigieran, fuera de las zonas de despliegue de la ONUCI;

- Ayudar a proteger a los civiles en las zonas en que estén desplegadas sus unidades;

- Colaborar en la vigilancia del embargo de armas impuesto en virtud de la resolución 1572 (2004), de conformidad con lo dispuesto en los párrafos 2 y 3 de la resolución 1584 (2005).

13. Decide seguir ocupándose activamente de la cuestión.

\section{ERITREA Y ETIOPÍA}

\section{RESOLUCIÓN 1586}

(14 de marzo de 2005)

\section{El Consejo de Seguridad,}

Reafirmando todas sus resoluciones y declaraciones anteriores relativas a la situación entre Etiopía y Eritrea y lo que en ellas se pedía, en particular la resolución 1560 (2004), de 14 de septiembre de 2004,

Destacando su compromiso inquebrantable con el proceso de paz, en particular a través del papel que desempeña la Misión de las Naciones Unidas en Etiopía y Eritrea (MINUEE), y la cabal y rápida aplicación del Acuerdo General de Paz firmado por los Gobiernos de Etiopía y Eritrea (denominados en lo sucesivo "las partes") el 12 de diciembre de 2000 y el anterior Acuerdo de Cesación de Hostilidades, de 18 de junio de 2000 (S/2000/1183 y $\mathrm{S} / 2000 / 601$, respectivamente, denominados en lo sucesivo "los Acuerdos 
de Argel"), así como de la decisión sobre la delimitación adoptada por la Comisión de Fronteras el 13 de abril de 2002 (S/2000/423), aceptada por las partes con carácter definitivo y obligatorio de conformidad con los Acuerdos de Argel,

Expresando su beneplácito por el hecho de que el Secretario General haya determinado que la MINUEE ha podido mantener la integridad de la zona temporal de seguridad,

Expresando su preocupación por la gran concentración de tropas etíopes observada recientemente en las zonas adyacentes a la zona temporal de seguridad,

Recordando que la paz duradera entre Etiopía y Eritrea, así como en la región, no podrá lograrse sin la plena demarcación de la frontera entre las partes,

Gravemente preocupado por la decisión de la Comisión de tomar medidas de inmediato para cerrar sus oficinas sobre el terreno debido a la falta de progreso con respecto a la demarcación de la frontera, como se advierte en el $16^{\circ}$ informe sobre la labor de la Comisión de Fronteras entre Eritrea y Etiopía de 24 de febrero de 2005 ,

Expresando su preocupación por el hecho de que Etiopía siga rechazando partes importantes de la decisión de la Comisión de Fronteras y no esté cooperando con ella, e incluso se haya negado a participar en la reunión del 22 de febrero de 2005 ,

Expresando su decepción por el hecho de que Eritrea se siga negando a entablar conversaciones con el Enviado Especial del Secretario General para Etiopía y Eritrea, cuyos buenos oficios representan una oportunidad concreta para que ambas partes hagan avanzar el proceso de paz,

Recordando el reciente aumento de las actividades de mantenimiento de la paz de las Naciones Unidas y la necesidad de asignar recursos para el mantenimiento de la paz de la manera más eficaz, y recordando a este respecto la carga adicional causada por las demoras en el proceso de demarcación,

Expresando su beneplácito por el hecho de que Eritrea haya aceptado incondicionalmente la decisión de la Comisión de Fronteras,

Expresando también su beneplácito por la propuesta de cinco puntos de Etiopía, de 25 de noviembre de 2004,

Habiendo examinado el informe del Secretario General (S/2005/142) y apoyando plenamente las observaciones formuladas en él,

1. Decide prorrogar el mandato de la MINUEE hasta el 15 de septiembre de 2005; 


\section{DOCUMENTACIÓN}

2. Hace un llamamiento a ambas partes para que se abstengan de aumentar el número de tropas en las zonas adyacentes a la zona temporal de seguridad, consideren seriamente la posibilidad de retornar al nivel de despliegue de efectivos existente al 16 de diciembre de 2004 y, en términos más generales, se abstengan de amenazarse mutuamente con el uso de la fuerza;

3. Hace un llamamiento a ambas partes para que cooperen cabal y prontamente con la MINUEE en el cumplimiento de su mandato, garanticen la seguridad del personal de la Misión y levanten inmediatamente y sin condiciones todos los obstáculos y restricciones a la labor y a la total libertad de circulación de la Misión y su personal;

4. Toma nota de la evolución positiva de ciertos aspectos de las relaciones entre la MINUEE y las dos partes y, a este respecto, insta a Eritrea a que tome medidas inmediatas, en consulta con la MINUEE, para que se efectúen vuelos directos entre Addis Abeba y Asmara y, también hace un llamamiento a Eritrea para que reabra el camino entre Asmara y Barentu;

5. Destaca que incumbe a Etiopía y Eritrea la responsabilidad primordial de la aplicación de los Acuerdos de Argel y de la decisión de la Comisión de Fronteras entre Eritrea y Etiopía y hace un llamamiento a ambas partes para que den muestras de liderazgo político a fin de lograr la plena normalización de sus relaciones, incluso mediante un diálogo político para la adopción de nuevas medidas de fomento de la confianza, y consoliden los progresos logrados hasta ahora haciendo pleno uso del marco de la Comisión de Fronteras;

6. Reitera su llamamiento a las partes para que cooperen plena y rápidamente con la Comisión de Fronteras y creen las condiciones necesarias para proceder sin demora a la demarcación, incluso mediante el nombramiento definitivo, por Etiopía, de sus oficiales de enlace sobre el terreno;

7. Insta a Etiopía a que, sin condiciones previas, comience a aplicar la demarcación tomando las medidas necesarias para que la Comisión pueda demarcar la frontera íntegra y rápidamente;

8. Expresa su preocupación por el empeoramiento de la situación humanitaria en Etiopía y Eritrea y por las consecuencias que ello podría tener para el proceso de paz e insta a los Estados Miembros a que sigan prestando apoyo generosamente y sin demora a las operaciones humanitarias en Etiopía y Eritrea;

9. Reitera su pleno apoyo al Enviado Especial del Secretario General para Etiopía y Eritrea, Lloyd Axworthy, y a sus gestiones para facilitar la aplicación de los Acuerdos de Argel, la decisión de la Comisión de Fronteras 
y la normalización de relaciones diplomáticas entre ambos países a través de sus buenos oficios, e insiste en que su nombramiento no constituye un mecanismo alternativo;

10. Hace un llamamiento a Eritrea para que acepte los buenos oficios del Secretario General y colabore con su Enviado Especial para Etiopía y Eritrea;

11. Hace un llamamiento a los testigos de los Acuerdos de Argel para que desempeñen un papel más coordinado y activo a fin de facilitar la plena aplicación de esos Acuerdos;

12. Decide seguir observando atentamente las medidas adoptadas por las partes para cumplir los compromisos que les incumben en virtud de las resoluciones pertinentes del Consejo de Seguridad y de los Acuerdos de Argel, incluso por conducto de la Comisión de Fronteras, y examinar las consecuencias que tengan esas medidas para la MINUEE;

13. Pide al Secretario General que siga observando atentamente la situación con el fin de revisar el mandato de la Misión habida cuenta de los progresos realizados en el proceso de paz y de las modificaciones introducidas en la MINUEE;

14. Decide seguir ocupándose activamente de la cuestión.

\section{RESOLUCIÓN 1622}

(13 de septiembre de 2005)

\section{El Consejo de Seguridad,}

Reafirmando todas sus resoluciones y declaraciones anteriores relativas a la situación entre Etiopía y Eritrea y lo que en ellas se pedía, en particular la resolución 1586 (2005), de 14 de marzo de 2005,

Destacando su adhesión inquebrantable al proceso de paz, en particular a través del papel que desempeña la Misión de las Naciones Unidas en Etiopía y Eritrea (MINUEE), y la cabal y rápida aplicación del Acuerdo General de Paz firmado por los Gobiernos de Etiopía y Eritrea (denominados en los sucesivo "las partes") el 12 de diciembre de 2000 y el anterior Acuerdo de cesación de hostilidades, de 18 de junio de 2000 (S/2000/1183 y S/2000/601, respectivamente, denominados en lo sucesivo "los Acuerdos de Argel"), así como la decisión sobre la delimitación adoptada por la Comisión de Fronteras entre Eritrea y Etiopía el 13 de abril de 2002 (S/2002/423), aceptada por las partes con carácter definitivo y obligatorio de conformidad con los Acuerdos de Argel, 


\section{DOCUMENTACIÓN}

Destacando que la paz duradera entre Etiopía y Eritrea, así como en la región, no podrá lograrse sin la plena demarcación de la frontera entre las partes,

Profundamente preocupado por que no se progresa en la aplicación de la decisión adoptada con carácter definitivo y obligatorio por la Comisión de Fronteras y por el rechazo actual por Etiopía de partes importantes de la decisión de la Comisión de Fronteras,

Observando con profunda preocupación que continúa la concentración elevada de tropas en las zonas adyacentes a la zona temporal de seguridad,

Habiendo examinado el informe del Secretario General (S/2005/553) y acogiendo con beneplácito las observaciones en él formuladas,

Observando que entre las posibles opciones para resolver el estancamiento del proceso de paz, están, si procede, una visita a Etiopía y Eritrea, como lo sugirió el Secretario General en el párrafo 38 de su informe, así como una reunión de los testigos de la firma del Acuerdo de Argel,

Acogiendo con beneplácito las medidas adoptadas por la MINUEE para abordar la cuestión de la explotación y el abuso sexuales, y en particular los esfuerzos dirigidos a la prevención mediante la capacitación, así como las medidas tomadas para hacer frente al VIH y el SIDA,

1. Decide prorrogar el mandato de la MINUEE hasta el 15 de marzo de 2006;

2. Aprueba la reconfiguración del componente militar de la MINUEE, incluido el aumento de 10 observadores militares, dentro de la actual dotación global de la MINUEE prevista en su mandato, y la asistencia a las partes en el sector de las actividades relativas a las minas, según lo recomendado por el Secretario General en los párrafos 11 y 42 de su informe;

3. Hace un llamamiento a ambas partes para que se abstengan de cualquier medida que pueda dar lugar a un aumento de la tensión y a ese respecto exhorta a ambas partes a que consideren seriamente la posibilidad de regresar a los niveles de despliegue de 16 de diciembre de 2004 y, más en general, se abstengan de toda amenaza de uso recíproco de la fuerza;

4. Reafirma que incumbe a Etiopía y Eritrea la responsabilidad primordial de aplicar los Acuerdos de Argel y la decisión de la Comisión de Fronteras entre Eritrea y Etiopía, haciendo pleno uso del marco existente de la Comisión de Fronteras entre Eritrea y Etiopía;

5. Exhorta a Etiopía a que acepte plenamente la decisión de la Comisión de Fronteras entre Eritrea y Etiopía y permita, sin condiciones previas, que la Comisión demarque las fronteras en su totalidad y con rapidez; 
6. Hace un llamamiento a las partes para que apliquen en su totalidad y con rapidez; y sin más tardanza la decisión de la Comisión de Fronteras entre Eritrea y Etiopía y creen las condiciones necesarias para proceder sin demora a la demarcación;

7. Toma nota de la mejora constante del clima de cooperación entre la MINUEE y las partes y exhorta a ambas partes a cooperar plenamente y sin tardanza con la MINUEE en el cumplimiento de su mandato para garantizar la seguridad de todo el personal de la MINUEE y eliminar inmediatamente y sin condiciones todos los obstáculos y restricciones a la labor y a la total libertad de circulación de la MINUEE y su personal; también a ese respecto, exhorta vigorosamente a Eritrea a que elimine las restricciones impuestas a la policía militar de la MINUEE en Asmara;

8. Insta a Eritrea a que adopte medidas inmediatas, en consulta con la MINUEE, para hacer efectivos los vuelos directos de las Naciones Unidas entre Addis Abeba y Asmara, y a que reabra la carretera de Asmara a Barentu al tráfico de la Misión;

9. Exhorta a ambas partes a que logren la plena normalización de sus relaciones, incluso mediante el diálogo político para la adopción de nuevas medidas de fomento de la confianza, y consoliden los progresos logrados hasta ahora;

10. Expresa su preocupación por que continúa la inseguridad alimentaria en Etiopía y Eritrea, lo cual puede crear mayor inestabilidad y exhorta a los Estados Miembros a que sigan prestando apoyo generoso a las actividades tanto humanitarias como de desarrollo para mejorar la seguridad alimentaria en Etiopía y Eritrea;

11. Hace un llamamiento a Eritrea para que levante todas las restricciones impuestas a las operaciones de las organizaciones de ayuda, para que puedan realizar sus actividades humanitarias;

12. Decide seguir observando atentamente las medidas adoptadas por las partes para cumplir los compromisos que les incumben en virtud de las resoluciones pertinentes del Consejo de Seguridad y de los Acuerdos de Argel, incluso por conducto de la Comisión de Fronteras, y examinar las consecuencias que puedan tener esas medidas para la MINUEE;

13. Pide al Secretario General que adopte las medidas necesarias para lograr el cumplimiento efectivo por la MINUEE de la política de tolerancia cero de las Naciones Unidas respecto de la explotación y el abuso sexuales, incluso mediante la elaboración de estrategias y mecanismos apropiados para prevenir, identificar y resolver todas las faltas de conducta, con inclusión de la ex- 


\section{DOCUMENTACIÓN}

plotación y el abuso sexuales, y una mejor capacitación del personal para prevenir esas faltas y asegurar el pleno cumplimiento del código de conducta de las Naciones Unidas, pide al Secretario General que adopte todas las medidas necesarias de conformidad con su boletín sobre medidas especiales de protección contra la explotación sexual y el abuso sexuales (ST/SGB/2003/13) y lo mantenga informado, e insta a los países que aportan contingentes a que adopten las medidas preventivas apropiadas, incluida la realización de cursos de concienciación previos al despliegue, y adopten medidas disciplinarias y de otro tipo para garantizar la plena rendición de cuentas en los casos de ese

tipo de conducta en que esté involucrado su personal;

14. Pide al Secretario General que siga observando atentamente la situación con el fin de revisar el mandato de la Misión habida cuenta de los progresos realizados en el proceso de paz y de las modificaciones introducidas en la MINUEE;

15. Decide seguir ocupándose activamente de la cuestión.

\section{GEORGIA}

\section{RESOLUCIÓN 1582}

(28 de enero de 2005)

\section{El Consejo de Seguridad,}

Recordando todas sus resoluciones sobre la cuestión, en particular la resolución 1554 (2004), de 29 de julio de 2004 (S/RES/1554),

Acogiendo con beneplácito el informe del Secretario General de 17 de enero de 2005,

Recordando las conclusiones de las cumbres de Lisboa (S/1997/57, anexo) y Estambul de la Organización para la Seguridad y la Cooperación en Europa (OSCE) relativas a la situación en Abjasia (Georgia),

Recordando los principios pertinentes que figuran en la Convención sobre la Seguridad del Personal de las Naciones Unidas y el Personal Asociado, aprobada el 9 de diciembre de 1994,

Deplorando que todavía no se haya identificado a los autores del derribo de un helicóptero de la Misión de Observadores de las Naciones Unidas en Georgia (UNOMIG) ocurrido el 8 de octubre de 2001, en que perdieron la vida las nueve personas que viajaban a bordo, 
Destacando que es inaceptable que se siga sin avanzar en cuestiones fundamentales para alcanzar un arreglo general del conflicto en Abjasia (Georgia),

Acogiendo con beneplácito, sin embargo, el impulso positivo que han dado al proceso de paz dirigido por las Naciones Unidas las reuniones de alto nivel del Grupo de Amigos celebradas periódicamente en Ginebra y las reuniones en la cumbre entre la Federación de Rusia y Georgia,

Acogiendo con beneplácito las importantes aportaciones que han hecho la UNOMIG y las Fuerzas Colectivas de Mantenimiento de la Paz de la Comunidad de Estados Independientes (fuerza de mantenimiento de la paz de la CEI) a la estabilización de la situación en la zona de conflicto, y destacando la importancia que asigna a la estrecha cooperación que existe entre ellas en la ejecución de sus mandatos respectivos,

1. Reafirma la determinación de todos los Estados Miembros de preservar la soberanía, independencia e integridad territorial de Georgia dentro de sus fronteras internacionalmente reconocidas, y la necesidad de definir el estatuto de Abjasia dentro del Estado de Georgia en estricta conformidad con esos principios;

2. Encomia y apoya firmemente las continuas gestiones realizadas por el Secretario General y su Representante Especial, con la asistencia de la Federación de Rusia en su calidad de facilitadora, así como del Grupo de Amigos del Secretario General y de la OSCE, para promover la estabilización de la situación y lograr un arreglo político general que debe comprender un acuerdo sobre el estatuto político de Abjasia dentro del Estado de Georgia;

3. Reitera su firme apoyo al documento titulado "Principios básicos de la distribución de competencias entre Tbilisi y Sujumi” y su carta de envío, preparados y respaldados plenamente por todos los miembros del Grupo de Amigos;

4. Deplora profundamente la negativa reiterada de la parte abjasia a debatir el fondo de ese documento, insta encarecidamente una vez más a la parte abjasia a acusar recibo del documento y su carta de envío, insta a ambas partes a que, seguidamente, los examinen con detenimiento y apertura de miras y entablen negociaciones constructivas sobre su fondo e insta a quienes tengan influencia sobre las partes a promover este resultado;

5. Deplora también que no se avance en la iniciación de negociaciones sobre el estatuto político y recuerda una vez más que esos documentos tienen por objeto facilitar la celebración de negociaciones provechosas entre las partes, bajo la dirección de las Naciones Unidas, sobre el estatuto de Abjasia 


\section{DOCUMENTACIÓN}

dentro del Estado de Georgia y no pretenden imponer ni dictar una solución concreta a las partes;

6. Señala su posición sobre las elecciones en Abjasia expresada en la resolución 1255 (1999) de 30 de julio de 1999 (S/RES/1255);

7. Exhorta a ambas partes a participar en negociaciones constructivas para lograr una solución política del conflicto y a no escatimar esfuerzos para superar la desconfianza mutua existente y subraya que el proceso de negociación para lograr un arreglo político duradero aceptable para las dos partes requerirá concesiones de ambas;

8. Acoge con beneplácito el compromiso de la parte georgiana de lograr una solución pacífica del conflicto y pide a ambas partes que sigan desvinculándose públicamente de toda retórica partidista y de manifestaciones de apoyo a las opciones militares;

9. Recuerda a todos los interesados que deben abstenerse de toda acción que pueda obstaculizar el proceso de paz;

10. Acoge con beneplácito la celebración de reuniones periódicas entre representantes superiores del Grupo de Amigos y las Naciones Unidas en Ginebra y alienta a ambas partes a participar activamente en la próxima reunión;

11. Insta a las partes a que participen en forma más activa, periódica y estructurada en la labor de los grupos de tareas establecidos en la primera reunión de Ginebra (para abordar cuestiones en las esferas prioritarias relativas a la cooperación económica, el retorno de refugiados y desplazados dentro del país, y cuestiones políticas y de seguridad) y complementados por los grupos de trabajo establecidos en Sochi en marzo de 2003, y reitera que las actividades que se realicen en esas tres esferas prioritarias con miras a obtener resultados concretos siguen siendo fundamentales para crear una base común entre las partes georgiana y abjasia y, en última instancia, celebrar negociaciones provechosas sobre la concertación de un arreglo político general basado en el documento titulado "Principios básicos de la distribución de competencias entre Tbilisi y Sujumi" y su carta de envío;

12. Alienta a las partes a que, a ese respecto, continúen sus deliberaciones sobre las garantías de seguridad con la participación del Grupo de Amigos;

13. Exhorta una vez más a las partes a que tomen medidas concretas para revitalizar el proceso de paz en todos sus aspectos principales, incluida su labor en el Consejo de Coordinación y sus mecanismos pertinentes, a fin de consolidar los resultados de la reunión de Yalta sobre medidas de fomento 
de la confianza celebrada en marzo de 2001 (S/2001/242) y poner en práctica las propuestas acordadas en esa ocasión de manera decidida y en cooperación, con miras a celebrar una cuarta conferencia sobre medidas de fomento de la confianza, y acoge con beneplácito el propósito manifestado por Alemania de ser país anfitrión de esa conferencia a la espera de que se avance en el proceso de solución del conflicto;

14. Destaca que los contactos a nivel de la sociedad civil pueden fortalecer la confianza mutua y exhorta a las dos partes a que faciliten esos contactos;

15. Destaca la necesidad urgente de lograr progresos en la cuestión de los refugiados y los desplazados dentro del país, exhorta a ambas partes a que demuestren verdadero empeño en prestar especial atención a su regreso y emprendan esa labor en estrecha coordinación con la UNOMIG y en consulta con el ACNUR y el Grupo de Amigos;

16. Insta a que la carta de intención sobre los que regresan propuesta por la Representante Especial del Secretario General sea ultimada y firmada cuanto antes y observa con beneplácito las reuniones que, con la participación de la Representante Especial del Secretario General y el ACNUR, celebró el grupo de trabajo de Sochi sobre refugiados y desplazados dentro del país;

17. Reafirma que son inaceptables los cambios de población resultantes del conflicto, reafirma también el derecho inalienable de todos los refugiados y desplazados dentro del país afectados por el conflicto a regresar a sus hogares en condiciones dignas y de seguridad, de conformidad con el derecho internacional y las disposiciones del Acuerdo Cuatripartito de 4 de abril de 1994 (S/1994/397, anexo II) y la Declaración de Yalta;

18. Recuerda que los abjasios tienen la responsabilidad particular de proteger a los que han regresado y facilitar el regreso de los que todavía siguen desplazados;

19. Manifiesta su beneplácito por la continuación de las actividades del PNUD en los distritos de Gali, Ochamchira y Tkvarcheli y la apertura de las oficinas del PNUD en Sujumi y Gali;

20. Insta una vez más a las partes a que pongan en práctica las recomendaciones de la Misión de Evaluación Conjunta al sector de Gali (noviembre de 2000), lamenta que no se haya logrado avanzar a ese respecto pese a la favorable acogida de esas recomendaciones por las partes en la primera reunión de Ginebra y pide una vez más a los abjasios que acepten que la filial en Gali de la Oficina de Derechos Humanos en Sujumi sea abierta lo antes posible y 


\section{DOCUMENTACIÓN}

establezcan las condiciones de seguridad necesarias para que funcione sin obstáculos;

21. Reitera su preocupación de que, pese a que ha comenzado el despliegue de un componente de policía civil como parte de la UNOMIG, aprobado en la resolución 1494 (2003) y acordado por las partes, todavía está pendiente el despliegue de los efectivos restantes en el sector de Gali y pide a los abjasios que permitan el rápido despliegue del componente de policía en esa región;

22. Insta en particular a los abjasios a que hagan cumplir mejor la ley respecto de la población local y resuelvan el problema que plantea el hecho de que aún no se imparte enseñanza en su idioma materno a la población de origen georgiano;

23. Acoge con satisfacción las medidas tomadas por los georgianos para poner fin a las actividades de los grupos armados ilícitos y alienta a que sigan adoptándose esas medidas;

24. Condena las transgresiones de lo dispuesto en el Acuerdo de Cesación del Fuego y Separación de Fuerzas firmado en Moscú el 14 de mayo de 1994 (S/1994/583, anexo I);

25. Observa con beneplácito que se sigue manteniendo la calma relativa en el valle del Kodori y condena las matanzas y los secuestros de civiles en el distrito de Gali;

26. Insta a las partes a que se atengan a las disposiciones de los protocolos sobre cuestiones de seguridad en el distrito de Gali firmados el 19 de enero de 2004 y el 8 de octubre de 2003, continúen celebrando reuniones periódicas y cooperen más estrechamente entre sí para mejorar la seguridad en el sector de Gali y toma nota de que los abjasios han vuelto a participar en las reuniones cuatripartitas y el Grupo Mixto de Investigación;

27. Reitera su llamamiento a los georgianos para que den garantías de seguridad amplias a fin de que las patrullas conjuntas de la UNOMIG y de la fuerza de mantenimiento de la paz de la CEI observen en forma independiente y periódica la situación en el valle del alto Kodori;

28. Subraya que ambas partes tienen la responsabilidad primordial de garantizar una seguridad adecuada y la libertad de circulación de la UNOMIG, la fuerza de mantenimiento de la paz de la CEI y demás personal internacional;

29. Condena enérgicamente a ese respecto los repetidos secuestros de personal de esas misiones en el pasado, deplora profundamente que no se haya identificado o puesto a disposición de los tribunales a ninguno de los au- 
tores, reitera que es responsabilidad de las partes poner fin a esa situación de impunidad y las exhorta a que tomen las medidas que corresponden;

30. Exhorta también una vez más a las partes a que tomen todas las medidas necesarias para identificar a los responsables del derribo de un helicóptero de la UNOMIG el 8 de octubre de 2001 y ponerlos a disposición de los tribunales, y a que informen a la Representante Especial del Secretario General de las medidas tomadas, en particular en la investigación penal;

31. Decide prorrogar el mandato de la UNOMIG por un nuevo período que concluirá el 31 de julio de 2005 y revisarlo, según corresponda, en caso de que se modifique el mandato de la fuerza de mantenimiento de la paz de la CEI;

32. Pide al Secretario General que siga manteniéndolo informado periódicamente y le presente un informe sobre la situación en Abjasia (Georgia) tres meses después de que se apruebe esta resolución;

33. Decide seguir ocupándose activamente de la cuestión.

\section{RESOLUCIÓN 1615}

(29 de julio de 2005)

\section{El Consejo de Seguridad,}

Recordando todas sus resoluciones sobre la cuestión, en particular la resolución 1582 (2005), de 28 de enero de 2005 (S/RES/1582),

Acogiendo con beneplácito el informe del Secretario General de 14 de julio de 2005,

Recordando las conclusiones de las cumbres de Lisboa (S/1997/57, anexo) y Estambul de la Organización para la Seguridad y la Cooperación en Europa (OSCE) relativas a la situación en Abjasia (Georgia),

Recordando los principios pertinentes que figuran en la Convención sobre la Seguridad del Personal de las Naciones Unidas y el Personal Asociado, aprobada el 9 de diciembre de 1994,

Deplorando que todavía no se haya identificado a los autores del derribo de un helicóptero de la Misión de Observadores de las Naciones Unidas en Georgia (UNOMIG) ocurrido el 8 de octubre de 2001, en que perdieron la vida las nueve personas que viajaban a bordo,

Destacando que es inaceptable que se siga sin avanzar en cuestiones fundamentales para alcanzar un arreglo general del conflicto en Abjasia (Georgia), 


\section{DOCUMENTACIÓN}

Acogiendo con beneplácito, sin embargo, el impulso positivo que han dado al proceso de paz dirigido por las Naciones Unidas las reuniones de alto nivel del Grupo de Amigos celebradas periódicamente en Ginebra y las reuniones en la cumbre entre la Federación de Rusia y Georgia,

Acogiendo con beneplácito las importantes aportaciones que han hecho la UNOMIG y las Fuerzas Colectivas de Mantenimiento de la Paz de la Comunidad de Estados Independientes (fuerza de mantenimiento de la paz de la CEI) a la estabilización de la situación en la zona de conflicto y destacando la importancia que asigna a la estrecha cooperación que existe entre ellas en la ejecución de sus mandatos respectivos,

1. Reafirma la determinación de todos los Estados Miembros de preservar la soberanía, independencia e integridad territorial de Georgia dentro de sus fronteras internacionalmente reconocidas y la necesidad de definir el estatuto de Abjasia dentro del Estado de Georgia en estricta conformidad con esos principios;

2. Encomia y apoya firmemente las continuas gestiones realizadas por el Secretario General y su Representante Especial, con la asistencia de la Federación de Rusia en su calidad de facilitadora, así como del Grupo de Amigos del Secretario General y de la OSCE, para promover la estabilización de la situación y lograr un arreglo político general que debe comprender un acuerdo sobre el estatuto político de Abjasia dentro del Estado de Georgia;

3. Reitera su firme apoyo al documento titulado "Principios básicos de la distribución de competencias entre Tbilisi y Sujumi” y su carta de envío, preparados y respaldados plenamente por todos los miembros del Grupo de Amigos;

4. Deplora profundamente la negativa reiterada de la parte de Abjasia a discutir el fondo de ese documento, insta encarecidamente una vez más a la parte de Abjasia a acusar recibo del documento y su carta de envío, insta a ambas partes a que, seguidamente, los examinen con detenimiento y apertura de miras y entablen negociaciones constructivas sobre su fondo, e insta a quienes tengan influencia sobre las partes a promover este resultado;

5. Deplora también que no se avance en la iniciación de negociaciones sobre el estatuto político y recuerda una vez más que esos documentos tienen por objeto facilitar la celebración de negociaciones provechosas entre las partes, bajo la dirección de las Naciones Unidas, sobre el estatuto de Abjasia dentro del Estado de Georgia y no pretenden imponer ni dictar una solución concreta a las partes;

6. Exhorta a ambas partes a participar en negociaciones constructivas para lograr una solución política del conflicto y a no escatimar esfuerzos para 
superar la desconfianza mutua existente, y subraya que el proceso de negociación para lograr un arreglo político duradero aceptable para las dos partes requerirá concesiones de ambas;

7. Acoge con beneplácito el compromiso de la parte de Georgia de lograr una solución pacífica del conflicto y pide a ambas partes que sigan desvinculándose públicamente de toda retórica partidista y de manifestaciones de apoyo a las opciones militares;

8. Recuerda a todos los interesados que deben abstenerse de toda acción que pueda obstaculizar el proceso de paz;

9. Observa con beneplácito la celebración de reuniones periódicas entre altos representantes del Grupo de Amigos y las Naciones Unidas en Ginebra, así como la participación de ambas partes en la reunión más reciente, celebrada los días 7 y 8 de abril de 2005, y los compromisos expresados por las partes durante esa reunión, e insta enérgicamente a ambas partes a seguir participando de forma constructiva en las reuniones futuras;

10. Insta a las partes a que participen en forma más activa, periódica y estructurada en la labor de los grupos especiales establecidos en la primera reunión de Ginebra (para examinar cuestiones en los ámbitos prioritarios de la cooperación económica, el retorno de refugiados y desplazados dentro del país, y cuestiones políticas y de seguridad) y complementados por los grupos de trabajo establecidos en Sochi en marzo de 2003, y reitera que las actividades que se realicen en esos tres ámbitos prioritarios con miras a obtener resultados concretos siguen siendo fundamentales para crear una base común entre las partes de Georgia y de Abjasia y, en última instancia, celebrar negociaciones provechosas sobre la concertación de un arreglo político general basado en el documento titulado "Principios básicos de la distribución de competencias entre Tbilisi y Sujumi" y su carta de envío;

11. Lamenta que se cancelara la reunión sobre garantías de seguridad prevista para julio de 2005 y espera que esa reunión se lleve a cabo cuanto antes con la participación plena de ambas partes;

12. Acoge favorablemente que el 12 de mayo de 2005 se firmara un protocolo que incluye medidas para fortalecer la aplicación del Acuerdo de Cesación del Fuego y Separación de Fuerzas firmado en Moscú en 1994;

13. Exhorta una vez más a las partes a que tomen medidas concretas para revitalizar el proceso de paz en todos sus aspectos principales, incluida su labor en el Consejo de Coordinación y sus mecanismos pertinentes, a fin de consolidar los resultados de la reunión de Yalta sobre medidas de fomento de la confianza celebrada en marzo de 2001 (S/2001/242) y poner en prácti- 


\section{DOCUMENTACIÓN}

ca las propuestas acordadas en esa ocasión de manera decidida y en cooperación, con miras a celebrar una cuarta conferencia sobre medidas de fomento de la confianza, y acoge con beneplácito el propósito manifestado por Alemania de ser el país anfitrión de esa conferencia sobre cooperación económica y medidas de fomento de la confianza a la espera de que se avance en el proceso de solución del conflicto;

14. Acoge favorablemente las novedades positivas que se han registrado para la reapertura del ferrocarril entre Sochi y Tbilisi y el retorno de los refugiados y los desplazados dentro del país;

15. Señala que los contactos a nivel de la sociedad civil pueden aumentar la confianza mutua y exhorta a las dos partes a que los faciliten;

16. Destaca la necesidad urgente de lograr progresos en la cuestión de los refugiados y los desplazados dentro del país, exhorta a ambas partes a que demuestren verdadero empeño en prestar especial atención a su regreso y emprendan esa labor en estrecha coordinación con la UNOMIG y en consulta con la Oficina del Alto Comisionado de las Naciones Unidas para los Refugiados (ACNUR) y el Grupo de Amigos;

17. Insta a que la carta de intención sobre los que regresan, propuesta por la Representante Especial del Secretario General, sea ultimada y firmada cuanto antes y observa con beneplácito las reuniones que, con la participación de la Representante Especial del Secretario General y el ACNUR, celebró el grupo de trabajo de Sochi sobre refugiados y desplazados dentro del país;

18. Reafirma que son inaceptables los cambios de población resultantes del conflicto, reafirma también los derechos inalienables de todos los refugiados y desplazados dentro del país afectados por el conflicto y subraya que tienen el derecho a regresar a sus hogares en condiciones dignas y de seguridad, de conformidad con el derecho internacional y las disposiciones del Acuerdo Cuatripartito de 4 de abril de 1994 (S/1994/397, anexo II) y la Declaración de Yalta;

19. Recuerda que la parte de Abjasia tiene la responsabilidad particular de proteger a los que han regresado y facilitar el regreso de los que todavía siguen desplazados;

20. Manifiesta su beneplácito por la continuación de las actividades del Programa de las Naciones Unidas para el Desarrollo (PNUD) en los distritos de Gali, Ochamchira y Tkvarcheli y la apertura de las oficinas del PNUD en Sujumi y Gali;

21. Insta una vez más a las partes a que pongan en práctica las recomendaciones de la Misión de Evaluación Conjunta al sector de Gali (noviembre 
de 2000), deplora que no se haya avanzado a ese respecto pese a la favorable acogida de esas recomendaciones por las partes en la primera reunión de Ginebra y exhorta una vez más a la parte de Abjasia que acepte que la filial en Gali de la Oficina de Derechos Humanos en Sujumi sea abierta lo antes posible y se establezcan las condiciones de seguridad necesarias para que funcione sin obstáculos;

22. Reitera su preocupación porque, pese a que ha comenzado el despliegue de un componente de policía civil como parte de la UNOMIG, aprobado en la resolución 1494 (2003) y convenido por las partes, todavía está pendiente el despliegue de los efectivos restantes en el sector de Gali, y exhorta a la parte de Abjasia que permita el rápido despliegue del componente de policía en esa región;

23. Insta en particular a la parte de Abjasia a que las fuerzas del orden protejan mejor a la población local y resuelva el problema que plantea el hecho de que aún no se imparta enseñanza en su idioma materno a la población de origen georgiano;

24. Observa con satisfacción las medidas tomadas por la parte de Georgia para poner fin a las actividades de los grupos armados ilícitos y alienta a que se sigan manteniendo esas medidas;

25. Condena las transgresiones de lo dispuesto en el Acuerdo de Cesación del Fuego y Separación de Fuerzas firmado en Moscú el 14 de mayo de 1994 (S/1994/583, anexo I);

26. Observa con beneplácito que se mantiene la calma relativa en el valle del Kodori y condena que prosigan las actividades delictivas, incluidas las matanzas y los secuestros de civiles, en los distritos de Gali y Zugdidi;

27. Insta a las partes a que se atengan a las disposiciones de los protocolos sobre cuestiones de seguridad en el distrito de Gali firmados el 19 de enero de 2004 y el 8 de octubre de 2003, continúen celebrando reuniones periódicas y cooperen más estrechamente entre sí para mejorar la seguridad en el sector de Gali, y toma nota de que la parte de Abjasia ha vuelto a participar en las reuniones cuatripartitas y el Grupo Mixto de Investigación;

28. Reitera su llamamiento a la parte de Georgia para que dé garantías de seguridad amplias a fin de que las patrullas conjuntas de la UNOMIG y de la fuerza de mantenimiento de la paz de la CEI observen en forma independiente y periódica la situación en el valle del alto Kodori;

29. Subraya que ambas partes tienen la responsabilidad primordial de garantizar una seguridad adecuada y la libertad de circulación de la UNOMIG, la fuerza de mantenimiento de la paz de la CEI y demás personal internacional, y les exhorta a que cumplan sus obligaciones al respecto; 


\section{DOCUMENTACIÓN}

30. Condena enérgicamente a ese respecto los repetidos secuestros de personal de esas misiones ocurridos en el pasado, deplora profundamente que no se haya identificado o puesto a disposición de los tribunales a ninguno de los autores, reitera que es responsabilidad de las partes poner fin a esa situación de impunidad y las exhorta a que tomen las medidas que corresponden;

31. Exhorta también una vez más a las partes a que tomen todas las medidas necesarias para identificar a los responsables del derribo de un helicóptero de la UNOMIG el 8 de octubre de 2001 y ponerlos a disposición de la justicia y a que informen a la Representante Especial del Secretario General de las medidas tomadas, en particular en la investigación penal;

32. Acoge favorablemente el esfuerzo que está realizando la UNOMIG para aplicar la política del Secretario General de tolerancia cero respecto de la explotación y los abusos sexuales y para asegurar que su personal cumpla cabalmente el código de conducta de las Naciones Unidas, pide al Secretario General que siga adoptando todas las medidas necesarias a este respecto y mantenga informado al Consejo de Seguridad, e insta a los países que aportan contingentes a que adopten las medidas preventivas apropiadas, incluso mediante actividades de concienciación previas al despliegue, y adopten medidas disciplinarias y de otra índole para asegurar una plena rendición de cuentas en los casos de conducta de esa índole en que esté involucrado su personal;

33. Decide prorrogar el mandato de la UNOMIG por un nuevo período que concluirá el 31 de enero de 2006 y revisarlo, según corresponda, en caso de que se modifique el mandato de la fuerza de mantenimiento de la paz de la CEI;

34. Pide al Secretario General que siga manteniéndolo informado periódicamente y le presente un informe sobre la situación en Abjasia (Georgia) tres meses después de que se apruebe esta resolución;

35. Decide seguir ocupándose activamente de la cuestión.

\section{GUINEA-BISSAU}

\section{RESOLUCIÓN 1580}

(22 de diciembre de 2004)

\section{El Consejo de Seguridad,}

Reafirmando sus resoluciones anteriores 1216 (1998), de 21 de diciembre de 1998, y 1233 (1999), de 6 de abril de 1999, y la declaración de su Presidente de 2 de noviembre de 2004 (S/PRST/2004/41), 
Expresando su profunda preocupación por los acontecimientos ocurridos en Guinea-Bissau, en particular la sublevación militar de 6 de octubre de 2004 que dio lugar al asesinato del Jefe de Estado Mayor de las Fuerzas Armadas, General Veríssimo Correia Seabra, y del portavoz de las Fuerzas Armadas, Coronel Domingos de Barros, y que ha puesto en peligro los progresos logrados desde la instalación del nuevo Gobierno después de las elecciones legislativas de marzo de 2004,

Destacando que esos acontecimientos demuestran la fragilidad del proceso de transición en curso y de las instituciones políticas nacionales, y reconociendo los riesgos que crean para la conclusión del proceso de transición,

Observando con preocupación que los actos reiterados de inestabilidad y agitación ponen en peligro las iniciativas encaminadas a un desarrollo económico y social sostenible y pueden reducir la confianza de los asociados bilaterales y de la comunidad internacional,

Subrayando que el Gobierno de Guinea-Bissau y las autoridades nacionales deben seguir dedicados a la promoción del imperio de la ley y la lucha contra la impunidad,

Acogiendo con beneplácito el informe del Secretario General sobre Guinea-Bissau y las actividades de la Oficina de las Naciones Unidas de Apoyo a la Consolidación de la Paz en ese país (UNOGBIS), de 15 de diciembre de 2004 (S/2004/969), y las recomendaciones en él contenidas,

Reafirmando su plena determinación de promover la paz y la estabilidad en Guinea-Bissau,

1. Decide prorrogar el mandato de la UNOGBIS, como misión política especial, por un año a partir de la fecha de aprobación de la presente resolución;

2. Decide también revisar el mandato de la UNOGBIS como sigue:

a) Apoyar todas las gestiones encaminadas a fortalecer el diálogo político y promover la reconciliación nacional y el respeto del imperio de la ley y de los derechos humanos;

b) Apoyar los esfuerzos de todas las partes interesadas nacionales para asegurar la plena restauración de la normalidad constitucional de acuerdo con las disposiciones de la Carta de Transición Política de 28 de septiembre de 2003, incluso mediante la celebración de elecciones presidenciales libres y transparentes;

c) Prestar asistencia para la celebración de esas elecciones en estrecha cooperación con el equipo de las Naciones Unidas en el país y otros asociados internacionales; 


\section{DOCUMENTACIÓN}

d) Prestar asistencia para fortalecer los mecanismos nacionales de prevención de conflictos durante el resto del período de transición y después de éste;

e) Alentar y apoyar las iniciativas nacionales para reformar el sector de la seguridad, incluido el establecimiento de relaciones estables entre civiles y militares, y recabar apoyo internacional para esas iniciativas;

f) Alentar al Gobierno a ejecutar plenamente el Programa de Acción de las Naciones Unidas para prevenir, combatir y erradicar el tráfico ilícito de armas pequeñas y armas ligeras en todos sus aspectos;

g) Colaborar estrechamente con el Coordinador Residente y el equipo de las Naciones Unidas en el país para movilizar asistencia financiera internacional a fin de que el Gobierno pueda atender sus necesidades logísticas y financieras inmediatas y aplicar su estrategia de reconstrucción nacional y desarrollo económico y social;

h) En el marco de una estrategia amplia de consolidación de la paz, apoyar activamente los esfuerzos del sistema de las Naciones Unidas y de los demás asociados de Guinea-Bissau con miras a fortalecer las instituciones y estructuras del Estado para que puedan sostener el imperio de la ley, el respeto de los derechos humanos y el funcionamiento libre e independiente de los poderes ejecutivo, legislativo y judicial del Estado;

3. Alienta a las autoridades de Guinea-Bissau a fortalecer el diálogo político y promover relaciones constructivas entre civiles y militares, como medio de avanzar hacia la conclusión pacífica de la transición política, incluida la celebración de elecciones presidenciales prevista en la Carta de Transición Política;

4. Exhorta a la Asamblea Nacional de Guinea-Bissau a que, al mismo tiempo que examina la posibilidad de conceder una amnistía a todas las personas que hayan participado en intervenciones militares desde 1980, tenga en cuenta los principios de justicia y de la lucha contra la impunidad;

5. Insta decididamente al Gobierno a que, junto con las autoridades militares y otras partes interesadas, llegue lo antes posible a un acuerdo sobre un plan nacional de reforma del sector de la seguridad, en particular la reforma militar;

6. Invita al Secretario General a establecer un Fondo de Emergencia, que será administrado por el Programa de las Naciones Unidas para el Desarrollo, para apoyar las iniciativas relacionadas con la planificación y ejecución de la reforma militar;

7. Hace un llamamiento a la comunidad internacional para que siga prestando asistencia con el objeto de ayudar a Guinea-Bissau a atender sus 
necesidades inmediatas y sus problemas estructurales, en particular mediante contribuciones adicionales al Fondo de Gestión Económica de Emergencia, así como al nuevo Fondo mencionado supra;

8. Alienta el establecimiento de un mecanismo conjunto de coordinación entre las Naciones Unidas, la Comunidad Económica de Estados del África Occidental y la Comunidad de Países de Lengua Portuguesa para asegurar la sinergia y la complementariedad;

9. Encomia a las instituciones de Bretton Woods por haber mantenido la asistencia a Guinea-Bissau y las alienta a continuar esa asistencia;

10. Pide al Secretario General que haga un examen de la UNOGBIS con miras a adaptar sus capacidades a las necesidades del mandato revisado;

11. Pide además al Secretario General que lo tenga estrecha y periódicamente informado de los acontecimientos sobre el terreno y de la aplicación de la presente resolución, en particular de lo dispuesto en los párrafos 2 y $5 \mathrm{su}$ pra, $\mathrm{y}$, a este respecto, pide al Secretario General que le presente un informe cada tres meses a partir de la fecha de aprobación de la presente resolución;

12. Decide seguir ocupándose activamente de la cuestión.

\section{HAITÍ}

\section{RESOLUCIÓN 1576}

(29 de noviembre de 2004)

\section{El Consejo de Seguridad,}

Reafirmando su resolución 1542 (2004), de 30 de abril de 2004, y recordando su resolución 1529 (2004), de 29 de febrero de 2004, y las declaraciones de su Presidencia sobre la situación en Haití,

Encomiando la labor realizada por el Representante Especial del Secretario General en apoyo de las actividades del Gobierno de transición y de todas las entidades políticas de Haití con miras a emprender un proceso de diálogo y reconciliación nacionales de carácter amplio e incluyente, en particular la celebración de elecciones libres e imparciales en 2005 y el subsiguiente traspaso de poderes a las autoridades elegidas,

Subrayando que la labor de reconciliación política y reconstrucción económica sigue siendo fundamental para la estabilidad y seguridad de Haití y destacando, en este sentido, que todos los Estados Miembros de las Naciones 


\section{DOCUMENTACIÓN}

Unidas, en particular los de la región, deben seguir respaldando esa labor en apoyo del Gobierno de transición,

Instando al Gobierno de transición a que siga avanzando en la aplicación del marco de cooperación provisional, especialmente elaborando proyectos concretos de desarrollo económico en estrecha cooperación con la comunidad internacional y con la plena asistencia de ésta, en particular las Naciones Unidas y las instituciones financieras internacionales,

Acogiendo con satisfacción el establecimiento del grupo básico que se ocupa de las cuestiones relativas a Haití y del Grupo Asesor Especial sobre Haití del Consejo Económico y Social,

Condenando todos los actos de violencia y los intentos por parte de algunos grupos armados de desempeñar en el país funciones no autorizadas de mantenimiento del orden público,

Destacando, en este contexto, la urgente necesidad de llevar a cabo programas de desarme, desmovilización y reinserción e instando al Gobierno de transición a que establezca sin dilación la Comisión Nacional de desarme, desmovilización y reinserción,

Condenando también todas las transgresiones de los derechos humanos e instando al Gobierno de transición de Haití a que adopte todas las medidas necesarias para poner fin a la impunidad,

Preocupado ante las detenciones arbitrarias por motivos exclusivamente políticos y exhortando al Gobierno de transición a que libere a aquellos contra los cuales no se hayan interpuesto cargos,

Exhortando también a la comunidad internacional a que continúe atendiendo, en pleno apoyo del Gobierno de transición, las necesidades humanitarias causadas por los desastres naturales en diversas partes del país,

Acogiendo con beneplácito la contribución hecha por los Estados Miembros a la Misión de Estabilización de las Naciones Unidas en Haití (MINUSTAH) e instando a los países que aportan contingentes y fuerzas de policía a que cumplan los cronogramas convenidos para el despliegue y observando en particular la necesidad de ampliar el número de agentes de policía francófonos,

Observando que persisten obstáculos a la estabilidad política, social y económica de Haití y determinando que la situación en Haití sigue constituyendo una amenaza para la paz y la seguridad internacionales en la región,

Actuando en virtud del Capítulo VII de la Carta de las Naciones Unidas en relación con lo descrito en la sección 1 del párrafo 7 de la parte dispositiva de la resolución 1542 (2004), 
1. Decide prorrogar el mandato de la MINUSTAH previsto en la resolución 1542 (2004) hasta el $1^{\circ}$ de junio de 2005, con la intención de renovarlo por nuevos períodos;

2. Alienta al Gobierno de transición a que siga explorando activamente todas las vías posibles para incluir en el proceso democrático y electoral a quienes han quedado actualmente excluidos del proceso de transición pero que hayan rechazado la violencia;

3. Acoge con satisfacción el informe del Secretario General de fecha 18 de noviembre de 2004 (S/2004/908) sobre la Misión de Estabilización de las Naciones Unidas en Haití (MINUSTAH) y hace suyas las recomendaciones hechas por el Secretario General en los párrafos 52 a 57;

4. Insta a las instituciones financieras internacionales competentes y a los países donantes interesados a que desembolsen sin demora los fondos prometidos en la Conferencia internacional de donantes para Haití, celebrada en Washington, D.C. los días 19 y 20 de julio de 2004;

5. Pide al Secretario General que le presente, al menos cada tres meses, un informe sobre la ejecución del mandato de la MINUSTAH;

6. Decide seguir ocupándose de la cuestión.

\section{RESOLUCIÓN 1601}

(31 de mayo de 2005)

El Consejo de Seguridad,

Reafirmando sus resoluciones 1576 (2004), de 29 de noviembre de 2004, y 1542 (2004) de 30 de abril de 2004, y recordando su resolución 1529 (2004), de 29 de febrero de 2004, las declaraciones pertinentes de su Presidencia, y el informe del Consejo de Seguridad sobre su misión en Haití del 13 al 16 de abril (S/2005/302),

Determinando que la situación en Haití sigue constituyendo una amenaza para la paz y la seguridad internacionales en la región,

Actuando en virtud del Capítulo VII de la Carta de las Naciones Unidas, en relación con lo descrito en la sección 1 del párrafo 7 de la parte dispositiva de la resolución 1542 (2004),

1. Decide prorrogar el mandato de la MINUSTAH, previsto en la resolución 1542 (2004), hasta el 24 de junio de 2005, con la intención de renovarlo por nuevos períodos;

2. Acoge con beneplácito el informe del Secretario General S/2005/313;

3. Decide seguir ocupándose de la cuestión. 


\section{DOCUMENTACIÓN}

\section{RESOLUCIÓN 1608}

(22 de junio de 2005)

\section{El Consejo de Seguridad,}

Reafirmando las resoluciones 1542 (2004) y 1576 (2004) y recordando la resolución 1529 (2004), las declaraciones de su Presidencia sobre la cuestión y el informe de la Misión del Consejo de Seguridad que visitó Haití del 13 al 16 de abril de 2005 (S/2005/302),

Reafirmando su firme adhesión a la soberanía, independencia, integridad territorial y unidad de Haití,

Insistiendo en que en 2005, de conformidad con el calendario establecido, deben celebrarse elecciones libres y limpias, abiertas a todos los partidos políticos que hayan renunciado a la violencia y con la más amplia participación posible del pueblo haitiano, y en que las autoridades democráticamente elegidas deberán asumir sus cargos el 7 de febrero de 2006,

Afirmando su determinación de asegurar un entorno seguro y estable en el que pueda tener lugar el proceso electoral,

Condenando todas las violaciones de los derechos humanos, entre ellas la falta de las debidas garantías procesales y las prolongadas detenciones en espera de juicio, y exhortando al Gobierno de Transición de Haití a que tome todas las medidas necesarias para poner fin a la impunidad y para avanzar en la observancia del imperio de la ley, incluso mediante la introducción de reformas en la Policía Nacional de Haití y en los sistemas judicial y penitenciario,

Reafirmando la importancia de contar con la competencia apropiada en las cuestiones relacionadas con el género en las operaciones de mantenimiento de la paz y en la consolidación de la paz después de los conflictos, de conformidad con la resolución 1325 (2000), recordando la necesidad de ocuparse de la violencia contra las mujeres y los niños, y alentando a la Misión de Estabilización de las Naciones Unidas en Haití (MINUSTAH) así como al Gobierno de Transición de Haití a que se ocupen activamente de esas cuestiones,

Subrayando que la pobreza generalizada es una causa importante de la agitación en Haití e insistiendo en que no puede haber verdadera estabilidad si Haití no afianza su economía, incluso mediante una estrategia a largo plazo para el desarrollo sostenible y la consolidación de sus instituciones,

Observando con satisfacción que el Gobierno de Transición de Haití, el Programa de las Naciones Unidas para el Desarrollo y la MINUSTAH han 
aprobado un programa nacional de desarme, desmovilización y reintegración, e insistiendo en que su aplicación es esencial para que la labor de estabilización en sentido más general tenga éxito,

Recordando que la seguridad, la reconciliación política y la reconstrucción económica siguen siendo fundamentales para la estabilidad de Haití,

Observando que la población de Haití debe asumir la responsabilidad de lograr la estabilidad, el desarrollo económico y social y el orden público,

Determinando que la situación en Haití sigue constituyendo una amenaza para la paz y la seguridad internacionales,

Actuando en virtud del Capítulo VII de la Carta de las Naciones Unidas, como se señala en la sección 1 del párrafo 7 de la resolución 1542 (2004),

1. Decide prorrogar el mandato de la MINUSTAH, que figura en la resolución 1542 (2004), hasta el 15 de febrero de 2006, con la intención de renovarlo por sucesivos períodos;

2. Acoge con beneplácito el informe del Secretario General de fecha 19 de mayo de 2005 sobre la MINUSTAH (S/2005/313) y apoya las siguientes recomendaciones que figuran en los párrafos 44 a 52:

a) Un aumento temporal de 750 efectivos en las fuerzas militares actualmente autorizadas de la MINUSTAH durante el período electoral y la ulterior transición política a fin de establecer una fuerza de reacción rápida en Haití que ofrezca una mayor seguridad, especialmente en Puerto Príncipe y sus alrededores;

b) Un aumento de 50 efectivos militares para establecer un cuartel general de sector en Puerto Príncipe, en la inteligencia de que la MINUSTAH mejorará a todos los niveles la coordinación entre el componente militar y el de policía para asegurar operaciones eficientes y mejor integradas, incluso destinando oficiales de policía civil de las Naciones Unidas a ese cuartel general;

c) Un aumento temporal de 275 oficiales de policía civil en el componente actual de la MINUSTAH, durante el período electoral y la ulterior transición política, para ofrecer una mayor seguridad;

d) Una evaluación de los sistemas judicial y penitenciario de Haití para estudiar, entre otras cosas, la posibilidad de un mayor apoyo de la comunidad internacional y de un papel más activo de la MINUSTAH, que será presentada al Consejo de Seguridad lo antes posible;

3. Decide que, por un período transitorio, la MINUSTAH constará de un componente militar de hasta 7.500 efectivos, entre oficiales y tropa, y de hasta 1.897 policías civiles. Pide al Secretario General que prepare a su debido 


\section{DOCUMENTACIÓN}

tiempo una estrategia de reducción progresiva de los efectivos de la MINUSTAH en el período postelectoral, en función de la situación sobre el terreno;

4. Pide al Secretario General que le comunique el plan general para la celebración satisfactoria de las elecciones en Haití, con inclusión de la inscripción de votantes, la seguridad, la logística, la educación cívica, la observación e información detallada sobre el presupuesto; exhorta a las autoridades de Haití a que aumenten y aceleren las diligencias para preparar las elecciones y asegurarse de que se celebren sin tropiezos; e insta a los donantes internacionales a que proporcionen los recursos necesarios para apoyar el proceso electoral;

5. Pide también al Secretario General que le comunique el plan de reforma de la Policía Nacional de Haití formulado por la MINUSTAH y las autoridades de Haití, en que se hace referencia a la dotación prevista, las normas, el calendario de ejecución y los recursos;

6. Pide que la MINUSTAH concentre la utilización de sus recursos, incluidos los de policía civil, en aumentar la seguridad y la protección en el período electoral; incluida una revisión, como corresponda, del mandato de cada uno de los oficiales de policía civil;

7. Pide que la MINUSTAH y las autoridades de Haití tomen todas las medidas necesarias para lograr una coordinación óptima entre la policía civil de la MINUSTAH y la Policía Nacional de Haití;

8. Reafirma la autoridad de la MINUSTAH para investigar y certificar al personal nuevo de la Policía Nacional de Haití y al existente a efectos de su prestación de servicios, y exhorta al Gobierno de Transición de Haití a que se asegure de que el personal de la Policía Nacional de Haití no preste servicios a menos que esté certificado y vele por que las autoridades de Haití apliquen plenamente y sin demora el asesoramiento técnico y las recomendaciones de la MINUSTAH a todos los niveles;

9. Insta a la MINUSTAH a que ponga en funcionamiento lo antes posible el Centro Mixto de Análisis de la Misión a fin de reunir y aprovechar mejor la información de que disponen sus componentes militar, de policía y civil; y le pide también que los recursos de aviación de la MINUSTAH sean utilizados en forma eficiente y eficaz en apoyo de las operaciones de seguridad;

10. Exhorta al Gobierno de Transición a que investigue en forma exhaustiva y transparente los casos de violaciones de los derechos humanos, especialmente aquellos en que se halla denunciado la participación de oficiales de la Policía Nacional de Haití; pide a la MINUSTAH que, para apoyar esa 
labor, ponga en funcionamiento lo antes posible la Brigada Conjunta de Investigaciones Especiales;

11. Acoge con satisfacción el inicio del "diálogo nacional” por el Gobierno de Transición de Haití el 7 de abril de 2005, y subraya que ese diálogo debe apuntar al objetivo a largo plazo de la reconciliación nacional y, a un plazo más corto, a la celebración de elecciones limpias e inclusivas; exhorta al Gobierno de Transición de Haití a que redoble sus esfuerzos en pro de este proceso esencial e invita a todos los haitianos a participar en este diálogo sin demora;

12. Exhorta al Gobierno de Transición de Haití y a la MINUSTAH a que comiencen de inmediato la aplicación efectiva del programa de desarme, desmovilización y reintegración e insta a todos los Estados Miembros a que proporcionen oportunamente recursos financieros, humanos y técnicos en apoyo de este programa;

13. Reitera su llamamiento para que se agilice el desembolso de los fondos prometidos por instituciones financieras internacionales y donantes en la conferencia internacional de donantes sobre Haití celebrada en julio de 2004; expresa su apoyo a la conferencia de seguimiento de Cayenne, celebrada en Montreal los días 16 y 17 de junio de 2005, e insta a todos los donantes a que sigan prestando asistencia a Haití;

14. Pide a la MINUSTAH que aumente su capacidad para ejecutar proyectos de efecto rápido e insta a que se estreche la coordinación entre las diversas entidades de desarrollo en Haití para lograr una mayor eficiencia en la labor de desarrollo;

15. Invita a las instituciones de Bretton Woods a examinar la cuestión de la sostenibilidad de la deuda y de las consecuencias para Haití de la Iniciativa a favor de los países pobres muy endeudados;

16. Exhorta a la MINUSTAH a que prepare y ponga en práctica con urgencia una estrategia proactiva de comunicación y relaciones públicas a fin de que la población de Haití comprenda mejor el mandato de la MINUSTAH y la función que realiza en el país;

17. Celebra los esfuerzos realizados por la MINUSTAH para poner en práctica la política de tolerancia cero propugnada por el Secretario General respecto de la explotación y los abusos sexuales, y para garantizar que el personal cumpla plenamente el código de conducta de las Naciones Unidas, pide al Secretario General que siga tomando todas las medidas necesarias a este respecto y lo mantenga informado, y exhorta a los países que aportan contingentes a que adopten las medidas preventivas y disciplinarias que correspon- 
da para garantizar que tales actos se investiguen y castiguen adecuadamente en los casos en que esté involucrado su personal;

18. Pide al Secretario General que le presente por lo menos cada tres meses un informe sobre la aplicación efectiva del mandato de la MINUSTAH y pide además que la Secretaría mantenga periódicamente informados a los miembros del Consejo del estado de los preparativos electorales, con inclusión de cifras relativas a la inscripción de partidos y votantes y de otros datos pertinentes;

19. Decide seguir ocupándose de la cuestión.

\section{IRAQ}

\section{RESOLUCIÓN 1618}

(4 de agosto de 2005)

\section{El Consejo de Seguridad,}

Reafirmando todas sus resoluciones anteriores sobre el Iraq, en particular la resolución 1546 (2004), de 8 de junio de 2004,

Reafirmando su apoyo inquebrantable al pueblo iraquí en su transición política, tal como se expone en la resolución 1546 (2004), reafirmando además la independencia, soberanía, unidad e integridad territorial del Iraq, e instando a la comunidad internacional a que apoye al pueblo iraquí en su intento de lograr la paz, la estabilidad y la democracia,

Reafirmando también los propósitos y principios de la Carta de las Naciones Unidas y sus resoluciones pertinentes, en particular sus resoluciones 1373 (2001), de 28 de septiembre de 2001, 1566 (2004), de 8 de octubre de 2004, y 1267 (1999), de 25 de octubre de 1999, así como las resoluciones posteriores,

Reafirmando la necesidad de combatir por todos los medios, de conformidad con la Carta de las Naciones Unidas, las amenazas a la paz y la seguridad internacionales causadas por actos terroristas,

Elogiando el valor del pueblo iraquí, que trabaja con valentía en apoyo de la transición política y económica que tiene lugar actualmente, a pesar de la grave amenaza del terrorismo,

Acogiendo con beneplácito las activas medidas adoptadas por el Gobierno del Iraq para conseguir el diálogo y la unidad nacionales y alentando a que se continúe en esa labor, 
1. Condena sin reservas y en los términos más enérgicos los atentados terroristas cometidos en el Iraq, y considera que todo acto de terrorismo constituye una amenaza a la paz y la seguridad;

2. Toma nota particularmente de los atentados horrendos e indignos cometidos en las últimas semanas, que han ocasionado más de un centenar de víctimas mortales, incluidos treinta y dos niños, además de empleados de la Comisión Electoral Independiente del Iraq y un miembro y un asesor experto de la Comisión encargada de la redacción de una constitución permanente para un nuevo Iraq democrático, Mijbil Sheikh Isa y Dhamin Hussin Ubaidi;

3. Toma nota asimismo con honda preocupación de que los ataques contra diplomáticos extranjeros en el Iraq han pasado a ser más numerosos y han dado como resultado el asesinato o el secuestro de esos diplomáticos;

4. Expresa su profundo pesar y sus condolencias a las víctimas de esos atentados terroristas y a sus familias, así como al pueblo y el Gobierno del Iraq;

5. Afirma que no se debe permitir que los actos de terrorismo perturben la transición política y económica que actualmente tiene lugar en el Iraq, incluido el proceso de redacción de la constitución y el correspondiente referéndum, descrito en la resolución 1546 (2004), de 8 de junio de 2004;

6. Reafirma las obligaciones contraídas por los Estados Miembros en virtud de las resoluciones 1373 (2001), de 28 de septiembre de 2001, 1267 (1999), de 15 de octubre de 1999, 1333 (2000), de 19 de diciembre de 2000, 1390 (2002), de 16 de enero de 2002, 1455 (2003), de 17 de enero de 2003, 1526 (2004), de 30 de enero de 2004, y 1617 (2005), de 29 de julio de 2005, y otras obligaciones internacionales pertinentes, con respecto, entre otras cosas, a las actividades terroristas cometidas u originadas en el Iraq o contra sus ciudadanos, concretamente insta con energía a los Estados Miembros a que impidan el tránsito de terroristas hacia o desde el Iraq, de armas destinadas a los terroristas y de financiación de apoyo a terroristas, e insiste una vez más en la importancia de estrechar la cooperación de los países de la región, en particular los vecinos del Iraq, en este sentido;

7. Insta a todos los Estados a que, de conformidad con las obligaciones que les incumben en virtud de la resolución 1373 (2001), cooperen activamente en la labor encaminada a hallar y hacer comparecer ante la justicia a los autores, organizadores y patrocinadores de estos actos de barbarie;

8. Expresa su absoluta determinación de luchar contra el terrorismo, de conformidad con las funciones que le encomienda la Carta de las Naciones Unidas; 
9. Exhorta a la comunidad internacional a apoyar plenamente al Gobierno del Iraq en el cumplimiento de su responsabilidad de brindar protección a la comunidad diplomática, al personal de las Naciones Unidas y a los demás funcionarios civiles extranjeros que trabajan en el Iraq;

10. Decide seguir ocupándose de la cuestión.

RESOLUCIÓN 1619

(11 de agosto de 2005)

\section{El Consejo de Seguridad,}

Recordando todas sus anteriores resoluciones pertinentes sobre el Iraq, en especial las resoluciones 1500 (2003), de 14 de agosto de 2003, 1546 (2004), de 8 de junio de 2004, y 1557 (2004), de 12 de agosto de 2004,

Reafirmando la independencia, soberanía, unidad e integridad territorial del Iraq,

Recordando el establecimiento de la Misión de Asistencia de las Naciones Unidas para el Iraq (UNAMI) el 14 de agosto de 2003, prorrogada el 12 de agosto de 2004, y reafirmando que las Naciones Unidas deben desempeñar un papel destacado en la prestación de ayuda a la labor del pueblo y el Gobierno iraquíes para crear instituciones de un gobierno representativo y promover el diálogo y la unidad nacionales,

Destacando que este diálogo nacional iraquí, al que la UNAMI debe prestar asistencia, es esencial para la unidad y la estabilidad política del Iraq,

Tomando nota de la carta de fecha 3 de agosto de 2005 dirigida al Presidente del Consejo de Seguridad por el Secretario General (S/2005/509),

1. Decide prorrogar el mandato de la Misión de Asistencia de las Naciones Unidas para el Iraq (UNAMI) por otro período de doce meses desde la fecha de la presente resolución;

2. Expresa su intención de revisar el mandato de la UNAMI al cabo de los doce meses, o antes si así lo solicita el Gobierno del Iraq;

3. Decide seguir ocupándose de la cuestión. 


\section{LIBERIA}

\section{RESOLUCIÓN 1579}

(21 de diciembre de 2004)

\section{El Consejo de Seguridad,}

Recordando sus anteriores resoluciones y declaraciones de su Presidencia sobre la situación en Liberia y el África occidental,

Tomando nota de los informes del Grupo de Expertos de las Naciones Unidas sobre Liberia de fechas 24 de septiembre (S/2004/752) y 6 de diciembre de 2004 (S/2004/955), presentados de conformidad con la resolución 1549 (2004),

Tomando nota de la carta de fecha 13 de diciembre de 2004 dirigida al Presidente del Comité establecido en virtud del párrafo 21 de la resolución 1521 (2003) por el Representante Especial del Secretario General en Liberia,

Reconociendo que el nexo entre la explotación ilegal de recursos naturales tales como los diamantes y la madera, el comercio ilícito de esos recursos y la proliferación y el tráfico de armas constituye una de las fuentes que alimentan y agravan los conflictos en el África occidental, especialmente en Liberia,

Recordando que las medidas impuestas en la resolución 1521 (2003) estaban destinadas a impedir que esa explotación ilegal avivara la reanudación del conflicto en Liberia, así como a apoyar la aplicación del Acuerdo General de Paz y la extensión de la autoridad del Gobierno de Transición Nacional a todo el territorio de Liberia,

Observando con satisfacción que el pleno despliegue de la Misión de las Naciones Unidas en Liberia (UNMIL) ha contribuido a una mayor seguridad en todo el territorio de ese país, pero reconociendo que el Gobierno de Transición Nacional todavía no ha establecido su autoridad en todo el territorio de Liberia,

Observando con preocupación que el ex Presidente Charles Taylor y otras personas todavía estrechamente asociadas con él siguen participando en actividades que socavan la paz y la estabilidad en Liberia y la región,

Habiendo pasado revista a las medidas impuestas en los párrafos 2, 4, 6 y 10 de la resolución 1521 (2003) y el párrafo 1 de la resolución 1532 (2004) y a los progresos realizados en el logro de los objetivos enunciados en los párrafos 5, 7 y 11 de la misma resolución, 


\section{DOCUMENTACIÓN}

Acogiendo con beneplácito las medidas adoptadas por el Gobierno de Transición Nacional de Liberia a fin de cumplir las condiciones establecidas para levantar las medidas impuestas en la resolución 1521 (2003),

Observando que se han completado la desmovilización y el desarme, se respeta la cesación del fuego y se aplica el Acuerdo General de Paz, pero subrayando que subsisten dificultades considerables para completar la reinserción y repatriación y la reestructuración del sector de la seguridad, así como para establecer y mantener la estabilidad en Liberia y en la subregión,

Observando con preocupación que, a pesar de haber iniciado reformas importantes, el Gobierno de Transición Nacional ha avanzado poco en la tarea de establecer plenamente su autoridad y control sobre las zonas productoras de madera y asegurar que los ingresos que percibe de la industria maderera de Liberia no sean utilizados para alimentar conflictos ni de otra manera contraria a las resoluciones del Consejo, sino para fines legítimos en beneficio del pueblo liberiano, incluido el desarrollo,

Observando con beneplácito que el Gobierno de Transición Nacional de Liberia ha iniciado los preparativos para establecer un régimen eficaz de certificados de origen para el comercio de diamantes en bruto que sea transparente e internacionalmente verificable, esperando con interés la visita de representantes del Proceso de Kimberley a Liberia a principios de 2005, alentando al Gobierno para que continúe sus preparativos a ese respecto e instando a los Estados a que aumenten su apoyo a ese empeño,

Determinando que la situación en Liberia sigue constituyendo una amenaza para la paz y la seguridad internacionales en la región,

Actuando en virtud del Capítulo VII de la Carta de las Naciones Unidas,

1. Decide, sobre la base de las evaluaciones precedentes de los progresos realizados por el Gobierno de Transición Nacional de Liberia en el cumplimiento de las condiciones necesarias para levantar las medidas impuestas en la resolución 1521 (2003);

a) Prorrogar las medidas relativas a las armas y a los viajes impuestas en los párrafos 2 y 4 de la resolución 1521 (2003) por un nuevo período de 12 meses a partir de la fecha de aprobación de la presente resolución y examinarlas al cabo de seis meses;

b) Prorrogar las medidas relativas a la madera impuestas en el párrafo 10 de la resolución 1521 (2003) por un nuevo período de 12 meses a partir de la fecha de aprobación de la presente resolución y examinarlas al cabo de seis meses;

c) Prorrogar las medidas relativas a los diamantes impuestas en el párrafo 6 de la resolución 1521 (2003) por un nuevo período de seis meses a 
partir de la fecha de aprobación de la presente resolución, pero examinarlas al cabo de tres meses a la luz de los resultados de la visita de los representantes del Proceso de Kimberley y del informe preliminar del Grupo de Expertos solicitado en el párrafo $8 \mathrm{f}$ ) infra, con el objeto de levantarlas lo antes posible cuando llegue a la conclusión de que el Gobierno de Transición Nacional ha establecido un régimen eficaz de certificados de origen para el comercio de diamantes en bruto que sea transparente e internacionalmente verificable;

2. Reitera que está dispuesto a poner término a esas medidas una vez que se hayan cumplido las condiciones a que se hace referencia en el párrafo 1 de la presente resolución;

3. Alienta al Gobierno de Transición Nacional de Liberia a intensificar sus esfuerzos por cumplir esas condiciones, en particular llevando a la práctica la Iniciativa Forestal de Liberia e introduciendo las reformas necesarias en la Dirección de Desarrollo Forestal e insta a todos los miembros del Gobierno de Transición Nacional a que se empeñen en ello en beneficio del pueblo de Liberia;

4. Señala que siguen estando en vigor las medidas impuestas en el párrafo 1 de la resolución 1532 (2004) para prevenir que el ex Presidente Charles Taylor, sus familiares inmediatos, funcionarios superiores del antiguo régimen de Taylor u otros aliados o asociados cercanos utilicen fondos y bienes obtenidos indebidamente para interferir en el restablecimiento de la paz y la estabilidad en Liberia y la subregión, y reafirma su intención de examinar esas medidas al menos una vez al año;

5. Reitera su llamamiento a la comunidad internacional de donantes para que siga prestando asistencia al proceso de paz, incluso para la reinserción y la reconstrucción, contribuya generosamente a los llamamientos humanitarios unificados, desembolse lo antes posible las contribuciones prometidas en la Conferencia para la Reconstrucción de Liberia celebrada en Nueva York los días 5 y 6 de febrero de 2004, y atienda a las necesidades financieras, administrativas y técnicas inmediatas del Gobierno de Transición Nacional de Liberia, en particular para ayudarle a cumplir las condiciones mencionadas en el párrafo 1 de la presente resolución a fin de que las medidas puedan levantarse lo antes posible;

6. Reitera su exigencia de que todos los Estados se abstengan de cualquier acto que pueda contribuir a la desestabilización de la situación en la subregión, y exige también que todos los Estados del África occidental tomen medidas para impedir que su territorio sea utilizado por personas y grupos armados para preparar y perpetrar ataques contra países vecinos; 


\section{DOCUMENTACIÓN}

7. Recuerda a todos los Estados su obligación de aplicar todas las medidas indicadas en las resoluciones 1521 (2003) y 1532 (2004) y, en particular, exhorta al Gobierno de Transición Nacional de Liberia a que cumpla sin demora su obligación en virtud del párrafo 1 de la resolución 1532 (2004) de congelar los activos de todas las personas designadas por el Comité establecido en virtud del párrafo 21 de la resolución 1521 (2003) (“el Comité”);

8. Decide restablecer el Grupo de Expertos designados en virtud de la resolución 1549 (2004) por un nuevo período que concluirá el 21 de junio de 2005, con el fin de llevar a cabo las siguientes tareas:

a) Efectuar una misión de evaluación complementaria en Liberia y los países vecinos, a fin de investigar y preparar un informe sobre la aplicación y las posibles infracciones de las medidas mencionadas en el párrafo 1 de la presente resolución, incluida información que pueda servir al Comité para preparar una lista de las personas indicadas en el párrafo 4 a) de la resolución 1521 (2003) y el párrafo 1 de la resolución 1532 (2004) y sobre las diversas fuentes de financiación del comercio ilícito de armas, como los recursos naturales;

b) Evaluar las consecuencias y la eficacia de las medidas impuestas en el párrafo 1 de la resolución 1532 (2004);

c) Evaluar los progresos realizados en el cumplimiento de las condiciones mencionadas en el párrafo 1 de la presente resolución;

d) Evaluar las repercusiones humanitarias y socioeconómicas de las medidas impuestas en los párrafos 2, 4, 6 y 10 de la resolución 1521 (2003);

e) Informarle, por conducto del Comité y a más tardar el 7 de junio de 2005, sobre todas las cuestiones enunciadas en el presente párrafo;

f) Presentarle un informe preliminar, por conducto del Comité y a más tardar el 21 de marzo de 2005, sobre los progresos realizados en el cumplimiento de las condiciones para levantar las medidas relativas a los diamantes que se imponen en el párrafo 6 de la resolución 1521 (2003);

9. Pide al Secretario General que, en consulta con el Comité, nombre lo antes posible un máximo de cinco expertos con los conocimientos técnicos necesarios, en particular sobre armas, madera, diamantes, finanzas, cuestiones humanitarias y socioeconómicas y otras cuestiones pertinentes, aprovechando en lo posible los conocimientos de los miembros del Grupo de Expertos establecido en virtud de la resolución 1549 (2004), y le pide además que adopte las disposiciones financieras y de seguridad necesarias para apoyar la labor del Grupo;

10. Exhorta a la UNMIL y a las Misiones de las Naciones Unidas en Sierra Leona y Côte d'Ivoire a que sigan prestando asistencia al Comité y al 
Grupo de Expertos de conformidad con el párrafo 23 de la resolución 1521 (2003);

11. Exhorta a todos los Estados y al Gobierno de Transición Nacional de Liberia a que cooperen plenamente con el Grupo de Expertos;

12. Pide al Secretario General que le presente un informe para el $7 \mathrm{de}$ junio de 2005, con datos procedentes de todas las fuentes pertinentes, en particular el Gobierno de Transición Nacional de Liberia, la UNMIL y la Comunidad Económica de los Estados del África Occidental, sobre los progresos realizados en el cumplimiento de las condiciones mencionadas en el párrafo 1 de la presente resolución;

13. Decide seguir ocupándose de la cuestión.

\section{RESOLUCIÓN 1607}

(21 de junio de 2005)

\section{El Consejo de Seguridad,}

Recordando las resoluciones y declaraciones anteriores de su Presidencia sobre la situación en Liberia y el África occidental,

Tomando nota de los informes del Grupo de Expertos de las Naciones Unidas sobre Liberia de fechas 17 de marzo de 2005 (S/2005/176) y 13 de junio de 2005 (S/2005/360), y del informe del Secretario General de fecha 7 de junio de 2005 (S/2005/376), presentados de conformidad con la resolución 1579 (2004); Reconociendo que el nexo entre la explotación ilegal de recursos naturales como los diamantes y la madera, el comercio ilícito de esos recursos, la proliferación y el tráfico de armas y el reclutamiento y la utilización de mercenarios constituye una de las fuentes que alimentan y agravan los conflictos en el África occidental, especialmente en Liberia,

Recordando que las medidas impuestas en la resolución 1521 (2003) estaban destinadas a impedir que esa explotación ilegal propiciara la reanudación del conflicto en Liberia, así como a apoyar la aplicación del Acuerdo General de Paz y la extensión de la autoridad del Gobierno de Transición Nacional a todo el territorio de Liberia,

Expresando su preocupación por el hecho de que, si bien el despliegue de la Misión de las Naciones Unidas en Liberia (UNMIL) ha contribuido a mejorar la seguridad en todo el país, el Gobierno de Transición Nacional no ha establecido aún su autoridad en toda Liberia,

Insistiendo en la necesidad de que la comunidad internacional ayude al Gobierno de Transición Nacional a aumentar su capacidad para establecer su 


\section{DOCUMENTACIÓN}

autoridad en toda Liberia y, en particular, para establecer su control sobre las zonas productoras de diamantes y madera y sobre las fronteras del país,

Expresando su profunda preocupación por la información de que el ex Presidente Charles Taylor y otras personas todavía estrechamente asociadas con él siguen participando en actividades que socavan la paz y la estabilidad en Liberia y la región,

Habiendo pasado revista a las medidas impuestas en los párrafos 2, 4, 6 y 10 de la resolución 1521 (2003) y el párrafo 1 de la resolución 1532 (2004) y a los progresos realizados en el logro de los objetivos enunciados en los párrafos 5, 7 y 11 de la resolución 1521 (2003),

Acogiendo complacido la determinación del Grupo de Expertos de que no hay pruebas de que se esté exportando ilegalmente madera de Liberia, pero observando con preocupación que se han introducido pocas de las reformas previstas en el plan del Gobierno de Transición Nacional de Liberia que son necesarias para cumplir las condiciones enunciadas en el párrafo 11 de la resolución 1521 (2003) a los efectos de levantar las medidas relativas a la madera impuestas en el párrafo 10 de esa misma resolución,

Reconociendo que recientemente se ha puesto término al examen de las concesiones forestales y acogiendo con agrado el informe del Comité de Examen de las Concesiones Forestales,

Acogiendo con satisfacción los avances realizados por el Gobierno de Transición Nacional de Liberia en la capacitación de funcionarios en el ámbito de la extracción de diamantes, pero observando con profunda preocupación que han aumentado la extracción no autorizada y las exportaciones ilícitas de diamantes, y que el Gobierno de Transición Nacional de Liberia ha decidido conceder derechos exclusivos de explotación a una sola empresa y sin transparencia en ese proceso,

Observando con preocupación que el Gobierno de Transición Nacional de Liberia ha avanzado poco en la tarea de establecer sistemas transparentes de gestión financiera que sirvan para asegurarse de que los ingresos públicos no sean utilizados para avivar el conflicto ni de otra manera contraria a las resoluciones del Consejo, sino para fines legítimos en beneficio del pueblo liberiano, incluido el desarrollo,

Tomando nota de las conversaciones que están en marcha acerca de un plan de acción para la gobernanza económica de Liberia concebido para aplicar cuanto antes el Acuerdo General de Paz y acelerar el levantamiento de las medidas impuestas en virtud de la resolución 1521 (2003) y expresando su intención de examinar, en su caso, el Plan de Acción, 
Insistiendo en que, a pesar de que se han completado la desmovilización y el desarme, subsisten grandes problemas para completar la reintegración y la repatriación de excombatientes y para reestructurar el sector de la seguridad, así como para establecer y mantener la estabilidad en Liberia y en la subregión,

Determinando que la situación en Liberia sigue constituyendo una amenaza para la paz y la seguridad internacionales en la región,

Actuando en virtud del Capítulo VII de la Carta de las Naciones Unidas,

1. Decide, en función de las evaluaciones mencionadas de los progresos realizados por el Gobierno de Transición Nacional de Liberia en el cumplimiento de las condiciones para levantar las medidas impuestas en la resolución 1521 (2003), prorrogar las medidas relativas a los diamantes impuestas en el párrafo 6 de la resolución 1521 (2003) por un nuevo período de seis meses a partir de la fecha de aprobación de la presente resolución;

2. Exhorta al Gobierno de Transición Nacional de Liberia a redoblar sus esfuerzos, con apoyo de la UNMIL, para establecer su autoridad en las zonas productoras de diamantes y a tratar de establecer un régimen oficial de certificados de origen para el comercio de diamantes en bruto que sea transparente e internacionalmente verificable, con miras a incorporarse al Proceso de Kimberley;

3. Reitera que está dispuesto a poner término a todas las medidas impuestas en la resolución 1521 (2003) una vez que se hayan cumplido las condiciones enunciadas en los párrafos 5, 7 y 11 de esa resolución;

4. Insta al Gobierno de Transición Nacional de Liberia a que redoble cuanto antes sus esfuerzos para reformar la Dirección de Desarrollo Forestal, poner en práctica la Iniciativa Forestal de Liberia y aplicar las recomendaciones en materia de reforma que ha formulado el Comité de Examen de las Concesiones Forestales, que asegurarán la transparencia, la rendición de cuentas y la ordenación sostenible de los bosques y coadyuvarán a que se dejen de aplicar las medidas relativas a la madera impuestas en el párrafo $10 \mathrm{de}$ la resolución 1521 (2003);

5. Invita al Gobierno de Transición Nacional de Liberia a considerar la posibilidad, con la asistencia de asociados internacionales y por un período determinado, de recabar asesoramiento exterior independiente sobre la ordenación de los recursos de diamantes y madera del país a fin de aumentar la confianza de los inversionistas y atraer mayor apoyo de los donantes;

6. Señala que siguen estando en vigor las medidas impuestas en el párrafo 1 de la resolución 1532 (2004) para impedir que el ex Presidente Charles 


\section{DOCUMENTACIÓN}

Taylor, sus familiares inmediatos, altos funcionarios del ex régimen de Taylor u otros aliados o asociados cercanos utilicen fondos y bienes obtenidos indebidamente para interferir en el restablecimiento de la paz y la estabilidad en Liberia y en la subregión y reafirma su intención de examinar esas medidas por lo menos una vez al año;

7. Reitera su intención de considerar si ha de poner a disposición del Gobierno de Liberia los fondos, otros activos financieros y recursos económicos congelados en virtud del párrafo 1 de la resolución 1532 (2004) y de ser así, de qué forma, una vez que el Gobierno haya instituido mecanismos transparentes de contabilidad y auditoría para asegurar que los ingresos públicos se utilicen de manera responsable y en beneficio directo del pueblo de Liberia;

8. Recalca su preocupación por el hecho de que el Gobierno de Transición Nacional de Liberia no haya tomado medidas para cumplir las obligaciones contraídas en virtud del párrafo 1 de la resolución 1532 (2004) e insta al Gobierno a que lo haga de inmediato, especialmente mediante la adopción de la legislación interna necesaria con apoyo técnico proporcionado por los Estados Miembros;

9. Observa asimismo que las medidas relativas a las armas, los viajes y la madera impuestas en los párrafos 2,4 y 10, respectivamente, de la resolución 1521 (2003) y prorrogadas en el párrafo 1 de la resolución 1579 (2004) siguen en vigor hasta el 21 de diciembre de 2005;

10. Exhorta a la UNMIL a redoblar sus esfuerzos, como dispone la resolución 1509 (2003), para ayudar al Gobierno de Transición Nacional de Liberia a restablecer su autoridad en todo el territorio del país, incluidas las zonas productoras de diamantes y de madera, y restablecer una ordenación adecuada de los recursos naturales;

11. Reitera la importancia de que la UNMIL siga prestando asistencia, en la medida de sus posibilidades, en las zonas en que esté desplegada y sin perjuicio de su mandato, al Gobierno de Transición Nacional de Liberia, al Comité establecido en virtud del párrafo 21 de la resolución 1521 (2003) ("el Comité") y el Grupo de Expertos a los efectos siguientes:

a) Supervisar la aplicación de las medidas impuestas en los párrafos 2 , 4, 6 y 10 de la resolución 1521 (2003) de conformidad con el párrafo 23 de esa resolución;

b) Apoyar los intentos del Gobierno de Transición por impedir la transgresión de esas medidas y comunicar dichas transgresiones;

c) Recoger, según proceda, las armas y los pertrechos conexos que hayan entrado en Liberia en contravención de las medidas adoptadas por los Es- 
tados para cumplir el párrafo 2 de la resolución 1521 (2003) y disponer de esas armas y pertrechos en la forma que corresponda;

d) Ayudar al Gobierno de Transición Nacional de Liberia a supervisar el reclutamiento y desplazamiento de excombatientes y presentar información al respecto al Grupo de Expertos y al Comité con el fin de reducir las posibilidades de que socaven el proceso de paz o causen nueva inestabilidad en Liberia y en la subregión;

e) Elaborar una estrategia, en conjunción con la Comunidad Económica de los Estados de África Occidental y otros asociados internacionales, para consolidar el marco jurídico nacional mencionado en la resolución 1509 (2003), incluida la aplicación por el Gobierno de Transición Nacional de Liberia de las medidas impuestas en el párrafo 1 de la resolución 1532 (2004);

12. Insta a la UNMIL y a las Misiones de las Naciones Unidas en Sierra Leona y en Côte d'Ivoire a que intensifiquen su cooperación, dentro de los límites de sus posibilidades y de las zonas en que estén desplegadas y sin perjuicio de sus mandatos, para vigilar el tráfico de armas y el reclutamiento de mercenarios en la subregión;

13. Reitera su llamamiento a la comunidad internacional de donantes para que siga prestando asistencia al proceso de paz, incluso para la reintegración de los excombatientes y la reconstrucción, contribuya generosamente a los llamamientos humanitarios unificados, desembolse lo antes posible las contribuciones prometidas en la Conferencia para la Reconstrucción de Liberia celebrada en Nueva York los días 5 y 6 de febrero de 2004 y atienda a las necesidades financieras, administrativas y técnicas inmediatas del Gobierno de Transición Nacional de Liberia, en particular para ayudarle a cumplir las condiciones mencionadas en el párrafo 3 de la presente resolución a fin de que las medidas puedan dejar de aplicarse lo antes posible;

14. Decide restablecer el Grupo de Expertos designados en virtud de la resolución 1579 (2004) por un nuevo período que concluirá el 21 de diciembre de 2005, con el fin de llevar a cabo las siguientes tareas:

a) Efectuar una misión de evaluación complementaria en Liberia y los países vecinos a fin de investigar y de preparar un informe sobre la aplicación y las posibles contravenciones de las medidas impuestas en la resolución 1521 (2003), incluida información que pueda servir al Comité para preparar una lista de las personas indicadas en el párrafo 4 a) de la resolución 1521 (2003) y el párrafo 1 de la resolución 1532 (2004) y sobre las diversas fuentes de financiación del comercio ilícito de armas, como los recursos naturales; 


\section{DOCUMENTACIÓN}

b) Evaluar las consecuencias y la eficacia de las medidas impuestas en el párrafo 1 de la resolución 1532 (2004);

c) Evaluar los progresos realizados en el cumplimiento de las condiciones para levantar las medidas impuestas en la resolución 1521 (2003);

d) Evaluar las repercusiones humanitarias y socioeconómicas de las medidas impuestas en los párrafos 2, 4, 6 y 10 de la resolución 1521 (2003);

e) Presentarle por conducto del Comité, a más tardar el 7 de diciembre de 2005, un informe sobre todas las cuestiones señaladas en el presente párrafo y, antes de esa fecha, poner oficiosamente al Comité al corriente de la situación, según corresponda, en particular de los progresos realizados en el cumplimiento de las condiciones para dejar de aplicar las medidas impuestas en los párrafos 6 y 10 de la resolución 1521 (2003);

f) Cooperar con otros grupos de expertos cuando corresponda, en particular el establecido en la resolución 1584 (2005) de $1^{\circ}$ de febrero de 2005, respecto de Côte d'Ivoire;

15. Pide al Secretario General que, en consulta con el Comité, designe lo antes posible un máximo de cinco expertos con los conocimientos técnicos necesarios, en particular sobre armas, madera, diamantes, finanzas, cuestiones humanitarias y socioeconómicas y otras cuestiones pertinentes, aprovechando en toda la medida de lo posible los conocimientos de los miembros del Grupo de Expertos establecido en virtud de la resolución 1579 (2004), y le pide además que adopte las disposiciones financieras y de seguridad necesarias para apoyar la labor del Grupo;

16. Insta a todos los Estados y al Gobierno de Transición Nacional de Liberia a que cooperen plenamente con el Grupo de Expertos;

17. Decide seguir ocupándose de la cuestión.

\section{RESOLUCIÓN 1626}

(19 de septiembre de 2005)

\section{El Consejo de Seguridad,}

Recordando sus anteriores resoluciones y declaraciones de la Presidencia sobre la situación en Liberia y en Sierra Leona, en particular sus resoluciones 1509 (2003), de 19 de septiembre de 2003, 1610 (2005), de 30 de junio de 2005 y 1620 (2005), de 31 de agosto de 2005,

Acogiendo con beneplácito el informe del Secretario General de $1^{\circ} \mathrm{de}$ septiembre de 2005 (S/2005/560), 
Acogiendo con beneplácito los progresos realizados en los preparativos de las elecciones presidenciales y legislativas que se celebrarán en octubre,

Observando con beneplácito que se ha extendido más la autoridad del Estado e incluso se ha avanzado en el establecimiento de un nuevo cuerpo de policía de Liberia y en el nombramiento de nuevos jueces y magistrados,

Expresando su reconocimiento por las continuas e indispensables contribuciones al proceso de paz de Liberia hechas por la Comunidad Económica de los Estados de África Occidental (CEDEAO) y la Unión Africana (UA) y por la asistencia financiera y de otro tipo prestada por la comunidad internacional,

Observando con beneplácito que el Gobierno Nacional de Transición de Liberia y el Grupo de Contacto Internacional sobre Liberia han firmado el Programa de asistencia en materia de gobernanza y gestión económica, que tiene por objeto asegurar la pronta aplicación del Acuerdo General de Paz y acelerar el levantamiento de las medidas impuestas por la resolución 1521 (2003),

Reiterando su reconocimiento por la labor esencial del Tribunal Especial para Sierra Leona y sus vitales aportaciones al establecimiento del imperio de la ley en Sierra Leona y la subregión y alentando a todos los Estados a que cooperen plenamente con el Tribunal cuando éste ponga en práctica su estrategia de conclusión,

Observando que la Misión de las Naciones Unidas en Sierra Leona (UNAMSIL) tiene previsto terminar sus operaciones el 31 de diciembre de 2005 ,

Recordando la exposición que le hizo el Presidente del Tribunal Especial para Sierra Leona el 24 de mayo de 2005, en que destacó la necesidad de que continuara la presencia internacional de seguridad para dar protección al Tribunal Especial tras la partida de la UNAMSIL, y acogiendo con beneplácito las recomendaciones del Secretario General al respecto,

Determinando que la situación en Liberia sigue constituyendo una amenaza para la paz y la seguridad internacionales en la región,

Actuando en virtud del Capítulo VII de la Carta de las Naciones Unidas,

1. Decide prorrogar el mandato de la Misión de las Naciones Unidas en Liberia (UNMIL) hasta el 31 de marzo de 2006;

2. Insta a todos los liberianos a que demuestren su plena adhesión a un proceso democrático de gobierno haciendo que las próximas elecciones presidenciales y legislativas sean pacíficas, transparentes, libres y limpias;

3. Insta a la comunidad internacional a que atienda a las constantes necesidades de recursos para la rehabilitación y reintegración de los excombatientes y para la reforma del sector de la seguridad; 
4. Aguarda con interés la ejecución del Programa de asistencia en materia de gobernanza y gestión económica por parte del Gobierno Nacional de Transición de Liberia y los gobiernos que le sucedan, en colaboración con sus asociados internacionales, y pide al Secretario General que incluya en sus informes periódicos sobre la UNMIL datos sobre la marcha de esa ejecución;

5. Autoriza a la UNMIL, con sujeción al consentimiento de los países que aportan contingentes a que concierna y del Gobierno de Sierra Leona, a desplegar, a partir de noviembre de 2005, hasta 250 efectivos militares de las Naciones Unidas en Sierra Leona para dar protección al Tribunal Especial para Sierra Leona, tal como se recomendó en los párrafos 90 a 94 del informe del Secretario General de $1^{\circ}$ de septiembre de 2005 (S/2005/560);

6. Autoriza un aumento transitorio de la dotación máxima de la UNMIL, hasta un total de 15.250 efectivos militares de las Naciones Unidas, para el período comprendido entre el 15 de noviembre de 2005 y el 31 de marzo de 2006, a fin de que el apoyo prestado al Tribunal no reduzca la capacidad de la UNMIL en Liberia durante el período de transición política;

7. Autoriza además a la UNMIL, con sujeción al consentimiento de los países que aportan contingentes a que concierna y del Gobierno de Sierra Leona, a desplegar un número suficiente de efectivos militares en Sierra Leona, siempre y cuando sea necesario, a fin de evacuar a su personal militar desplegado en Sierra Leona de conformidad con lo dispuesto en el párrafo 5 de la presente resolución, así como a los funcionarios del Tribunal Especial para Sierra Leona, en caso de que se produzca una crisis grave de seguridad que afecte a dicho personal y al Tribunal;

8. Pide a la Oficina Integrada de las Naciones Unidas en Sierra Leona (UNIOSIL) que, una vez establecida, ayude a prestar apoyo logístico al personal militar de la UNMIL desplegado en Sierra Leona de conformidad con la presente resolución;

9. Pide al Secretario General y al Gobierno de Sierra Leona que lleguen a un acuerdo sobre el estatuto del personal militar de la UNMIL desplegado en Sierra Leona de conformidad con la presente resolución, teniendo en cuenta la resolución 59/47 de la Asamblea General relativa al alcance de la protección jurídica en virtud de la Convención sobre la Seguridad del Personal de las Naciones Unidas y el Personal Asociado, y decide que, hasta que se alcance dicho acuerdo, se aplique a título provisional el modelo de acuerdo sobre el estatuto de las fuerzas de fecha 9 de octubre de 1990 (A/45/594);

10. Apoya la recomendación del Secretario General de que, para el 31 de marzo de 2006, la dotación máxima de personal militar de las Naciones Unidas vuelva a ser la autorizada en la resolución 1509 (2003); 
11. Alienta a las misiones de las Naciones Unidas en la región a que, dentro de los límites de sus posibilidades y de sus zonas de despliegue y sin perjuicio de sus mandatos, sigan tratando de mejorar la cooperación entre misiones, especialmente para prevenir la circulación de armas y combatientes y la explotación ilícita de los recursos naturales a través de las fronteras y llevar a la práctica programas de desarme, desmovilización y reintegración;

12. Observa con satisfacción la labor realizada por la UNMIL para poner en práctica la política de tolerancia cero respecto a la explotación y los abusos sexuales propugnada por el Secretario General y para asegurar el pleno cumplimiento por su personal del código de conducta de las Naciones Unidas pide al Secretario General que adopte todas las medidas necesarias a tal efecto y que lo mantenga informado e insta a los países que aportan contingentes a que tomen las medidas preventivas que procedan, incluida la instrucción para tomar conciencia de la cuestión antes del despliegue, y a que adopten medidas disciplinarias y de otra índole para asegurar que se investiguen adecuadamente las denuncias de explotación o abusos sexuales contra su personal y que, en caso de ser ciertas, se castigue a los culpables;

13. Pide al Secretario General que, en su informe de marzo de 2006, presente recomendaciones sobre un plan de retirada gradual de la UNMIL, con puntos de referencia específicos y un calendario provisional;

14. Pide al Secretario General que continúe informándole periódicamente sobre los progresos realizados por la UNMIL en la ejecución de su mandato;

15. Decide seguir ocupándose activamente de la cuestión.

\section{NIÑOS Y CONFLICTOS ARMADOS}

\section{RESOLUCIÓN 1612}

(26 de julio de 2005)

\section{El Consejo de Seguridad,}

Reafirmando sus resoluciones 1261 (1999), de 25 de agosto de 1999, 1314 (2000), de 11 de agosto de 2000, 1379 (2001), de 20 de noviembre de 2001, 1460 (2003), de 30 de enero de 2003 y 1539 (2004) de 22 de abril de 2004, que contribuyen a establecer un marco general para la protección de los niños afectados por conflictos armados,

Observando que se ha avanzado en la protección de los niños afectados por conflictos armados, especialmente en los aspectos de la promoción y la 


\section{DOCUMENTACIÓN}

formulación de normas y principios, pero observando aún con profunda preocupación que en general no ocurre así en el terreno, donde las partes en conflicto siguen contraviniendo con impunidad las disposiciones pertinentes del derecho internacional aplicable relativo a los derechos y a la protección de los niños en los conflictos armados,

Recalcando que incumbe a los gobiernos nacionales la función primordial de proporcionar protección y socorro eficaces a todos los niños afectados por conflictos armados,

Recordando la responsabilidad de los Estados de poner fin a la impunidad y llevar ante la justicia a los responsables de genocidio, crímenes de lesa humanidad, crímenes de guerra y otros crímenes atroces perpetrados contra los niños,

Convencido de que la protección de los niños en los conflictos armados debe ser considerada un aspecto importante de toda estrategia general para la solución de un conflicto,

Reiterando que le incumbe la responsabilidad primordial por el mantenimiento de la paz y la seguridad internacionales y, en ese contexto, su compromiso de hacer frente a las consecuencias generalizadas que tienen los conflictos armados para los niños,

Subrayando su determinación de hacer respetar sus resoluciones y otras normas y principios internacionales para la protección de los niños afectados por conflictos armados,

Habiendo examinado el informe del Secretario General de 9 de febrero de 2005 (S/2005/72) y subrayando que la presente resolución no pretende determinar desde un punto de vista jurídico si las situaciones a que se hace referencia en ese informe son o no conflictos armados en el contexto de los Convenios de Ginebra y sus Protocolos Adicionales, ni prejuzga la condición jurídica de las partes que no son Estados y están involucradas en esas situaciones,

Observando con profunda preocupación el nexo documentado que existe entre la utilización de niños soldados en contravención del derecho internacional aplicable y el tráfico ilícito de armas pequeñas y armas ligeras y subrayando la necesidad de que todos los Estados tomen medidas para prevenir ese tráfico y ponerle término,

1. Condena enérgicamente el reclutamiento y la utilización de niños soldados por las partes en conflictos armados en contravención de las obligaciones internacionales que les son aplicables y todas las demás infracciones y abusos cometidos contra niños en situaciones de conflicto armado; 
2. Toma nota del plan de acción presentado por el Secretario General para el establecimiento de un mecanismo de supervisión y presentación de informes en relación con los niños y los conflictos armados, tal como se pedía en el párrafo 2 de la resolución 1539 (2004), y, a este respecto:

a) Subraya que el mecanismo ha de reunir y proporcionar información oportuna, objetiva, precisa y fiable acerca del reclutamiento y la utilización de niños soldados en contravención del derecho internacional aplicable y de otras infracciones y abusos cometidos contra los niños afectados por los conflictos armados y habrá de presentar sus informes al grupo de trabajo que se establecerá de conformidad con el párrafo 8 de la presente resolución;

b) Subraya además que este mecanismo debe funcionar con la participación de los gobiernos nacionales y las entidades correspondientes de las Naciones Unidas y la sociedad civil, incluso en el plano nacional, y en cooperación con ellos;

c) Destaca que todas las medidas que tomen las entidades de las Naciones Unidas dentro del marco de este mecanismo de supervisión y presentación de informes deben estar destinadas a apoyar y complementar, según proceda, la función de protección y rehabilitación que cabe a los gobiernos nacionales;

d) Destaca también que los diálogos que se entablen en el marco del mecanismo de supervisión y presentación de informes entre entidades de las Naciones Unidas y grupos armados que no sean Estados a los efectos de proteger a los niños y tener acceso a ellos deben tener lugar en el contexto de los procesos de paz que existan y del marco de cooperación que haya entre las Naciones Unidas y el gobierno de que se trate;

3. Pide al Secretario General que ponga en marcha sin demora el mecanismo de supervisión y presentación de informes que antecede y, en primer lugar, lo haga aplicable, dentro del marco de los recursos existentes y en estrecha consulta con los países a que concierna, a las partes en las situaciones de conflicto armado enumeradas en los anexos del informe del Secretario General (S/2005/72) y que se hallan sometidas a la consideración del Consejo de Seguridad y luego, en estrecha consulta con los países a que concierna, a las partes en otras situaciones de conflicto armado enumeradas en los anexos del informe del Secretario General (S/2005/72), teniendo presentes los debates del Consejo y las opiniones expresadas por los Estados Miembros, en particular en el debate anual sobre los niños y los conflictos armados, y teniendo también en cuenta las conclusiones y recomendaciones de un estudio independiente sobre la aplicación del mecanismo que se comunicarán al Consejo para el 31 de julio de 2006. El estudio independiente incluirá: 
a) Una evaluación de la eficacia general del mecanismo, así como de la oportunidad, precisión, objetividad y fiabilidad de la información reunida por su conducto;

b) Información sobre la vinculación efectiva del mecanismo con la labor del Consejo de Seguridad y otros órganos de las Naciones Unidas;

c) Información acerca de la pertinencia y claridad de la división de funciones;

d) Información sobre las consecuencias para el presupuesto y otros recursos de las entidades de las Naciones Unidas y las organizaciones financiadas con contribuciones voluntarias que hagan aportaciones al mecanismo;

e) Recomendaciones relativas a la puesta en práctica cabal del mecanismo;

4. Destaca que el Secretario General procederá a poner en práctica el mecanismo de supervisión y presentación de informes únicamente en el contexto de la protección de los niños afectados por conflictos armados y para el objetivo concreto de asegurar esa protección y, por lo tanto, el mecanismo no prejuzgará ni entrañará una decisión del Consejo de Seguridad acerca de si ha o no de incluir esa situación entre los temas que trate;

5. Observa con beneplácito las iniciativas que han tomado el UNICEF y otras entidades de las Naciones Unidas para reunir información sobre el reclutamiento y la utilización de niños soldados en contravención del derecho internacional aplicable y sobre infracciones y abusos cometidos contra los niños en situaciones de conflicto armado e invita al Secretario General a tenerlas debidamente en cuenta en la etapa inicial de puesta en práctica del mecanismo a que se hace referencia en el párrafo 3;

6. Señala que la información reunida por este mecanismo, y que el Secretario General transmitirá a la Asamblea General y al Consejo de Seguridad, podrá tenerse en cuenta en otros órganos internacionales, regionales y nacionales, en el marco de su mandato y ámbito de competencia, a los efectos de la protección, los derechos y el bienestar de los niños afectados por un conflicto armado;

7. Observa con profunda preocupación que no se ha avanzado en la preparación y ejecución de los planes de acción previstos en el párrafo 5 a) de su resolución 1539 (2004) y, en este contexto, insta a las partes interesadas a que los preparen y pongan en práctica sin más demora, en estrecha colaboración con las misiones de las Naciones Unidas para el mantenimiento de la paz y los equipos de las Naciones Unidas en los países, de conformidad con sus respectivos mandatos y dentro de los límites de sus posibilidades, y pide al 
Secretario General que imparta criterios que sean útiles en la preparación de esos planes;

8. Decide establecer un grupo de trabajo del Consejo integrado por todos sus miembros para examinar los informes del mecanismo a que se hace referencia en el párrafo 3 de la presente resolución, pasar revista a la marcha de la preparación y ejecución de los planes de acción mencionados en el párrafo 7 de la presente resolución y examinar la demás información pertinente que le sea presentada; decide además que el grupo de trabajo:

a) Le hará recomendaciones sobre posibles medidas para promover la protección de los niños afectados por un conflicto armado, que se refieran también a los mandatos apropiados para las misiones de mantenimiento de la paz y a las partes en el conflicto;

b) Dirigirá solicitudes, según proceda, a otros órganos del sistema de las Naciones Unidas para que tomen medidas en apoyo de la aplicación de la presente resolución de conformidad con sus respectivos mandatos;

9. Recuerda el párrafo 5 c) de su resolución 1539 (2004) y reafirma su intención de considerar la posibilidad de imponer medidas con objetivos precisos y graduados mediante resoluciones que se refieran a determinados países, como por ejemplo la prohibición de exportar o suministrar armas pequeñas y armas ligeras y otros pertrechos y asistencia militares, contra las partes en situaciones de conflicto armado que se hallen sometidas a su consideración y constituyan una contravención del derecho internacional aplicable en relación con los derechos y la protección de los niños en un conflicto armado;

10. Subraya la responsabilidad de las misiones de las Naciones Unidas para el mantenimiento de la paz y de los equipos de las Naciones Unidas en los países, de conformidad con sus respectivos mandatos, de cerciorarse de que se cumplan efectivamente las resoluciones del Consejo, de que haya una respuesta coordinada a los problemas relativos a los niños y los conflictos armados y de vigilar la situación y presentar informes al Secretario General;

11. Acoge con satisfacción la labor realizada por las operaciones de las Naciones Unidas para el mantenimiento de la paz para poner en práctica la política de tolerancia cero propugnada por el Secretario General respecto de la explotación y los abusos sexuales y para que su personal cumpla cabalmente el código de conducta de las Naciones Unidas, pide al Secretario General que siga tomando todas las medidas necesarias a este respecto y lo mantenga informado y exhorta a los países que aportan contingentes a que adopten las medidas preventivas que procedan, incluso formación para tomar conciencia de la cuestión antes del despliegue, y que adopten las medidas dis- 


\section{DOCUMENTACIÓN}

ciplinarias y de otra índole que sean necesarias para asegurar que se rinda cuenta plenamente de los casos de falta de conducta en que esté involucrado su personal;

12. Decide seguir incluyendo disposiciones concretas para la protección de los niños en los mandatos de las operaciones de las Naciones Unidas para el mantenimiento de la paz, incluido el despliegue, según cada caso, de asesores para la protección de menores, pide al Secretario General que se asegure de que, durante la preparación de cada operación de las Naciones Unidas para el mantenimiento de la paz, se evalúen sistemáticamente el número y las funciones de dichos asesores y observa con agrado que se ha procedido a una evaluación completa de las funciones y actividades de los asesores con miras a aprovechar la experiencia adquirida y las prácticas más idóneas;

13. Acoge con satisfacción las iniciativas recientes de organizaciones y mecanismos regionales y subregionales para proteger a los niños afectados por conflictos armados y alienta a que sigan incluyendo la cuestión de la protección de los niños en sus programas, sus políticas y sus actividades de promoción, establezcan mecanismos de examen por los pares y de vigilancia y presentación de informes, establezcan en sus secretarías mecanismos de protección de los niños, incluyan personal encargado de la protección de los niños y de capacitación en sus operaciones de paz y sobre el terreno y adopten iniciativas a nivel subregional e interregional para poner fin a las actividades perjudiciales para los niños en tiempos de conflicto, en particular el reclutamiento y secuestro de niños a través de las fronteras, el movimiento ilícito de armas pequeñas y el tráfico ilícito de recursos naturales, mediante la formulación y aplicación de directrices sobre los niños y los conflictos armados;

14. Pide a todas las partes interesadas que se aseguren de que la protección de los niños y de sus derechos y bienestar esté expresamente incorporada en los procesos y acuerdos de paz y en los programas de recuperación y reconstrucción después del conflicto y su planificación;

15. Insta a todas las partes interesadas a que cumplan las obligaciones internacionales que les son aplicables en relación con la protección de los niños afectados por un conflicto armado, así como las promesas concretas que han hecho al Representante Especial del Secretario General para la cuestión de los niños y los conflictos armados, al UNICEF y a otros organismos de las Naciones Unidas, y cooperen plenamente con las misiones de las Naciones Unidas para el mantenimiento de la paz y los equipos de las Naciones Unidas en los países, cuando proceda en el contexto del marco de cooperación entre las Naciones Unidas y el gobierno de que se trate, en el seguimiento y la materialización de esas promesas; 
16. Exhorta a los Estados Miembros, a las entidades de las Naciones Unidas, a las organizaciones regionales y subregionales y a otras partes interesadas a que adopten medidas adecuadas para controlar las actividades subregionales y transfronterizas ilícitas que redundan en perjuicio de los niños, entre ellas la explotación ilícita de recursos naturales, el comercio ilícito de armas pequeñas, el secuestro de niños y su utilización y reclutamiento como soldados, así como otras infracciones y abusos cometidos contra niños en situaciones de conflicto armado en contravención del derecho internacional aplicable;

17. Exhorta a todas las partes interesadas, con inclusión de los Estados Miembros, entidades de las Naciones Unidas e instituciones financieras, a que apoyen el desarrollo y fortalecimiento de la capacidad de las instituciones nacionales y las redes de la sociedad civil local para la labor de defensa, protección y rehabilitación de los niños afectados por un conflicto armado y aseguren la viabilidad de las iniciativas locales de protección de los niños;

18. Pide al Secretario General que imparta instrucciones a todas las entidades pertinentes de las Naciones Unidas para que, dentro de los límites de los recursos existentes, adopten medidas concretas a fin de que las cuestiones relativas a los niños y los conflictos armados se incorporen sistemáticamente en sus respectivos programas, entre otras cosas, asignando recursos humanos $\mathrm{y}$ financieros adecuados en todas las oficinas y departamentos competentes y sobre el terreno para proteger a los niños afectados por la guerra e intensifiquen, en el marco de sus respectivos mandatos, su cooperación y coordinación cuando se trate de la protección de niños en un conflicto armado;

19. Reitera su petición al Secretario General de que se asegure de que, en todos sus informes sobre la situación en determinados países, se incluya como aspecto concreto la protección de los niños y expresa su intención de prestar su plena atención a la información proporcionada en ellos cuando examine situaciones de esa índole sometidas a su consideración;

20. Pide al Secretario General que para noviembre de 2006 presente un informe sobre la aplicación de esta resolución y de las resoluciones 1379 (2001), 1460 (2003) y 1539 (2004) en el que incluya, entre otras cosas:

a) Información sobre el cumplimiento por las partes del compromiso de poner fin al reclutamiento o la utilización de niños en conflictos armados en contravención del derecho internacional aplicable y otras infracciones cometidas contra niños afectados por un conflicto armado;

b) Información sobre los progresos realizados en la puesta en práctica del mecanismo de supervisión y presentación de informes mencionado en el párrafo 3; 


\section{DOCUMENTACIÓN}

c) Información sobre los progresos realizados en la preparación y ejecución de los planes de acción a que se hace referencia en el párrafo 7 de la presente resolución;

d) Información sobre la evaluación de la función y las actividades de los asesores para la protección de menores;

21. Decide seguir ocupándose activamente de la cuestión.

\section{ORIENTE MEDIO}

\section{RESOLUCIÓN 1578}

(15 de diciembre de 2004)

\section{El Consejo de Seguridad,}

Habiendo examinado el informe del Secretario General sobre la Fuerza de las Naciones Unidas de Observación de la Separación, de 7 de diciembre de 2004 (S/2004/948) y reafirmando también su resolución 1308 (2000), de 17 de julio de 2000 ,

1. Exhorta a las partes interesadas a que apliquen de inmediato su resolución 338 (1973), de 22 de octubre de 1973;

2. Decide prorrogar el mandato de la Fuerza de las Naciones Unidas de Observación de la Separación por un período de seis meses, es decir, hasta el 30 de junio de 2005 ;

3. Pide al Secretario General que, una vez concluido ese período, presente un informe sobre la evolución de la situación y sobre las medidas adoptadas para aplicar la resolución 338 (1973).

\section{RESOLUCIÓN 1583}

(28 de enero de 2005)

\section{El Consejo de Seguridad,}

Recordando todas sus resoluciones anteriores sobre el Líbano, en particular las resoluciones 425 (1978) y 426 (1978), de 19 de marzo de 1978, y 1553 (2004), de 29 de julio de 2004, así como las declaraciones de su Presidente sobre la situación en el Líbano, en particular la hecha el 18 de junio de 2000 (S/PRST/2000/21), 
Recordando asimismo la carta de fecha 18 de mayo de 2001 dirigida al Secretario General por su Presidente (S/2001/500),

Recordando también que el Secretario General había llegado a la conclusión de que, al 16 de junio de 2000, Israel había retirado sus fuerzas del Líbano de conformidad con la resolución 425 (1978) y cumplido los requisitos establecidos en el informe del Secretario General de 22 de mayo de 2000 (S/2000/460) y de que la Fuerza Provisional de las Naciones Unidas en el Líbano (FPNUL) había completado en lo fundamental dos de las tres partes de su mandato, centrándose ahora en la tarea pendiente de restablecer la paz y la seguridad internacionales,

Profundamente preocupado por el hecho de que persisten las tensiones y los incidentes de violencia a lo largo de la Línea Azul,

Haciendo hincapié una vez más en el carácter provisional de la FPNUL,

Recordando su resolución 1308 (2000), de 17 de julio de 2000,

Recordando también su resolución 1325 (2000), de 31 de octubre de 2000,

Recordando asimismo los principios pertinentes que figuran en la Convención sobre la Seguridad del Personal de las Naciones Unidas y el Personal Asociado, aprobada el 9 de diciembre de 1994,

Atendiendo a la solicitud del Gobierno del Líbano de prorrogar el mandato de la FPNUL por otro período de seis meses, formulada en la carta de fecha 11 de enero de 2005 dirigida al Secretario General por su Representante Permanente ante las Naciones Unidas (S/2005/13), y reafirmando a la vez que el Consejo ha reconocido que la Línea Azul es válida a los fines de confirmar la retirada de Israel de conformidad con la resolución 425 (1978) y que la Línea Azul debe ser respetada en su totalidad,

Observando con preocupación las tensiones y la posibilidad de un agravamiento de la situación, tal como señala el Secretario General en su informe de 20 de enero de 2005 (S/2005/36),

1. Aprueba el informe del Secretario General sobre la FPNUL de 20 de enero de 2005 (S/2005/36);

2. Decide prorrogar el actual mandato de la FPNUL hasta el 31 de julio de 2005;

3. Reitera su firme apoyo a la integridad territorial, la soberanía y la independencia política del Líbano dentro de sus fronteras internacionalmente reconocidas y bajo la autoridad única y exclusiva del Gobierno del Líbano;

4. Alienta al Gobierno del Líbano a que amplíe y ejerza plenamente su autoridad única y efectiva en todo el sur del país, en particular mediante el 


\section{DOCUMENTACIÓN}

despliegue de las fuerzas armadas y de seguridad del Líbano, en número suficiente, a fin de asegurar un ambiente de calma en toda la región, particularmente a lo largo de la Línea Azul, y a que controle el uso de la fuerza en su territorio y desde éste;

5. Pide a las partes que aseguren que la FPNUL tenga plena libertad de circulación en toda la zona de operaciones indicada en el informe del Secretario General, y pide a la FPNUL que informe de todo obstáculo que se interponga en el cumplimiento de su mandato;

6. Reitera su llamamiento a las partes para que continúen cumpliendo los compromisos que han contraído de respetar plenamente la línea de repliegue determinada por las Naciones Unidas e indicada en el informe del Secretario General de 16 de junio de 2000 (S/2000/590), proceder con la máxima moderación y cooperar cabalmente con las Naciones Unidas y la FPNUL;

7. Condena todos los actos de violencia, en particular los incidentes ocurridos recientemente de un lado al otro de la Línea Azul en los que resultaron muertos y heridos observadores militares de las Naciones Unidas, expresa profunda preocupación por las graves contravenciones e infracciones de la línea de repliegue por mar y tierra y por las que se siguen produciendo en el espacio aéreo, e insta a las partes a que les pongan fin, se abstengan de realizar cualquier acto o provocación que pudiera agravar más la tensión y cumplan estrictamente su obligación de respetar la seguridad del personal de la FPNUL y de otras entidades de las Naciones Unidas;

8. Apoya la constante labor de la FPNUL para mantener la cesación del fuego a lo largo de la línea de repliegue mediante patrullas móviles, equipos de observación desde posiciones fijas y estrechos contactos con las partes con miras a rectificar las infracciones, resolver los incidentes y prevenir su aumento, destacando al mismo tiempo la responsabilidad primordial que cabe a las partes a ese respecto;

9. Observa con beneplácito que la FPNUL sigue contribuyendo a las operaciones de remoción de minas, alienta a las Naciones Unidas a que sigan prestando asistencia al Gobierno del Líbano en las actividades relativas a las minas, tanto para que siga aumentando su capacidad nacional en la materia como para las actividades de remoción de minas y municiones y artefactos explosivos no detonados en el sur, encomia a los países donantes por haber respaldado esas medidas mediante contribuciones financieras y en especie y alienta a que se aporten contribuciones internacionales adicionales, e insiste en la necesidad de proporcionar al Gobierno del Líbano y a la FPNUL mapas y registros adicionales sobre la ubicación de las minas; 
10. Pide al Secretario General que continúe celebrando consultas con el Gobierno del Líbano y otras partes directamente interesadas sobre la aplicación de esta resolución y que presente al Consejo, antes del fin del actual mandato, un informe al respecto y sobre las actividades de la FPNUL y las tareas que realiza actualmente el Organismo de las Naciones Unidas para la Vigilancia de la Tregua (ONUVT);

11. Expresa su intención de examinar el mandato y las estructuras de la FPNUL cuando termine el actual mandato y pide al Secretario General que, tras celebrar las consultas que correspondan, incluso con el Gobierno del Líbano, incluya en su informe recomendaciones sobre este particular, teniendo en cuenta la situación prevaleciente sobre el terreno, las actividades que realmente lleva a cabo la Fuerza en la zona de operaciones y su contribución a la tarea pendiente de restablecer la paz y la seguridad internacionales;

12. Espera con interés el pronto cumplimiento del mandato de la FPNUL;

13. Destaca la importancia y la necesidad de lograr una paz completa, justa y duradera en el Oriente Medio, basada en todas las resoluciones en la materia, entre ellas sus resoluciones 242 (1967), de 22 de noviembre de 1967, y 338 (1973), de 22 de octubre de 1973.

\section{RESOLUCIÓN 1595}

(7 de abril de 2005)

\section{El Consejo de Seguridad,}

Reiterando su llamamiento para que se respeten estrictamente la soberanía, la integridad territorial, la unidad y la independencia política del Líbano bajo la autoridad única y exclusiva del Gobierno de ese país,

Haciendo suya la opinión expresada por el Secretario General en la carta que con fecha 24 de marzo de 2005 dirigió a su Presidente en el sentido de que el Líbano está pasando por un período difícil y delicado, de que es imperativo que todos los interesados obren con la máxima prudencia y de que el futuro del Líbano se debe decidir exclusivamente por medios pacíficos,

Reafirmando su inequívoca condena del atentado terrorista perpetrado el 14 de febrero de 2005 en Beirut que causó la muerte al ex Primer Ministro del Líbano, Sr. Rafiq Hariri, y a otras personas, así como heridas a docenas de personas, y condenando los ulteriores ataques en el Líbano,

Habiendo examinado el informe de la Misión de determinación de los hechos en el Líbano que hizo indagaciones acerca de las circunstancias, cau- 


\section{DOCUMENTACIÓN}

sas y consecuencias de este acto terrorista (S/2005/203) y que le transmitió el Secretario General tras la declaración formulada por su Presidencia el 15 de febrero de 2005 ,

Observando con preocupación que la Misión de determinación de los hechos llegó a la conclusión de que el proceso de investigación en el Líbano adolecía de graves deficiencias y que no se tenía ni la capacidad ni el empeño necesarios para llegar a una conclusión satisfactoria y fidedigna,

Recordando asimismo en este contexto su opinión de que, para aclarar todos los aspectos de este horrendo crimen, sería necesario proceder a una investigación internacional independiente con facultades de ejecución y recursos autónomos en todas las especializaciones pertinentes,

Consciente de que el pueblo libanés exige unánimemente que los responsables sean identificados y rindan cuentas de sus actos y animado del deseo de ayudar al Líbano en la búsqueda de la verdad,

Observando con beneplácito la aprobación por el Gobierno del Líbano de la decisión que ha de adoptar el Consejo de Seguridad sobre el establecimiento de una comisión internacional independiente de investigación y $o b$ servando también con beneplácito que está dispuesto a cooperar plenamente con ella en el marco de la soberanía del Líbano y de su sistema jurídico, según se indicaba en la carta de fecha 29 de marzo de 2005 dirigida al Secretario General por el Encargado de Negocios interino del Líbano ante las Naciones Unidas (S/2005/208),

1. Decide, de conformidad con la carta anteriormente mencionada del Encargado de Negocios interino del Líbano, establecer una comisión internacional independiente de investigación ("la Comisión") basada en el Líbano que ayude a las autoridades del Líbano a investigar todos los aspectos de este acto terrorista e incluso a identificar a sus autores, patrocinadores, organizaciones y cómplices;

2. Reitera su llamamiento al Gobierno del Líbano para que someta a la acción de la justicia a los autores, organizadores y patrocinadores del atentado terrorista perpetrado el 14 de febrero de 2005 y le insta a que se cerciore de que se tengan plenamente en cuenta las observaciones y conclusiones de la investigación hecha por la Comisión;

3. Decide que la Comisión, a los efectos de desempeñar eficazmente sus funciones:

- Contará con la plena cooperación de las autoridades del Líbano y pleno acceso a toda la información y pruebas documentales, testimoniales y físicas que obren en poder de ellas y la Comisión considere pertinentes a la investigación; 
- Estará autorizada a reunir información y pruebas adicionales, tanto documentales como físicas, que se refieran a ese acto terrorista, así como a entrevistar a todos los funcionarios y otras personas en el Líbano que considere pertinentes a la investigación;

- Tendrá libertad de desplazamiento en todo el territorio del Líbano y acceso a todos los lugares e instalaciones que considere pertinentes a la investigación;

- Contará con los servicios necesarios para desempeñar su función y le serán reconocidos, al igual que a sus locales, personal y equipo, las prerrogativas e inmunidades a que tiene derecho en virtud de la Convención sobre las Prerrogativas e Inmunidades de las Naciones Unidas;

4. Pide al Secretario General que celebre consultas con urgencia con el Gobierno del Líbano a fin de facilitar el establecimiento y funcionamiento de la Comisión de conformidad con su mandato y atribuciones enunciadas en los párrafos 2 y 3 de la presente resolución y le pide también que le informe sobre el particular y le notifique la fecha en que la Comisión comience a funcionar plenamente;

5. Pide además al Secretario General que, no obstante lo dispuesto en el párrafo que antecede, proceda sin demora a tomar las medidas y disposiciones necesarias para que la Comisión sea establecida con rapidez y funcione plenamente, entre ellas las de contratar personal imparcial y experimentado que tenga la pericia y especialización que correspondan;

6. Dispone que la Comisión establezca los procedimientos para llevar a cabo su investigación, teniendo en cuenta el derecho y los procedimientos judiciales del Líbano;

7. Insta a todos los Estados y a todas las partes a que cooperen plenamente con la Comisión y, en particular, le proporcionen la información que obre en su poder respecto del acto terrorista antes mencionado;

8. Pide a la Comisión que complete su labor en un plazo de tres meses contados a partir del inicio de su pleno funcionamiento, con arreglo a lo notificado por el Secretario General, y autoriza a éste a que prorrogue el funcionamiento de la Comisión durante un nuevo período no superior a tres meses, si lo considera necesario para que la Comisión pueda concluir la investigación, y le pide que informe al Consejo de Seguridad sobre el particular;

9. Pide a la Comisión que le presente un informe sobre las conclusiones de su investigación y pide al Secretario General que le presente oralmente información actualizada sobre los progresos de la Comisión cada dos meses durante el funcionamiento de ésta o con mayor frecuencia de ser necesario. 


\section{DOCUMENTACIÓN}

\section{RESOLUCIÓN 1605}

(17 de junio de 2005)

\section{El Consejo de Seguridad,}

Habiendo examinado el informe del Secretario General sobre la Fuerza de las Naciones Unidas de Observación de la Separación, de 10 de junio de 2005 (S/2005/379), y reafirmando también su resolución 1308 (2000), de 17 de julio de 2000,

1. Insta a las partes interesadas a que apliquen de inmediato su resolución 338 (1973), de 22 de octubre de 1973;

2. Acoge con satisfacción las medidas que está adoptando la Fuerza de las Naciones Unidas de Observación de la Separación (FNUOS) para aplicar la política del Secretario General de tolerancia cero de la explotación y el abuso sexuales y asegurar el cumplimiento pleno por su personal del código de conducta de las Naciones Unidas, pide al Secretario General que siga adoptando todas las medidas necesarias al respecto y que le mantenga informado y exhorta a los países que aportan contingentes a que adopten las medidas preventivas y disciplinarias que sean necesarias para asegurar que esos actos se investiguen y castiguen como corresponda cuando esté involucrado su personal;

3. Decide prorrogar el mandato de la Fuerza de las Naciones Unidas de Observación de la Separación por un período de seis meses, es decir, hasta el 31 de diciembre de 2005;

4. Pide al Secretario General que, una vez concluido ese período, presente un informe sobre la evolución de la situación y sobre las medidas adoptadas para aplicar la resolución 338 (1973).

\section{RESOLUCIÓN 1614}

(29 de julio de 2005)

\section{El Consejo de Seguridad,}

Recordando todas sus resoluciones anteriores sobre el Líbano, en particular las resoluciones 425 (1978) y 426 (1978), de 19 de marzo de 1978, y 1583 (2005), de 28 de enero de 2005, así como las declaraciones de su Presidente sobre la situación en el Líbano, en particular la hecha el 18 de junio de 2000 (S/PRST/2000/21),

Recordando asimismo la carta de fecha 18 de mayo de 2001 dirigida al Secretario General por su Presidente (S/2001/500), 
Recordando también que el Secretario General había llegado a la conclusión de que, al 16 de junio de 2000, Israel había retirado sus fuerzas del Líbano de conformidad con la resolución 425 (1978) y cumplido los requisitos establecidos en el informe del Secretario General de 22 de mayo de 2000 (S/2000/460) y de que la Fuerza Provisional de las Naciones Unidas en el Líbano (FPNUL) había completado en lo fundamental dos de las tres partes de su mandato, centrándose ahora en la tarea pendiente de restablecer la paz y la seguridad internacionales,

Reafirmando que el Consejo ha reconocido que la Línea Azul es válida a los fines de confirmar la retirada de Israel de conformidad con la resolución 425 (1978) y que la Línea Azul debe ser respetada en su totalidad,

Profundamente preocupado por el hecho de que persisten las tensiones y la violencia a lo largo de la Línea Azul, en particular las hostilidades ocurridas en mayo y el grave incidente del 29 de junio, que demostraron una vez más que la situación sigue siendo inestable y frágil, como se señala en el informe del Secretario General de 21 de julio de 2005 (S/2005/460),

Haciendo hincapié una vez más en el carácter provisional de la FPNUL,

Recordando su resolución 1308 (2000), de 17 de julio de 2000,

Recordando también su resolución 1325 (2000), de 31 de octubre de 2000 ,

Recordando asimismo los principios pertinentes que figuran en la Convención sobre la Seguridad del Personal de las Naciones Unidas y el Personal Asociado, aprobada el 9 de diciembre de 1994,

Atendiendo a la solicitud del Gobierno del Líbano de prorrogar el mandato de la FPNUL por otro período de seis meses, formulada en la carta de fecha 11 de julio de 2005 dirigida al Secretario General por su Encargado de Negocios ante las Naciones Unidas (S/2005/444),

Tomando nota de la opinión del Secretario General de que la situación no permite modificar el mandato de la FPNUL ni que se reconfigure la Fuerza en este momento, y su recomendación de que el mandato de la misma se prorrogue sin modificar la dotación ni la composición de la Fuerza,

1. Aprueba el informe del Secretario General sobre la FPNUL, de 21 de julio de 2005 (S/2005/460);

2. Decide prorrogar el actual mandato de la FPNUL hasta el 31 de enero de 2006;

3. Reitera su firme apoyo a la integridad territorial, la soberanía y la independencia política del Líbano dentro de sus fronteras internacionalmente reconocidas y bajo la autoridad única y exclusiva del Gobierno del Líbano; 


\section{DOCUMENTACIÓN}

4. Condena todos los actos de violencia, en particular los incidentes ocurridos recientemente de un lado al otro de la Línea Azul que dejaron un saldo de muertos y heridos para ambas partes, expresa profunda preocupación por las graves contravenciones e infracciones de la línea de repliegue por mar y tierra y por las que se siguen produciendo en el espacio aéreo, e insta a las partes a que les pongan fin, se abstengan de realizar cualquier acto o provocación que pudiera agravar aún más la tensión y cumplan estrictamente su obligación de respetar la seguridad del personal de la FPNUL y de otras entidades de las Naciones Unidas, incluso evitando cualquier medida que pueda poner en peligro al personal de las Naciones Unidas;

5. Reitera su llamamiento a las partes para que sigan cumpliendo los compromisos que han contraído de respetar plenamente la línea de repliegue determinada por las Naciones Unidas e indicada en el informe del Secretario General de 16 de junio de 2000 (S/2000/590) y para que procedan con la máxima moderación;

6. Exhorta al Gobierno del Líbano a que amplíe y ejerza plenamente su autoridad única y efectiva en todo el sur del país, en particular mediante el despliegue de las fuerzas armadas y de seguridad del Líbano, en número suficiente, a fin de asegurar un ambiente de calma en toda la región, particularmente a lo largo de la Línea Azul, mantenga el control y el monopolio del uso de la fuerza en todo su territorio, y evite que se lancen ataques desde el Líbano hacia el otro lado de la Línea Azul;

7. Acoge con beneplácito la intención del Secretario General de analizar con el Gobierno del Líbano los próximos pasos en los preparativos para ampliar la autoridad del Gobierno en el sur del país;

8. Apoya la constante labor de la FPNUL para mantener la cesación del fuego a lo largo de la línea de repliegue mediante patrullas móviles terrestres y aéreas, equipos de observación desde posiciones fijas y estrechos contactos con las partes con miras a rectificar las infracciones, resolver los incidentes y prevenir su aumento, destacando al mismo tiempo la responsabilidad primordial que cabe a las partes a ese respecto;

9. Observa con beneplácito que la FPNUL sigue contribuyendo a las operaciones de remoción de minas, alienta a las Naciones Unidas a que sigan prestando asistencia al Gobierno del Líbano en las actividades relativas a las minas, tanto para que siga aumentando su capacidad nacional en la materia como para las actividades de remoción de minas y municiones y artefactos explosivos no detonados en el sur, encomia a los países donantes por haber respaldado esas medidas con contribuciones financieras y en especie y alienta a que se aporten contribuciones internacionales adicionales, e insiste en la 
necesidad de proporcionar al Gobierno del Líbano y a la FPNUL mapas y registros adicionales sobre la ubicación de las minas;

10. Insta a las partes que aseguren que la FPNUL tenga plena libertad de circulación en toda la zona de operaciones indicada en el informe del Secretario General, pide a la FPNUL que informe de todo obstáculo que se interponga en el cumplimiento de su mandato, y reitera su llamamiento a las partes para que cooperen cabalmente con las Naciones Unidas y la FPNUL;

11. Observa complacido las medidas tomadas por la FPNUL para aplicar la política del Secretario General de tolerancia cero respecto de la explotación y el abuso sexuales y para asegurar el pleno cumplimiento por su personal del código de conducta de las Naciones Unidas, pide al Secretario General que siga adoptando todas las medidas necesarias al respecto y que le mantenga informado, e insta a los países que aportan contingentes a que tomen las medidas preventivas que procedan, incluida la instrucción para tomar conciencia de la cuestión antes del despliegue, y a que adopten las medidas disciplinarias y de otra índole que sean necesarias para asegurar que se rinda cuenta plenamente de los casos en que su personal haya incurrido en tal conducta;

12. Pide al Secretario General que continúe celebrando consultas con el Gobierno del Líbano y otras partes directamente interesadas sobre la aplicación de esta resolución y que presente al Consejo, antes del fin del actual mandato, un informe al respecto y sobre las actividades de la FPNUL y las tareas que lleva a cabo actualmente el Organismo de las Naciones Unidas para la Vigilancia de la Tregua (ONUVT);

13. Expresa su intención de seguir examinando periódicamente el mandato y las estructuras de la FPNUL, teniendo en cuenta la situación prevaleciente sobre el terreno, las actividades que realmente lleva a cabo la Fuerza en la zona de operaciones, su contribución a la tarea pendiente de restablecer la paz y la seguridad internacionales, las opiniones del Gobierno del Líbano y las consecuencias para la Fuerza de una mayor presencia del ejército libanés en el sur del país;

14. Espera con interés el pronto cumplimiento del mandato de la FPNUL;

15. Destaca la importancia y la necesidad de lograr una paz completa, justa y duradera en el Oriente Medio, basada en todas las resoluciones en la materia, entre ellas sus resoluciones 242 (1967), de 22 de noviembre de 1967, y 338 (1973), de 22 de octubre de 1973. 


\title{
REPÚBLICA DEMOCRÁTICA DEL CONGO
}

\author{
RESOLUCIÓN 1565
}

(1 de octubre de 2004)

\section{El Consejo de Seguridad,}

Recordando sus resoluciones anteriores y las declaraciones de su Presidente relativas a la República Democrática del Congo,

Reafirmando su determinación de que se respeten la soberanía, la integridad territorial y la independencia política de la República Democrática del Congo y de todos los Estados de la región,

Reafirmando su apoyo al proceso del Acuerdo global e inclusivo sobre la transición en la República Democrática del Congo (firmado en Pretoria el 17 de diciembre de 2002), celebrando los esfuerzos realizados hasta la fecha por el Gobierno de unidad nacional y transición para su aplicación, e instan$d o$ a todas las partes congoleñas a que cumplan sus compromisos a este respecto, en particular para que puedan celebrarse elecciones libres, limpias y pacíficas en el plazo acordado,

Profundamente preocupado por la continuación de las hostilidades en el este de la República Democrática del Congo, en particular en las provincias de Kivu del norte y del sur y en el distrito de Ituri, y por las graves violaciones de los derechos humanos y del derecho internacional humanitario que conllevan,

Recordando que todas las partes tienen la obligación de garantizar la seguridad de la población civil, y recordando en particular a este respecto sus resoluciones 1325 (2000) sobre la mujer, la paz y la seguridad, 1379 (2001), 1460 (2003) y 1539 (2004) sobre los niños en los conflictos armados, y 1265 (1999) y 1296 (2000) sobre la protección de los civiles en los conflictos armados,

Tomando nota del tercer informe especial del Secretario General sobre la Misión de las Naciones Unidas en la República Democrática del Congo (MONUC), de 16 de agosto de 2004 (S/2004/650), y de sus recomendaciones,

Tomando nota de la carta del Secretario General de fecha 3 de septiembre de 2004 (S/2004/715),

Observando que la situación en la República Democrática del Congo sigue siendo una amenaza para la paz y la seguridad internacionales en la región, 
Actuando en virtud del Capítulo VII de la Carta de las Naciones Unidas,

1. Decide prorrogar el despliegue de la MONUC hasta el 31 de marzo de 2005;

2. Pide al Secretario General que organice el despliegue rápido de más capacidad militar para la MONUC con arreglo a la recomendación contenida en su carta de fecha 3 de septiembre de 2004 y, posteriormente, que despliegue lo antes posible en las provincias de Kivu del norte y del sur todas las brigadas y el apoyo a la fuerza que corresponda;

3. Autoriza el incremento de los efectivos de la MONUC en 5.900 miembros, incluidos 341 policías civiles, así como el despliegue del personal civil que corresponda, la capacidad de movilidad aérea correspondiente y proporcional y otro apoyo a la fuerza, y expresa su determinación de examinar periódicamente los objetivos y la estructura de la MONUC, teniendo en cuenta la evolución de la situación sobre el terreno;

4. Decide que la MONUC tenga el mandato siguiente:

a) Desplegar y mantener una presencia en las zonas clave de posible inestabilidad con el fin de promover el restablecimiento de la confianza, desalentar la violencia, en particular disuadiendo del recurso a la fuerza para amenazar el proceso político, y permitir que el personal de las Naciones Unidas se mueva libremente, en particular en la parte oriental de la República Democrática del Congo;

b) Garantizar la protección de los civiles, incluido el personal humanitario, que se encuentren en peligro inminente de violencia física;

c) Garantizar la protección del personal, los locales, las instalaciones y el equipo de las Naciones Unidas;

d) Garantizar la seguridad y la libertad de desplazamiento de su personal;

e) Establecer los vínculos operacionales necesarios con la Operación de las Naciones Unidas en Burundi (ONUB) y con los Gobiernos de la República Democrática del Congo y Burundi, con el fin de coordinar las actividades de supervisión y desalentar los desplazamientos transfronterizos de combatientes entre los dos países;

f) Supervisar la aplicación de las medidas impuestas en virtud del párrafo 20 de la resolución 1493, de 28 de julio de 2003, incluso en los lagos, en cooperación con la ONUB y, cuando corresponda, con los gobiernos interesados y con el grupo de expertos mencionado en el párrafo 10 de la resolución 1533, de 12 de marzo de 2004, incluso inspeccionando, si lo considera necesario y sin aviso previo, la carga de los aviones y de cualquier vehículo 


\section{DOCUMENTACIÓN}

de transporte que utilice los puertos, los aeropuertos, los aeródromos, las bases militares y los puestos de cruce fronterizo en Kivu del norte y del sur y en Ituri;

g) Confiscar o recoger, cuando corresponda, las armas y cualquier material conexo cuya presencia en el territorio de la República Democrática del Congo viole las medidas impuestas en virtud del párrafo 20 de la resolución 1493, y eliminar dichas armas y material conexo como corresponda;

h) Observar e informar en forma oportuna sobre la posición de los grupos y movimientos armados y la presencia de fuerzas militares extranjeras en las zonas clave de inestabilidad, especialmente supervisando la utilización de las pistas de aterrizaje y las fronteras, en particular en los lagos;

5. Decide que la MONUC tenga también el mandato siguiente, en apoyo del Gobierno de unidad nacional y transición:

a) Contribuir a los mecanismos adoptados para la seguridad de las instituciones y la protección de los funcionarios de la transición en Kinshasa hasta que la unidad de policía integrada para Kinshasa esté preparada para asumir sus responsabilidades y ayudar a las autoridades congoleñas en el mantenimiento del orden en otras zonas estratégicas, como se recomienda en el apartado c) del párrafo 103 del tercer informe especial del Secretario General;

b) Contribuir a mejorar las condiciones de seguridad en que se presta la asistencia humanitaria, y ayudar en las operaciones de regreso voluntario de refugiados y desplazados internos;

c) Apoyar las operaciones de desarme de combatientes extranjeros dirigidas por las Fuerzas Armadas de la República Democrática del Congo, incluso tomando las medidas enumeradas en los apartados b), c), d) y e) del párrafo 75 del tercer informe especial del Secretario General;

d) Facilitar la desmovilización y la repatriación voluntaria de los combatientes extranjeros desarmados y las personas a su cargo;

e) Contribuir a la parte dedicada al desarme del programa nacional de desarme, desmovilización y reintegración de combatientes congoleños y las personas a su cargo, supervisando el proceso y proporcionando las condiciones de seguridad que corresponda en algunos lugares difíciles;

f) Contribuir a la conclusión con éxito del proceso electoral establecido en el acuerdo global e inclusivo, ayudando a establecer un entorno seguro para celebrar elecciones libres, transparentes y pacíficas;

g) Ayudar a promover y proteger los derechos humanos, prestando especial atención a las mujeres, los niños y las personas vulnerables, investigar las violaciones de los derechos humanos con el fin de acabar con la impunidad, 
y seguir cooperando en las acciones para garantizar que los responsables de violaciones graves de los derechos humanos y el derecho internacional humanitario sean llevados ante la justicia, trabajando estrechamente con los organismos pertinentes de las Naciones Unidas;

6. Autoriza a la MONUC a utilizar todos los medios necesarios, dentro de sus posibilidades y en las zonas en que estén desplegadas sus unidades armadas, para desempeñar las tareas enumeradas en los apartados a) a g) del párrafo 4 supra y los apartados a), b), c), e) y f) del párrafo 5 supra;

7. Decide que la MONUC tenga también el mandato, dentro de sus posibilidades y sin perjuicio del desempeño de las tareas establecidas en los párrafos 4 y 5 supra, de prestar asesoramiento y asistencia al Gobierno y las autoridades de transición, de conformidad con los compromisos contraídos en el Acuerdo global e inclusivo, incluso apoyando a las tres comisiones conjuntas mencionadas en el párrafo 62 del tercer informe especial del Secretario General, con el fin de contribuir a sus esfuerzos, con miras a promover:

a) Legislación esencial, incluida la futura constitución;

b) La reforma del sector de la seguridad, incluida la integración de las fuerzas nacionales de defensa y seguridad interna junto con el desarme, la desmovilización y la reintegración y, en particular, el adiestramiento y la supervisión de la policía, garantizando al mismo tiempo que sean democráticas y respeten plenamente los derechos humanos y las libertades fundamentales;

c) El proceso electoral;

8. Pide al Secretario General que informe al Consejo en el plazo de un mes después de la aprobación de la presente resolución de las reformas necesarias para mejorar las estructuras de mando y control y la gestión de la información militar dentro de la MONUC y racionalizar los componentes civil y de policía de la MONUC;

9. Pide al Secretario General que, por conducto de su Representante Especial para la República Democrática del Congo, coordine todas las actividades del sistema de las Naciones Unidas en ese país;

10. Pide al Secretario General que disponga que sus Representantes Especiales para la República Democrática del Congo y para Burundi coordinen las actividades de la MONUC y la ONUB y, en particular:

- Compartan la información militar de que dispongan, especialmente la relativa a los desplazamientos de elementos armados y al tráfico de armas a través de las fronteras;

- Aúnen sus recursos logísticos y administrativos, en la medida en que no redunde en desmedro de la capacidad de esas misiones para desem- 


\section{DOCUMENTACIÓN}

peñar sus respectivos mandatos, a fin de lograr la mayor eficiencia y la mejor relación costo-eficacia, y

- Coordinen, según proceda, la ejecución de los programas nacionales de desarme y desmovilización y de repatriación, reinserción y reasentamiento;

11. Destaca la necesidad de que el Gobierno de unidad nacional y transición lleve a cabo el proceso previsto en el Acuerdo global e inclusivo y, en particular, ponga en práctica las recomendaciones formuladas en el párrafo 54 del tercer informe especial del Secretario General incluso preparando, con el apoyo de la MONUC, planes y cronogramas precisos en cada una de las materias indicadas;

12. Pide al Gobierno de unidad nacional y transición que coopere estrechamente con la MONUC en el establecimiento de tres comisiones mixtas sobre legislación básica, reforma del sector de la seguridad y elecciones y en la introducción de la reforma del sector de seguridad de conformidad con el párrafo 7 de la presente resolución;

13. Insta al Gobierno de unidad nacional y transición a que prosiga con determinación y rapidez la integración de las fuerzas de seguridad, en particular la de las fuerzas armadas, y destaca la importancia de que el Consejo Supremo de Defensa se reúna periódicamente y coopere con los asociados internacionales de la República Democrática del Congo, especialmente con la MONUC, como señales positivas del compromiso del Gobierno de unidad nacional y transición a ese respecto;

14. Insta al Gobierno de unidad nacional y transición a que prepare sin más dilación un plan para el desarme de los combatientes extranjeros y encomiende su aplicación a las Fuerzas Armadas de la República Democrática del Congo, con el apoyo de la MONUC;

15. Insta a los Gobiernos de la República Democrática del Congo, Burundi, Rwanda y Uganda a que cada uno se cerciore de que su territorio no sea utilizado para infringir la soberanía de los demás, a que normalicen cabalmente y sin más demora sus relaciones bilaterales y a que cooperen activamente en la tarea de afianzar la seguridad en sus fronteras comunes, en particular poniendo en práctica los acuerdos firmados para el establecimiento de mecanismos conjuntos de verificación con la activa participación de la MONUC y les exhorta a cumplir a este respecto las recomendaciones formuladas en el párrafo 55 del tercer informe especial del Secretario General;

16. Insta, en particular, a los Gobiernos de la República Democrática del Congo y Rwanda a que colaboren entre sí y con la MONUC y la Unión Afri- 
cana con miras a eliminar la amenaza que plantean los grupos armados extranjeros, como ya lo decidieron en el Acuerdo firmado en Pretoria el 30 de julio de 2002 y la Declaración firmada en Pretoria el 27 de noviembre de 2003 y de conformidad con los "parámetros" firmados en Nueva York el 22 de septiembre de 2004;

17. Pide al Gobierno de unidad nacional y transición y a los funcionarios congoleños de todos los niveles que adopten las medidas que sean necesarias, sin dejar de respetar la libertad de expresión y de prensa, para impedir que se utilicen los medios de difusión a fin de instigar al odio o a la tensión entre comunidades;

18. Pide a los Estados Miembros, a las organizaciones internacionales interesadas y a la comunidad de donantes que presten su pleno apoyo al proceso de transición, a la extensión de la autoridad del Estado en todo el territorio y al desarrollo económico y social a largo plazo en la República Democrática del Congo y, en este sentido, les alienta a responder en forma positiva a las recomendaciones formuladas en el párrafo 57 del tercer informe especial del Secretario General;

19. Condena enérgicamente los actos de violencia y las transgresiones del derecho internacional humanitario y los derechos humanos, en particular los cometidos contra civiles, en la República Democrática del Congo y exige que todas las partes y los gobiernos interesados de la región, con inclusión del Gobierno de unidad nacional y transición, tomen sin demora todas las medidas necesarias para someter a la justicia a los responsables y asegurar el respeto de los derechos humanos y el derecho internacional humanitario, según proceda con la asistencia internacional pertinente, así como para garantizar la seguridad y el bienestar de la población civil;

20. Exige que todas las partes cooperen plenamente con las operaciones de la MONUC y aseguren la protección del personal de las Naciones Unidas y personal asociado y le den acceso inmediato y sin trabas en el desempeño de su mandato en todo el territorio de la República Democrática del Congo, exige en particular que todas las partes den pleno acceso a los observadores militares de la MONUC, incluso en todos los puertos, aeropuertos, aeródromos, bases militares y puestos de cruce fronterizos, y pide al Secretario General que dé cuenta sin demora de todo incumplimiento de estas exigencias;

21. Recordando su resolución 1502, de 26 de agosto de 2003, reafirma la obligación de todas las partes de cumplir cabalmente las normas y los principios del derecho internacional humanitario que les son aplicables en relación con la protección del personal de asistencia humanitaria y de las Naciones Unidas e insta también a quienes concierna a que den al personal de 


\section{DOCUMENTACIÓN}

asistencia humanitaria acceso inmediato, cabal e irrestricto a todos los que necesiten asistencia, como dispone el derecho internacional humanitario aplicable;

22. Recuerda que la explotación y el comercio ilícitos de los recursos naturales en ciertas regiones son un factor que aviva los conflictos armados y, de conformidad con sus resoluciones 1493 (2003), 1533 (2004) y 1552 (2004), condena categóricamente la explotación ilegal de los recursos naturales y otras fuentes de riqueza de la República Democrática del Congo, insta a todos los Estados, especialmente los de la región y la propia República Democrática del Congo, a tomar las medidas adecuadas para poner fin a esas actividades ilícitas, incluso por medios judiciales de ser necesario, y a que presenten al Consejo los informes que corresponda y exhorta a las instituciones financieras internacionales a que presten asistencia al Gobierno de unidad nacional y transición en la tarea de establecer un control eficiente y transparente de la explotación de los recursos naturales;

23. Acoge con satisfacción la convocación de la conferencia internacional sobre paz, seguridad y democracia y desarrollo en la región de los Grandes Lagos de África, con la participación de todos los gobiernos interesados y bajo los auspicios de la Unión Africana y de las Naciones Unidas, con miras a consolidar la estabilidad en la región y establecer condiciones que permitan a cada Estado disfrutar del derecho de vivir en paz;

24. Alienta a todos los Estados Miembros a que, como se pide en el párrafo 57 del tercer informe del Secretario General, aumenten el compromiso político internacional con el proceso de paz en la región;

25. Expresando profunda preocupación por las denuncias de faltas de conducta y explotación sexual por personal civil y militar de la MONUC, pide al Secretario General que siga investigándolas plenamente para adoptar las medidas que procedan de conformidad con su boletín relativo a las medidas especiales para la protección respecto de la explotación y el abuso sexuales (ST/SGB/2003/13) y que le mantenga al corriente, alienta además a la MONUC a que imparta capacitación al personal pertinente a fin de asegurar el pleno cumplimiento de su código de conducta relativo a la falta de conducta sexual e insta a los países que aportan contingentes a que adopten las medidas disciplinarias y de otra índole que procedan para hacer valer cabalmente la responsabilidad por los casos de falta de conducta de esa índole en que esté involucrado personal suyo;

26. Pide al Secretario General que lo mantenga informado periódicamente de la evolución de la situación en la República Democrática del Congo y que le presente antes del 28 de febrero de 2005 un informe sobre el cum- 
plimiento del mandato de la MONUC que incluya una evaluación de la estructura y la dotación de sus componentes militar, civil y de policía con miras a modificarlos según los progresos realizados sobre el terreno y las tareas que queden por cumplir;

27. Reitera su firme apoyo al Representante Especial del Secretario General y a la MONUC, así como a la labor que siguen haciendo para ayudar a las partes en la República Democrática del Congo y en la región a hacer avanzar el proceso de paz;

28. Decide seguir ocupándose activamente de la cuestión.

\section{RESOLUCIÓN 1592}

(30 de marzo de 2005)

\section{El Consejo de Seguridad,}

Recordando sus anteriores resoluciones y declaraciones de su Presidencia relativas a la República Democrática del Congo, en particular la resolución 1565 (2003), de $1^{\circ}$ de octubre de 2004, y la declaración de 2 de marzo de 2005,

Reafirmando su determinación de que se respeten la soberanía, la integridad territorial y la independencia política de la República Democrática del Congo y de todos los Estados de la región y su apoyo al proceso del Acuerdo global e inclusivo sobre la transición en la República Democrática del Congo, firmado en Pretoria el 17 de diciembre de 2002, e instando a todas las partes congoleñas a que cumplan sus compromisos a este respecto, en particular para que puedan celebrarse elecciones libres, limpias y pacíficas,

Observando una vez más con profunda preocupación que continúan las hostilidades por parte de grupos armados y milicias en el este de la República Democrática del Congo, en particular en las provincias de Kivu del norte y del sur y en el distrito de Ituri, y las graves infracciones de los derechos humanos y del derecho internacional humanitario que conllevan, exhortando al Gobierno de Unidad Nacional y Transición a que lleve ante la justicia sin demora a los responsables y reconociendo que la permanencia de elementos de las ex Fuerzas Armadas Rwandesas y de Interahamwe sigue siendo una amenaza para la población civil local y un impedimento para las relaciones de buena vecindad entre la República Democrática del Congo y Rwanda,

Acogiendo con satisfacción a este respecto el apoyo de la Unión Africana a las iniciativas encaminadas a promover la paz en el este de la República Democrática del Congo y haciendo un llamamiento a la Unión Africana para 


\section{DOCUMENTACIÓN}

que colabore estrechamente con la MONUC a fin de definir su función en la región,

Recordando su condena del ataque perpetrado por una de esas milicias contra miembros de la Misión de las Naciones Unidas en la República Democrática del Congo (MONUC) el 25 de febrero de 2005 y acogiendo con satisfacción las primeras medidas adoptadas hasta la fecha para llevar a los culpables ante la justicia, en particular la detención de los líderes de milicias presuntamente responsables de infracciones de los derechos humanos,

Reiterando su llamamiento a las partes congoleñas para que, al elegir a quienes han de ocupar cargos en el Gobierno de Unidad Nacional y Transición, incluidas las fuerzas armadas y la policía nacional, tengan en cuenta su historial y su compromiso con el respeto del derecho internacional humanitario y los derechos humanos,

Recordando que incumbe a todas las partes la responsabilidad de velar por la seguridad de la población civil, en particular las mujeres, los niños y otras personas vulnerables, y expresando preocupación por el grado en que persiste la violencia sexual,

Reafirmando su pleno apoyo a la MONUC y a su personal, que operan en condiciones particularmente peligrosas, y acogiendo con beneplácito las medidas firmes que está tomando en cumplimiento de su mandato,

Recordando que la explotación y el comercio ilícitos de los recursos naturales en ciertas regiones son un factor que aviva los conflictos armados, condenando categóricamente la explotación ilegal de los recursos naturales y otras fuentes de riqueza

de la República Democrática del Congo e instando a todos los Estados, especialmente los de la región y la propia República Democrática del Congo, a tomar las medidas adecuadas para poner fin a esas actividades ilícitas,

Teniendo presente el tercer informe especial del Secretario General sobre la MONUC, de 16 de agosto de 2004 (S/2004/650), y sus recomendaciones y consciente de la importancia de mantener en examen la situación en las provincias de Katanga y Kasaï,

Tomando nota del $17^{\circ}$ informe del Secretario General sobre la MONUC, de 21 de marzo de 2005 (S/2005/167), y esperando con interés el informe especial sobre el proceso electoral anunciado por el Secretario General en el párrafo 34 de ese documento,

Observando que la situación en la República Democrática del Congo sigue constituyendo una amenaza para la paz y la seguridad internacionales en la región, 
Actuando con arreglo al Capítulo VII de la Carta de las Naciones Unidas,

1. Decide prorrogar el mandato de la MONUC, establecido en la resolución 1565 (2004), hasta el $1^{\circ}$ de octubre de 2005, con la intención de prorrogarlo por períodos sucesivos;

2. Exige nuevamente que todas las partes cooperen plenamente con las operaciones de la MONUC, aseguren la protección del personal de las Naciones Unidas y personal asociado y le den acceso inmediato y sin trabas en el desempeño de su mandato en todo el territorio de la República Democrática del Congo, exige en particular que todas las partes den pleno acceso a los observadores militares de la MONUC, incluso en todos los puertos, aeropuertos, aeródromos, bases militares y puestos de cruces fronterizos, y pide al Secretario General que dé cuenta sin demora de todo incumplimiento de estas exigencias;

3. Insta al Gobierno de Unidad Nacional y Transición a hacer cuanto esté a su alcance para garantizar la seguridad de los civiles, incluido el personal humanitario, extendiendo efectivamente la autoridad del Estado en todo el territorio de la República Democrática del Congo y, en particular, en Kivu del norte y del sur y en Ituri;

4. Exhorta al Gobierno de Unidad Nacional y Transición a llevar a cabo la reforma del sector de seguridad, integrando rápidamente las fuerzas armadas y la policía nacional de la República Democrática del Congo y, en particular, asegurando una paga y apoyo logístico suficientes a su personal y subraya la necesidad a este respecto de poner en práctica sin demora el programa nacional de desarme, desmovilización y reintegración de los combatientes congoleños;

5. Exhorta además al Gobierno de Unidad Nacional y Transición a formular con la MONUC un concepto conjunto de operaciones para el desarme de los combatientes extranjeros por las fuerzas armadas de la República Democrática del Congo, con la asistencia de la MONUC, dentro de los límites de su mandato y de sus posibilidades;

6. Exhorta a la comunidad de donantes a que, con carácter urgente, mantenga su firme compromiso de prestar toda la asistencia necesaria para la integración, el entrenamiento y equipamiento de las fuerzas armadas y de la policía nacional de la República Democrática del Congo y exhorta al Gobierno de Unidad Nacional y Transición a que promueva todos los medios posibles para facilitar y acelerar la cooperación con este fin;

7. Subrayando que la MONUC está autorizada a utilizar todos los medios necesarios, dentro de sus posibilidades y en las zonas donde estén des- 


\section{DOCUMENTACIÓN}

plegadas sus unidades armadas, para evitar todo intento de emplear la fuerza a fin de poner en peligro el proceso político y asegurar la protección de los civiles que estén bajo una amenaza inminente de violencia física por parte de cualquier grupo armado, extranjero o congoleño, en particular las antiguas Fuerzas Armadas Rwandesas (FAR) y las milicias Interahamwe, alienta a la MONUC en este sentido a que siga aplicando plenamente el mandato que le confiere la resolución 1565 (2004) en el este de la República Democrática del Congo y subraya que, de conformidad con su mandato, la MONUC puede utilizar tácticas de acordonamiento y registro para evitar ataques contra civiles y desbaratar la capacidad militar de los grupos armados ilegales que siguen recurriendo a la violencia en esa zona;

8. Exhorta a todas las partes en la transición de la República Democrática del Congo a avanzar en forma concreta hacia la celebración de elecciones, como se dispone en el Acuerdo global e inclusivo, en particular promoviendo la pronta adopción de la constitución y la ley electoral, así como el empadronamiento de los votantes;

9. Exige que los Gobiernos de Uganda, Rwanda y la República Democrática del Congo pongan fin a la utilización de sus respectivos territorios en apoyo de las violaciones del embargo impuesto en la resolución 1493 (2003) de 28 de julio de 2003, o de las actividades de grupos armados que operan en la región;

10. Insta además a todos los Estados vecinos de la República Democrática del Congo a que impidan todo tipo de apoyo a la explotación ilegal de los recursos naturales congoleños, en particular evitando el paso de esos recursos a través de sus respectivos territorios;

11. Reafirma su preocupación por los actos de explotación y abuso sexuales cometidos por personal de las Naciones Unidas contra la población local y pide al Secretario General que se asegure de que se cumplan la política de tolerancia cero que ha instituido y las medidas establecidas para prevenir e investigar las faltas de conducta de todo tipo, sancionar a aquellos cuya responsabilidad se determine y prestar apoyo a las víctimas, así como de que se proceda activamente a la formación y toma de conciencia de todo el personal de la MONUC, y pide además al Secretario General que le informe regularmente de las medidas aplicadas y su eficacia;

12. Exhorta a los países que aportan contingentes a que estudien detenidamente la carta del Secretario General de 24 de marzo de 2005 (A/59/710) y tomen las medidas apropiadas para evitar la explotación y el abuso sexuales por el personal que aportan a la MONUC, incluida la realización de actividades de toma de conciencia previas al despliegue, y que tomen medidas 
disciplinarias y de otro tipo para hacer valer plenamente la responsabilidad en los casos en que su personal esté involucrado en conductas de esa índole;

13. Decide seguir ocupándose activamente de la cuestión.

\section{RESOLUCIÓN 1596}

(18 de abril de 2005)

\section{El Consejo de Seguridad,}

Recordando sus resoluciones relativas a la República Democrática del Congo, en particular las resoluciones 1493 (2003), de 28 de julio de 2003, 1533 (2004), de 12 de marzo de 2004, 1552 (2004), de 27 de julio de 2004, 1565 (2004), de 1 de octubre de 2004 y 1592 (2005), de 30 de marzo de 2005, y recordando también las declaraciones de su Presidencia relativas a la República Democrática del Congo, en particular la del 7 de diciembre de 2004,

Reiterando su profunda preocupación por la presencia de grupos armados y milicias en la parte oriental de la República Democrática del Congo, especialmente en las provincias de Kivu del norte y Kivu del sur y en el distrito de Ituri, que perpetúan el clima de inseguridad en toda la región,

Observando con beneplácito que algunos de estos grupos y milicias han comenzado a presentar un inventario de las armas y pertrechos que obran en su poder y de su localización con miras a participar en los programas de desarme y alentando a quienes no lo hayan hecho aún a que procedan a ello con rapidez,

Expresando que está dispuesto a revisar las disposiciones de sus resoluciones 918, de 17 de mayo de 1994, 997, de 9 de junio de 1995 y 1011, de 16 de agosto de 1995, desde una perspectiva más amplia, teniendo en cuenta las consecuencias para la paz y la seguridad en la región de los Grandes Lagos de África de que persista la inestabilidad en el este de la República Democrática del Congo,

Condenando la continuación de la corriente ilícita de armas dentro de la República Democrática del Congo y hacia ella y declarando su determinación de seguir vigilando atentamente la aplicación del embargo de armas impuesto en su resolución 1493 (2003), de 28 de julio de 2003,

Recordando la importancia de que el Gobierno de Unidad Nacional y Transición lleve a cabo sin demora la integración de las fuerzas armadas de la República Democrática del Congo, cuya responsabilidad le compete y, a esos efectos, siga trabajando en el marco de la Comisión Mixta sobre refor- 


\section{DOCUMENTACIÓN}

ma del sector de la seguridad y alentando a la comunidad de donantes a que preste asistencia financiera y técnica coordinada para tal fin,

Encomiando las gestiones realizadas por el Secretario General, la Unión Africana y otros interesados para restablecer la paz y la seguridad en la República Democrática del Congo y acogiendo con agrado a este respecto la Declaración aprobada en Dar es Salam el 20 de noviembre de 2004 al concluir la primera reunión en la cumbre de la Conferencia Internacional sobre la paz, la seguridad, la democracia y el desarrollo en la región de los Grandes Lagos de África,

Tomando nota de los informes y las recomendaciones del Grupo de Expertos a que se hace referencia en el párrafo 10 de la resolución 1533 (2004), de 15 de julio de 2004 (S/2004/551) y 25 de enero de 2005 (S/2005/30), que le transmitió el Comité establecido en virtud del párrafo 8 de dicha resolución (en adelante el Comité),

Observando que la situación en la República Democrática del Congo sigue constituyendo una amenaza para la paz y la seguridad internacionales en la región,

Actuando en virtud del Capítulo VII de la Carta de las Naciones Unidas,

1. Reafirma las medidas establecidas en el párrafo 20 de la resolución 1493 (2003), de 28 de julio de 2003, y prorrogadas hasta el 31 de julio de 2005 en virtud de la resolución 1552 (2004), de 27 de julio de 2004, decide que de ahora en adelante serán aplicables a cualquier destinatario en la República Democrática del Congo y reitera que la asistencia incluye el financiamiento y la asistencia financiera relacionados con actividades militares;

2. Decide que las medidas que anteceden no serán aplicables a:

a) Los suministros de armas y pertrechos o la asistencia o formación técnica destinados exclusivamente a prestar apoyo a las unidades del ejército y la policía de la República Democrática del Congo o a ser utilizados por éstas, a condición de que esas unidades:

- Hayan completado el proceso de integrarse;

- Operen bajo el mando, respectivamente, del Estado Mayor integrado de las Fuerzas Armadas o de la Policía Nacional de la República Democrática del Congo;

- Estén en proceso de integrarse en el territorio de la República Democrática del Congo fuera de las provincias de Kivu del norte o Kivu del sur y del distrito de Ituri;

b) Los suministros de armas y pertrechos y la asistencia o formación técnica destinados exclusivamente a prestar apoyo a la Misión de las Naciones 
Unidas en la República Democrática del Congo (MONUC) o a ser utilizados por ella;

c) Los suministros de equipo militar no mortífero destinados exclusivamente a fines humanitarios o de protección y la asistencia y la formación técnicas conexas que sean notificados con antelación al Comité con arreglo a lo dispuesto en el párrafo 8 e) de la resolución 1533 (2004);

3. Pide a la MONUC, dentro de los límites de sus actuales posibilidades y de manera que no redunde en desmedro del desempeño de su mandato actual, y al Grupo de Expertos a que se hace referencia en el párrafo 21, que sigan centrando sus actividades de vigilancia en Kivu del norte y Kivu del sur y en Ituri;

4. Decide que, en el futuro, todos los envíos autorizados de armas y pertrechos comprendidos en las exenciones indicadas en el párrafo 2 a) de la presente resolución únicamente serán hechos a los sitios de recepción que indique el Gobierno de Unidad Nacional y Transición en coordinación con la MONUC y que sean notificados con antelación al Comité;

5. Exige que todas las partes que no sean aquellas a que se hace referencia en el párrafo 2 a) y que tengan capacidad militar en Ituri, en Kivu del norte o en Kivu del sur ayuden al Gobierno de Unidad Nacional y Transición a cumplir sus compromisos relativos al desarme, la desmovilización y la reintegración de los combatientes extranjeros y congoleños y los relativos a la reforma del sector de la seguridad;

6. Decide que, en el período en que se apliquen las medidas a que se hace referencia en el párrafo 1 , todos los gobiernos de la región y, en particular, los de la República Democrática del Congo y los Estados fronterizos con las regiones de Ituri y los Kivus adopten las medidas necesarias con miras a:

- Cerciorarse de que las aeronaves operen en la región de conformidad con el Convenio sobre Aviación Civil Internacional firmado en Chicago el 7 de diciembre de 1944, en particular verificando la validez de la documentación a bordo de las aeronaves y de las licencias de los pilotos;

- Prohibir de inmediato en sus respectivos territorios las operaciones de toda aeronave que no cumpla las condiciones enunciadas en ese Convenio o las normas establecidas por la Organización de Aviación Civil Internacional, en particular en lo que respecta al uso de documentación falsa o caducada, notificar al Comité y mantener esa prohibición hasta que éste sea informado por Estados o por el Grupo de Expertos de que esas aeronaves cumplen las condiciones y normas enunciadas 


\section{DOCUMENTACIÓN}

en el capítulo V del Convenio de Chicago y determine que no serán utilizadas para un fin que contravenga lo dispuesto en las resoluciones del Consejo de Seguridad;

- Cerciorarse de que los aeropuertos o aeródromos civiles y militares en sus respectivos territorios no serán utilizados para fines incompatibles con las medidas impuestas en el párrafo 1;

7. Decide además que cada uno de los gobiernos de la región, en particular los de los Estados fronterizos con Ituri y los Kivus, así como el de la República Democrática del Congo, llevará un registro, para su examen por el Comité y por el Grupo de Expertos, de toda la información relativa a los vuelos con origen en sus territorios respectivos y destino en la República Democrática del Congo y a los vuelos con origen en esta República y destino en sus territorios respectivos;

8. Insta al Gobierno de Unidad Nacional y Transición a que refuerce la vigilancia de la actividad en todos los aeropuertos y aeródromos, en particular los de Ituri y los Kivus, para asegurarse en particular de que sólo se utilicen aeropuertos con aduanas para el servicio aéreo internacional y pide a la MONUC que, en los aeropuertos y aeródromos en los que tiene una presencia permanente, coopere, dentro de los límites de sus actuales posibilidades, con las autoridades congoleñas competentes a fin de aumentar la capacidad de estas últimas para vigilar y controlar la utilización de los aeropuertos;

9. Recomienda, en este contexto, a los Estados de la región y en particular a los que son partes en la Declaración aprobada en Dar es Salam el 20 de noviembre de 2004 que promuevan la cooperación regional en el control del tráfico aéreo;

10. Decide que, en el período en que se apliquen las medidas a que se hace referencia en el párrafo 1, el Gobierno de la República Democrática del Congo, por un lado, y los Gobiernos de los Estados fronterizos con las regiones de Ituri y los Kivus, por el otro, adoptarán las medidas necesarias con el fin de:

- Hacer más estrictos, en la medida en que concierna a cada uno, los controles aduaneros en las fronteras entre Ituri o los Kivus y los Estados vecinos;

- Cerciorarse de que no se utilicen en sus respectivos territorios medios de transporte en violación de las medidas adoptadas por los Estados Miembros de conformidad con el párrafo 1 y notificar esas medidas a la MONUC, y pide a la MONUC y a la Operación de las Naciones Unidas en Burundi (ONUB) que, de conformidad con sus respectivos 
mandatos y en los lugares en que tengan una presencia permanente, presten asistencia para tal fin a las autoridades aduaneras competentes de la República Democrática del Congo y de Burundi;

11. Reitera su llamamiento a la comunidad internacional, en particular a los organismos internacionales especializados interesados, especialmente la Organización de Aviación Civil Internacional y la Organización Mundial de Aduanas, para que presten asistencia financiera y técnica al Gobierno de Unidad Nacional y Transición a fin de ayudarle a ejercer un control efectivo sobre sus fronteras y su espacio aéreo e invita a este respecto al Fondo Monetario Internacional y al Banco Mundial a que presten asistencia a fin de evaluar y mejorar el desempeño y aumentar la capacidad del Servicio de Aduanas de la República Democrática del Congo;

12. Exhorta a todos los Estados a que investiguen las actividades de sus nacionales que operen aeronaves u otros medios de transporte de la índole a que se hace referencia en los párrafos 6 y 10 que se utilicen para el transporte de armas o pertrechos en violación de las medidas impuestas en el párrafo 1 o estén relacionados con esa operación y, a que, si es necesario, entablen las acciones judiciales que procedan en su contra;

13. Decide que, en el período en que se apliquen las medidas a que se hace referencia en el párrafo 1, todos los Estados adopten las medidas necesarias para impedir la entrada en sus territorios o el tránsito por ellos de quienes, según determine el Comité, estén actuando en contravención de las medidas adoptadas por Estados Miembros de conformidad con el párrafo 1, en la inteligencia de que nada de lo dispuesto en el presente párrafo obligará a un Estado a denegar la entrada en su territorio a sus propios nacionales;

14. Decide que las medidas impuestas en virtud del párrafo precedente no serán aplicables cuando el Comité determine con antelación y en cada caso concreto que el viaje de que se trate está justificado por motivos humanitarios, entre ellos obligaciones religiosas, o cuando el Comité llegue a la conclusión de que una exención promovería los objetivos de las resoluciones del Consejo, es decir, la paz y la reconciliación nacional en la República Democrática del Congo y la estabilidad en la región;

15. Decide que, en el período en que se apliquen las medidas a que se hace referencia en el párrafo 1, los Estados congelen de inmediato los fondos y otros activos financieros y recursos económicos que se encuentren en sus territorios a partir de la fecha de aprobación de la presente resolución y que sean de propiedad o estén bajo el control directo o indirecto de personas designadas por el Comité de conformidad con el párrafo 13 o que obren en poder de entidades o estén bajo el control directo o indirecto de cualquier per- 


\section{DOCUMENTACIÓN}

sona que actúe en su nombre o siguiendo sus instrucciones, según determine el Comité, y decide también que todos los Estados se cercioren de que ningún fondo, activo financiero o recurso económico sea puesto por nacionales suyos o por personas que se encuentren en sus territorios a disposición o a la orden de esas personas o entidades;

16. Decide que las disposiciones del párrafo que antecede no serán aplicables a fondos, otros activos financieros y recursos económicos que, según hayan determinado los Estados correspondientes:

a) Son necesarios para gastos básicos, entre ellos, pagos por alimentos, alquileres o hipotecas, medicamentos y tratamiento médico, impuestos, primas de seguros y tarifas de servicios públicos o para el pago de honorarios profesionales de un monto razonable y el reembolso de gastos efectuados en relación con la prestación de servicios jurídicos u honorarios o tasas, de conformidad con la legislación nacional, por servicios de administración o mantenimiento ordinarios de fondos, otros activos financieros y recursos económicos congelados, previa notificación de esos Estados al Comité de la intención de autorizar, cuando proceda, el acceso a dichos fondos, otros activos financieros y recursos económicos y de no haber una decisión negativa del Comité en el plazo de cuatro días laborables a partir de la notificación;

b) Son necesarios para gastos extraordinarios, siempre y cuando esa determinación haya sido notificada por los Estados correspondientes al Comité y éste las haya aprobado; o

c) Son objeto de un gravamen o un dictamen judicial, administrativo o arbitral, en cuyo caso los fondos, otros activos financieros y recursos económicos podrán utilizarse para cumplir el gravamen o dictamen a condición de que haya sido dictado con antelación a la fecha de la presente resolución, no beneficie a una persona o entidad designada por el Comité con arreglo al párrafo 15 y haya sido notificado al Comité por los Estados correspondientes;

17. Decide que, el 31 de julio de 2005 a más tardar, examinará las medidas impuestas en los párrafos 1, 6, 10, 13 y 15 a la luz de los avances realizados en el proceso de paz y transición en la República Democrática del Congo, en particular en lo que respecta a la integración de las Fuerzas Armadas y la Policía Nacional;

18. Decide que el Comité se encargará de las siguientes tareas, además de las enumeradas en el párrafo 8 de la resolución 1533 (2004):

a) Designar a las personas y entidades sujetas a las medidas mencionadas en los párrafos 6, 10, 13 y 15, incluidas aeronaves y líneas aéreas, y actualizar esa lista periódicamente; 
b) Recabar información de todos los Estados interesados, en particular los de la región, sobre las medidas que hayan tomado para aplicar las medidas impuestas en los párrafos 1, 6, 10, 13 y 15 y la demás información que considere útil, incluso dando a todos los Estados la ocasión de enviar representantes para que se reúnan con él a fin de discutir más detalladamente cualquier cuestión pertinente;

c) Pedir a todos los Estados interesados, en particular los de la región, que le proporcionen información acerca de las medidas que hayan tomado para investigar y procesar, según corresponda, a las personas que el Comité haya indicado de conformidad con el apartado a);

d) Examinar las solicitudes de exención a que se hace referencia en los párrafos 14 y 16 y decidir al respecto;

e) Promulgar las directrices que sean necesarias para facilitar la aplicación de los párrafos $6,10,13$ y 15 ;

19. Exige que todas las partes y todos los Estados cooperen plenamente con la labor del Grupo de Expertos a que se hace referencia en el párrafo 21 y laMONUC y que garanticen:

- La seguridad de sus miembros;

- Que los miembros del Grupo de Expertos tengan acceso inmediato y sin obstáculos y que, en particular, les proporcionen la información de que dispongan sobre posibles violaciones de las medidas tomadas por Estados Miembros de conformidad con los párrafos 1, 6, 10, 13 y 15 y que faciliten el acceso del Grupo de Expertos a las personas, los documentos y los lugares que éste considere pertinentes para el cumplimiento de su mandato;

20. Pide a todos los Estados interesados, en particular a los de la región, que informen al Comité, en un plazo de cuarenta y cinco días a partir de la fecha de aprobación de la presente resolución, sobre las disposiciones que hayan adoptado para aplicar las medidas impuestas en los párrafos 6, 10, 13 y 15 y autoriza al Comité a que posteriormente pida a cualquier Estado Miembro la información que considere necesaria para cumplir su mandato;

21. Pide al Secretario General que, en consulta con el Comité, vuelva a establecer, en un plazo de treinta días a partir de la fecha de aprobación de la presente resolución y por un período que concluirá el 31 de julio de 2005, el Grupo de Expertos mencionado en el párrafo 10 de la resolución 1533 (2004), con la adición de un quinto experto para cuestiones financieras y pide además al Secretario General que proporcione al Grupo de Expertos los recursos necesarios para el cumplimiento de su mandato; 


\section{DOCUMENTACIÓN}

22. Pide al Grupo de Expertos que le informe por escrito antes del 1 de julio de 2005, por conducto del Comité, incluso sobre la aplicación de las medidas impuestas en los párrafos $1,6,10,13$ y 15 ;

23. Decide seguir ocupándose de la cuestión.

\section{RESOLUCIÓN 1616}

(29 de julio de 2005)

\section{El Consejo de Seguridad,}

Recordando sus resoluciones anteriores y las declaraciones de su Presidencia sobre la República Democrática del Congo, en particular sus resoluciones 1493 (2003), de 28 de julio de 2003, 1533 (2004), de 12 de marzo de 2004, 1552 (2004), de 27 de julio de 2004, 1565 (2004), de $1^{\circ}$ de octubre de 2004, 1592 (2005), de 30 de marzo de 2005, y 1596 (2005), de 18 de abril de 2005 ,

Reiterando su grave preocupación por la presencia de grupos armados y milicias en la parte oriental de la República Democrática del Congo, especialmente en las provincias de Kivu del norte y Kivu del sur y en el distrito de Ituri, que perpetúan el clima de inseguridad en toda la región,

Condenando el hecho de que continúe la corriente ilícita de armas dentro de la República Democrática del Congo y hacia ella, y declarando su determinación de vigilar atentamente el cumplimiento del embargo de armas impuesto en su resolución 1493 (2003) y ampliado en su resolución 1596 (2005), y de hacer cumplir las medidas establecidas en los párrafos 13 y 15 de la resolución 1596 (2005) contra las personas y entidades que actúen en violación de ese embargo,

Reconociendo que el nexo entre la explotación ilegal de los recursos naturales, el comercio ilícito de esos recursos y la proliferación y el tráfico de armas es uno de los factores que alimentan y agravan los conflictos en la región de los Grandes Lagos de África,

Tomando nota del informe del Grupo de Expertos a que se hace referencia en el párrafo 10 de la resolución 1533 (2004) y el párrafo 21 de la resolución 1596 (2005) (en adelante, el Grupo de Expertos), de fecha 5 de julio de 2005 (S/2005/436), que le transmitió el Comité establecido en virtud del párrafo 8 de la resolución 1533 (2004) (en adelante, el Comité),

Observando que la situación en la República Democrática del Congo sigue constituyendo una amenaza para la paz y la seguridad internacionales 
en la región, Actuando en virtud del Capítulo VII de la Carta de las Naciones Unidas,

1. Reafirma las exigencias formuladas en los párrafos 15,18 y 19 de la resolución 1493 (2003) y en los párrafos 5 y 19 de la resolución 1596 (2005);

2. Decide, en vista de que las partes no han cumplido las exigencias del Consejo, prorrogar hasta el 31 de julio de 2006 las disposiciones de los párrafos 20 a 22 de la resolución 1493 (2003), enmendadas y ampliadas en virtud del párrafo 1 de la resolución 1596 (2005), y reafirma lo dispuesto en los párrafos 2, 6, 10 y 13 a 16 de la resolución 1596 (2005);

3. Expresa su intención de modificar o eliminar esas disposiciones si determina que se han satisfecho las exigencias mencionadas anteriormente;

4. Pide al Secretario General que, en consulta con el Comité, vuelva a establecer el Grupo de Expertos dentro de los treinta días siguientes a la aprobación de la presente resolución y por un período que finalizará el 31 de enero de 2006, aprovechando, según proceda, la experiencia de los miembros del Grupo de Expertos establecido en virtud de la resolución 1596 (2005);

5. Pide al Grupo de Expertos que continúe cumpliendo su mandato, enunciado en las resoluciones 1533 (2004) y 1596 (2005), que presente al Comité información actualizada sobre su labor antes del 10 de diciembre de 2005 y que informe por escrito al Consejo, por conducto del Comité, a más tardar el 10 de enero de 2006, refiriéndose, entre otras cosas, a la aplicación de las medidas impuestas en el párrafo 20 de la resolución 1493 (2003) y ampliadas en la resolución 1596 (2005) y formulando recomendaciones al respecto, en particular acerca de las listas mencionadas en el apartado g) del párrafo 10 de la resolución 1533 (2004), con inclusión de información sobre las fuentes de financiación, como la explotación de los recursos naturales, con los que se financia el tráfico ilícito de armas;

6. Decide seguir ocupándose activamente de la cuestión.

\section{RESOLUCIÓN 1621}

(6 de septiembre de 2005)

\section{El Consejo de Seguridad,}

Recordando sus anteriores resoluciones y las declaraciones de su Presidente relativas a la República Democrática del Congo, en particular las resoluciones 1565 (2004), de $1^{\circ}$ de octubre de 2004, y 1592 (2005), de 30 de marzo de 2005, y la declaración de 29 de junio de 2005 (S/PRST/2005/27), 


\section{DOCUMENTACIÓN}

Reafirmando su determinación de que se respeten la soberanía, la integridad territorial y la independencia política de la República Democrática del Congo y de todos los Estados de la región, y su apoyo al proceso del Acuerdo global e inclusivo sobre la transición en la República Democrática del Congo, firmado en Pretoria el 17 de diciembre de 2002,

Destacando la importancia que revestirán las elecciones como fundamento a largo plazo del restablecimiento de la paz y la estabilidad, la reconciliación nacional y la instauración de un Estado de derecho en la República Democrática del Congo,

Pidiendo a las instituciones de transición y a todas las partes congoleñas que velen por que se celebren elecciones libres, justas y pacíficas y por que se respete escrupulosamente el calendario electoral establecido por la Comisión Electoral Independiente,

Rindiendo homenaje a la comunidad de donantes por la asistencia que presta al proceso electoral en la República Democrática del Congo, y alentándola a mantenerla,

Acogiendo con beneplácito el interés y el empeño de las autoridades congoleñas en promover la buena gobernanza y una gestión económica transparente, y alentándolas a perseverar en sus esfuerzos en tal sentido,

Reiterando su grave preocupación por el hecho de que milicias y grupos armados continúan las hostilidades en la parte oriental de la República Democrática del Congo, por las violaciones de los derechos humanos y del derecho internacional humanitario que las acompañan, y por la amenaza que dichas hostilidades suponen para la celebración de elecciones en la República Democrática del Congo,

Tomando nota del informe especial del Secretario General sobre las elecciones en la República Democrática del Congo, de fecha 26 de mayo de 2005 (S/2005/320), y de sus recomendaciones,

Observando que la situación en la República Democrática del Congo sigue constituyendo una amenaza a la paz y la seguridad internacionales en la región,

Actuando con arreglo al Capítulo VII de la Carta de las Naciones Unidas,

1. Aprueba las recomendaciones y el concepto de las operaciones que figuran en los párrafos 50 a 57 del informe especial del Secretario General y autoriza que se aumenten los efectivos de la Misión de las Naciones Unidas en la República Democrática del Congo (MONUC) en 841 personas, incluidos un máximo de cinco unidades de policía constituidas de 125 efectivos cada una y el personal de policía adicional; 
2. Destaca el carácter temporal de los despliegues a que se hace referencia en el párrafo anterior y pide al Secretario General que adopte las medidas necesarias con miras a reducir ese personal adicional o a repatriarlo a partir del $1^{\circ}$ de julio de 2006 a más tardar, e informe al Consejo antes del $1^{\circ}$ de junio de 2006 acerca de la evaluación mencionada en el párrafo 47 de su informe especial;

3. Aprueba la recomendación del Secretario General que figura en los párrafos 58 y 59 de su informe especial y autoriza a la MONUC a que, de conformidad con dicha recomendación y con el mandato que se define en el apartado f) del párrafo 5 y en el apartado c) del párrafo 7 de la resolución 1565 (2004), y actuando en estrecha coordinación con el Programa de las Naciones Unidas para el Desarrollo, preste apoyo suplementario a la Comisión Electoral Independiente para el transporte del material electoral;

4. Alienta a la MONUC a que, en la medida de su capacidad y de conformidad con su mandato, preste asesoramiento y asistencia, así como el apoyo necesario, al Gobierno de Transición, las instituciones financieras internacionales y los donantes en el establecimiento de un mecanismo para reforzar el apoyo a la gobernanza y a una gestión económica transparente;

5. Decide seguir ocupándose activamente de la cuestión.

\section{RESOLUCIÓN 1628}

(30 de septiembre de 2005)

\section{El Consejo de Seguridad,}

Recordando sus resoluciones sobre la República Democrática del Congo, en particular las resoluciones 1565 (2004), de $1^{\circ}$ de octubre de 2004, 1592 (2005), de 30 de marzo de 2005, 1596 (2005), de 18 de abril de 2005, y 1621 (2005), de 6 de septiembre de 2005,

Reafirmando su determinación de que se respeten la soberanía, la integridad territorial y la independencia política de la República Democrática del Congo y su disposición a apoyar el proceso de paz y de reconciliación nacional en ese país, en particular por conducto de la Misión de las Naciones Unidas en la República Democrática del Congo (MONUC),

Observando que la situación en la República Democrática del Congo sigue constituyendo una amenaza para la paz y la seguridad internacionales en la región,

1. Decide prorrogar hasta el 31 de octubre de 2005 el mandato de la MONUC, establecido en sus resoluciones 1565 (2004), 1592 (2005), 1596 


\section{DOCUMENTACIÓN}

(2005) y 1621 (2005), aprobadas con arreglo al Capítulo VII de la Carta de las Naciones Unidas;

2. Decide seguir ocupándose de la cuestión.

SÁHARA OCCIDENTAL

\section{RESOLUCIÓN 1570}

(28 de octubre de 2004)

\section{El Consejo de Seguridad,}

Recordando todas sus resoluciones anteriores sobre el Sáhara Occidental, incluidas la resolución 1495 (2003), de 31 de julio de 2003, y la resolución 1541 (2004), de 29 de abril de 2004,

Reafirmando su empeño en ayudar a las partes a alcanzar una solución política justa, duradera y mutuamente aceptable que prevea la libre determinación del pueblo del Sáhara Occidental en el marco de disposiciones conformes a los principios y propósitos de la Carta de las Naciones Unidas y teniendo presentes la función y las obligaciones que incumben a las partes a este respecto,

Reiterando su llamamiento a las partes y a los Estados de la región para que sigan colaborando plenamente con las Naciones Unidas para poner fin a la actual situación de estancamiento y progresar hacia una solución política,

Habiendo examinado el informe del Secretario General de 20 de octubre de 2004 (S/2004/827),

1. Decide prorrogar el mandato de la Misión de las Naciones Unidas para el Referéndum del Sáhara Occidental (MINURSO) hasta el 30 de abril de 2005;

2. Pide al Secretario General que presente un informe sobre la situación antes de la expiración del mandato y un informe provisional, dentro de los tres meses siguientes a la aprobación de la presente resolución, sobre la evolución de la situación y sobre el tamaño y concepto de las operaciones de la Misión, con mayores detalles sobre las opciones que se exponen en el informe del Secretario General de 20 de octubre

de 2004 (S/2004/827) para la posible reducción del personal de la MINURSO, incluido el personal civil y administrativo;

3. Pide a los Estados Miembros que estudien la posibilidad de hacer contribuciones voluntarias para financiar medidas de fomento de la confian- 
za que permitan establecer mayores contactos personales, en particular el intercambio de visitas de familiares;

4. Decide seguir ocupándose de la cuestión.

\section{RESOLUCIÓN 1598}

(28 de abril de 2005)

\section{El Consejo de Seguridad,}

Recordando todas sus resoluciones anteriores sobre el Sáhara Occidental, entre ellas la resolución 1495 (2003), de 31 de julio de 2003, la resolución 1541 (2004), de 29 de abril de 2004, y la resolución 1570 (2004), de 28 de octubre de 2004,

Reafirmando su empeño en ayudar a las partes a alcanzar una solución política justa, duradera y mutuamente aceptable que prevea la libre determinación del pueblo del Sáhara Occidental en el marco de disposiciones conformes a los principios y propósitos de la Carta de las Naciones Unidas, y observando la función y las obligaciones que incumben a las partes a este respecto,

Reiterando su llamamiento a las partes y a los Estados de la región para que sigan colaborando plenamente con las Naciones Unidas de manera de poner fin a la actual situación de estancamiento y avanzar hacia una solución política,

Instando al Frente POLISARIO a que ponga en libertad sin más demora, de conformidad con el derecho internacional humanitario, a todos los prisioneros de guerra que queden y haciendo un llamamiento a Marruecos y al Frente POLISARIO para que sigan cooperando con el Comité Internacional de la Cruz Roja a fin de determinar la suerte de aquellos cuyo paradero se desconoce desde el comienzo del conflicto;

Habiendo examinado el informe del Secretario General de 19 de abril de 2005 (S/2005/254) y tomando nota de su informe provisional de 27 de enero de 2005 (S/2005/49),

1. Decide prorrogar el mandato de la Misión de las Naciones Unidas para el Referéndum del Sáhara Occidental (MINURSO) hasta el 31 de octubre de 2005 ;

2. Afirma la necesidad de que se respeten plenamente los acuerdos militares concertados con la MINURSO en relación con la cesación del fuego;

3. Exhorta a los Estados Miembros a que consideren la posibilidad de hacer contribuciones voluntarias para financiar medidas de fomento de la 


\section{DOCUMENTACIÓN}

confianza que permitan un aumento de los contactos entre familiares separados y especialmente de las visitas para la reunión de familias;

4. Espera con interés recibir los resultados del completo examen de la estructura del componente administrativo y otros componentes civiles de la misión que figura en el informe del Secretario General de 19 de abril de 2005 (S/2005/254);

5. Pide al Secretario General que presente un informe sobre la situación en el Sáhara Occidental antes del fin del período del mandato;

6. Decide seguir ocupándose de la cuestión.

\section{SIERRA LEONA}

\section{RESOLUCIÓN 1610}

(30 de junio de 2005)

\section{El Consejo de Seguridad,}

Recordando sus anteriores resoluciones y declaraciones de su Presidencia relativas a la situación en Sierra Leona,

Afirmando la determinación de todos los Estados de respetar la soberanía, la independencia política y la integridad territorial de Sierra Leona,

Destacando la importancia de que las Naciones Unidas y la comunidad internacional sigan prestando apoyo para la seguridad y el desarrollo a largo plazo de Sierra Leona,

Habiendo examinado el informe del Secretario General de 26 de abril de 2005 (S/2005/273), y tomando nota con aprobación de sus observaciones sobre el plan para el retiro paulatino de la Misión de las Naciones Unidas en Sierra Leona (UNAMSIL), que figuran en el párrafo 65, y sobre la necesidad de una presencia sólida del sistema de las Naciones Unidas en Sierra Leona después del retiro de la UNAMSIL, que figuran en los párrafos 63 y 64,

Encomiando la labor de la Comisión para la Verdad y la Reconciliación en Sierra Leona y alentando al Gobierno de Sierra Leona a que difunda ampliamente el informe de la Misión y su respuesta a él,

Expresando su reconocimiento por la labor esencial del Tribunal Especial para Sierra Leona, observando su contribución vital al establecimiento del Estado de derecho en Sierra Leona y, en este sentido, subrayando la importancia de que todos los acusados por el Tribunal comparezcan ante él a fin de afianzar la estabilidad en Sierra Leona y la subregión y poner fin a la im- 
punidad e instando a todos los Estados a que cooperen plenamente con el Tribunal,

Determinando que la situación en Sierra Leona sigue constituyendo una amenaza para la paz y la seguridad internacionales en la región,

Actuando en virtud del Capítulo VII de la Carta de las Naciones Unidas,

1. Decide prorrogar el mandato de la UNAMSIL por un período final de seis meses hasta el 31 de diciembre de 2005;

2. Pide al Secretario General que concluya los planes necesarios para una presencia apropiada e integrada del sistema de las Naciones Unidas en Sierra Leona, como se recomienda en los párrafos 63 y 64 de su informe, que tenga la capacidad y la pericia necesarias para coordinar las actividades de los organismos, fondos y programas de las Naciones Unidas, para colaborar con la comunidad de donantes y para seguir apoyando la labor del Gobierno de Sierra Leona en pro de la consolidación de la paz y el desarrollo a largo plazo tras el retiro de la UNAMSIL;

3. Alienta a la UNAMSIL y al equipo de las Naciones Unidas en Sierra Leona a que continúen su estrecha colaboración para que haya una transición sin tropiezos del mantenimiento a la consolidación de la paz, entre otras cosas, mediante la aplicación de su plan conjunto para la transición;

4. Recuerda que las fuerzas de seguridad de Sierra Leona asumirán efectivamente la plena responsabilidad por la seguridad del país tras el retiro de la UNAMSIL;

5. Subraya también la importancia de que se presten servicios de seguridad eficaces al Tribunal Especial para Sierra Leona tras el retiro de la UNAMSIL, y pide al Secretario General que le presente recomendaciones al respecto a la brevedad posible;

6. Insta al Gobierno de Sierra Leona a que continúe su labor de establecer una fuerza de policía, fuerzas armadas, un sistema penal y un poder judicial independiente que sean eficaces, asequibles y duraderos y de seguir promoviendo el buen gobierno y reforzando los mecanismos para combatir la corrupción y alienta a los donantes y a la UNAMSIL, de conformidad con su mandato, a que presten asistencia al Gobierno en esta cuestión, así como en el restablecimiento de los servicios públicos en todo el país;

7. Alienta a las misiones de las Naciones Unidas en la región a que continúen su labor para mejorar la cooperación entre ellas, especialmente en lo que respecta a la prevención de la circulación de armas y combatientes a través de las fronteras y a la aplicación de los programas de desarme, desmovilización y reintegración; 


\section{DOCUMENTACIÓN}

8. Observa con satisfacción la labor realizada por la UNAMSIL para poner en práctica la política propugnada por el Secretario General de tolerancia cero respecto de la explotación y los abusos sexuales y asegurar el pleno cumplimiento por su personal del código de conducta de las Naciones Unidas, pide al Secretario General que siga adoptando todas las medidas necesarias al respecto y que le mantenga informado y exhorta a los países que aportan contingentes a que adopten las medidas preventivas que procedan, incluida la formación para tomar conciencia de la cuestión antes del despliegue, y a que adopten las medidas disciplinarias y de otra índole que sean necesarias para asegurar que se investiguen y castiguen los casos en que su personal haya incurrido en tal conducta;

9. Observa con satisfacción la intención del Secretario General de mantener en atento examen la situación de seguridad, política, humanitaria y de derechos humanos en Sierra Leona y de informarle periódicamente, tras las debidas consultas con los países que aportan contingentes y con el Gobierno de Sierra Leona;

10. Decide seguir ocupándose activamente de la cuestión.

\section{RESOLUCIÓN 1620}

(31 de agosto de 2005)

\section{El Consejo de Seguridad,}

Recordando sus anteriores resoluciones y las declaraciones de su Presidente relativas a la situación en Sierra Leona,

Encomiando la valiosa aportación que la Misión de las Naciones Unidas en Sierra Leona (UNAMSIL) ha hecho a la recuperación de Sierra Leona después del conflicto y a la paz, la seguridad y el desarrollo de ese país,

Habiendo examinado el informe del Secretario General de 26 de abril de 2005 (S/2005/273) y su adición de 28 de julio de 2005 (S/2005/273/Add.2), y acogiendo complacido su recomendación de que, tras el retiro de la UNAMSIL a finales de 2005, se establezca en Sierra Leona una oficina integrada de las Naciones Unidas para seguir ayudando al Gobierno a consolidar la paz fortaleciendo la gobernanza política y económica, creando capacidad nacional para la prevención de conflictos y preparando la celebración de elecciones en 2007 ,

Tomando conocimiento de la carta de fecha 21 de junio de 2005 dirigida al Secretario General por el Presidente de Sierra Leona (S/2005/419), en la 
que se subraya igualmente la necesidad de contar con una oficina integrada de las Naciones Unidas para apoyar los citados objetivos,

Destacando la importancia de una transición fluida entre la UNAMSIL y la nueva oficina integrada de las Naciones Unidas y del funcionamiento eficaz y eficiente de la oficina,

Destacando la importancia de que las Naciones Unidas y la comunidad internacional sigan prestando un apoyo continuo a la seguridad y el desarrollo a largo plazo de Sierra Leona, en particular para fomentar la capacidad del Gobierno de Sierra Leona,

Reiterando su reconocimiento a la labor esencial que desempeña el Tribunal Especial para Sierra Leona y su contribución vital al establecimiento del imperio de la ley en Sierra Leona y en la subregión, subrayando su esperanza de que el Tribunal ultime su labor con arreglo a su estrategia de conclusión y, a ese respecto, alentando a todos los Estados a que cooperen plenamente con el Tribunal y le presten los recursos financieros necesarios,

Acogiendo complacido la publicación del informe de la Comisión de la Verdad y Reconciliación en Sierra Leona y alentando al Gobierno de Sierra Leona a que adopte nuevas medidas para poner en práctica sus recomendaciones,

1. Pide al Secretario General que establezca la Oficina Integrada de las Naciones Unidas en Sierra Leona (UNIOSIL), según se recomienda en la adición a su informe (S/2005/273/Add.2), por un período inicial de 12 meses a partir del 1 de enero de 2006, a la que se asignarán las siguientes tareas fundamentales:

a) Asistir al Gobierno de Sierra Leona a:

i) Aumentar la capacidad de las instituciones estatales para seguir tratando de eliminar las causas fundamentales del conflicto, prestar servicios básicos y acelerar los progresos hacia la consecución de los objetivos de desarrollo del Milenio mediante la reducción de la pobreza y el crecimiento económico sostenible, incluso creando un marco propicio para la inversión privada y mediante una labor sistemática de lucha contra el VIH/SIDA;

ii) Elaborar un plan nacional de acción para los derechos humanos y crear una comisión nacional de derechos humanos;

iii) Reforzar la capacidad de la Comisión Electoral Nacional para dirigir en 2007 un proceso electoral libre, justo y digno de crédito;

iv) Mejorar la gobernanza, la transparencia y la rendición de cuentas en las instituciones públicas, incluso adoptando medidas contra la corrupción y mejorando la gestión fiscal; 


\section{DOCUMENTACIÓN}

v) Fortalecer el imperio de la ley, incluso promoviendo la independencia y capacidad del sistema judicial y aumentando la capacidad de los sistemas policial y penitenciario;

vi) Reforzar el sector de la seguridad de Sierra Leona, en cooperación con el Equipo Internacional de Capacitación y Asesoramiento Militar y otros colaboradores;

vii) Promover una cultura de paz, diálogo y participación respecto de los principales problemas del país mediante un planteamiento estratégico de las actividades de información pública y comunicación, incluso creando un servicio público de radio independiente y capaz;

viii) Fomentar iniciativas para la protección y el bienestar de los jóvenes, las mujeres y los niños;

b) Establecer vínculos con el sector de seguridad de Sierra Leona y otros colaboradores, informar sobre la situación de seguridad y formular recomendaciones sobre amenazas externas e internas a la seguridad;

c) Coordinar con las misiones y oficinas de las Naciones Unidas, así como con las organizaciones regionales del África occidental, medidas destinadas a resolver problemas transfronterizos como la circulación ilícita de armas pequeñas, la trata de personas y el contrabando y tráfico ilícito de recursos naturales;

d) Coordinar actividades con el Tribunal Especial para Sierra Leona;

2. Destaca que el Gobierno de Sierra Leona es el principal responsable de consolidar la paz y la seguridad en el país, e insta a los donantes internacionales a que sigan apoyando las actividades del Gobierno en tal sentido;

3. Subraya la importancia de establecer una oficina plenamente integrada, coordinando con eficacia la estrategia y los programas entre los diversos organismos especializados, fondos y programas de las Naciones Unidas presentes en Sierra Leona, así como entre las Naciones Unidas y otros donantes internacionales, y entre la oficina integrada, la Comunidad Económica de los Estados de África Occidental y otras misiones de las Naciones Unidas en la región;

4. Acoge complacido la recomendación que figura en la adición del informe del Secretario General (S/2005/273/Add.2), de que la oficina integrada este dirigida por un Representante Ejecutivo del Secretario General, así como la intención del Secretario General de que dicho funcionario también actúe como Representante Residente del Programa de las Naciones Unidas para el Desarrollo y Coordinador Residente de las Naciones Unidas;

5. Pide al Secretario General que siga planificando los aspectos relacionados con la seguridad del Tribunal Especial para Sierra Leona, basándose en 
los párrafos 15 a 24 de la adición de su informe (S/2005/273/Add.2), y espera con interés conocer más detalles sobre las disposiciones propuestas;

6. Pide al Secretario General que mantenga informado periódicamente al Consejo de los progresos relacionados con la creación de la oficina integrada de las Naciones Unidas en Sierra Leona, y posteriormente respecto de la aplicación de la presente resolución;

7. Decide seguir ocupándose activamente de la cuestión.

\section{SOMALIA}

\section{RESOLUCIÓN 1587}

(15 de marzo de 2005)

\section{El Consejo de Seguridad,}

Reafirmando sus anteriores resoluciones y las declaraciones de su Presidencia relativas a la situación en Somalia, en particular la resolución 733 (1992), de 23 de enero de 1992, en que se impuso un embargo a todos los suministros de armas y equipo militar a Somalia (denominado en adelante el "embargo de armas"), y las resoluciones 1519 (2003), de 16 de diciembre de 2003, y 1558 (2004), de 17 de agosto de 2004,

Acogiendo con satisfacción que se registren nuevos avances en el proceso de reconciliación nacional en Somalia y esperando que el Gobierno Federal de Transición adopte nuevas medidas para establecer un gobierno nacional efectivo,

Reafirmando la importancia de la soberanía, integridad territorial, independencia política y unidad de Somalia,

Encomiando las gestiones de la Unión Africana y la Autoridad Intergubernamental para el Desarrollo en apoyo del Gobierno Federal de Transición y acogiendo con beneplácito el apoyo permanente de la Unión Africana a la reconciliación en Somalia,

Tomando nota del informe presentado por el Grupo de supervisión el 14 de febrero de 2005 (S/2005/153) de conformidad con el apartado e) del párrafo 3 de la resolución 1558 (2004) y de las observaciones y recomendaciones que figuran en él,

Condenando la constante corriente de armas y municiones que entra en Somalia y pasa por ese país en contravención del embargo de armas y expre- 


\section{DOCUMENTACIÓN}

sando su decisión de que quienes infrinjan el embargo rindan cuentas de sus actos,

Reiterando la importancia de que los Estados Miembros apliquen el embargo de armas y de supervisarlo mejor mediante una investigación continua y atenta en Somalia de sus infracciones, teniendo presente que la situación general de seguridad en el país mejorará si se hace cumplir estrictamente el embargo de armas,

Determinando que la situación en Somalia constituye una amenaza a la paz y la seguridad internacionales en la región,

Actuando en virtud del Capítulo VII de la Carta de las Naciones Unidas,

1. Subraya la obligación de todos los Estados de cumplir plenamente las medidas impuestas por la resolución 733 (1992);

2. Expresa su intención de considerar atentamente el informe del Grupo de supervisión de fecha 14 de febrero de 2005 (S/2005/153) con miras a mejorar la aplicación y el cumplimiento de las medidas impuestas por la resolución 733 (1992);

3. Pide al Secretario General que, en consulta con el Comité establecido en virtud de la resolución 751 (1992), de 24 de abril de 1992 (denominado en adelante "el Comité"), vuelva a establecer, dentro de los treinta días siguientes a la fecha en que se apruebe la presente resolución y por un período de seis meses, el Grupo de supervisión a que se hace referencia en el párrafo 3 de la resolución 1558 (2004), con el mandato siguiente:

a) Seguir investigando la aplicación del embargo de armas por los Estados Miembros y sus infracciones mediante, entre otras cosas, investigaciones sobre el terreno en Somalia cuando sea posible y, según proceda, en otros Estados, en particular los de la región,

b) Evaluar las medidas tomadas por las autoridades de Somalia, así como por los Estados Miembros, en particular los de la región, para aplicar cabalmente el embargo de armas,

c) Formular recomendaciones concretas sobre la base de información detallada en los distintos campos de especialización pertinentes en relación con las infracciones, así como medidas para poner en vigor el embargo de armas en sus diversos aspectos y aplicarlo en forma más estricta,

d) Seguir afinando y actualizando la información sobre la lista preliminar de los individuos y entidades que infrinjan las medidas que han de tomar los Estados Miembros de conformidad con la resolución 733 (1992), dentro y fuera de Somalia, y quienes los apoyen activamente, con vistas a la posible 
adopción de medidas en el futuro por el Consejo, y presentar esa información al Comité cuando éste lo considere apropiado,

e) Seguir formulando recomendaciones sobre la base de sus investigaciones, de los informes anteriores del Grupo de Expertos (S/2003/223 y $\mathrm{S} / 2003 / 1035)$ designado de conformidad con las resoluciones 1425 (2002), de 22 de julio de 2002, y 1474 (2003), de 8 de abril de 2003, y de los informes anteriores del Grupo de supervisión (S/2004/604 y S/2005/153), designado de conformidad con las resoluciones 1519 (2003), de 16 de diciembre de 2003 y 1558 (2004), de 17 de agosto de 2004,

f) Colaborar estrechamente con el Comité en la formulación de recomendaciones concretas para tomar medidas adicionales a fin de que se cumpla mejor en general el embargo de armas,

g) Ayudar a determinar los aspectos en que se puede aumentar la capacidad de los Estados de la región para facilitar la aplicación del embargo de armas,

h) Presentarle, por conducto del Comité, un informe de mitad de período dentro de los 90 días siguientes a su establecimiento,

i) Presentarle, por conducto del Comité, a más tardar treinta días antes de que termine su mandato, un informe definitivo que se refiera a todas las tareas mencionadas precedentemente, que el Comité procederá a examinar y le transmitirá posteriormente,

4. Pide además al Secretario General que tome las disposiciones financieras necesarias para apoyar la labor del Grupo de supervisión;

5. Reafirma los párrafos 4, 5, 7, 8 y 10 de la resolución 1519 (2003);

6. Pide al Comité que, de conformidad con su mandato y en consulta con el Grupo de supervisión y otras entidades competentes de las Naciones Unidas, estudie y le recomiende medios de mejorar la aplicación y el cumplimiento del embargo de armas, con inclusión de medios de desarrollar la capacidad de los Estados de la región para aplicar el embargo de armas como respuesta si persisten las infracciones;

7. Pide además al Comité que considere, cuando proceda, la posibilidad de que su Presidente y quienes él designe, previa aprobación del Comité, efectúen una visita a Somalia o a la región para demostrar la determinación del Consejo de Seguridad de dar pleno efecto al embargo de armas;

8. Decide seguir ocupándose activamente de la cuestión. 


\section{SUDÁN}

\section{RESOLUCIÓN 1569}

(26 de octubre de 2004)

\section{El Consejo de Seguridad,}

Actuando de conformidad con el párrafo 3 del Artículo 28 de la Carta de las Naciones Unidas,

1. Decide celebrar sesiones en Nairobi los días 18 y 19 de noviembre de 2004 y decide que el tema del orden del día de esas sesiones será "Informes del Secretario General sobre el Sudán";

2. Decide también examinar la situación en el Sudán con representantes de la Unión Africana y de la Autoridad Intergubernamental para el Desarrollo durante las sesiones mencionadas y aprovechar la oportunidad que ofrece la presencia del Consejo de Seguridad en Nairobi para examinar otras gestiones de paz en la región con la Unión Africana y la Autoridad Intergubernamental;

3. Decide además, con respecto a las sesiones mencionadas en el párrafo 1 anterior, que se prescinda del requisito estipulado en el artículo 49 del reglamento provisional del Consejo de que el acta literal de cada sesión del Consejo esté disponible el primer día hábil siguiente a la sesión, y decide que las actas literales se publiquen posteriormente en Nueva York.

\section{RESOLUCIÓN 1574}

(19 de noviembre de 2004)

\section{El Consejo de Seguridad,}

Recordando sus resoluciones 1547 (2004), de 11 de junio de 2004, 1556 (2004), de 30 de julio de 2004, y 1564 (2004), de 18 de septiembre de 2004, y las declaraciones de su Presidencia relativas al Sudán,

Reafirmando su determinación de preservar la soberanía, la unidad, la independencia y la integridad territorial del Sudán y recordando la importancia de los principios de buena vecindad, no injerencia y cooperación regional,

Reafirmando también su apoyo al Protocolo de Machakos, de 20 de julio de 2002, y a los acuerdos ulteriores basados en ese Protocolo, 
Expresando su determinación de ayudar al pueblo del Sudán a promover la reconciliación nacional, la paz duradera y la estabilidad, y a construir un Sudán próspero y unido en que se respeten los derechos humanos y se garantice la protección de todos los ciudadanos,

Recordando que acogió con beneplácito la firma de la Declaración de 5 de junio de 2004 en Nairobi (Kenya), en la que las partes confirmaron su acuerdo con los seis protocolos firmados entre el Gobierno del Sudán y el Movimiento/Ejército de Liberación del Pueblo Sudanés y reconfirmaron su compromiso de completar las restantes etapas de las negociaciones,

Encomiando nuevamente la labor y el apoyo constante de la Autoridad Intergubernamental para el Desarrollo (IGAD), en particular del Gobierno de Kenya en su carácter de Presidente del Subcomité sobre el Sudán, para facilitar las conversaciones de paz en Nairobi, reconociendo la labor realizada por el Equipo de vigilancia de la Protección de los Civiles, la Comisión Militar Conjunta de las Montañas Nuba y el Equipo de Verificación y Vigilancia en apoyo del Proceso de Paz y expresando su esperanza de que la IGAD siga desempeñando una función fundamental durante el período de transición,

Alentando a las partes a que concierten prontamente un acuerdo general de paz y destacando la necesidad de que la comunidad internacional, una vez que se haya firmado ese acuerdo y se comience a ponerlo en práctica, preste asistencia para este fin,

Destacando que el avance hacia una solución del conflicto de Darfur crearía las condiciones apropiadas para la prestación de ese tipo de asistencia,

Expresando su profunda preocupación por la inseguridad y la violencia cada vez mayores en Darfur, la terrible situación humanitaria, la continua vulneración de los derechos humanos y las reiteradas violaciones de la cesación del fuego y reafirmando a ese respecto la obligación de todas las partes de cumplir los compromisos a que hizo referencia en sus resoluciones anteriores sobre el Sudán,

Condenando todos los actos de violencia y vulneración de los derechos humanos y del derecho internacional humanitario cometidos por todas las partes y destacando la necesidad de que los autores de todos los crímenes de esa índole sean sometidos sin demora a la acción de la justicia,

Recordando a ese respecto que todas las partes, incluidos los grupos rebeldes sudaneses, como el Movimiento de Justicia e Igualdad y el Ejército de Liberación del Sudán, deben respetar los derechos humanos y el derecho internacional humanitario y recordando además la responsabilidad primordial 


\section{DOCUMENTACIÓN}

del Gobierno del Sudán de proteger a su población dentro de su territorio y de mantener el orden público, respetando a la vez los derechos humanos,

Destacando la importancia de seguir avanzando hacia la solución de la crisis de Darfur, acogiendo con beneplácito la función fundamental y de vasto alcance que desempeña la Unión Africana con tal fin y acogiendo con beneplácito la decisión del Gobierno del Sudán en favor de la ampliación de la Misión de la Unión Africana,

Tomando nota de los informes del Secretario General de 28 de septiembre de 2004 (S/2004/763) y de 2 de noviembre de 2004 (S/2004/881),

Profundamente preocupado por la situación en el Sudán y sus consecuencias para la paz y la seguridad internacionales y la estabilidad de la región,

1. Declara su decidido apoyo a los esfuerzos del Gobierno del Sudán y del Movimiento/Ejército de Liberación del Pueblo Sudanés por alcanzar un acuerdo de paz general, alienta a las partes a que redoblen sus esfuerzos, acoge con beneplácito la firma de un Memorando de Entendimiento en Nairobi, el 19 de noviembre de 2004, titulado "Declaración sobre la conclusión de las negociaciones de la IGAD relacionadas con la paz en el Sudán”, adjunto a la presente resolución, así como el acuerdo en que los seis protocolos mencionados en la Declaración de Nairobi de 5 de junio de 2004 constituyan y formen el Acuerdo de Paz básico y apoya decididamente el compromiso de las partes de llegar a un acuerdo general definitivo antes del 31 de diciembre de 2004 y espera que ese acuerdo se aplique de forma plena y transparente, con la supervisión internacional adecuada;

2. Declara su empeño en prestar asistencia al pueblo del Sudán, una vez concertado un acuerdo general de paz, para establecer una nación pacífica, unida y próspera siempre que las partes cumplan todos sus compromisos, incluso los convenidos en Abuja (Nigeria) y Ndyamena (Chad);

3. Insta a la Misión Conjunta de Evaluación de las Naciones Unidas, el Banco Mundial y las partes, en asociación con otros donantes bilaterales y multilaterales, a que sigan preparándose para la pronta aplicación de un conjunto de medidas de asistencia para la reconstrucción y el desarrollo económico del Sudán que incluya la asistencia oficial para el desarrollo, la posible mitigación de la deuda y el acceso al comercio y que se pondrán en práctica una vez que se haya firmado un acuerdo general de paz y comience su aplicación;

4. Acoge con beneplácito la iniciativa del Gobierno de Noruega de convocar una conferencia internacional de donantes para la reconstrucción 
y el desarrollo económico del Sudán después que se firme un acuerdo general de paz;

5. Observa con satisfacción que la Comisión Militar Conjunta, el Equipo de Vigilancia de la Protección de los Civiles y el Equipo de Verificación y Vigilancia continúan sus operaciones en previsión de la puesta en práctica de un acuerdo general de paz y el establecimiento de una operación de las Naciones Unidas de apoyo al proceso de paz;

6. Reitera que está dispuesto, cuando se firme un acuerdo general de paz, a considerar el establecimiento de una operación de las Naciones Unidas para apoyar la aplicación del acuerdo y reitera su petición al Secretario General de que le presente, lo antes posible después de la firma del acuerdo general de paz, recomendaciones sobre el número, la estructura y el mandato de tal operación, incluido un calendario para su despliegue;

7. Observa con beneplácito la labor preparatoria ya realizada por la Misión de Avanzada de las Naciones Unidas en el Sudán (UNAMIS), establecida por la resolución 1547 (2004), hace suyas las propuestas contenidas en los informes del Secretario General de 28 de septiembre de 2004 y 2 de noviembre de 2004 de aumentar su dotación de personal, prorroga el mandato de la UNAMIS por un nuevo período de tres meses hasta el 10 de marzo de 2005 y hace un llamamiento al Movimiento/ Ejército de Liberación del Pueblo Sudanés para que se comprometa a cooperar plenamente con la UNAMIS;

8. Exhorta a todos los países de la región a que hagan todo lo posible por apoyar activamente la aplicación cabal y oportuna de un acuerdo general de paz;

9. Destaca que un acuerdo general de paz contribuirá a la paz y la estabilidad sostenibles en todo el Sudán y a los intentos de resolver la crisis de Darfur y subraya la necesidad de adoptar un planteamiento nacional e inclusivo de la reconciliación y la consolidación de la paz, que incluya el papel de la mujer;

10. Subraya la importancia de que avancen las conversaciones de paz de Abuja entre el Gobierno del Sudán y el Ejército de Liberación Sudanés y el Movimiento de Justicia e Igualdad con miras a resolver la crisis de Darfur, insiste en que todas las partes en las conversaciones de paz de Abuja negocien de buena fe para llegar rápidamente a un acuerdo, acoge con beneplácito la firma del protocolo humanitario y el protocolo de seguridad el 9 de noviembre de 2004, insta a las partes a que los apliquen rápidamente y espera que se firme pronto una declaración de principios con miras a llegar a un arreglo político; 


\section{DOCUMENTACIÓN}

11. Exige que el Gobierno y las fuerzas rebeldes y todos los demás grupos armados pongan fin inmediatamente a todos los actos de violencia y ataques, incluidos los secuestros, se abstengan de reasentar civiles por la fuerza, cooperen con las actividades de socorro humanitario y de observación internacionales, se aseguren de que sus miembros cumplan el derecho internacional humanitario, faciliten la seguridad y protección del personal humanitario y hagan cumplir a todas sus tropas el acuerdo en permitir el acceso y el paso irrestrictos a los organismos humanitarios y a quienes trabajan para ellos, de conformidad con la resolución 1502 (2003), de 26 de agosto de 2003, sobre el acceso del personal de asistencia humanitaria a las poblaciones necesitadas, y con los protocolos de Abuja de 9 de noviembre de 2004;

12. Decide, de conformidad con sus resoluciones anteriores sobre el Sudán, vigilar el cumplimiento por las partes de sus obligaciones al respecto y, con sujeción a una decisión ulterior, adoptar las medidas que corresponda contra cualquiera de las partes que no cumpla sus compromisos;

13. Apoya resueltamente las decisiones de la Unión Africana de aumentar su misión en Darfur a 3.320 efectivos y ampliar su mandato para que incluya las tareas enumeradas en el párrafo 6 del comunicado de 20 de octubre de 2004 del Consejo de Paz y Seguridad de la Unión Africana, insta a los Estados Miembros a que aporten el equipo logístico, financiero y material necesario y otros recursos necesarios e insta al Gobierno del Sudán y a todos los grupos rebeldes de Darfur a que cooperen plenamente con la Unión Africana;

14. Reitera su llamamiento a los Estados Miembros para que aporten con urgencia generosas contribuciones a las actividades humanitarias en curso en el Sudán y el Chad;

15. Hace un llamamiento a todas las partes para que cooperen plenamente con la Comisión Internacional de Investigación que estableció el Secretario General y describe en su carta de 4 de octubre de 2004 dirigida al Presidente del Consejo de Seguridad (S/2004/812), cuyas conclusiones serán comunicadas al Consejo;

16. Reitera la importancia de desplegar más observadores de derechos humanos en Darfur;

17. Pide al Secretario General que le mantenga periódicamente informado de la evolución de la situación del Sudán y recomiende medidas para aplicar la presente resolución y las resoluciones anteriores sobre el Sudán;

18. Decide seguir ocupándose de la cuestión. 
RESOLUCIONES DEL CONSEJO DE SEGURIDAD DE LAS NACIONES UNIDAS

\section{ANEXO}

Declaración sobre la conclusión de las negociaciones de la IGAD relacionadas con la paz en el Sudán, Gigiri, Nairobi-Viernes 19 de noviembre de 2004

Considerando que el Gobierno de la República del Sudán y el Movimiento y Ejército de Liberación del Pueblo Sudanés (las Partes) reconfirmaron en la Declaración de Nairobi de 5 de junio de 2004 relativa a la fase final de las negociaciones para la paz en el Sudán dirigidas por la Autoridad Intergubernamental para el Desarrollo (IGAD), su acuerdo sobre los seis textos, incluido el Protocolo de Machakos, así como los textos relativos a la distribución del poder, la distribución de la riqueza, los dispositivos de seguridad y la solución del conflicto en las montañas de Nuba del Kordofan meridional, el Nilo azul y la zona de Abyei;

Considerando que las Partes, en un comunicado de prensa conjunto, de fecha 16 de octubre de 2004, "se comprometieron nuevamente a concluir y concertar un acuerdo general de paz en reconocimiento de que la rápida conclusión del proceso de paz es fundamental para todo el pueblo sudanés, pues ayudará a solucionar los problemas con que se enfrenta el país";

Reconociendo los progresos logrados hasta la fecha acerca de los dispositivos de seguridad y los detalles de la cesación del fuego, incluida la extensa labor relativa a los anexos sobre modalidades de ejecución; y

Declarando que la conclusión de la iniciativa dirigida por la IGAD es fundamental para lograr un Acuerdo General de Paz en el Sudán, que incluya la solución del conflicto de Darfur;

Las Partes afirman que los seis Protocolos a que se hace referencia en la Declaración de Nairobi de 5 de junio de 2004 constituyen y conforman el Acuerdo de Paz básico y, por consiguiente, invitan al Consejo de Seguridad de las Naciones Unidas, reunido en Nairobi, a que apruebe una resolución en que haga suyos los seis Protocolos.

Las Partes expresan asimismo su compromiso de terminar en la mayor brevedad posible las negociaciones sobre los dos anexos relativos al acuerdo de cesación del fuego y a las modalidades de ejecución a fin de concertar y firmar el Acuerdo General de Paz a más tardar el 31 de diciembre de 2004.

(Firmado) Hon. Yahya Hussein Babikar

Por el Gobierno de la República del Sudán

(Firmado) Cte. Nhial Deng Nhial

Por el Movimiento y Ejército de Liberación del Pueblo Sudanés 


\section{DOCUMENTACIÓN}

Testigo:

(Firmado) Tte. Gen. Lazaro K. Sumbeiywo (Ret.)

En nombre de los Enviados de la IGAD

(Firmado) Dr. Jan Pronk

Representante Especial del Secretario General ante las Naciones Unidas

En presencia del Consejo de Seguridad de las Naciones Unidas

(Firmado) Embajador Gunter Pleuger

Representante Permanente de Alemania ante las Naciones Unidas

(Firmado) Embajador Ismael Gaspar Martins

Representante Permanente de Angola ante las Naciones Unidas

(Firmado) Embajador Abdallah Baali

Representante Permanente de Argelia ante las Naciones Unidas

(Firmado) Embajador Joel Adechi

Representante Permanente de Benin ante las Naciones Unidas

(Firmado) Embajador Ronaldo Sardenberg

Representante Permanente del Brasil ante las Naciones Unidas

(Firmado) Embajador Heraldo Muñoz

Representante Permanente de Chile ante las Naciones Unidas

(Firmado) Embajador Wang Guangya

Representante Permanente de China ante las Naciones Unidas

(Firmado) Embajador Juan Antonio Yañez Barnuevo

Representante Permanente de España ante las Naciones Unidas

(Firmado) Embajador John Danforth

Representante Permanente de los Estados Unidos de América ante las Naciones Unidas

(Firmado) Embajador Andrey Denisov

Representante Permanente de la Federación de Rusia ante las Naciones Unidas

(Firmado) Embajador Lauro Baja Jr.

Representante Permanente de Filipinas ante las Naciones Unidas

(Firmado) Embajador Jean-Marc de la Sablière

Representante Permanente de Francia ante las Naciones Unidas

(Firmado) Embajador Munir Akram

Representante Permanente de Pakistán ante las Naciones Unidas

(Firmado) Embajador Emyr Jones Parry

Representante Permanente del Reino Unido ante las Naciones Unidas

(Firmado) Embajador Mihnea Motoc

Representante Permanente de Rumania ante las Naciones Unidas 


\section{RESOLUCIÓN 1585}

(10 de marzo de 2005)

El Consejo de Seguridad,

Recordando sus resoluciones 1547 (2004), de 11 de junio de 2004, 1556 (2004), de 30 de julio de 2004, y 1574 (2004), de 19 de noviembre de 2004,

Reafirmando su disposición a apoyar el proceso de paz,

Decide prorrogar hasta el 17 de marzo de 2005 el mandato de la Misión Preparatoria de las Naciones Unidas en el Sudán, establecida en virtud de su resolución 1547 (2004);

Decide seguir ocupándose activamente de la cuestión.

\section{RESOLUCIÓN 1588}

(17 de marzo de 2005)

\section{El Consejo de Seguridad,}

Recordando sus resoluciones 1547 (2004), de 11 de junio de 2004, 1556 (2004), de 30 de julio de 2004, 1574 (2004), de 19 de noviembre de 2004, y 1585 (2005), de 10 de marzo de 2005,

Reafirmando su disposición a apoyar el proceso de paz,

Decide prorrogar hasta el 24 de marzo de 2005 el mandato de la Misión de Avanzada de las Naciones Unidas en el Sudán, establecida en virtud de su resolución 1547 (2004);

Decide seguir ocupándose activamente de la cuestión.

\section{RESOLUCIÓN 1590}

(24 de marzo de 2005)

\section{El Consejo de Seguridad,}

Recordando sus resoluciones 1547 (2004), de 11 de junio de 2004, 1556 (2004), de 30 de julio de 2004, 1564 (2004), de 18 de septiembre de 2004, 1574 (2004), de 19 de noviembre de 2004, 1585 (2005), de 10 de marzo de 2005, y 1588 (2005), de 17 de marzo de 2005, y las declaraciones de su Presidencia relativas al Sudán,

Reafirmando su determinación de preservar la soberanía, unidad, independencia e integridad territorial del Sudán y recordando la importancia 


\section{DOCUMENTACIÓN}

que revisten los principios de buena vecindad, no injerencia y cooperación regional,

Expresando su beneplácito por la firma del Acuerdo General de Paz entre el Gobierno del Sudán y el Movimiento y Ejército de Liberación del Pueblo Sudanés (SPLM/A), que tuvo lugar el 9 de enero de 2005 en Nairobi (Kenya),

Recordando los compromisos contraídos por las partes en el Acuerdo de Cesación del Fuego de Nyamena de 8 de abril y en los Protocolos Humanitario y de Seguridad de Abuja de 9 de noviembre de 2004, concertados entre el Gobierno del Sudán, el Movimiento y Ejército de Liberación del Sudán y el Movimiento Justicia e Igualdad, y recordando los contraídos en el comunicado conjunto de 3 de julio de 2004 emitido por el Gobierno del Sudán y el Secretario General,

Expresando su determinación de ayudar al pueblo del Sudán a promover la reconciliación nacional y la paz y la estabilidad duraderas y construir un Sudán próspero y unido en que se respeten los derechos humanos y se garantice la protección de todos los ciudadanos,

Tomando nota de las declaraciones formuladas por Ali Osman Taha, Vicepresidente del Gobierno del Sudán, y el Presidente Garang del SPLM/A en la sesión celebrada el 8 de febrero de 2005 y de la firme voluntad y determinación que expresaron en esa sesión de hallar una solución pacífica al conflicto en Darfur,

Reconociendo que las partes en el Acuerdo General de Paz deben tomar como base el Acuerdo para lograr la paz y la estabilidad en todo el país y exhortando a todas las partes en el Sudán y, en particular, a las que son partes en el Acuerdo General de Paz a tomar medidas de inmediato para lograr un arreglo pacífico del conflicto en Darfur y hacer cuanto sea necesario para impedir nuevas infracciones de los derechos humanos y el derecho humanitario internacional y para poner fin a la impunidad, incluso en la región de Darfur,

Expresando su enorme preocupación por las terribles consecuencias que tiene el prolongado conflicto para la población civil en la región de Darfur, así como en todo el Sudán, en particular el aumento del número de refugiados y personas desplazadas dentro del país,

Considerando que el regreso voluntario y sostenible de los refugiados y las personas desplazadas dentro del país constituirá un factor esencial para la consolidación del proceso de paz,

Expresando también su profunda preocupación por la seguridad del personal humanitario y su acceso a las poblaciones necesitadas, con inclusión de 
refugiados, personas desplazadas dentro del país y otros damnificados por la guerra,

Condenando que todas las partes en Darfur sigan infringiendo el Acuerdo de Cesación del Fuego de Nyamena de 8 de abril de 2004 y los Protocolos de Abuja de 9 de noviembre de 2004, así como el deterioro de la situación de seguridad y la repercusión negativa que ello ha tenido en la labor de asistencia humanitaria,

Condenando enérgicamente todas las infracciones de los derechos humanos y el derecho internacional humanitario en la región de Darfur, en particular la persistencia de la violencia contra civiles y la violencia sexual contra mujeres y niñas desde la aprobación de la resolución 1574 (2004), instando a todas las partes a que tomen todas las medidas necesarias para impedir que se cometan nuevas infracciones y expresando su determinación de que los responsables de esas infracciones sean identificados y sometidos sin demora a la acción de la justicia,

Recordando que en las resoluciones 1556 (2004), 1564 (2004) y 1574 (2004) exigió que todas las partes en el conflicto de Darfur se abstuvieran de cometer actos de violencia contra civiles y cooperaran plenamente con la Misión de la Unión Africana en Darfur,

Encomiando las gestiones realizadas por la Unión Africana, en particular su Presidente, reconociendo los avances logrados por la Unión Africana en el despliegue de una fuerza internacional de protección, policías y observadores militares e instando a todos los Estados Miembros a que aporten con urgencia generosas contribuciones a la Misión de la Unión Africana en Darfur,

Encomiando también las gestiones realizadas por la Autoridad Intergubernamental para el Desarrollo, en particular el Gobierno de Kenya en su calidad de Presidente del Subcomité sobre el Sudán,

Reafirmando sus resoluciones 1325 (2000), relativa a las mujeres, la paz y la seguridad, y 1379 (2001) y 1460 (2003), relativas a los niños y los conflictos armados, así como sus resoluciones 1265 (1999) y 1296 (2000), relativas a la protección de la población civil y los conflictos armados, y 1502 (2003), relativa a la protección del personal humanitario y de las Naciones Unidas,

Observando con satisfacción la labor realizada por las Naciones Unidas para que su personal cobre conciencia de la prevención y el control del VIH/SIDA y otras enfermedades transmisibles en todas sus operaciones establecidas, 


\section{DOCUMENTACIÓN}

Expresando profunda preocupación por las denuncias de explotación sexual y faltas de conducta de carácter sexual formuladas contra personal de las Naciones Unidas en operaciones establecidas de las Naciones Unidas y observando con satisfacción la carta que con fecha 9 de febrero de 2005 le dirigió el Secretario General a este respecto, en la que afirmaba que habría una política de tolerancia cero de la explotación y el abuso sexuales de toda índole en todas las operaciones de las Naciones Unidas para el mantenimiento de la paz,

Reconociendo que el apoyo internacional a la aplicación del Acuerdo General de Paz reviste importancia decisiva para su buen resultado, insistiendo en que un avance hacia la solución del conflicto en Darfur crearía condiciones propicias para la prestación de ese apoyo y observando con alarma que, a pesar de todo, continúa la violencia en Darfur,

Tomando nota de los informes del Secretario General de 31 de enero de 2005 (S/2005/57 y Add.1), 4 de febrero de 2005 (S/2005/68) y 4 de marzo de 2005 (S/2005/140), así como del informe de la Comisión Internacional de Investigación (S/2005/60), de 25 de enero de 2005,

Tomando nota de que las partes en el Acuerdo General de Paz han pedido que se establezca una misión de apoyo a la paz,

Expresando su reconocimiento por las importantes contribuciones que la Brigada Multinacional de Despliegue Rápido de las Fuerzas de Reserva de las Naciones Unidas ha aportado a la planificación, la preparación y el despliegue inicial de una operación de mantenimiento de la paz, así como por la labor preparatoria realizada por la Misión de Avanzada de las Naciones Unidas en el Sudán,

Determinando que la situación en el Sudán sigue constituyendo una amenaza para la paz y la seguridad internacionales,

1. Decide establecer la Misión de las Naciones Unidas en el Sudán (UNMIS) por un período inicial de seis meses y decide además que la Misión conste de hasta 10.000 efectivos militares y de un componente civil apropiado que incluya hasta 715 policías civiles;

2. Pide que la UNMIS mantenga una coordinación y un enlace continuos y estrechos a todos los niveles con la Misión de la Unión Africana en el Sudán (AMIS) con miras a afianzar rápidamente la labor de promoción de la paz en Darfur, especialmente con respecto al proceso de paz de Abuja y la Misión de la Unión Africana en el Sudán;

3. Pide al Secretario General que, por conducto de su Representante Especial en el Sudán, coordine todas las actividades del sistema de las Naciones 
Unidas en el país, movilice recursos y apoyo de la comunidad internacional destinados tanto a la asistencia inmediata como al desarrollo económico a largo plazo del Sudán y facilite la coordinación con otras entidades internacionales, en particular la Unión Africana y la Autoridad Intergubernamental para el Desarrollo, de las actividades en apoyo del proceso de transición establecido por el Acuerdo General de Paz y ofrezca sus buenos oficios y apoyo político a las gestiones encaminadas a resolver todos los conflictos en curso en el Sudán;

4. Decide que el mandato de la UNMIS sea el siguiente:

a) Prestar apoyo para la aplicación del Acuerdo General de Paz desempeñando las funciones siguientes:

i) Supervisar y verificar el cumplimiento del Acuerdo de Cesación del Fuego e investigar sus infracciones;

ii) Hacer de enlace con donantes bilaterales respecto de la formación de unidades integradas conjuntas;

iii) Observar y supervisar el desplazamiento de grupos armados y el redespliegue de fuerzas en las zonas en que esté desplegada la UNMIS de conformidad con el Acuerdo de Cesación del Fuego;

iv) Prestar asistencia en el establecimiento del programa de desarme, desmovilización y reintegración previsto en el Acuerdo General de Paz, prestando particular atención a las necesidades especiales de las mujeres y los niños combatientes y a la aplicación de dicho programa por conducto del desarme voluntario y de la recogida y destrucción de las armas;

v) Ayudar a las partes en el Acuerdo General de Paz a promover una mejor comprensión del proceso de paz y de la función que cabe a la UNMIS mediante una eficaz campaña de información pública destinada a todos los sectores de la sociedad, en coordinación con la Unión Africana;

vi) Ayudar a las partes en el Acuerdo General de Paz a atender a la necesidad de un planteamiento nacional incluyente, que comprenda el papel de la mujer, con miras a la reconciliación y la consolidación de la paz;

vii) Ayudar a las partes en el Acuerdo General de Paz, en coordinación con programas de asistencia bilateral y multilateral, a preparar un programa de formación y evaluación de la policía para reestructurar el servicio de policía en el Sudán de manera compatible con los principios de una policía democrática y a prestar asistencia de cualquier otra índole en la formación de la policía civil; 
viii) Ayudar a las partes en el Acuerdo General de Paz a promover el Estado de derecho, con inclusión de un poder judicial independiente, y a proteger los derechos humanos de toda la población del Sudán por conducto de una estrategia completa y coordinada que apunte a luchar contra la impunidad y contribuir a la paz y la estabilidad a largo plazo, así como ayudar a las partes en el Acuerdo General de Paz a desarrollar y consolidar la estructura legal en el país;

ix) Asegurar que haya capacidad, pericia y un componente adecuado en materia de derechos humanos a fin de llevar a cabo actividades de promoción, protección y supervisión de esos derechos;

x) Impartir orientación y prestar asistencia técnica a las partes en el Acuerdo General de Paz, en cooperación con otras entidades internacionales, para apoyar la preparación y celebración de las elecciones y los referendos previstos en el Acuerdo;

b) Facilitar y coordinar, en la medida de sus posibilidades y en las zonas en que esté desplegada, el regreso voluntario de los refugiados y personas desplazadas dentro del país y la asistencia humanitaria, ayudando a establecer, entre otras cosas, las condiciones de seguridad necesarias;

c) Ayudar a las partes en el Acuerdo General de Paz, en cooperación con otros asociados internacionales en el sector de las actividades relativas a las minas, ocupándose de la asistencia, el asesoramiento técnico y la coordinación respecto de la remoción humanitaria de minas;

d) Contribuir, en la medida de sus posibilidades, a la labor internacional para proteger y promover los derechos humanos en el Sudán y coordinar la labor internacional destinada a la protección de los civiles, prestando especial atención a grupos vulnerables, entre ellos las personas desplazadas dentro del país, los refugiados que regresan y las mujeres y los niños, en la medida de sus posibilidades y trabajando en estrecha cooperación con otros organismos de las Naciones Unidas, organizaciones asociadas y organizaciones no gubernamentales;

5. Pide al Secretario General que le presente un informe en un plazo de 30 días acerca de las opciones que tiene la UNMIS para afianzar la labor de promoción de la paz en Darfur mediante la prestación de asistencia adecuada a la Misión de la Unión Africana en el Sudán, con inclusión de apoyo logístico y asistencia técnica y, en enlace con la Unión Africana, indique medios para utilizar los recursos de la Misión con ese fin, en particular los componentes de apoyo logístico y apoyo a las operaciones, y la capacidad de reserva; 
6. Exhorta a todas las partes a cooperar plenamente en el despliegue y las operaciones de la Misión, en particular garantizando la seguridad, protección y libertad de desplazamiento del personal de las Naciones Unidas y del personal asociado en todo el territorio del Sudán;

7. Recalca que no puede haber una solución militar al conflicto en Darfur, exhorta al Gobierno del Sudán y a los grupos rebeldes, en particular el Movimiento Justicia e Igualdad y el Movimiento y Ejército de Liberación del Pueblo Sudanés a reanudar rápidamente las conversaciones de Abuja sin condiciones previas y negociar de buena fe para llegar rápidamente a un acuerdo e insta a las partes en el Acuerdo General de Paz a desempeñar una función activa y constructiva en apoyo de las conversaciones de Abuja y a tomar medidas de inmediato para apoyar una solución pacífica del conflicto en Darfur;

8. Exhorta a los Estados Miembros a que aseguren el desplazamiento libre, sin trabas y expedito al Sudán de todo el personal, así como del equipo, las provisiones, los suministros y otros artículos, entre ellos vehículos y piezas de repuesto, destinados a su utilización oficial y exclusiva por la Misión;

9. Exhorta a todas las partes a que, de conformidad con las disposiciones pertinentes del derecho internacional, aseguren plenamente, en condiciones de seguridad y sin trabas el acceso del personal de socorro a quienes lo necesiten y la prestación de la asistencia humanitaria, en particular a las personas desplazadas dentro del país y los refugiados;

10. Pide al Secretario General que traspase a la UNMIS las funciones que desempeñaba la misión política especial en el Sudán (UNAMIS), junto con el personal y los arreglos logísticos de la oficina que corresponda, en la fecha en que se establezca la Misión, y se asegure de que haya una fluida transición entre las Naciones Unidas y las misiones de vigilancia y supervisión existentes, a saber, el Equipo de Verificación y Vigilancia, la Misión Conjunta de Supervisión y el Equipo de Vigilancia de la Protección de los Civiles;

11. Pide al Secretario General que le mantenga informado con regularidad de los avances en la aplicación del Acuerdo General de Paz, la observancia de la cesación del fuego y la ejecución del mandato de la UNMIS, con inclusión de una revisión del nivel de efectivos con miras a reducirlos, teniendo en cuenta los avances logrados sobre el terreno y las tareas que queden por cumplir y le presente también cada tres meses un informe a este respecto;

12. Pide al Secretario General que siga presentándole informes mensuales sobre la situación en Darfur;

13. Insta a la Misión de Evaluación Conjunta de las Naciones Unidas, el Banco Mundial y las partes a que, en asociación con otros donantes bilatera- 
les y multilaterales, perseveren en sus esfuerzos por preparar la pronta aplicación de un conjunto de medidas de asistencia para la reconstrucción y el desarrollo económico del Sudán que incluya asistencia oficial para el desarrollo y el acceso al comercio y que se pondrá en práctica una vez que se comience a aplicar el Acuerdo General de Paz, observa con beneplácito la iniciativa del Gobierno de Noruega de convocar una conferencia internacional de donantes para la reconstrucción y el desarrollo económico del Sudán e insta a la comunidad internacional a que, en consecuencia, haga donaciones generosas teniendo presente las necesidades de las personas desplazadas dentro del país y los refugiados;

14. Pide al Secretario General que adopte las medidas necesarias para lograr el cumplimiento efectivo en la UNMIS de la política de tolerancia cero de las Naciones Unidas respecto de la explotación y el abuso sexuales, con inclusión la formulación de estrategias y el establecimiento de mecanismos adecuados para prevenir, identificar y reprimir las faltas de conducta en todas sus formas, entre ellas la explotación y el abuso sexuales, y de una mejor formación del personal para prevenir esas faltas y asegurar el cumplimiento cabal del código de conducta de las Naciones Unidas, pide al Secretario General que tome todas las medidas necesarias de conformidad con su boletín sobre medidas especiales de protección contra la explotación y el abuso sexuales (ST/SGB/2003/13) y lo mantenga informado e insta a los países que aportan contingentes a que adopten medidas preventivas apropiadas, entre ellas la realización antes del despliegue de cursos de toma de conciencia, y adopten medidas disciplinarias y de otra índole para asegurar una plena rendición de cuentas en los casos de faltas de conducta de esa índole en que esté involucrado su personal;

15. Reafirma la importancia de que haya una pericia adecuada en cuestiones relacionadas con el género en las operaciones de mantenimiento de la paz y la consolidación de la paz después del conflicto de conformidad con la resolución 1325 (2000), recuerda la necesidad de hacer frente a la violencia contra mujeres y niñas como instrumento de guerra y alienta a la UNMIS y a las partes sudanesas a ocuparse activamente de estas cuestiones;

16. Actuando en virtud del Capítulo VII de la Carta de las Naciones Unidas,

i) Decide autorizar a la UNMIS a adoptar, en las zonas en que estén desplegadas sus fuerzas y en el grado en que considere que esté dentro de sus posibilidades, las medidas necesarias para proteger al personal, los recintos, las instalaciones y el equipo de las Naciones Unidas, garantizar la seguridad y libertad de desplazamiento del personal de las Naciones Unidas, el personal humanitario y el personal del mecanismo 
conjunto de evaluación y de la comisión de evaluación y, sin perjuicio de la responsabilidad que atañe al Gobierno del Sudán, proteger a los civiles que se encuentren bajo una amenaza inminente de violencia física;

ii) Pide que el Secretario General y el Gobierno del Sudán, tras celebrar las consultas del caso con el Movimiento de Liberación del Pueblo Sudanés, concierten un acuerdo sobre el estatuto de las fuerzas en un plazo de 30 días contados a partir de la aprobación de la presente resolución, teniendo en cuenta la resolución 58/82 de la Asamblea General, relativa al alcance de la protección jurídica en virtud de la Convención sobre la Seguridad del Personal de las Naciones Unidas y el Personal Asociado, y señala que, mientras se concierta ese acuerdo, será aplicable a título provisional el modelo de acuerdo sobre el estatuto de las fuerzas de 9 de octubre de 1990 (A/45/594);

17. Recalca la inmediata necesidad de aumentar rápidamente el número de observadores de derechos humanos en Darfur, insta al Secretario General y a la Alta Comisionada de las Naciones Unidas para los Derechos Humanos a que aceleren el despliegue de esos observadores a Darfur y aumenten su número y avancen en la formación de equipos de vigilancia de la protección de los civiles, y espera que el Secretario General le comunique los progresos realizados en la formación de esos equipos en los informes que le presente con arreglo al párrafo 11 de la presente resolución;

18. Decide seguir ocupándose de la cuestión.

\section{RESOLUCIÓN 1591}

(29 de marzo de 2005)

\section{El Consejo de Seguridad,}

Recordando sus resoluciones 1547 (2004) de 11 de junio de 2004, 1556 (2004) de 30 de julio de 2004, 1564 (2004) de 18 de septiembre de 2004, 1574 (2004) de 19 de noviembre de 2004, 1585 (2005) de 10 de marzo de 2005, 1588 (2005) de 17 de marzo de 2005 y 1590 (2005), de 24 de marzo de 2005, y las declaraciones de su Presidencia relativas al Sudán,

Reafirmando su determinación de preservar la soberanía, unidad, independencia e integridad territorial del Sudán y recordando la importancia que revisten los principios de buena vecindad, no injerencia y cooperación regional, 


\section{DOCUMENTACIÓN}

Recordando los compromisos contraídos por las partes en el Acuerdo de Cesación del Fuego de Nyamena de 8 de abril y en los Protocolos Humanitario y de Seguridad de Abuja de 9 de noviembre de 2004, concertados entre el Gobierno del Sudán, el Movimiento y Ejército de Liberación del Sudán y el Movimiento Justicia e Igualdad, y recordando los contraídos en el comunicado conjunto de fecha 3 de julio de 2004 emitido por el Gobierno del Sudán y el Secretario General,

Observando con beneplácito la firma del Acuerdo General de Paz entre el Gobierno del Sudán y el Movimiento y Ejército de Liberación del Pueblo Sudanés, que tuvo lugar el 9 de enero de 2005 en Nairobi (Kenya),

Reconociendo que las partes en el Acuerdo General de Paz deben tomar como base el Acuerdo para lograr la paz y la estabilidad en todo el país y exhortando a todas las partes en el Sudán, y en particular a las que son partes en el Acuerdo General de Paz, a tomar medidas de inmediato para lograr un arreglo pacífico del conflicto en Darfur y hacer cuanto sea necesario para impedir nuevas infracciones de los derechos humanos y el derecho humanitario internacional y para poner fin a la impunidad, incluso en la región de Darfur,

Expresando su enorme preocupación por las terribles consecuencias que tiene el prolongado conflicto para la población civil en la región de Darfur, así como en todo el Sudán, en particular el aumento del número de refugiados y personas desplazadas dentro del país,

Considerando que el regreso voluntario y sostenible de los refugiados y las personas desplazadas dentro del país constituirá un factor esencial para la consolidación del proceso de paz,

Expresando también su profunda preocupación por la seguridad del personal humanitario y su acceso a las poblaciones necesitadas, con inclusión de refugiados, personas desplazadas dentro del país y otros damnificados por la guerra,

Condenando que todas las partes en Darfur sigan infringiendo el Acuerdo de Cesación del Fuego de Nyamena de 8 de abril de 2004 y los Protocolos de Abuja de 9 de noviembre de 2004, así como el deterioro de la situación de seguridad y la repercusión negativa que ello ha tenido en la labor de asistencia humanitaria,

Condenando enérgicamente todas las infracciones de los derechos humanos y el derecho internacional humanitario en la región de Darfur, en particular la persistencia de la violencia contra civiles y de la violencia sexual contra mujeres y niñas desde la aprobación de la resolución 1574 (2004), instando a todas las partes a tomar las medidas necesarias para prevenir nuevas 
infracciones y expresando su determinación de que los responsables de esas infracciones sean identificados y sometidos sin demora a la acción de la justicia,

Reconociendo que el apoyo internacional a la aplicación del Acuerdo General de Paz reviste importancia decisiva para su buen resultado, insistiendo en que un avance hacia la solución del conflicto en Darfur crearía condiciones propicias para la prestación de ese apoyo y observando con alarma que, a pesar de todo, continúa la violencia en Darfur,

Recordando que en las resoluciones 1556 (2004), 1564 (2004) y 1574 (2004) exigió que todas las partes en el conflicto de Darfur se abstuvieran de cometer actos de violencia contra civiles y cooperaran plenamente con la Misión de la Unión Africana en Darfur,

Acogiendo con beneplácito la Cumbre sobre Darfur celebrada el 16 de febrero de 2005 en Nyamena y el hecho de que la Unión Africana siga empeñada en cumplir una función esencial en la tarea de facilitar una solución del conflicto en Darfur en todos los aspectos, así como el anuncio hecho por el Gobierno del Sudán el 16 de febrero de 2005 de que adoptaría medidas inmediatas, entre ellas las de retirar sus fuerzas de Labado, Qarifa y Marla en Darfur y retirar sus aviones Antonov de Darfur,

Encomiando las gestiones realizadas por la Unión Africana, en particular su Presidente, reconociendo los avances logrados por la Unión Africana en el despliegue de una fuerza internacional de protección, policías y observadores militares e instando a todos los Estados Miembros a que aporten con urgencia generosas contribuciones a la Misión de la Unión Africana en Darfur,

Reafirmando sus resoluciones 1325 (2000), relativa a las mujeres, la paz y la seguridad, y 1379 (2001) y 1460 (2003), relativas a los niños y los conflictos armados, así como las resoluciones 1265 (1999) y 1296 (2000), relativas a la protección de la población civil y los conflictos armados, y 1502 (2003), relativa a la protección del personal humanitario y de las Naciones Unidas,

Tomando nota de los informes del Secretario General de fechas 31 de enero de 2005 (S/2005/57 y Add.1), 3 de diciembre de 2004 (S/2004/947), 4 de febrero de 2005 (S/2005/68) y 4 de marzo de 2005 (S/2005/140), así como del informe de la Comisión Internacional de Investigación de fecha 25 de enero de 2005 (S/2005/60),

Determinando que la situación en el Sudán sigue constituyendo una amenaza para la paz y la seguridad internacionales, 


\section{DOCUMENTACIÓN}

Actuando en virtud del Capítulo VII de la Carta de las Naciones Unidas,

1. Deplora profundamente que el Gobierno del Sudán y las fuerzas rebeldes y los demás grupos armados de Darfur no hayan cumplido plenamente sus compromisos ni las exigencias del Consejo a que se hace referencia en las resoluciones 1556 (2004), 1564 (2004) y 1574 (2004), condena las persistentes infracciones del Acuerdo de Cesación del Fuego de Nyamena de 8 de abril de 2004 y de los Protocolos de Abuja de 9 de noviembre de 2004, en particular los ataques aéreos efectuados por el Gobierno del Sudán en diciembre de 2004 y enero de 2005 y los ataques cometidos por rebeldes contra aldeas de Darfur en enero de 2005, así como el hecho de que el Gobierno del Sudán no haya desarmado a las milicias Janjaweed ni haya aprehendido y sometido a la justicia a los líderes Janjaweed y sus asociados que hayan perpetrado infracciones de los derechos humanos y el derecho internacional humanitario y otras atrocidades y exige que todas las partes tomen de inmediato medidas para cumplir todos sus compromisos con respecto al Acuerdo de Cesación del Fuego de Nyamena y los Protocolos de Abuja, entre ellos los de notificar la posición de sus fuerzas, facilitar la asistencia humanitaria y cooperar plenamente con la Misión de la Unión Africana;

2. Recalca que no puede haber una solución militar al conflicto en Darfur, exhorta al Gobierno del Sudán y a los grupos rebeldes, en particular el Movimiento Justicia e Igualdad y el Movimiento y Ejército de Liberación del Pueblo Sudanés a reanudar rápidamente las conversaciones de Abuja sin condiciones previas y negociar de buena fe para llegar rápidamente a un acuerdo e insta a las partes en el Acuerdo General de Paz a desempeñar una función activa y constructiva en apoyo de las conversaciones de Abuja y tomar medidas de inmediato para apoyar una solución pacífica del conflicto en Darfur;

3. Decide, en vista de que ninguna de las partes en el conflicto en Darfur ha cumplido sus compromisos:

a) Establecer, de conformidad con el artículo 28 de su reglamento provisional, un Comité del Consejo de Seguridad integrado por todos sus miembros (en lo sucesivo "el Comité") para que desempeñe las funciones siguientes:

i) Vigilar la aplicación de las medidas a que se hace referencia en los apartados d) y e) del presente párrafo, en los párrafos 7 y 8 de la resolución 1556 (2004), y en el párrafo 7 de la presente resolución;

ii) Designar a las personas sujetas a las medidas impuestas en los apartados d) y e) de este párrafo y estudiar las solicitudes de exención de conformidad con los apartados f) y g); 
iii) Establecer las directrices que sean necesarias para facilitar la aplicación de las medidas impuestas en los apartados d) y e);

iv) Presentarle informes acerca de su labor cada 90 días por lo menos;

v) Examinar las solicitudes del Gobierno del Sudán relativas al desplazamiento de equipo y suministros militares a la región de Darfur de conformidad con el párrafo 7 y dar su aprobación por anticipado cuando proceda;

vi) Evaluar los informes del Grupo de Expertos establecido en el apartado b) del presente párrafo y de Estados Miembros, en particular los de la región, sobre las disposiciones concretas que estén adoptando para poner en práctica las medidas impuestas en los apartados d) y e) del párrafo 7;

vii) Alentar un diálogo entre el Comité y los Estados Miembros interesados, en particular los de la región, incluso invitando a los representantes de esos Estados a reunirse con el Comité para discutir la aplicación de las medidas;

b) Pedir al Secretario General que, en consulta con el Comité, establezca un grupo de expertos integrado por cuatro miembros y con sede en Addis Abeba (Etiopía) que se desplace periódicamente a El-Fasher (Sudán) y otras localidades en el Sudán y desempeñe, bajo la dirección del Comité, y durante un período de seis meses, las funciones siguientes:

i) Prestar asistencia al Comité en la supervisión de la aplicación de las medidas previstas en los apartados d) y e), los párrafos 7 y 8 de la resolución 1556 (2004) y el párrafo 7 de la presente resolución y formular recomendaciones acerca de medidas que podría considerar el Consejo;

ii) Presentar un informe de mitad de mandato al Comité sobre su labor, un informe provisional al Consejo a más tardar dentro de los 90 días siguientes a la aprobación de la presente resolución y un informe definitivo al Consejo, por conducto del Comité, a más tardar con 30 días de antelación a la fecha en que termine su mandato, en que consten sus conclusiones y recomendaciones; y

iii) Coordinar sus actividades, según proceda, con las operaciones en curso de la Misión de la Unión Africana en el Sudán;

c) Que las personas que indique el Comité establecido en el apartado a) sobre la base de la información que proporcionen los Estados Miembros, el Secretario General, la Alta Comisionada de las Naciones Unidas para los Derechos Humanos, el Grupo de Expertos establecido en el apartado b) u otras fuentes pertinentes que entraben el proceso de paz, constituyan una amenaza 
para la estabilidad en Darfur y en la región, perpetren infracciones del derecho internacional humanitario o las normas relativas a los derechos humanos $\mathrm{u}$ otras atrocidades, infrinjan las medidas aplicadas por Estados Miembros en cumplimiento de los párrafos 7 y 8 de la resolución 1556 (2004) o el párrafo 7 de la presente resolución o sean responsables de vuelos militares ofensivos según se describe en el párrafo 6 serán objeto de las medidas indicadas en los apartados d) y e);

d) Que los Estados adopten las medidas necesarias para impedir el ingreso en sus territorios o el tránsito por ellos de todas las personas designadas por el Comité de conformidad con el apartado c), en la inteligencia de que nada de lo dispuesto en este párrafo obligará a un Estado a denegar a sus propios nacionales la entrada en su territorio;

e) Que todos los Estados congelen todos los fondos, activos financieros y recursos económicos que se encuentren en su territorio a la fecha de aprobación de la presente resolución o en una fecha posterior y que sean de propiedad o estén bajo el control directo o indirecto de las personas designadas por el Comité de conformidad con el apartado c) o se encuentren en poder de entidades que sean de propiedad o estén bajo el control directo o indirecto de esas personas o de otras que actúen en su nombre o bajo su dirección y decide además que todos los Estados se cercioren de que sus nacionales u otras personas que se encuentran en sus territorios no pongan fondos, activos financieros ni recursos económicos a disposición de esas personas o entidades o para su beneficio;

f) Que las medidas impuestas en el apartado d) no serán aplicables cuando el Comité establecido en el apartado a) determine en cada caso que el viaje se justifica por razones humanitarias, incluidas obligaciones religiosas, o llegue a la conclusión de que una exención promovería de algún otro modo los objetivos de las resoluciones del Consejo para la consecución de la paz y la estabilidad en el Sudán y en la región;

g) Que las medidas impuestas en el apartado e) de la presente resolución no serán aplicables a los fondos, otros activos financieros y recursos económicos cuando los Estados que corresponda hayan determinado que:

i) Son necesarios para gastos básicos, entre ellos, alimentos, alquiler o hipotecas, medicamentos y tratamiento médico, impuestos, primas de seguros y tarifas de servicios públicos o exclusivamente para el pago de honorarios profesionales de monto razonable y el reembolso de gastos efectuados en relación con la prestación de servicios jurídicos u honorarios o tasas, de conformidad con la legislación nacional, por servicios de administración o mantenimiento ordinario de fondos congelados, 
otros activos financieros y recursos económicos, previa notificación de esos Estados al Comité de la intención de autorizar, cuando proceda, el acceso a esos fondos, otros activos financieros y recursos económicos y de no haber una decisión negativa del Comité en el plazo de dos días laborables a partir de la notificación,

ii) Son necesarios para gastos extraordinarios, siempre y cuando lo hayan notificado al Comité y éste los haya aprobado, o

iii) Son objeto de un gravamen o una decisión judicial, administrativa o arbitral, en cuyo caso los fondos, otros activos financieros o recursos económicos podrán utilizarse para levantar el gravamen o cumplir la decisión a condición de que el gravamen se hubiese impuesto o la decisión se hubiese adoptado antes de la fecha de la presente resolución, no beneficie a ninguna de las personas o entidades designadas por el Comité y lo hayan notificado al Comité;

4. Decide que las medidas a que se hace referencia en los apartados d) y e) del párrafo precedente entrarán en vigor en el plazo de 30 días a partir de la fecha de aprobación de la presente resolución a menos que el Consejo determine antes de ese plazo que las partes en el conflicto de Darfur han cumplido todas las condiciones y exigencias a que se hace referencia en los párrafos 1 y 6 de la presente resolución;

5. Expresa que está dispuesto a considerar la modificación y revocación de las medidas que se imponen en el párrafo 3 por recomendación del Comité o una vez transcurrido un plazo de 12 meses a partir de la fecha de aprobación de la presente resolución o antes si determina antes de ese plazo que las partes en el conflicto de Darfur han cumplido todos los compromisos y exigencias a que se hace referencia en los párrafos 1 y 6 de la presente resolución;

6. Exige que el Gobierno del Sudán, de conformidad con los compromisos que contrajo en el Acuerdo de Cesación del Fuego de Nyamena de 8 de abril de 2004 y el Protocolo de Seguridad de Abuja de 9 de noviembre de 2004, ponga término de inmediato a los vuelos militares ofensivos en la región de Darfur y sobre ésta e invita a la Comisión de Cesación del Fuego de la Unión Africana a que intercambie la información que corresponda a este respecto con el Secretario General, el Comité o el grupo de expertos establecido en el párrafo 3 b);

7. Reafirma las medidas impuestas en los párrafos 7 y 8 de la resolución 1556 (2004) y decide que esas medidas serán también aplicables inmediatamente después de aprobada la presente resolución a todas las partes en el Acuerdo de Cesación del Fuego de Nyamena y cualesquiera otros beligeran- 


\section{DOCUMENTACIÓN}

tes en los estados de Darfur septentrional, Darfur meridional y Darfur occidental; observa que esas medidas no serán aplicables a los suministros ni a la asistencia y la formación técnica conexas a que se hace referencia en el párrafo 9 de la resolución 1556 (2004); decide que esas medidas no serán aplicables con respecto a la asistencia y los suministros proporcionados en apoyo de la aplicación del Acuerdo General de Paz; decide además que esas medidas no serán aplicables al desplazamiento de equipo, personal y suministros militares hacia la región de Darfur que el Comité establecido en el párrafo 3 a) apruebe con antelación, previa solicitud del Gobierno del Sudán, e invita a la Comisión de Cesación del Fuego de la Unidad Africana a que intercambie la información que corresponda a este respecto con el Secretario General, el Comité y el Grupo de Expertos establecido en virtud del párrafo 3 b);

8. Reitera que, en el caso de que las partes no cumplan los compromisos y las exigencias que se describen en los párrafos 1 y 6 y la situación en Darfur continúe deteriorándose, considerará la posibilidad de adoptar nuevas medidas con arreglo a lo dispuesto en el Artículo 41 de la Carta de las Naciones Unidas;

9. Decide seguir ocupándose de la cuestión.

\section{RESOLUCIÓN 1593}

(31 de marzo de 2005)

\section{El Consejo de Seguridad,}

Tomando nota del informe de la Comisión Internacional de Investigación sobre las transgresiones del derecho internacional humanitario y las normas de derechos humanos en Darfur (S/2005/60),

Recordando el artículo 16 del Estatuto de Roma, con arreglo al cual la Corte Penal Internacional no puede iniciar ninguna investigación ni enjuiciamiento durante un plazo de 12 meses después de que el Consejo de Seguridad le haya formulado una petición a tal efecto,

Recordando también los artículos 75 y 79 del Estatuto de Roma y alentando a los Estados a que aporten contribuciones al Fondo Fiduciario de la Corte Penal Internacional para las víctimas,

Tomando nota de la existencia de los acuerdos mencionados en el artículo 98-2 del Estatuto de Roma,

Determinando que la situación en el Sudán sigue constituyendo una amenaza a la paz y la seguridad internacionales, 
Actuando en virtud del Capítulo VII de la Carta de las Naciones Unidas,

1. Decide remitir la situación en Darfur desde el $1^{\circ}$ de julio de 2002 al Fiscal de la Corte Penal Internacional;

2. Decide que el Gobierno del Sudán y todas las demás partes en el conflicto de Darfur deben cooperar plenamente con la Corte y el Fiscal y prestarles toda la asistencia necesaria en aplicación de la presente resolución y, aunque reconoce que los Estados que no son partes en el Estatuto de Roma no tienen obligación alguna con arreglo a dicho Estatuto, exhorta a todos los Estados y organizaciones regionales y demás organizaciones internacionales competentes a que también cooperen plenamente;

3. Invita a la Corte y a la Unión Africana a que examinen arreglos prácticos que faciliten la labor del Fiscal y de la Corte, incluida la posibilidad de llevar a cabo actuaciones en la región, lo que contribuiría a las iniciativas regionales de lucha contra la impunidad;

4. Alienta también a la Corte a que, según corresponda y de conformidad con el Estatuto de Roma, apoye la cooperación internacional con medidas nacionales destinadas a promover el imperio de la ley, proteger los derechos humanos y combatir la impunidad en Darfur;

5. Subraya también la necesidad de promover la recuperación y la reconciliación y alienta a este respecto la creación, con la intervención de todos los sectores de la sociedad sudanesa, de instituciones como las comisiones de verdad o de reconciliación, para complementar los procesos judiciales y fortalecer así las medidas encaminadas a restablecer una paz duradera, con el apoyo de la Unión Africana y de la comunidad internacional en caso necesario;

6. Decide que los nacionales, los ex funcionarios o funcionarios o el personal de un Estado contribuyente que no sea el Sudán y no sea parte en el Estatuto de Roma de la Corte Penal Internacional se sometan a la jurisdicción exclusiva de ese Estado contribuyente respecto de todos los supuestos actos u omisiones derivados de las operaciones en el Sudán o relacionados con ellas establecidas o autorizadas por el Consejo o la Unión Africana, a menos que ese Estado contribuyente haya renunciado expresamente a dicha jurisdicción exclusiva;

7. Reconoce que ninguno de los gastos derivados de la remisión a la Corte, incluidos los gastos relativos a las investigaciones o los enjuiciamientos relacionados con dicha remisión, deberán ser sufragados por las Naciones Unidas y que dichos gastos serán sufragados por las partes en el Estatuto de Roma y por aquellos Estados que deseen contribuir voluntariamente; 


\section{DOCUMENTACIÓN}

8. Invita al Fiscal a que se dirija al Consejo para informar de las medidas adoptadas de conformidad con la presente resolución dentro de los tres meses siguientes a la fecha de aprobación de la presente resolución y posteriormente cada seis meses;

9. Decide continuar ocupándose de esta cuestión.

\section{RESOLUCIÓN 1627}

(23 de septiembre de 2005)

\section{El Consejo de Seguridad,}

Recordando sus anteriores resoluciones, en particular la resolución 1590, de 24 de marzo de 2005, y declaraciones de su Presidencia relativas al Sudán,

Reafirmando su determinación de preservar la soberanía, la unidad, la independencia y la integridad territorial del Sudán,

Reiterando sus expresiones de pésame y condolencias por la muerte del Primer Vicepresidente, Dr. John Garang de Mabior, ocurrida el 30 de julio de 2005, y encomiando al Gobierno del Sudán y al Vicepresidente Salva Kiir Mayardit por sus continuas gestiones encaminadas a consolidar la paz en el Sudán,

Acogiendo con beneplácito la aplicación por el Gobierno del Sudán y el Movimiento y Ejército de Liberación del Pueblo Sudanés del Acuerdo General de Paz de 9 de enero de 2005 y, en particular, la formación del Gobierno de Unidad Nacional como paso significativo e histórico hacia una paz duradera en el Sudán,

Instando a las partes a cumplir sus compromisos pendientes con el Acuerdo General de Paz, en particular, como cuestión prioritaria, el establecimiento de una Comisión de Evaluación y Valoración,

Considerando que la situación en el Sudán sigue constituyendo una amenaza para la paz y la seguridad internacionales,

Reconociendo los compromisos contraídos por los países que aportan contingentes en apoyo de la Misión de las Naciones Unidas en el Sudán (UNMIS) y alentando el despliegue a fin de que la UNMIS pueda prestar apoyo a la aplicación oportuna del Acuerdo General de Paz,

1. Decide prorrogar el mandato de la UNMIS hasta el 24 de marzo de 2006, con la intención de renovarlo por otros períodos;

2. Pide al Secretario General que le presente informes cada tres meses sobre la ejecución del mandato de la UNMIS, incluida su labor encaminada a 
intensificar las gestiones de la Misión de la Unión Africana en el Sudán para promover la paz en Darfur;

3. Insta a los países que aportan contingentes a estudiar detenidamente la carta del Secretario General de 24 de marzo de 2005 (A/59/710) y a tomar las medidas apropiadas para evitar la explotación y el abuso sexuales por el personal que aportan a la UNMIS, incluida la instrucción para la toma de conciencia sobre la cuestión antes del despliegue, así como a tomar medidas disciplinarias y de otra índole para hacer valer cabalmente la responsabilidad en los casos en que su personal esté involucrado en faltas de conducta de esa naturaleza;

4. Decide seguir ocupándose activamente de la cuestión.

\section{TERRORISMO Y AMENAZAS A LA PAZ} Y SEGURIDAD INTERNACIONALES

\section{RESOLUCIÓN 1566}

(8 de octubre de 2004)

\section{El Consejo de Seguridad,}

Reafirmando sus resoluciones 1267 (1999), de 15 de octubre de 1999, y 1373 (2001), de 28 de septiembre de 2001, así como sus otras resoluciones relativas a las amenazas a la paz y la seguridad internacionales causadas por el terrorismo,

Recordando a este respecto su resolución 1540 (2004), de 28 de abril de 2004,

Reafirmando también, la necesidad imperiosa de combatir por todos los medios, de conformidad con la Carta de las Naciones Unidas y con el derecho internacional, contra el terrorismo en todas sus formas y manifestaciones,

Observando con profunda preocupación el número cada vez mayor de víctimas, entre ellas niños, como consecuencia de actos de terrorismo motivados por la intolerancia o el extremismo en varias regiones del mundo,

Instando a los Estados a que cooperen plenamente con el Comité contra el Terrorismo establecido en virtud de la resolución 1373 (2001), con inclusión de su recientemente establecida Dirección Ejecutiva, el Comité de Sanciones contra Al-Qaida y los Talibanes establecido en virtud de la resolución 1267 (1999) y su equipo encargado de prestar apoyo analítico y vigilar la aplicación de las sanciones y el Comité establecido en virtud de la resolución 


\section{DOCUMENTACIÓN}

1540 (2004), e instando además a esos órganos a que estrechen la cooperación entre ellos,

Recordando a los Estados que deben asegurarse de que las medidas que tomen para luchar contra el terrorismo cumplan con todas las obligaciones que les incumben en virtud del derecho internacional y que deben tomarlas de conformidad con el derecho internacional, y en particular, las normas internacionales de derechos humanos, el derecho de los refugiados y el derecho humanitario,

Reafirmando que el terrorismo, en todas sus formas y manifestaciones, constituye una de las más graves amenazas a la paz y la seguridad,

Considerando que los actos de terrorismo constituyen un grave obstáculo para el disfrute de los derechos humanos y una amenaza para el desarrollo económico y social de todos los Estados y que socavan la prosperidad y estabilidad en el mundo,

Destacando que un mejor diálogo y un entendimiento más amplio entre las civilizaciones, en un intento de prevenir el ataque indiscriminado contra distintas religiones y culturas, y el hecho de hacer frente a conflictos regionales no resueltos y a toda la variedad de problemas mundiales, incluidos los de desarrollo, contribuirán a la cooperación internacional que, a su vez, es necesaria para sustentar la lucha más amplia posible contra el terrorismo,

Reafirmando su profunda solidaridad con las víctimas del terrorismo y sus familias,

Actuando en virtud del Capítulo VII de la Carta de las Naciones Unidas,

1. Condena en los términos más enérgicos todos los actos de terrorismo, cualquiera que sea su motivación y cuando quiera y por quienquiera sean cometidos, que constituyen una de las más graves amenazas a la paz y la seguridad;

2. Insta a todos los Estados a que, de conformidad con las obligaciones que les impone el derecho internacional, cooperen plenamente en la lucha contra el terrorismo, especialmente con aquellos en cuyo territorio o contra cuyos ciudadanos se cometan actos de terrorismo, a fin de encontrar, negar refugio seguro y someter a la justicia, sobre la base del principio del enjuiciamiento o la extradición, a quien apoye o facilite la financiación, la planificación, la preparación o la comisión de actos de terrorismo o la provisión de refugio seguro o participe o intente participar en esos actos;

3. Recuerda que los actos criminales, inclusive contra civiles, cometidos con la intención de causar la muerte o lesiones corporales graves o de tomar rehenes con el propósito de provocar un estado de terror en la población en 
general, en un grupo de personas o en determinada persona, intimidar a una población u obligar a un gobierno o a una organización internacional a realizar un acto, o a abstenerse de realizarlo, que constituyen delitos definidos en los convenios, las convenciones y los protocolos internacionales relativos al terrorismo y comprendidos en su ámbito, no admiten justificación en circunstancia alguna por consideraciones de índole política, filosófica, ideológica, racial, étnica, religiosa u otra similar e insta a todos los Estados a prevenirlos y, si ocurren, a cerciorarse de que sean sancionados con penas compatibles con su grave naturaleza;

4. Insta a todos los Estados a hacerse partes, con carácter urgente, a los convenios, las convenciones y los protocolos internacionales, con independencia de si son o no partes en los convenios o las convenciones regionales en la materia;

5. Insta a los Estados Miembros a que cooperen plena y rápidamente para resolver todas las cuestiones pendientes con miras a aprobar por consenso el proyecto de convenio general sobre el terrorismo internacional y el proyecto de convenio internacional para la represión de los actos de terrorismo nuclear;

6. Insta a las organizaciones internacionales, regionales y subregionales competentes a que estrechen la cooperación internacional en la lucha contra el terrorismo e intensifiquen sus relaciones con las Naciones Unidas y, en particular, con el Comité contra el Terrorismo a fin de facilitar la aplicación cabal y oportuna de la resolución 1373 (2001);

7. Pide al Comité contra el Terrorismo que, en consulta con las organizaciones internacionales, regionales y subregionales y los órganos de las Naciones Unidas competentes, formulen una serie de prácticas recomendadas para ayudar a los Estados a poner en práctica las disposiciones de la resolución 1373 (2001) relativa a la financiación del terrorismo;

8. Encomienda al Comité contra el Terrorismo que, como cuestión prioritaria y, cuando proceda, en estrecha cooperación con las organizaciones internacionales, regionales y subregionales competentes, comience a hacer visitas a los Estados, con el consentimiento de éstos, a fin de vigilar mejor el cumplimiento de la resolución 1373 (2001) y facilitar la prestación de asistencia técnica y de otra índole para cumplirla;

9. Decide establecer un grupo de trabajo integrado por todos los miembros del Consejo de Seguridad para que estudie y le presente recomendaciones sobre las medidas prácticas que se han de imponer contra las personas, los grupos y las entidades involucrados en actividades terroristas o asociados 


\section{DOCUMENTACIÓN}

con ellas, además de las ya enunciadas por el Comité de Sanciones contra AlQaida y los Talibanes, entre ellas establecer los procedimientos más eficaces que se consideren adecuados para someterlos a la justicia mediante el enjuiciamiento o la extradición, congelar sus activos financieros, impedir su desplazamiento por los territorios de Estados Miembros y prevenir que les sean suministrados armas y material conexo de todo tipo, así como sobre los procedimientos para poner en práctica esas medidas;

10. Pide además al grupo de trabajo establecido en el párrafo precedente que considere la posibilidad de establecer un fondo internacional para indemnizar a las víctimas de actos de terrorismo y sus familias, que se financiaría con contribuciones voluntarias, que podrían a su vez consistir en parte de los bienes confiscados a organizaciones terroristas, sus miembros y patrocinantes, y que le presente sus recomendaciones al respecto;

11. Pide al Secretario General que tome, con carácter urgente, las medidas que procedan para que la Dirección Ejecutiva del Comité contra el Terrorismo entre plenamente en funciones y que le presente un informe para el 15 de noviembre de 2004;

12. Decide seguir ocupándose activamente de la cuestión.

\section{RESOLUCIÓN 1611}

(7 de julio de 2005)

\section{El Consejo de Seguridad,}

Reafirmando los propósitos y principios de la Carta de las Naciones Unidas y sus resoluciones en la materia, en particular sus resoluciones 1373 (2001), de 28 de septiembre de 2001, y 1566 (2004), de 8 de octubre de 2004,

Reafirmando la necesidad de combatir por todos los medios, de conformidad con la Carta de las Naciones Unidas, las amenazas para la paz y la seguridad internacionales causadas por actos terroristas,

1. Condena sin reservas los atentados terroristas cometidos en Londres el 7 de julio de 2005 y considera que todo acto de terrorismo constituye una amenaza para la paz y la seguridad;

2. Expresa su más sentido pésame y condolencias a las víctimas de esos atentados terroristas y a sus familias, así como al pueblo y al Gobierno del Reino Unido;

3. Insta a todos los Estados a que, de conformidad con las obligaciones que les incumben en virtud de la resolución 1373 (2001), cooperen activa- 
mente en la labor encaminada a hallar y someter a la acción de la justicia a los autores, organizadores y patrocinadores de estos actos de barbarie;

4. Expresa su absoluta determinación de luchar contra el terrorismo, de conformidad con las funciones que le encomienda la Carta de las Naciones Unidas.

\section{RESOLUCIÓN 1617}

(29 de julio de 2005)

\section{El Consejo de Seguridad,}

Recordando sus resoluciones 1267 (1999) de 15 de octubre de 1999, 1333 (2000) de 19 de diciembre de 2000, 1363 (2001) de 30 de julio de 2001, 1373 (2001) de 28 de septiembre de 2001, 1390 (2002) de 16 de enero de 2002, 1452 (2002) de 20 de diciembre de 2002, 1455 (2003) de 17 de enero de 2003, 1526 (2004) de 30 de enero de 2004 y 1566 (2004) de 8 de octubre de 2004 y las declaraciones de su Presidencia en la materia,

Reafirmando que el terrorismo en todas sus formas y manifestaciones constituye una de las amenazas más graves para la paz y la seguridad y que los actos de terrorismo son criminales e injustificables, cualquiera que sea su motivación y dondequiera y por quienquiera sean cometidos; y reiterando su inequívoca condena de Al-Qaida, Osama bin Laden, los talibanes, y las personas, los grupos, las empresas y las entidades asociados con ellos, por sus constantes y múltiples actos criminales de terrorismo que tienen como finalidad causar la muerte de civiles inocentes y otras víctimas y la destrucción de bienes, y socavar gravemente la estabilidad,

Expresando su preocupación por el uso que Al-Qaida, Osama bin Laden y los talibanes y quienes están asociados con ellos hacen de distintos medios de información, incluida la Internet, como instrumentos de propaganda del terrorismo y de instigación a la violencia terrorista, y exhortando al grupo de trabajo creado en virtud de la resolución 1566 (2004) a que examine estas cuestiones,

Reafirmando la necesidad de combatir por todos los medios, de conformidad con la Carta de las Naciones Unidas y el derecho internacional, las amenazas que los actos terroristas constituyen para la paz y la seguridad internacionales y haciendo hincapié, a ese respecto, en la importante función que desempeñan las Naciones Unidas en la dirección y coordinación de este empeño, 


\section{DOCUMENTACIÓN}

Recalcando la obligación impuesta a todos los Estados Miembros de aplicar cabalmente la resolución 1373 (2001), especialmente en lo que respecta a los talibanes o Al-Qaida y a las personas, los grupos, las empresas y las entidades asociados con Al-Qaida, Osama bin Laden o los talibanes que hayan participado en la financiación, planificación, facilitación, preparación o comisión de actos de terrorismo, reclutado gente para cometerlos o prestado apoyo de otro tipo para ellos, así como de facilitar el cumplimiento de las obligaciones de luchar contra el terrorismo de conformidad con las resoluciones del Consejo de Seguridad en la materia,

Destacando la importancia de aclarar qué personas, grupos, empresas o entidades podrán ser incluidos en la lista a la luz de la información relativa a los cambios en el carácter de Al-Qaida y en la amenaza que representa, especialmente los indicados por el equipo encargado de prestar apoyo analítico y vigilar la aplicación de las sanciones ("Equipo de Vigilancia”),

Recalcando la importancia de que los Estados Miembros hagan las designaciones previstas en las resoluciones pertinentes y pongan enérgicamente en práctica las medidas vigentes, como importante medida preventiva en la lucha contra la actividad terrorista,

Observando que, al hacer efectivas las medidas impuestas en el apartado b) del párrafo 4 de la resolución 1267 (1999), el apartado c) del párrafo 8 de la resolución 1333 (2000) y los párrafos 1 y 2 de la resolución 1390 (2002), es preciso tener plenamente en cuenta lo dispuesto en los párrafos 1 y 2 de la resolución 1452 (2002),

Acogiendo con satisfacción la labor que realiza la Organización de Aviación Civil Internacional para impedir que se faciliten documentos de viaje a terroristas y sus asociados,

Alentando a los Estados Miembros a trabajar en el marco de la Interpol, en particular utilizando la base de datos de documentos de viaje robados y perdidos que lleva esa organización, para hacer más estricta la aplicación de las medidas contra Al-Qaida, Osama bin Laden y los talibanes y quienes están asociados con ellos,

Expresando su preocupación por la posibilidad de que Al-Qaida, Osama bin Laden o los talibanes y quienes están asociados con ellos utilicen sistemas portátiles de defensa antiaérea, explosivos que se pueden adquirir en el comercio y armas o materiales químicos, biológicos, radiológicos o nucleares, y alentando a los Estados Miembros a considerar la posibilidad de adoptar medidas para reducir esas amenazas,

Instando a todos los Estados, órganos internacionales y organizaciones regionales a que destinen recursos suficientes, incluso mediante alianzas in- 
ternacionales, para hacer frente a la amenaza directa que en todo momento representan Al-Qaida, Osama bin Laden y los talibanes y las personas, los grupos, las empresas y las entidades asociados con ellos,

Recalcando la importancia de hacer frente a la amenaza que Al-Qaida, Osama bin Laden y los talibanes y las personas, grupos, empresas y entidades asociados con ellos siguen representando para la paz y la seguridad internacionales,

Actuando en virtud del Capítulo VII de la Carta de las Naciones Unidas,

1. Decide que todos los Estados deben adoptar las medidas impuestas en el apartado b) del párrafo 4 de la resolución 1267 (1999), el apartado c) del párrafo 8 de la resolución 1333 (2000) y los párrafos 1 y 2 de la resolución 1390 (2002) con respecto a Al-Qaida, Osama bin Laden y los talibanes y otras personas, grupos o empresas y entidades asociados con ellos que figuren en la lista elaborada de conformidad con las resoluciones 1267 (1999) y 1333 (2000) (la "lista consolidada"):

a) Congelar sin demora los fondos y otros activos financieros o recursos económicos de esas personas, grupos, empresas y entidades, incluidos los fondos derivados de bienes que directa o indirectamente pertenezcan a ellos o a personas que actúen en su nombre o siguiendo sus indicaciones o que estén bajo su control, y cerciorarse de que sus nacionales u otras personas que se hallen en su territorio no pongan esos u otros fondos, activos financieros o recursos financieros, directa o indirectamente, a disposición de esas personas;

b) Impedir la entrada en su territorio o el tránsito por él de esas personas, en la inteligencia de que nada de lo dispuesto en este párrafo obligará a un Estado a negar la entrada en su territorio o exigir la salida de él a sus propios nacionales y de que este párrafo no será aplicable cuando la entrada o el tránsito sean necesarios para una diligencia judicial o cuando el Comité establecido en virtud de la resolución 1267 (1999) (el "Comité") determine, para cada caso en particular, que la entrada o el tránsito tienen justificación;

c) Impedir el suministro, la venta y la transferencia, directos o indirectos, a esas personas, grupos, empresas o entidades, desde su territorio o por sus nacionales fuera de su territorio o mediante buques o aeronaves de su pabellón, de armas y materiales conexos de todo tipo, incluidos armas y municiones, vehículos y pertrechos militares, pertrechos paramilitares y las piezas de repuesto correspondientes, así como asesoramiento técnico, asistencia o adiestramiento relacionados con actividades militares;

2. Decide además que los actos o actividades que determinarán qué personas, grupos, empresas o entidades pueden calificarse de "asociados" con Al-Qaida, Osama bin Laden y los talibanes serán, entre otros: 


\section{DOCUMENTACIÓN}

- La participación en la financiación, planificación, facilitación, preparación o comisión de actos o actividades ejecutados por Al-Qaida, Osama bin Laden o los talibanes o por una célula, entidad afiliada o grupo escindido o derivado de ellos o realizados en o bajo su nombre, junto con ellos o en apoyo de ellos;

- El suministro, la venta o la transferencia de armas y pertrechos a AlQaida, Osama bin Laden o los talibanes o a una célula, entidad afiliada o grupo escindido o derivado de ellos;

- El reclutamiento en favor de Al-Qaida, Osama bin Laden o los talibanes o de una célula, entidad afiliada o grupo escindido o derivado de ellos;

- El apoyo de otro tipo a actos o actividades ejecutados por Al-Qaida, Osama bin Laden o los talibanes o por una célula, entidad afiliada o grupo escindido o derivado de ellos;

3. Decide asimismo que recibirán idéntica calificación las entidades o empresas que sean de propiedad directa o indirecta o estén bajo el control directo o indirecto de una persona, grupo, empresa o entidad asociada con AlQaida, Osama bin Laden o los talibanes, o le presten apoyo de otro tipo;

4. Decide que, al proponer nombres para su inclusión en la lista consolidada, los Estados se atendrán a lo dispuesto en el párrafo 17 de la resolución 1526 (2004) y, en lo sucesivo, también proporcionarán al Comité una exposición en que se describa la justificación de la propuesta; y exhorta además a los Estados a indicar las empresas y entidades que sean de propiedad directa o indirecta o estén bajo el control directo o indirecto de la persona, grupo o entidad cuya inclusión en la lista propongan;

5. Pide a todos los Estados que comuniquen por escrito, en la medida de lo posible, a las personas y entidades incluidas en la lista consolidada las medidas impuestas en su contra, las directrices vigentes del Comité y, en particular, el procedimiento para ser incluido en la lista y suprimido de ella y las disposiciones de la resolución 1452 (2002);

6. Decide que el Comité podrá utilizar la exposición presentada por el Estado que haga la designación a que se refiere el párrafo 4 al responder a indagaciones de Estados Miembros que tengan a nacionales, residentes o entidades suyos incluidos en la lista consolidada; decide además que el Comité podrá decidir, según cada caso, que se dé a conocer la información a otras partes, con el consentimiento previo del Estado que hizo la designación, por razones operativas o para ayudar a poner en práctica las medidas, por ejemplo; decide asimismo que los Estados podrán seguir proporcionando al Comi- 
té información adicional, cuyo carácter confidencial será preservado, a menos que el Estado que la presente esté de acuerdo en que sea divulgada;

7. Insta encarecidamente a todos los Estados Miembros a que pongan en práctica las normas internacionales completas incorporadas en las cuarenta recomendaciones sobre el blanqueo de dinero del Grupo de Acción Financiera y sus nueve recomendaciones especiales sobre la financiación del terrorismo;

8. Pide al Secretario General que tome las medidas necesarias para estrechar la cooperación entre las Naciones Unidas y la Interpol de modo que el Comité disponga de mejores mecanismos para cumplir con mayor eficacia su mandato y los Estados Miembros cuenten con mejores instrumentos para aplicar las medidas contempladas en el párrafo 1 de la presente resolución;

9. Insta a todos los Estados Miembros a que, al poner en práctica las medidas previstas en el párrafo 1 de la presente resolución, se aseguren de que los pasaportes y otros documentos de viaje robados o extraviados sean anulados cuanto antes e intercambien información sobre esos documentos con otros Estados Miembros a través de la base de datos de la Interpol;

10. Exhorta a todos los Estados Miembros a que utilicen la lista de verificación que figura en el anexo II de la presente resolución para informar al Comité, antes del $1^{\circ}$ de marzo de 2006, acerca de las medidas concretas que hayan tomado para poner en práctica las indicadas en el párrafo 1 de la presente resolución con respecto a las personas y las entidades que en lo sucesivo se incluyan en la lista consolidada y, más adelante, con la frecuencia que determine el Comité;

11. Pide al Comité que aliente a los Estados Miembros a que presenten nombres y otros datos identificativos para incluirlos en la lista consolidada;

12. Exhorta al Comité a que, en cooperación con el Comité establecido en virtud de la resolución 1373 (el "Comité contra el Terrorismo"), le comunique qué otras medidas concretas podrían adoptar los Estados para poner en práctica las que se indican en el párrafo 1 de la presente resolución;

13. Reitera la necesidad de que en todo momento haya una estrecha cooperación y se intercambie información entre el Comité, el Comité contra el Terrorismo y el Comité establecido en virtud de la resolución 1540 (2004), así como entre sus respectivos grupos de expertos, y que haya un mejor intercambio de información y de asistencia técnica y una mayor coordinación en las visitas a los países y en las demás cuestiones pertinentes a los tres comités;

14. Reitera además la importancia de que el Comité supervise, mediante comunicaciones orales o escritas con los Estados Miembros, la eficaz apli- 


\section{DOCUMENTACIÓN}

cación de las medidas de sanción y ofrezca a los Estados Miembros la oportunidad de que sus representantes participen en las reuniones del Comité, a petición de éste, para discutir más a fondo las cuestiones que resulten pertinentes;

15. Pide al Comité que estudie la posibilidad de que, cuando proceda, el Presidente o los miembros del Comité realicen visitas a determinados países para contribuir a la cabal y eficaz aplicación de las medidas a que se refiere el párrafo 1 de la presente resolución, con el fin de alentar a los Estados a cumplir plenamente la presente resolución y las resoluciones 1267 (1999), 1333 (2000), 1390 (2002), 1455 (2003) y 1526 (2004);

16. Pide al Comité que, por conducto de su Presidente, le presente informes orales, por lo menos cada 120 días, acerca de su labor en general y la del Equipo de Vigilancia y, según proceda, en relación con los informes de los Presidentes del Comité contra el Terrorismo y el Comité establecido en virtud de la resolución 1540 (2004), junto con exposiciones informativas para todos los Estados Miembros interesados;

17. Recuerda al Comité las funciones que le incumben, enunciadas en el párrafo 14 de la resolución 1455 (2003) y el párrafo 13 de la resolución 1526 (2004), y le pide que le presente, a más tardar el 31 de julio de 2006, una versión actualizada de la evaluación por escrito a que se refiere el párrafo $13 \mathrm{de}$ la resolución 1526 (2004) acerca de las medidas que hayan adoptado los Estados Miembros para aplicar las indicadas en el párrafo 1 de la presente resolución;

18. Pide al Comité que siga trabajando en la elaboración de sus directrices, incluido el procedimiento para incluir nombres en la lista o suprimirlos, y la aplicación de la resolución 1452 (2002), y pide al Presidente que, en los informes periódicos que le presente conforme al párrafo 16 de esta resolución, incluya información actualizada sobre las actividades del Comité en esos ámbitos;

19. Decide prorrogar el mandato del Equipo de Vigilancia, con sede en Nueva York, por un período de 17 meses para que, bajo la dirección del Comité, desempeñe las funciones que se indican en el anexo I y preste asistencia al Comité en el cumplimiento de su mandato;

20. Pide al Secretario General que, una vez aprobada la presente resolución y actuando en estrecha consulta con el Comité, nombre, de acuerdo con las normas y los procedimientos de las Naciones Unidas, un máximo de ocho miembros, incluido un coordinador, del Equipo de Vigilancia, teniendo en cuenta los ámbitos de especialización a que se refiere el párrafo 7 de la resolución 1526 (2004); 
21. Decide revisar las medidas descritas en el párrafo 1 de la presente resolución, en un plazo de 17 meses o antes, de ser necesario, con miras a la posibilidad de hacerlas más estrictas;

22. Decide seguir ocupándose activamente de la cuestión.

\section{ANEXO I}

De conformidad con el párrafo 19 de la presente resolución, el Equipo de Vigilancia trabajará bajo la dirección del Comité establecido en virtud de la resolución 1267 (1999) y ejercerá las siguientes funciones:

a) Reunir y evaluar información, vigilar la aplicación de las medidas y presentar informes y formular recomendaciones al respecto; realizar estudios de casos, según proceda, y examinar a fondo las demás cuestiones pertinentes que le indique el Comité;

b) Presentar un programa de trabajo completo al Comité, para su aprobación y revisión, según sea necesario, en que describa detalladamente las actividades previstas para el desempeño de sus funciones, en particular los viajes propuestos, manteniendo una estrecha coordinación con la Dirección Ejecutiva del Comité contra el Terrorismo para evitar la duplicación y reforzar las sinergias;

c) Presentar por escrito al Comité tres informes completos e independientes sobre la aplicación por los Estados de las medidas a que se hace referencia en el párrafo 1 de esta resolución, el primero a más tardar el 31 de enero de 2006, el segundo a más tardar el 31 de julio de 2006 y el tercero a más tardar el 10 de diciembre de 2006, que comprendan recomendaciones concretas para mejorar la aplicación de las medidas vigentes y sobre otras medidas posibles, así como información sobre la inclusión de nombres en la lista, la supresión de ellos y las exenciones concedidas según lo previsto en la resolución 1452 (2003);

d) Analizar los informes presentados de conformidad con el párrafo 6 de la resolución 1455 (2003), las listas de verificación presentadas de conformidad con el párrafo 10 de la presente resolución y otra información que los Estados Miembros presenten al Comité según sus instrucciones;

e) Colaborar estrechamente y compartir información con la Dirección Ejecutiva del Comité contra el Terrorismo y el Grupo de Expertos del Comité 1540 a fin de determinar los puntos de convergencia y ayudar a facilitar una coordinación concreta entre los tres Comités; 


\section{DOCUMENTACIÓN}

f) Preparar un plan para ayudar al Comité a tratar los casos de incumplimiento de las medidas a que se hace referencia en el párrafo 1 de esta resolución;

g) Presentar al Comité recomendaciones a fin de ayudar a los Estados Miembros a aplicar las medidas a que se hace referencia en el párrafo 1 de la presente resolución y a preparar propuestas de adiciones a la lista consolida$\mathrm{da}$;

h) Celebrar consultas con los Estados Miembros antes de viajar a alguno de ellos, según el programa de trabajo aprobado por el Comité;

i) Alentar a los Estados Miembros a que presenten nombres y otros datos identificativos para su inclusión en la lista consolidada, de conformidad con las instrucciones del Comité;

j) Estudiar la naturaleza cambiante de la amenaza que representan AlQaida y los talibanes y las medidas más eficaces para hacerle frente, e informar al Comité sobre la materia;

k) Celebrar consultas con los Estados Miembros, incluso entablando un diálogo periódico con sus representantes en Nueva York y en sus capitales, teniendo en cuenta sus observaciones, especialmente respecto de cualquier cuestión incluida en los informes del Equipo de Vigilancia a que se hace referencia en el apartado c) del presente anexo;

1) Informar al Comité, periódicamente o cuando el Comité lo solicite, en forma oral o por escrito, de la labor del Equipo de Vigilancia y en particular de sus visitas a los Estados Miembros y de sus actividades;

m) Ayudar al Comité a preparar evaluaciones orales y escritas para el Consejo, en particular los resúmenes analíticos a que se hace referencia en los párrafos 17 y 18 de la presente resolución;

n) Las demás funciones que indique el Comité.

\section{ANEXO II:}

Lista de verificación del Comité establecido en virtud de la resolución 1267 (1999) del Consejo de Seguridad

Sírvase suministrar al Comité establecido en virtud de la resolución 1267 (1999) del Consejo de Seguridad (sobre las sanciones relativas a Al-Qaida y los talibanes), a más tardar el__ de de información sobre los siguientes individuos, grupos, empresas y entidades, incluidos en los últimos seis meses en la lista consolidada que prepara el Comité de particulares o entidades 
RESOLUCIONES DEL CONSEJO DE SEGURIDAD DE LAS NACIONES UNIDAS

sujetos a las sanciones estipuladas en la resolución 1267 (1999) del Consejo de Seguridad y resoluciones subsiguientes.

El Gobierno de presenta esta información el __ de de Sí No

1. Sr. (Número de la lista consolidada)

A. ¿Se ha agregado su nombre a la lista de control de visados?

B. ¿Se le ha denegado algún visado?

C. ¿Se ha dado notificación a las instituciones financieras?

D. ¿Se han congelado bienes de su propiedad?

E. ¿Se le han aplicado medidas de embargo o prohibición de la compra de armas?

F. ¿Ha intentado adquirir armas?

Otra información disponible:

Sí No

2. La empresa (Número de la lista consolidada)

A. ¿Se ha dado notificación a las instituciones financieras?

B. ¿Se han congelado bienes de su propiedad?

C. ¿Se le han aplicado medidas de embargo o prohibición de la compra de armas?

D. ¿Ha intentado adquirir armas?

Otra información disponible:

\section{RESOLUCIÓN 1624}

(14 de septiembre de 2005)

\section{El Consejo de Seguridad,}

Reafirmando sus resoluciones 1267 (1999), de 15 de octubre de 1999, 1373 (2001), de 28 de septiembre de 2001, 1535 (2004), de 26 de marzo de 2004, 1540 (2004), de 28 de abril de 2004, 1566 (2004), de 8 de octubre de 2004, y 1617 (2005), de 29 de julio de 2005, la declaración adjunta a su resolución 1456 (2003), de 20 de enero de 2003, y sus demás resoluciones relativas a las amenazas a la paz y la seguridad internacionales ocasionadas por actos de terrorismo,

Reafirmando también la necesidad de luchar contra el terrorismo en todas sus formas y manifestaciones por todos los medios, de conformidad con la Carta de las Naciones Unidas, y subrayando además que los Estados deben asegurarse de que cualquier medida adoptada para luchar contra el terrorismo se ajuste a las obligaciones que les incumben en virtud del derecho interna- 


\section{DOCUMENTACIÓN}

cional, y que deben adoptar dichas medidas de conformidad con ese derecho, en particular el derecho internacional relativo a los derechos humanos, el derecho relativo a los refugiados y el derecho humanitario,

Condenando en los términos más enérgicos todos los actos de terrorismo, independientemente de su motivación y de cuándo y por quién sean cometidos, como una de las más graves amenazas a la paz y la seguridad, y reafirmando la responsabilidad primordial del Consejo de Seguridad en el mantenimiento de la paz y la seguridad internacionales en virtud de la Carta de las Naciones Unidas,

Condenando también en los términos más enérgicos la incitación a la comisión de actos de terrorismo y repudiando los intentos de justificación o glorificación (apología) de actos de terrorismo que puedan incitar a la comisión de nuevos actos de terrorismo,

Profundamente preocupado por el hecho de que la incitación a la comisión de actos de terrorismo por motivos de extremismo e intolerancia constituye un peligro grave y creciente para el goce de los derechos humanos y una amenaza para el desarrollo social y económico de todos los Estados, socava la estabilidad y prosperidad mundiales, y debe ser afrontada por las Naciones Unidas y todos los Estados con urgencia y de manera activa, y subrayando la necesidad de adoptar todas las medidas necesarias y apropiadas de conformidad con el derecho internacional, en los planos nacional e internacional, para proteger el derecho a la vida,

Recordando el derecho a la libertad de expresión que se recoge en el artículo 19 de la Declaración Universal de Derechos Humanos, aprobada por la Asamblea General en 1948 ("Declaración Universal"), y recordando también el derecho a la libertad de expresión, que se proclama en el artículo 19 del Pacto Internacional de Derechos Civiles y Políticos, aprobado por la Asamblea General en 1966, y que sólo se podrán imponer a esos derechos las restricciones previstas por la ley y que sean necesarias con arreglo a lo dispuesto en el párrafo 3 del artículo 19 del Pacto,

Recordando asimismo que el derecho a solicitar asilo y gozar de él, que se recoge en el artículo 14 de la Declaración Universal, y la prohibición de devolución por los Estados establecida en la Convención sobre el Estatuto de los Refugiados, aprobada el 28 de julio de 1951, y en su Protocolo, aprobado el 31 de enero de 1967 ("la Convención sobre los Refugiados y su Protocolo"), y recordando también que las medidas de protección enunciadas en la Convención sobre los Refugiados y su Protocolo no serán aplicables a nadie respecto de quien halla razones fundadas para considerar que ha cometido actos contrarios a los propósitos y principios de las Naciones Unidas, 
Reafirmando que los actos, métodos y prácticas terroristas son contrarios a los propósitos y principios de las Naciones Unidas y que la financiación y planificación de actos terroristas, así como la incitación a su comisión, son también contrarios a los propósitos y principios de las Naciones Unidas,

Profundamente preocupado por el creciente número de víctimas, especialmente civiles de diversas nacionalidades y creencias, causadas por el terrorismo por motivos de intolerancia o extremismo en diversas regiones del mundo, reafirmando su profunda solidaridad con las víctimas del terrorismo y sus familias, y subrayando la importancia de prestar asistencia a las víctimas del terrorismo y brindarles a ellas y sus familias apoyo para que superen sus pérdidas y su dolor,

Reconociendo el papel esencial que las Naciones Unidas desempeñan en la labor mundial de lucha contra el terrorismo y acogiendo complacido la identificación por el Secretario General de los elementos de una estrategia de lucha contra el terrorismo, que la Asamblea General debe examinar y elaborar sin demora con miras a la aprobación y aplicación de una estrategia que promueva respuestas amplias, coordinadas y coherentes contra el terrorismo en los planos nacional, regional e internacional,

Haciendo hincapié en su llamamiento a todos los Estados para que entren a se parte, con carácter de urgencia, en los convenios, convenciones y protocolos internacionales contra el terrorismo, sean o no parte en instrumentos regionales sobre esta cuestión, y consideren con carácter prioritario la firma del Convenio internacional para la represión de los actos de terrorismo nuclear aprobado por la Asamblea General el 13 de abril de 2005,

Haciendo especial hincapié en que la continuación de la labor internacional para promover el diálogo y mejorar el entendimiento entre las civilizaciones, en un intento por prevenir que se atente indiscriminadamente contra diferentes religiones y culturas, y la solución de los conflictos regionales no resueltos y los muy diversos problemas mundiales, en particular los problemas de desarrollo, contribuirán a fortalecer la lucha internacional contra el terrorismo,

Insistiendo en la importancia del papel que desempeñan los medios de comunicación, la sociedad civil y religiosa, la comunidad empresarial y las instituciones educativas en la labor de fomentar el diálogo y mejorar el entendimiento, alentar a la coexistencia y la tolerancia y promover un entorno que no favorezca la incitación al terrorismo,

Reconociendo la importancia de que, en un mundo cada vez más globalizado, los Estados actúen en colaboración a fin de impedir que los terroristas 


\section{DOCUMENTACIÓN}

se aprovechen de tecnologías, comunicaciones y recursos avanzados para incitar al apoyo a actos delictivos,

Recordando que todos los Estados deben colaborar plenamente en la lucha contra el terrorismo, de conformidad con las obligaciones que les incumben en virtud del derecho internacional, a fin de detener, denegar protección y llevar ante la justicia, en aplicación del principio de extraditar o procesar, a todo el que apoye o facilite la financiación, planificación, preparación o comisión de actos de terrorismo o la facilitación de refugio, o participe o intente participar en dichas actividades,

1. Insta a todos los Estados a que adopten las medidas necesarias y adecuadas en cumplimiento de sus obligaciones de derecho internacional para:

a) Prohibir por ley la incitación a la comisión de un acto o actos de terrorismo;

b) Impedir dicha conducta;

c) Denegar protección a toda persona respecto de la cual se disponga de información fidedigna y pertinente por la que haya razones fundadas para considerar que es culpable de esa conducta;

2. Insta a todos los Estados a cooperar, entre otras cosas, para reforzar la seguridad de sus fronteras internacionales, en particular combatiendo la utilización de documentos de viaje fraudulentos y, en la medida de lo posible, aplicando procedimientos más eficaces de detección de terroristas y de seguridad en el transporte, con miras a impedir que las personas culpables de los actos a que se hace referencia en el apartado a) del párrafo 1 entren en su territorio;

3. Hace un llamamiento a todos los Estados para que prosigan los esfuerzos internacionales encaminados a promover el diálogo y mejorar el entendimiento entre las civilizaciones, en un intento por prevenir que se atente indiscriminadamente contra diferentes religiones y culturas, y adopten todas las medidas que sean necesarias y adecuadas y conformes con las obligaciones que les incumben en virtud del derecho internacional para luchar contra la incitación a la comisión de actos de terrorismo por motivos de extremismo e intolerancia e impedir la subversión de las instituciones educativas, culturales y religiosas por parte de terroristas y de quienes los apoyan;

4. Subraya que los Estados deben asegurarse de que cualesquiera medidas que se adopten para aplicar los párrafos 1,2 y 3 de la presente resolución se ajusten a las obligaciones que les incumben en virtud del derecho internacional, en particular el derecho internacional relativo a los derechos humanos, el derecho relativo a los refugiados y el derecho humanitario; 
5. Insta a todos los Estados a que informen al Comité contra el Terrorismo, en el marco del diálogo que mantienen con él, de las medidas adoptadas para aplicar la presente resolución;

6. Encomienda al Comité contra el Terrorismo que:

a) Incluya en su diálogo con los Estados Miembros la labor que llevan a cabo para aplicar la presente resolución;

b) Colabore con los Estados Miembros para ayudarles a crear capacidad al respecto, incluso mediante la difusión de las prácticas jurídicas más adecuadas y la promoción del intercambio de información;

c) Informe al Consejo, en un plazo de doce meses, sobre la aplicación de la presente resolución;

7. Decide seguir ocupándose activamente de la cuestión.

\section{RESOLUCIÓN 1625}

(14 de septiembre de 2005)

\section{El Consejo de Seguridad,}

Decide aprobar la declaración adjunta sobre el fortalecimiento de la eficacia del papel del Consejo de Seguridad en la prevención de conflictos, en particular en África.

\section{ANEXO}

El Consejo de Seguridad,

Reunido el 14 de septiembre de 2005 a nivel de Jefes de Estado y de Gobierno para examinar los medios de aumentar la eficacia de la función del Consejo de Seguridad en la prevención de conflictos armados, en particular en África,

Reafirmando su adhesión a los propósitos y principios de la Carta de las Naciones Unidas,

Teniendo presente su responsabilidad primordial en el mantenimiento de la paz y la seguridad internacionales,

Profundamente preocupado por el gran costo humano y las elevadas pérdidas materiales ocasionadas por los conflictos armados, y reconociendo que la paz, la seguridad y el desarrollo se refuerzan mutuamente, particularmente en la prevención de conflictos armados,

Reafirmando la importancia de respetar el principio de la abstención de la amenaza o de la utilización de la fuerza en las relaciones internacionales de 


\section{DOCUMENTACIÓN}

manera incompatible con los propósitos de las Naciones Unidas, y del arreglo pacífico de las controversias internacionales,

Reafirmando la necesidad de adoptar una estrategia amplia de prevención de conflictos, en la que se tengan en cuenta las causas básicas de los conflictos armados y de las crisis políticas y sociales de manera global, en especial mediante la promoción del desarrollo sostenible, la erradicación de la pobreza, la reconciliación nacional, la buena gobernanza, la democracia, la igualdad entre los sexos, el imperio de la ley y el respeto y la protección de los derechos humanos,

Reconociendo la necesidad de fortalecer el importante papel de las Naciones Unidas en la prevención de conflictos violentos y de desarrollar una colaboración eficaz entre el Consejo y las organizaciones regionales, en particular la Unión Africana y sus organizaciones subregionales, a fin de facilitar respuestas oportunas a las controversias y las crisis emergentes,

Recordando el Acta Constitutiva de la Unión Africana, el Protocolo relativo a la creación del Consejo de Paz y Seguridad de la Unión Africana, y el Pacto de la Unión Africana de no agresión y defensa común, aprobado en Abuja el 31 de enero de 2005, así como la posición de la Unión Africana sobre los cambios inconstitucionales de gobierno, expuesta en la Declaración de Argel de 1999 y la Declaración de Lomé de 2000,

Reconociendo el importante papel que desempeñan la sociedad civil, las mujeres y los hombres, en la prevención de conflictos y la necesidad de que se tomen en consideración todas las contribuciones que pueda hacer la sociedad civil local,

1. Expresa su determinación de aumentar la eficacia de las Naciones Unidas en la prevención de conflictos armados y en el seguimiento de situaciones que puedan llevar a conflictos armados;

2. Afirma su determinación de aumentar la capacidad de las Naciones Unidas para la prevención de conflictos:

a) Evaluando periódicamente la situación en las regiones que estén en peligro de conflicto armado y alentando al Secretario General a que facilite información al Consejo sobre esa situación, de conformidad con el Artículo 99 de la Carta;

b) Promoviendo el seguimiento de iniciativas de diplomacia preventiva del Secretario General;

c) Apoyando las iniciativas de mediación regionales, en estrecha consulta con las organizaciones regionales y subregionales interesadas; 
d) Fomentando la capacidad regional y subregional de alerta temprana para propiciar la instauración de mecanismos apropiados que permitan adoptar medidas oportunas de acuerdo con los indicadores de alerta temprana;

e) Solicitando la información y la asistencia necesarias y apropiadas al Consejo Económico y Social, de conformidad con el Artículo 65 de la Carta;

f) Adoptando medidas para contribuir a luchar contra el comercio ilícito de armas en todos sus aspectos y la utilización de mercenarios;

g) Contribuyendo a establecer instituciones duraderas que promuevan la paz, la estabilidad y el desarrollo sostenible; h) Apoyando los esfuerzos de los Estados de África para establecer instituciones judiciales nacionales independientes y fiables;

3. Pide al Secretario General que:

a) Proporcione al Consejo informes periódicos y análisis de la situación en regiones en peligro de conflicto armado, en particular en África, y, cuando proceda, le informe debidamente de las iniciativas de diplomacia preventiva en curso;

b) Preste asistencia a los países en peligro de conflicto armado para realizar evaluaciones estratégicas del riesgo de conflicto y aplicar las medidas acordadas por los países afectados, a fin de aumentar la capacidad nacional para el arreglo de controversias y afrontar las causas básicas del conflicto armado;

c) Promueva la coordinación con el mecanismo regional de solución de conflictos en África, lo que permitiría al Consejo de Seguridad contar con información adicional fiable y oportuna para facilitar la adopción rápida de decisiones;

4. Subraya la importancia de elaborar estrategias eficaces amplias centradas en la prevención de conflictos, a fin de evitar la evolución negativa del sector de la seguridad, los sectores económico, social y humanitario y la esfera de la gobernanza y los derechos humanos en países que afrontan crisis, prestando atención especial a lo siguiente:

a) El desarrollo de actividades de resultados rápidos para prevenir conflictos causados por la competencia por los recursos económicos y vigilar la tensión que se produce en relación con cuestiones económicas y sociales;

b) El estímulo de las oficinas regionales de las Naciones Unidas para que faciliten la aplicación de estrategias destinadas a frenar las actividades transfronterizas ilícitas;

c) El fortalecimiento de la capacidad de los grupos de la sociedad civil, incluidos los grupos de mujeres, que se dedican a promover una cultura de paz, y movilizar a los donantes en apoyo de esos esfuerzos; 


\section{DOCUMENTACIÓN}

d) La adopción de medidas de política para fomentar la buena gobernanza y la protección de los derechos humanos con el fin de reforzar los mecanismos de gobernanza debilitados o desmoronados y poner fin a la cultura de impunidad;

e) La promoción de la limpieza y la transparencia de los procesos electorales;

5. Destaca la importancia decisiva de adoptar un enfoque regional con respecto a la prevención de conflictos, en particular programas de desarme, desmovilización y reintegración, así como la reintegración efectiva y sostenible de los excombatientes;

6. Reafirma su determinación de adoptar medidas contra la explotación ilícita y el tráfico de recursos naturales y de bienes de gran valor donde contribuyan al estallido, la escalada o la continuación de conflictos armados;

7. Insta a que aumenten la cooperación y las comunicaciones entre las Naciones Unidas y las organizaciones o mecanismos regionales o subregionales, de conformidad con el Capítulo VIII de la Carta, en particular con respecto a las iniciativas de mediación;

8. Alienta a todos los Estados de África a que se adhieran al Pacto de la Unión Africana de no agresión y defensa común aprobado en Abuja el 31 de enero de 2005, y a que firmen, cuando proceda, los pactos subregionales en pro de la paz, la seguridad, la democracia, la buena gobernanza y el desarrollo, e insta al sistema de las Naciones Unidas y a la comunidad internacional en general a prestar apoyo a la aplicación de los pactos;

9. Alienta también a los países de la región de África a seguir colaborando estrechamente con la Secretaría de las Naciones Unidas y las oficinas regionales de las Naciones Unidas en la aplicación de medidas destinadas a garantizar la paz, la seguridad, la estabilidad, la democracia y el desarrollo sostenible, de conformidad con los objetivos de la Nueva Alianza para el Desarrollo de África;

10. Exhorta a la comunidad internacional, en especial al sistema de las Naciones Unidas y a las instituciones financieras internacionales, a que apoyen a los Estados de África en sus esfuerzos por lograr los objetivos mencionados y, a ese respecto, acoge complacido las decisiones adoptadas por la Cumbre del Grupo de los Ocho para luchar contra la pobreza en África, celebrada en Gleneagles del 6 al 8 de julio de 2005;

11. Insta a todos los Estados africanos y a la comunidad internacional a que colaboren plenamente en el fomento de la capacidad de las organizaciones regionales y subregionales de África para desplegar rápidamente a su per- 
sonal civil y militar cuando sea necesario, incluido el establecimiento de la Fuerza de Reserva Africana de la Unión Africana, acoge con agrado los programas bilaterales y multilaterales formulados con este fin, y manifiesta su apoyo a la propuesta del Secretario General de establecer un programa decenal de fomento de la capacidad de la Unión Africana;

12. Decide seguir ocupándose de la cuestión.

\section{TIMOR-LESTE}

RESOLUCIÓN 1573

(16 de noviembre de 2004)

\section{El Consejo de Seguridad,}

Reafirmando sus resoluciones anteriores sobre la situación de TimorLeste, en particular las resoluciones 1410 (2002), de 17 de mayo de 2002, 1473 (2003), de 4 de abril de 2003, 1480 (2003), de 19 de mayo de 2003 y 1543 (2004), de 14 de mayo de 2004,

Encomiando al pueblo y al Gobierno de Timor-Leste por la paz y la estabilidad que han logrado en el país, así como por sus esfuerzos constantes por consolidar la democracia y crear instituciones estatales,

Encomiando además la labor de la Misión de Apoyo de las Naciones Unidas en Timor Oriental (UNMISET), bajo la dirección del Representante Especial del Secretario General, y observando con satisfacción que se sigue avanzando hacia el cumplimiento de las tareas fundamentales de su mandato, en particular en su etapa de consolidación, de conformidad con la resolución 1543 (2004),

Rindiendo homenaje a quienes colaboran con Timor-Leste a título bilateral y multilateral por su inapreciable asistencia, en particular en lo que respecta a la formación de capacidad institucional y al desarrollo social y económico,

Observando que, a pesar de los notables avances realizados en los últimos meses, Timor-Leste no ha llegado aún al umbral crítico de autosuficiencia, principalmente en ámbitos fundamentales como la administración pública, la aplicación coercitiva de la ley y la seguridad,

Observando con satisfacción el aumento de la cooperación y las buenas relaciones entre Timor-Leste y sus vecinos y alentando a que se siga avanzando para concertar acuerdos concretos acerca del trazado de fronteras y otras cuestiones pendientes, 


\section{DOCUMENTACIÓN}

Encomiando a la Dependencia de Delitos Graves por la labor que ha realizado para terminar sus investigaciones en noviembre de 2004 y todos los nuevos procesos y otras actividades a más tardar el 20 de mayo de 2005 ,

Observando con preocupación que tal vez no sea posible que la Dependencia de Delitos Graves atienda plenamente a las aspiraciones de justicia de los afectados por la violencia en 1999 en vista del tiempo y los recursos limitados de que dispone,

Tomando nota del informe especial del Secretario General sobre la UNMISET de 29 de abril de 2004 (S/2004/333), así como del informe de 19 de noviembre de 2004 (S/2004/888), y acogiendo con beneplácito las recomendaciones en ellos contenidas,

Reiterando que sigue plenamente empeñado en la promoción de la seguridad y de la estabilidad duradera en Timor-Leste,

1. Decide prorrogar el mandato de la UNMISET por un último período de seis meses hasta el 20 de mayo de 2005;

2. Decide también mantener las tareas actuales, la configuración y el tamaño de la UNMISET a fin de que la Misión pueda cumplir las tareas fundamentales de su mandato y consolide los progresos logrados hasta la fecha;

3. Pide a la UNMISET que preste cada vez mayor atención a la ejecución de su estrategia de salida, en particular con miras a que los timorenses participen cada vez más en los tres componentes del programa de la Misión, y se identifiquen cada vez más con ellos, de manera que, cuando la Misión se retire de Timor-Leste, puedan hacerse cargo de sus funciones con la asistencia continua del sistema de las Naciones Unidas y quienes colaboran a título bilateral y multilateral;

4. Exhorta a la comunidad de donantes a que sigan prestando su indispensable asistencia a Timor-Leste, incluso mediante su participación activa en la conferencia de donantes programada para marzo de 2005 ;

5. Exhorta, en particular, a los organismos de desarrollo y humanitarios de las Naciones Unidas y a las instituciones financieras multilaterales a que comiencen inmediatamente a planificar una transición fluida en Timor-Leste de una operación de mantenimiento de la paz a un marco de asistencia para el desarrollo sostenible;

6. Reafirma la necesidad de combatir la impunidad y, a este respecto, toma nota de que el Secretario General se propone seguir estudiando posibles medios de resolver esta cuestión con miras a hacer las propuestas que correspondan;

7. Pide al Secretario General que le mantenga periódicamente muy al corriente de los acontecimientos sobre el terreno y de la aplicación de esta re- 
solución, en particular de los párrafos 3 y 5 y, a ese respecto le pide que presente un informe dentro de los tres meses siguientes a la fecha de aprobación de esta resolución, seguido de un informe final en mayo de 2005;

8. Decide seguir ocupándose activamente de la cuestión.

\section{RESOLUCIÓN 1599}

(28 de abril de 2005)

\section{El Consejo de Seguridad,}

Reafirmando sus resoluciones anteriores sobre la situación en TimorLeste, en particular las resoluciones 1543 (2004), de 14 de mayo de 2004, y 1573 (2004), de 16 de noviembre de 2004,

Habiendo examinado el informe del Secretario General de 18 de febrero de 2005 (S/2005/99),

Encomiando al pueblo y al Gobierno de Timor-Leste por la paz y la estabilidad que han logrado en el país, así como por sus esfuerzos constantes por consolidar la democracia y afianzar las instituciones estatales,

Encomiando además a la Misión de Apoyo de las Naciones Unidas en Timor-Leste (UNMISET), bajo la dirección del Representante Especial del Secretario General, y observando con satisfacción que sigue avanzando hacia el cumplimiento de las tareas fundamentales de su mandato, en particular en su etapa de consolidación, de conformidad con las resoluciones 1543 (2004) y 1573 (2004),

Rindiendo homenaje a quienes colaboran con Timor-Leste a título bilateral y multilateral por su inapreciable asistencia, en particular en lo que respecta a la formación de capacidad institucional y al desarrollo social y económico,

Expresando su reconocimiento a los Estados Miembros que han prestado apoyo a la UNMISET,

Habiendo examinado la carta de fecha 20 de enero de 2005 dirigida al Secretario General por el Primer Ministro de Timor-Leste (S/2005/103),

Observando el análisis que hace el Secretario General de la necesidad de que siga habiendo una presencia de las Naciones Unidas, aunque más reducida, despuésdel 20 de mayo de 2005,

Observando además que las instituciones que van surgiendo en TimorLeste se encuentran aún en proceso de consolidación y que se necesita más asistencia a los efectos del desarrollo y fortalecimiento sostenidos de compo- 


\section{DOCUMENTACIÓN}

nentes fundamentales, primordialmente el imperio de la ley, con inclusión de la justicia, los derechos humanos y el apoyo a la policía de Timor-Leste y otros componentes de la administración pública,

Reconociendo la excelente comunicación y la buena voluntad que han caracterizado a las relaciones entre Timor-Leste e Indonesia, en particular la decisión de establecer una Comisión de la Verdad y la Amistad y el acuerdo sobre la frontera terrestre firmado en Dili el 8 de abril de 2005, que comprende aproximadamente el $96 \%$ de la frontera terrestre, y alentando el empeño continuo de ambos Gobiernos por resolver ésta y todas las cuestiones bilaterales pendientes,

Reconociendo la decisión del Secretario General, indicada en su carta al Consejo de Seguridad de fecha 11 de enero de 2005 (S/2005/96), de enviar una comisión de expertos a Timor-Leste y a Indonesia a fin de que examine los procedimientos para hacer valer la responsabilidad por delitos graves y de recomendar las medidas ulteriores que procedan,

Reafirmando que sigue plenamente empeñado en promover la estabilidad duradera en Timor-Leste,

1. Decide establecer por un año una misión política especial de seguimiento en Timor-Leste, la Oficina de las Naciones Unidas en Timor-Leste (UNOTIL), que permanecerá en el país hasta el 20 de mayo de 2006;

2. Decide además que el mandato de la UNOTIL será el siguiente:

i) Prestar apoyo para el desarrollo de instituciones fundamentales del Estado, proporcionando hasta 45 asesores civiles;

ii) Prestar apoyo para el desarrollo ulterior de la policía, proporcionando hasta 40 asesores de policía, y para el desarrollo de la Unidad de Patrulla de Frontera, proporcionando hasta 35 asesores más, de los cuales 15 podrán ser asesores militares;

iii) Impartir formación sobre observancia del gobierno democrático y los derechos humanos, proporcionando hasta 10 oficiales de derechos humanos; y

iv) Supervisar y examinar los avances realizados en relación con los tres incisos que anteceden;

3. Pide que, en el ejercicio de su mandato, la UNOTIL preste especial atención a la debida transferencia de pericia y conocimientos con miras a formar capacidad en las instituciones públicas de Timor-Leste para prestar sus servicios con arreglo a los principios internacionales de imperio de la ley, justicia, derechos humanos, gobierno democrático, transparencia, rendición de cuentas y profesionalismo; 
4. Pide además que la UNOTIL esté encabezada por un Representante Especial del Secretario General, que dirigirá las operaciones de la misión y coordinará todas las actividades de las Naciones Unidas en Timor-Leste por conducto de su oficina, prestando debida atención a la seguridad del personal, y a quien se le facilitará un volumen adecuado de apoyo logístico, con inclusión de medios de transporte, entre otros de transporte aéreo cuando sea necesario;

5. Pide al Secretario General que despliegue algunos de los asesores autorizados en el párrafo 2 ii) a fin de que ayuden a la Policía Nacional de Timor-Leste a establecer procedimientos para la Unidad de Patrulla de Frontera y en su adiestramiento y para ayudar al Gobierno de Timor-Leste a coordinar los contactos con los militares indonesios, con el objetivo de poner a la Unidad de Patrulla de Frontera en condiciones de asumir lo antes posible toda la responsabilidad de esa coordinación;

6. Recalca que la asistencia de las Naciones Unidas a Timor-Leste debe coordinarse con la labor de los donantes bilaterales y multilaterales, los mecanismos regionales, las organizaciones no gubernamentales, las organizaciones del sector privado y otras entidades de la comunidad internacional y alienta al Representante Especial del Secretario General a que establezca y presida un grupo asesor, integrado por esas entidades en Timor-Leste, que habrá de reunirse periódicamente con ese fin;

7. Exhorta a la comunidad de donantes, así como a los organismos de las Naciones Unidas y a las instituciones financieras bilaterales, a que sigan proporcionando recursos y asistencia para la ejecución de proyectos de desarrollo sostenible y a largo plazo en Timor-Leste y exhorta a la comunidad de donantes a que participe activamente en la conferencia de donantes prevista para abril de 2005;

8. Alienta, en particular al Gobierno de Timor-Leste, a la UNOTIL, a la Secretaría de las Naciones Unidas, a los organismos de desarrollo y humanitarios de las Naciones Unidas y a las instituciones financieras internacionales a que comiencen inmediatamente a planificar una transición rápida y fluida en Timor-Leste de una misión política especial a un marco de asistencia para el desarrollo sostenible;

9. Reafirma la necesidad de que se rindan cuentas en forma verosímil de las transgresiones de los derechos humanos cometidas en Timor Oriental en 1999 y, a ese respecto, destaca la necesidad de que la Secretaría de las Naciones Unidas, previo acuerdo con las autoridades de Timor-Leste, conserve copia íntegra de todos los expedientes reunidos por la Dependencia de Delitos Graves, insta a todas las partes a que cooperen plenamente con la labor de la 
comisión de expertos que nombre el Secretario General y espera con interés el próximo informe de la comisión, en que se estudiarán posibles medios de hacer frente a esa cuestión, con inclusión de medios para prestar asistencia a la Comisión de la Verdad y la Amistad que Indonesia y Timor-Leste han convenido en establecer;

10. Pide al Secretario General que le mantenga periódicamente muy al corriente de los acontecimientos sobre el terreno, de la ejecución del mandato de la UNOTIL y de los planes para la transición a un marco de asistencia para el desarrollo sostenible y que le presente un informe dentro de los cuatro meses siguientes a la fecha de aprobación de esta resolución, y posteriormente cada cuatro meses, con recomendaciones acerca de las modificaciones que los avances realizados permitan introducir en el tamaño, el mandato y la duración de la presencia de la UNOTIL;

11. Decide seguir ocupándose activamente de la cuestión.

\section{TRIBUNAL INTERNACIONAL PARA LA EX YUGOSLAVIA}

\section{RESOLUCIÓN 1567}

(14 de octubre de 2004)

\section{El Consejo de Seguridad,}

Recordando sus resoluciones 827 (1993), de 25 de mayo de 1993, 1166 (1998), de 13 de mayo de 1998, 1329 (2000), de 30 de noviembre de 2000, 1411 (2002), de 17 de mayo de 2002, 1481 (2003), de 19 de mayo de 2003, 1503 (2003), de 28 de agosto de 2003, y 1534 (2004), de 26 de marzo de 2004,

Habiendo examinado las candidaturas para ocupar los cargos de magistrados permanentes del Tribunal Internacional para la ex Yugoslavia recibidas por el Secretario General,

Transmite a la Asamblea General las siguientes candidaturas, de conformidad con el párrafo 1 d) del artículo 13 bis del Estatuto del Tribunal Internacional:

Sr. Carmel A. Agius (Malta)

Sr. Jean-Claude Antonetti (Francia)

Sr. Iain Bonomy (Reino Unido de Gran Bretaña e Irlanda del Norte)

Sr. Liu Daqun (China)

Sr. Mohamed Amin El-Abbassi El Mahdi (Egipto) 


\author{
Sr. Elhagi Abdulkader Emberesh (Jamahiriya Árabe Libia) \\ Sr. Rigoberto Espinal Irias (Honduras) \\ Sr. O-gon Kwon (República de Corea) \\ Sr. Theodor Meron (Estados Unidos de América) \\ Sr. Bakone Melema Moloto (Sudáfrica) \\ Sra. Prisca Matimba Nyambe (Zambia) \\ Sr. Alphonsus Martinus Maria Orie (Países Bajos) \\ Sr. Kevin Horace Parker (Australia) \\ Sr. Fausto Pocar (Italia) \\ Sr. Yenyi Olungu (República Democrática del Congo) \\ Sr. Sharada Prasad Pandit (Nepal) \\ Sra. Vonimbolana Rasoazanany (Madagascar) \\ Sr. Patrick Lipton Robinson (Jamaica) \\ Sr. Wolfgang Schomburg (Alemania) \\ Sr. Mohamed Shahabuddeen (Guyana) \\ Sra. Christine Van den Wyngaert (Bélgica) \\ Sr. Volodymyr A. Vassylenko (Ucrania)
}

\title{
RESOLUCIÓN 1581
}

(18 de enero de 2005)

\section{El Consejo de Seguridad,}

Tomando nota de la carta de fecha 6 de enero de 2005 dirigida al Presidente del Consejo por el Secretario General (S/2005/9),

Recordando sus resoluciones 1503 (2003), de 28 de agosto de 2003, y 1534 (2004), de 26 de marzo de 2004,

Teniendo presente la declaración formulada ante el Consejo de Seguridad en su 5086 a sesión, celebrada el 23 de noviembre de 2004, por el Presidente del Tribunal Penal Internacional para la ex Yugoslavia, en que expresó la adhesión del Tribunal Internacional a la estrategia de conclusión,

Expresando su esperanza de que la prórroga de los mandatos de los magistrados ad lítem de que se trata aumente la eficacia de las actuaciones procesales y contribuya a la aplicación de la estrategia de conclusión,

1. Decide, atendiendo a la petición del Secretario General, que:

a) La Magistrada Rasoazanany y el Magistrado Swart, una vez reemplazados como magistrados ad lítem del Tribunal Internacional, terminen la causa Had.ihasanović, que han iniciado antes del término de su mandato; 


\section{DOCUMENTACIÓN}

b) El Magistrado Brydensholt y el Magistrado Eser, una vez reemplazados como magistrados ad lítem del Tribunal Internacional, terminen la causa Orić, que han iniciado antes del término de su mandato;

c) El Magistrado Thelin y la Magistrada Van Den Wyngaert, una vez reemplazados como magistrados ad lítem del Tribunal Internacional, terminen la causa Limaj, que han iniciado antes del término de su mandato;

d) El Magistrado Canivell, una vez reemplazado como magistrado ad lítem del Tribunal Internacional, termine la causa Kraji.nik, que ha iniciado antes del término de su mandato;

e) El Magistrado Szénási, en caso de que se lo designe para prestar servicios en el Tribunal Internacional para el juicio de la causa Halilović, proceda, una vez reemplazado como magistrado ad lítem del Tribunal Internacional, a finalizar esa causa, que habrá iniciado antes del término de su mandato;

f) El Magistrado Hanoteau, en caso de que se lo designe para prestar servicios en el Tribunal Internacional para el juicio de la causa Kraji.nik, proceda, una vez reemplazado como magistrado ad lítem en el Tribunal Internacional, a finalizar esa causa, que habrá iniciado antes del término de su mandato;

2. Toma nota al respecto de la intención del Tribunal Internacional de finalizar la causa Had.ihasanović antes del final de septiembre de 2005, la causa Halilović antes del final de octubre de 2005, las causas Orić y Limaj antes del final de noviembre de 2005 y la causa Kraji.nik antes del final de abril de 2006.

\section{RESOLUCIÓN 1597}

(20 de abril de 2005)

\section{El Consejo de Seguridad,}

Reafirmando sus resoluciones 827 (1993), de 25 de mayo de 1993, 1166 (1998), de 13 de mayo de 1998, 1329 (2000), de 30 de noviembre de 2000, 1411 (2002), de 17 de mayo de 2002, 1431 (2002), de 14 de agosto de 2002, 1481 (2003), de 19 de mayo de 2003, 1503 (2003), de 28 de agosto de 2003 y 1534 (2004), de 28 de marzo de 2004,

Habiendo examinado la carta que con fecha 24 de febrero de 2005 dirigió el Secretario General a su Presidente (S/2005/127) en que transmitía la lista de candidatos para la elección de magistrados ad lítem del Tribunal Internacional para la ex Yugoslavia,

Observando que el Secretario General sugirió que el plazo para presentar candidaturas se prorrogara hasta el 31 de marzo de 2005 y que el Presi- 
dente indicó, en su respuesta de fecha 14 de marzo de 2005 (S/2005/159), que el Consejo había aprobado esa prórroga,

Habiendo examinado también la carta que con fecha 11 de abril de 2005 dirigió el Secretario General a su Presidente (S/2005/236) en que sugería que se volviera a prorrogar el plazo para presentar candidaturas para la elección de magistrados ad lítem,

Observando que el número de candidatos sigue siendo inferior al mínimo exigido por el Estatuto del Tribunal,

Considerando que los 27 magistrados ad lítem que eligió la Asamblea General en su $102^{\mathrm{a}}$ sesión plenaria, celebrada el 12 de junio de 2001, y cuyo mandato expira el 11 de junio de 2005 deberían ser reelegibles y deseando enmendar el Estatuto para ese fin,

Observando que el hecho de que el período total de servicios de un magistrado ad lítem del Tribunal Internacional para la ex Yugoslavia sea de tres años o más no entrañará cambio alguno en sus derechos o prestaciones y, en particular, no dará lugar a ningún derecho o prestación que no sean los ya existentes, los cuales, en tal caso, se prorrogarán proporcionalmente en razón de la prórroga del servicio,

Actuando en virtud del Capítulo VII de la Carta de las Naciones Unidas,

1. Decide enmendar el artículo 13 ter del Estatuto del Tribunal Internacional para la ex Yugoslavia y reemplazarlo por el texto que figura en el anexo de la presente resolución;

2. Decide, de conformidad con la carta del Secretario General de 11 de abril de 2005 (S/2005/236), prorrogar el plazo para presentar candidaturas a cargos de magistrados ad lítem con arreglo a la disposición enmendada del Estatuto por otros 30 días contados a partir de la fecha de aprobación de la presente resolución;

3. Decide seguir ocupándose activamente de la cuestión.

ANEXO: Artículo 13 ter. Elección y nombramiento de magistrados ad lítem

1. Los magistrados ad lítem del Tribunal Internacional serán elegidos por la Asamblea General a partir de una lista presentada por el Consejo de Seguridad, en la forma siguiente:

a) El Secretario General invitará a los Estados Miembros de las Naciones Unidas y a los Estados no miembros que mantengan misiones permanentes de observación en la Sede de las Naciones Unidas a que propongan candidatos a magistrados ad lítem del Tribunal Internacional; 


\section{DOCUMENTACIÓN}

b) En el plazo de sesenta días contados desde la fecha de la invitación del Secretario General, cada Estado podrá proponer un máximo de cuatro candidatos que reúnan las condiciones establecidas en el artículo 13 del Estatuto, teniendo en cuenta la importancia de que haya un número equitativo de candidatas y candidatos;

c) El Secretario General enviará las candidaturas recibidas al Consejo de Seguridad. De las candidaturas recibidas, el Consejo de Seguridad confeccionará una lista de no menos de cincuenta y cuatro candidatos, teniendo debidamente en cuenta la representación de los principales sistemas jurídicos mundiales y teniendo presente la importancia de la distribución geográfica;

d) El Presidente del Consejo de Seguridad enviará la lista de candidatos al Presidente de la Asamblea General. Basándose en esa lista, la Asamblea General elegirá a los veintisiete magistrados ad lítem del Tribunal Internacional. Los candidatos que obtengan una mayoría absoluta de los votos de los Estados Miembros de las Naciones Unidas y de los Estados no miembros que mantengan misiones permanentes de observación en la Sede de las Naciones Unidas serán declarados electos;

e) Los magistrados ad lítem serán elegidos por un período de cuatro años y podrán ser reelegidos.

2. En cualquiera de los períodos de su mandato, los magistrados ad lítem podrán ser designados por el Secretario General, a petición del Presidente del Tribunal Internacional, para prestar servicios en las Salas de Primera Instancia en uno o más juicios, por un período acumulativo de hasta tres años, pero que no podrá incluir ningún período de tres años consecutivos. Cuando solicite la designación de un determinado magistrado ad lítem, el Presidente del Tribunal Internacional tendrá en cuenta los criterios enunciados en el artículo 13 del Estatuto respecto de la composición de las Salas y de las secciones de las Salas de Primera Instancia, las consideraciones enunciadas en los apartados b) y c) del párrafo 1 supra y el número de votos que ese magistrado ad lítem haya obtenido en la Asamblea General. 


\section{RESOLUCIÓN 1613}

(26 de julio de 2005)

\section{El Consejo de Seguridad,}

Recordando sus resoluciones 827 (1993), de 25 de mayo de 1993, 1166 (1998), de 13 de mayo de 1998, 1329 (2000), de 30 de noviembre de 2000, 1411 (2002), de 17 de mayo de 2002, 1431 (2002), de 14 de agosto de 2002, 1481 (2003), de 19 de mayo de 2003, 1503 (2003), de 28 de agosto de 2003, 1534 (2004), de 26 de marzo de 2004, y 1597 (2005), de 20 de abril de 2005,

Habiendo examinado las candidaturas a cargos de magistrados ad lítem del Tribunal Internacional para la ex Yugoslavia recibidas por el Secretario General,

Transmite a la Asamblea General la siguiente lista de candidatos de conformidad con el inciso d) del párrafo 1) del artículo 13 ter del Estatuto del Tribunal Internacional:

Sr. Tanvir Bashir Ansari (Pakistán)

Sr. Melville Baird (Trinidad y Tobago)

Sr. Frans Bauduin (Países Bajos)

Sr. Giancarlo Roberto Belleli (Italia)

Sr. Ishaq Usman Bello (Nigeria)

Sr. Ali Nawaz Chowhan (Pakistán)

Sr. Pedro David (Argentina)

Sr. Ahmad Farawati (República Árabe Siria)

Sra. Elizabeth Gwaunza (Zimbabwe)

Sr. Burton Hall (Bahamas)

Sr. Frederik Harhoff (Dinamarca)

Sr. Frank Höpfel (Austria)

Sra. Tsvetana Kamenova (Bulgaria)

Sr. Muhammad Muzammal Khan (Pakistán)

Sr. Uldis Kinis (Letonia)

Sr. Raimo Lahti (Finlandia)

Sra. Flavia Lattanzi (Italia)

Sr. Antoine Mindua (República Democrática del Congo)

Sr. Jawdat Naboty (República Árabe Siria)

Sra. Janet Nosworthy (Jamaica)

Sra. Chioma Egondu Nwosu-Iheme (Nigeria)

Sra. Prisca Matimba Nyambe (Zambia)

Sra. Michèle Picard (Francia)

Sr. Brynmor Pollard (Guyana) 
DOCUMENTACIÓN

\author{
Sr. Árpád Prandler (Hungría) \\ Sra. Kimberly Prost (Canadá) \\ Sr. Sheikh Abdul Rashid (Pakistán) \\ Sra. Vonimbolana Rasoazanany (Madagascar) \\ Sr. Ole Bjørn Støle (Noruega) \\ Sr. Krister Thelin (Suecia) \\ Sr. Klaus Tolksdorf (Alemania) \\ Sr. Stefan Trechsel (Suiza) \\ Sr. Abubakar Bashir Wali (Nigeria) \\ Sr. Tan Sri Dato Lamin Haji Mohd Yunus (Malasia)
}


Recensiones 